\title{
Untersuchung der sub-mitochondrialen Lokalisation des MINOS-Komplexes in humanen Zellen
}

\author{
Dissertation \\ Zur Erlangung des mathematisch-naturwissenschaftlichen Doktorgrades \\ „Doctor rerum naturalium“ \\ der Georg-August-Universität Göttingen
}

Grundprogramm Biologie
der Georg-August University School of Science (GAUSS)

vorgelegt von

Christian Daniel Jans

aus Neuwied

Göttingen, 2013 


\section{Betreuungsausschuss}

Prof. Dr. Stefan Jakobs, Forschungsgruppe Struktur und Dynamik von Mitochondrien, Abt. NanoBiophotonik, Max-Planck-Institut für Biophysikalische Chemie

PD Dr. Thomas Teichmann, Abt. Zellbiologie der Pflanze, Schwann-Schleiden Zentrum, Georg-August-Universität Göttingen

\section{Mitglieder der Prüfungskommission}

Referent: $\quad$ PD Dr. Thomas Teichmann, Abt. Zellbiologie der Pflanze, Schwann-Schleiden Zentrum, Georg-August-Universität Göttingen

Koreferent: Prof. Dr. Stefan Jakobs, Forschungsgruppe Struktur und Dynamik von Mitochondrien, Abt. NanoBiophotonik, Max-Planck-Institut für Biophysikalische Chemie

Weitere Mitglieder der Prüfungskommission

Prof. Dr. Peter Rehling, Abt. Biochemie II, Universitätsmedizin Göttingen Prof. Dr. Dr. Stefan W. Hell, Abt. NanoBiophotonik, Max-Planck-Institut für Biophysikalische Chemie Prof. Dr. Michael Meinecke, Abt. Biochemie II, Universitätsmedizin Göttingen Prof. Dr. Gerhard Braus, Abt. Molekulare Mikrobiologie und Genetik, Institut für Mikrobiologie und Genetik, Georg-August-Universität Göttingen

Tag der mündlichen Prüfung: 09.08.2013 



\section{Inhaltsverzeichnis}

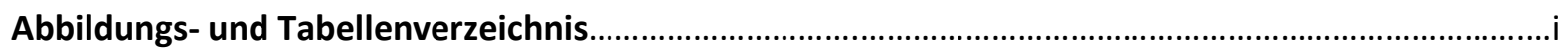

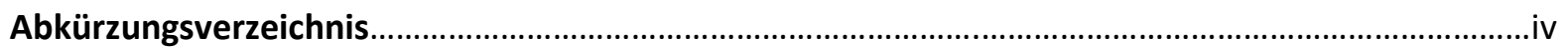

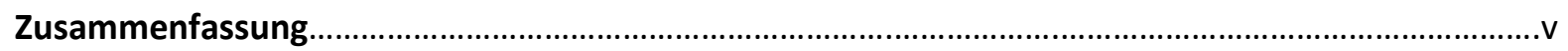

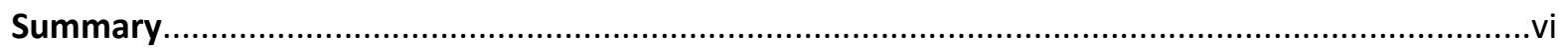

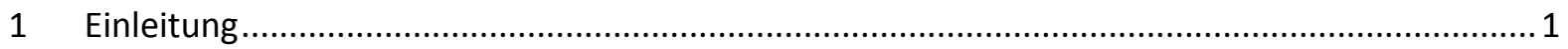

1.1 Mitochondrien: Funktion und Evolution ….................................................................. 1

1.2 Morphologie und Interaktionen von Mitochondrien ....................................................... 2

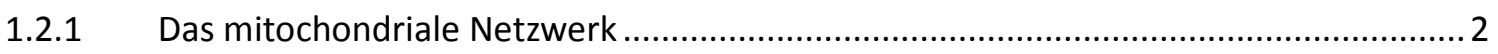

1.2.2 Fusion und Fission von Mitochondrien ............................................................... 2

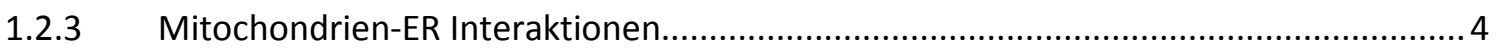

1.2.4 Mitochondrien-Zytoskelett Interaktionen und Transport von Mitochondrien..............6 6

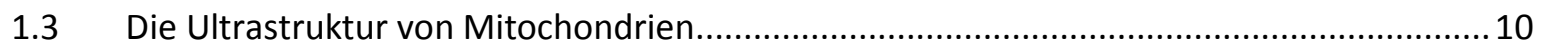

1.3.1 Cristae Junctions und Cristaemorphologie ............................................................... 12

1.4 Bildgebende Verfahren zur Untersuchung der mitochondrialen Ultrastruktur und

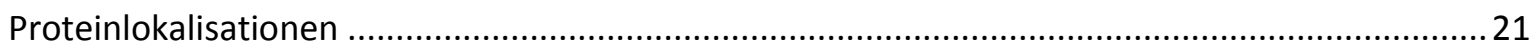

1.4.1 Hochauflösende Lichtmikroskopie (Nanoskopie) ..................................................... 21

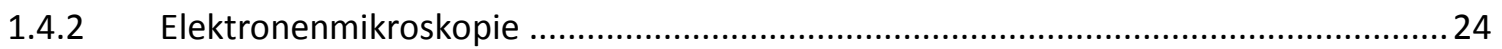

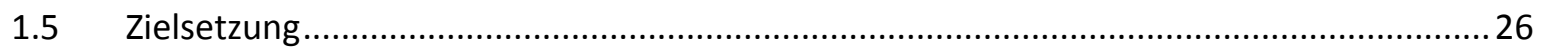

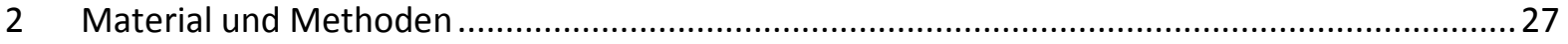

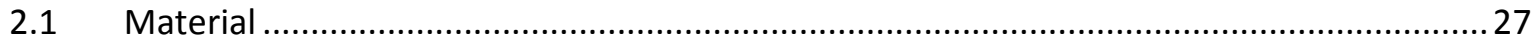

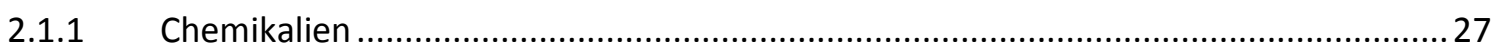

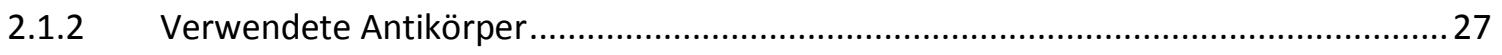

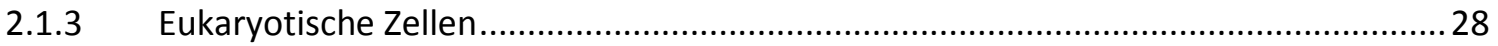

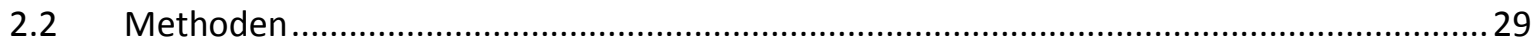

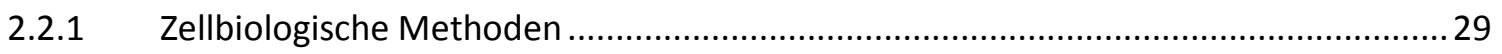

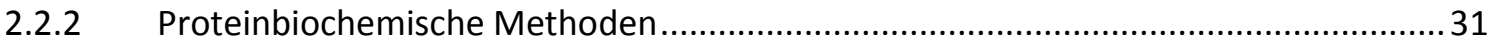

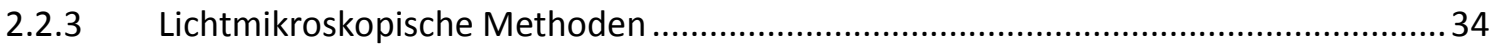

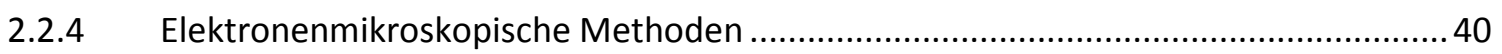


3.1 Analyse der sub-mitochondrialen Lokalisation des humanen MINOS-Komplexes ..............43

3.1.1 Nachweis von Mitofilin mit lichtmikroskopischen Mitteln ........................................... 44

3.1.2 Optimierung und Kontrolle der Probenvorbereitung für die STED-Mikroskopie..........48

3.1.3 Das humane Mitofilin ist innerhalb der Mitochondrien in Clustern lokalisiert............52

3.1.4 Die Mitofilin-Lokalisation weist einen intrazellulären Gradienten auf ........................53

3.1.5 Die sub-mitochondriale Mitofilin-Lokalisation ist hoch geordnet..............................59

3.1.6 Mitofilin ist in einer Vielzahl von verschiedenen Zelllinien hoch geordnet ................65

3.1.7 Kernkomponenten des MINOS-Komplexes haben eine ähnliche Lokalisation wie Mitofilin 68

3.2 Analyse der Mitochondrien-Ultrastruktur und Position der Mitofilin-Cluster.....................73

3.2.1 Mitofilin ist an Cristae Junctions angereichert .......................................................... 73

3.2.2 Cristae Junctions sind häufig parallel zur Wachstumsebene ausgerichtet ..................77

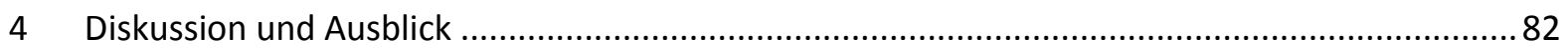

4.1 Der MINOS-Komplex als mögliches mitochondriales Skelett............................................82

4.2 Die Lokalisation des MINOS-Komplexes und seiner Interaktionspartner ..........................87

4.2.1 Der MINOS-Komplex ist räumlich hoch organisiert ................................................ 90

4.3 Der MINOS-Komplex und die Cristae (Junction)-Struktur .................................................95

4.4 Die Ultrastruktur der inneren Membran ........................................................................ 97

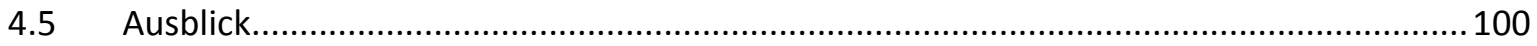

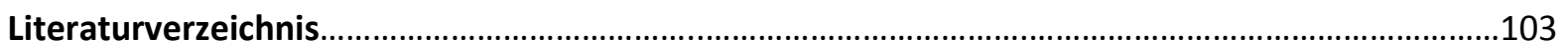

Veröffentlichungen und Konferenzbeiträge .....................................................................................117

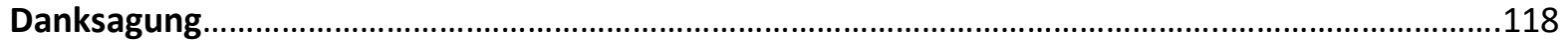

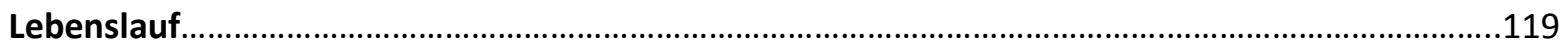





\section{Abbildungsverzeichnis}

Abb. 1.1: Mitochondrienmorphologien in verschiedenen Organismen.

Abb. 1.2: Schematische Darstellung einiger Komponenten der ER-Mitochondrien-Interaktion. .5

Abb. 1.3 Mitochondrien werden in Säuger-Zellen entlang des Mikrotubuli-Zytoskelettes transportiert. 7

Abb. 1.4: Ultrastruktur und Subkompartimente eines Mitochondriums

Abb. 1.5: Diversität der Cristaemorphologien in verschiedenen Zelltypen.

Abb. 1.6: Modell eines Hühner-Cerebellum-Mitochodriums erstellt aus einem segmentierten Tomogramm...12

Abb. 1.7: ATP-Synthase-Dimere sind wichtige, strukturgebende Elemente der Cristaemorphologie.

Abb. 1.8 Vergleich der Größe einer vereinfacht dargestellten konfokalen PSF („point spread function“) mit der Größe eines typischen Mitochondriums.

Abb. 1.9 Gezieltes Auslesen verglichen mit stochastischem, zeit-sequenziellem Auslesen der Fluoreszenzmarker eines nanostrukturierten Objektes innerhalb eines beugungsbegrenzten Bereiches dessen Grenzen durch $\lambda / 2 \mathrm{n}$ gegeben sind (bearbeitet aus (Hell, 2007))..

Abb. 1.10 Schematische Darstellung des Prinzips der STED-Mikroskopie.

Abb. 1.11 Schematische Darstellung verschiedener Möglichkeiten der Probenvorbereitung von biologischen Präparaten für die Transmissionselektronenmikroskopie.

Abb. 2.1 Schematische Darstellung des Aufbaus, der für die ein-Farben-STED-Mikroskopie verwendet wurde (bearbeitet aus (Harke et al., 2008)).

Abb. 2.2 Schematische Darstellung des Aufbaus, der für die zwei-Farben-STED-Mikroskopie verwendet wurde (bearbeitet aus (Buckers et al., 2011)).

Abb. 3.1 Der Mitofilin-Antikörper erkennt spezifisch Mitofilin

Abb. 3.2 Mitofilin ist ein mitochondriales Protein.

Abb. 3.3 Kontrolle des Mitofilin-STED-Signals in Mitochondrien primärer, humaner Fibroblasten bei Verwendung verschiedener Fixative.

Abb. 3.4 Kontrolle des Mitofilin-STED-Signals in Mitochondrien primärer, humaner Fibroblasten bei Verwendung verschiedener Detergenzien.

Abb. 3.5 Kontrolle des Mitofilin-STED-Signals in Mitochondrien primärer, humaner Fibroblasten bei Verwendung verschiedener Einbett-Medien.

Abb. 3.6 Mitofilin ist in einzelnen Clustern in Mitochondrien primärer, adulter, humaner Fibroblasten lokalisiert (bearbeitet aus (Jans et al., 2013)).

Abb. 3.7 Mitofilin-Cluster sind in der Nähe des Zellkerns dichter als am Rand der Zelle (bearbeitet aus (Jans et al., 2013)). 
Abb. 3.8 Mitofilin-Cluster sind in der Nähe des Zellkerns dichter als am Rand der Zelle (bearbeitet aus (Jans et al., 2013)).

Abb. 3.9 Lokalisation von Mitofilin-Clustern in HeLa-Zell-Mitochondrien

Abb. 3.10 Mitofilin-Cluster weisen in den meisten HeLa-Zellen einen Gradienten von einer dichten Verteilung um den Zellkern zu einer weniger dichten Verteilung am Rand der Zelle auf.

Abb. 3.11 Mitofilin weist einen Gradienten vom Zentrum zum Rand der Zelle hin auf, während das Peroxisomen-Protein PMP70 keinen bzw. einen umgekehrten Gradienten aufweist.

Abb. 3.12 Simulation verschiedener Dichten von zufällig verteilten Punkten auf einer dreidimensionalen Röhre mit einem Durchmesser von $200 \mathrm{~nm}$. 60

Abb. 3.13 Mitofilin ist am Rand der Mitochondrien lokalisiert (bearbeitet aus (Jans et al., 2013)). 62

Abb. 3.14 Mitofilin-Cluster sind horizontal auf beiden Seiten der Mitochondrien lokalisiert (bearbeitet aus (Jans et al., 2013))

Abb. 3.15 Lokalisation von Mitofilin in verschiedenen Zelllinien (bearbeitet aus (Jans et al., 2013)).

Abb. 3.16 STED-Mikroskopie von MINOS-Komplex-Komponenten und möglichen Interaktionspartnern (bearbeitet aus (Jans et al., 2013)).

Abb. 3.17 Zwei-Farben STED-Mikroskopie von, mit Antikörpern gegen CHCHD3 und Mitofilin (A) sowie MINOS1 und Mitofilin (B), gefärbten primären, humanen Fibroblastenzellen (bearbeitet aus (Jans et al., 2013).

Abb. 3.18 Repräsentative transmissionselektronenmikroskopische Aufnahmen von HeLa-Zell-Mitochondrien, die mit einem primären Mitofilin-Antikörper und sekundärem Gold-Konjugat markiert wurden.

Abb. 3.19 Schematische Darstellung der Auswertung der einzelnen Gold-Lokalisationen in den transmissionselektronenmikroskopischen Aufnahmen von mit einem Mitofilin-Antikörper markierten HeLaZell-Mitochondrien (exemplarisch in Abb. 3.16 gezeigt).

Abb. 3.20 Mitofilin ist in HeLa-Zell-Mitochondrien bevorzugt in der Nähe der Cristae Junctions lokalisiert (bearbeitet aus (Jans et al., 2013)).

Abb. 3.21 Cristae Junction-Ausrichtung und Cristae-Morphologie in primären, humanen Fibroblastenmitochondrien, analysiert durch zwei-Achsen Elektronen-Tomographie (Jans et al., 2013). 78

Abb. 3.22 Transmissionselektronenemikroskopische Aufnahmen von Dünnschnitten primärer, humaner Fibroblasten, die senkrecht (A) bzw. parallel (B) zur Wachstumsebene geschnitten und aufgenommen wurden. In den vergrößerten Ausschnitten sind jeweils Mitochondrien gezeigt, die in den senkrechten Schnitten bevorzugt rund $(A)$ und in parallelen Schnitten bevorzugt länglich (B) aussahen.

Abb. 3.23 Analyse der Ausrichtung von Cristae Junctions in senkrecht zur Wachstumsoberfläche angefertigten elektronenmikroskopischen Schnitten.

Abb. 4.1 Modell der Reticulons als formgebende Komponente der Membran des Endoplasmatischen Retikulums (ER) (Friedman \& Voeltz, 2011). 
Abb. 4.2 Mitochondriale Morphologie von wildtypischen Hefezellen (WT) und von Hefezellen mit einem knock-out einer der Kernkomponenten des MINOS-Komplexes (Mio10 und Fcj1).

Abb. 4.3 Schematische Darstellung von MitOS (=MINOS) als komplexe, zusammenhängende Struktur, die die Mitochondrien umschließt und dadurch eine Art mitochondriales Skelett bildet (bearbeitet aus (Hoppins et al., 2011)).

Abb. 4.4 Schematische Darstellung des veränderten Modells von (Hoppins et al., 2011) wie es sich durch STEDmikroskopische Analysen von MINOS-Kernkomponenten in Mitochondrien von adhärenten Säugerzellen darstellte..

Abb. 4.5 Vereinfachte, schematische Darstellung der Clusterverteilung von Mitofilin (A) und von Tom20 (B) in Mitochondrien wie sie z. B. in Abb. 3.9 zu sehen ist.

Abb. 4.6 Zwei-Farben STED-Mikroskopie von Mitofilin und TTubulin.

Abb. 4.7 Die Cristae-Morphologie von Hefezellen ist bei einem knock-out der MINOS-Kernkomponenten Mio10 und Fcj1 sowie bei einem knock-out der Untereinheit der ATP-Synthase Atp20, verändert (bearbeitet aus (Alkhaja et al., 2012)).

Abb. 4.8 Modell eines ovalen Mitochondriums mit tubulären Cristae und eines tubulären Mitochondriums mit lamellaren Cristae. Gibt es einen Wiederspruch zwischen den Modellen?

Abb. 4.9 Modell der Struktur der mitochondrialen Membranen, wie sie aus Elektronen-Tomographischen

\section{Tabellenverzeichnis}

Tab. 1.1: Hauptakteure der mitochondrialen Fusion und Fission, ihre zelluläre Lokalisation und Funktion.........3

Tab. 1.2: Lipidkomposition der mitochondrialen Membranen in Saccharomyces cerevisiae (Zinser et al., 1991).

Tab. 1.3 Untereinheiten des MINOS/MitOS/MICOS Komplexes.

Tab. 1.4 Interaktionspartner von Mitofilin (MINOS2; IMMT) 


\section{Abkürzungsverzeichnis}

\begin{tabular}{|c|c|}
\hline ATP & Adenosintriphosphat \\
\hline BSA & bovine serum albumin (Rinderserumalbumin) \\
\hline d.h. & das heißt \\
\hline $\mathrm{Da}$ & Dalton \\
\hline DABCO & 1,4-diazabicyclo[2.2.2]octane \\
\hline ER & endoplasmatisches Reticulum \\
\hline FA & Formaldehyd \\
\hline GA & Glutaraldehyd \\
\hline $\mathrm{H}$ & hour (Stunde) \\
\hline $\mathrm{MeOH}$ & Methanol \\
\hline MICOS & mitochondrial contact site \\
\hline $\min$ & Minute \\
\hline MINOS & mitochondrial inner-membrane organizing structure \\
\hline MitOS & mitochondrial organizing structure \\
\hline NA & numerische Apertur \\
\hline OD & optische Dichte \\
\hline PBS & phosphate buffered saline (phoshatgepufferte Salzlösung) \\
\hline PFA & Paraformaldehyd \\
\hline PSF & point spread function (Punktspreizfunktion/Punktbildfunktion) \\
\hline SAM & sorting and assembly maschinery \\
\hline SDS & sodium dodecyl sulfate (Natriumdodecylsulfat) \\
\hline STED & stimulated emission depletion \\
\hline TOM & translocase of the outer membrane \\
\hline Tris & Tris(hydroxymethyl)-aminomethan \\
\hline UAC & Uranylacetat \\
\hline $\mathrm{v} / \mathrm{v}$ & volume/volume (Volumen/Volumen) \\
\hline$w / v$ & weight/volume (Gewicht/Volumen) \\
\hline z. B. & zum Beispiel \\
\hline
\end{tabular}




\section{Zusammenfassung}

MINOS (mitochondrial inner membrane organizing structure) ist ein großer heterooligomerer Protein-Komplex in der inneren Mitochondrienmembran, der ursprünglich in Mitochondrien von Hefezellen identifiziert wurde. In diesen Zellen wurden die Komponenten des Komplexes an Cristae Junctions angereichert gefunden und es wurde gezeigt, dass sie für die Aufrechterhaltung dieser Verbindungen zwischen der inneren Grenzflächenmembran und der Cristae eine zentrale Rolle spielen. Zusätzlich wurde spekuliert, ob der MINOS-Komplex eine zentrale Komponente eines die Mitochondrien umschließenden Proteinnetzwerkes ist, das die Struktur und Funktion der Mitochondrien kontrolliert. Über die Anordnung der Komponenten dieses Komplexes in Mitochondrien ist bisher jedoch wenig bekannt. Durch überauflösende Fluoreszenzmikroskopie (Nanoskopie; super-resolution microscopy) wurde in dieser Arbeit die Lokalisation von zentralen Komponenten sowie von Interaktionspartnern des MINOS-Komplexes in Säugerzellen untersucht und es konnte gezeigt werden, dass die Kern-Komponenten des Komplexes in einzelnen, distinkten Clustern lokalisiert sind, die einen Dichtegradienten vom Zentrum zum Rand der Zellen hin aufweisen. Es konnte außerdem gezeigt werden, dass MINOS-Cluster in adhärenten Säugerzellen hochgeordnet und parallel zur Wachstumsoberfläche ausgerichtet sind. Interaktionspartner des MINOS-Komplexes wiesen jedoch keine solche Organisation auf und waren unterschiedlich lokalisiert. Durch quantitative ImmunoElektronenmikroskopie wurde festgestellt, dass das humane Mitofilin an Cristae Junctions lokalisiert ist und durch Elektronen-Tomographie konnte belegt werden, dass die Cristae in den untersuchten Zellen hoch organisiert sind und die Cristae Junctions eine der MINOSCluster entsprechende geordnete Ausrichtung parallel zur Wachstumsebene aufweisen.

Somit konnte gezeigt werden, dass der MINOS-Komplex in Mitochondrien der untersuchten humanen Zellen in distinkten Clustern an Cristae Junctions lokalisiert ist und ein unerwartet hohes Maß an Organisation aufweist, was eine zentrale Rolle dieses Komplexes in der Regulation vieler weiterer mitochondrialer Funktionen wahrscheinlich macht. 


\section{Summary}

MINOS (mitochondrial inner membrane organizing structure) is a large hetero-oligomeric complex in the inner mitochondrial membrane. Originally identified in mitochondria of yeast cells, components of the complex were found to be enriched at cristae junctions, where they have been shown to be essential in maintaining these connections between the inner boundary membrane and the cristae membrane. Additionally, it has been speculated that the MINOS-complex is the core of an extended network that controls both the structure and the function of mitochondria. So far, however, the spatial arrangement of the complex remained ill-defined.

In this dissertation I used super-resolution microscopy (nanoscopy) to show that core components of the MINOS-complex are localized in distinct clusters within the mitochondria of mammalian cells. The distribution of these clusters exhibits an inner cellular gradient from the center to the rim of the cells. The arrangement of the clusters is highly ordered forming a regularly spaced pattern parallel to the growth surface. No such pattern could be determined for interaction partners of the MINOS-complex. Using quantitative immuno-electron microcopy, this study shows that the human protein mitofilin is localized at cristae junctions. Electron tomography revealed a highly ordered arrangement of the cristae. The cristae junctions are shown to be aligned parallel to the growth surface, thereby reflecting the spatial arrangement of the MINOS-clusters.

Conclusively, I showed in this study that the MINOS-complex is localized in distinct clusters at cristae junctions and that the complex demonstrates an unexpectedly high level of regularity. This strongly suggests that MINOS plays a central role in the structural organization and the regulation of mitochondria. 


\section{Einleitung}

\subsection{Mitochondrien: Funktion und Evolution}

Mitochondrien sind essentielle Organellen aller Eukaryoten. Ihre prominenteste Funktion besteht in der Bereitstellung des zellulären Energieäquivalentes ATP. Mitochondrien sind jedoch an einer Vielzahl weiterer entscheidender zellulärer Prozesse beteiligt. Die Bedeutung dieser weiteren Prozesse, zu denen der Harnstoffzyklus, die Häm-Biosynthese, die Bildung von Eisen-Schwefel-Clustern, der Aminosäure-Metabolismus und eine wichtige Rolle bei der $\mathrm{Ca}^{2+}$-Homöostase sowie dem induzierten Zelltod gehören, zeigt sich in der Tatsache, dass Eukaryoten, die zur Bereitstellung von ATP nicht zwingend auf Atmung angewiesen sind (z.B. Saccharomyces cerevisiae), dennoch ohne Mitochondrien nicht überlebensfähig sind (Lill et al., 2005).

Mitochondrien sind in tierischen Zellen mit Ausnahme des Zellkerns das einzige Zellorganell, das von zwei Lipidmembranen umschlossen ist. Diese Tatsache ist auf den evolutionären Ursprung der eukaryotischen Zelle zurückzuführen. Nach der Endosymbiontentheorie sind Mitochondrien ursprünglich $\alpha$-Proteobakterien, die in frühe Archaebakterien oder in andere, heute ausgestorbene Vorläuferzellen eingewandert sind (Gray et al., 1999; Katz, 2012). Dies führte auch dazu, dass Mitochondrien das einzige Zellorganell mit eigener DNA sind. Im Laufe der Evolution wurde jedoch der Großteil der für die ca. 800 (Saccharomyces cerevisiae) bis ca. 1500 (Homo sapiens) mitochondrialen Proteine kodierenden Gene (Mootha et al., 2003; Sickmann et al., 2003; Taylor et al., 2003) in den Nucleus verlagert, so dass in der menschlichen mitochondrialen DNA (mtDNA) nur noch 13 und in der mtDNA der Bäckerhefe (Saccharomyces cerevisiae) nur noch 8 Proteine kodiert sind. Dies sind jeweils große hydrophobe integrale Innenmembranproteine, die an der Atmungskette beteiligt sind. 


\subsection{Morphologie und Interaktionen von Mitochondrien}

\subsubsection{Das mitochondriale Netzwerk}

Mitochondrien können eine Vielzahl verschiedener Morphologien aufweisen. Diese reichen von kugelförmigen Strukturen in vielen Pflanzenzellen über mehr oder weniger verzweigte tubuläre Strukturen in S. cerevisiae bis zu komplexen tubulären Netzwerken in vielen Säugerzellen (Abb.1.1). Die Struktur der Mitochondrien und ihre Funktion hängen oft zusammen und sie erfordern eine komplexe Regulation (Scorrano, 2007; Herzig \& Martinou, 2008; Perkins et al., 2009; Westermann, 2010; Escobar-Henriques \& Anton, 2013).
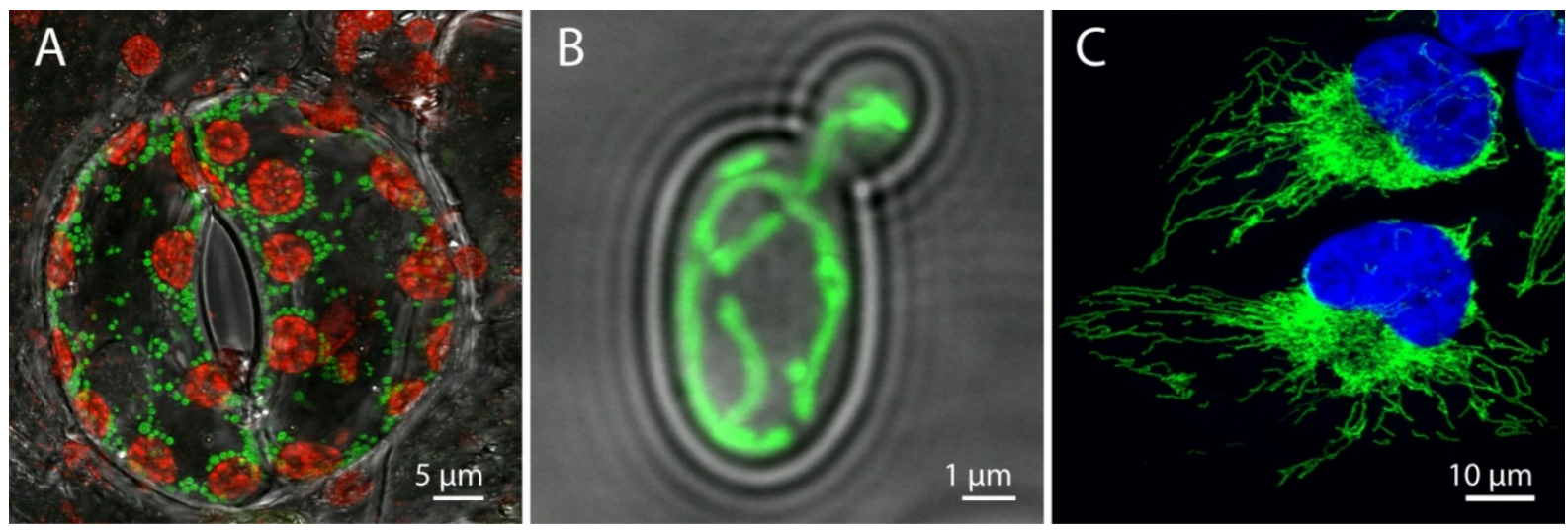

Abb. 1.1: Mitochondrienmorphologien in verschiedenen Organismen.

(A) Schließzellen einer Tabakpflanze (Nicotiana tabacum) (Jakobs et al., 2011). (B) Knospende Zelle der Hefe Saccharomyces cerevisiae. (C) Humane Cervix-Karzinom Zellen der Zelllinie HeLa. Dargestellt sind in grün jeweils Maximalprojektionen der Mitochondrien ((A) und (B) jeweils mitochondrial lokalisiertes GFP-Fusionsprotein, (C) Immunofluoreszenz eines mitochondrial lokalisierten Proteins). In rot (A) sind die Chloroplasten und in blau (C) sind die Nuclei zu sehen.

\subsubsection{Fusion und Fission von Mitochondrien}

Eine entscheidende Rolle bei der Regulation der Struktur des mitochondrialen Netzwerkes kommt der Fusion und der Teilung zu. Diese beiden Prozesse haben eine Vielzahl von Funktionen (Chan, 2012). Eine Funktion der Teilung von Mitochondrien ist das Entfernen von geschädigten Mitochondrien-Abschnitten aus dem Netzwerk und die Reaktion auf sich lokal verändernde Energiebedürfnisse der Zelle (Zhao et al., 2012). Die Fusion dieser 
Organellen könnte wiederum zu einer konstanten Durchmischung des Mitochondriengehaltes führen, welche unter anderem positive Auswirkungen auf die Energieproduktion der Mitochondrien haben könnte (Mitra et al., 2009; Westermann, 2010; Escobar-Henriques \& Anton, 2013). Die Hauptakteure der Fusion und Teilung von Mitochondrien sind in Tab. 1.1 dargestellt.

Tab. 1.1: Hauptakteure der mitochondrialen Fusion und Fission, ihre zelluläre Lokalisation (OM (outer membrane): mitochondriale Außenmembran; IM (inner membrane): mitochondriale Innenmembran; IMS (intermembrane space): mitochondrialer Intermembranraum) und Funktion.

\begin{tabular}{|c|c|c|c|c|}
\hline & S. cerevisiae & Säuger & Lokalisation & Funktion \\
\hline \multirow{6}{*}{ Fission } & Dnm 1 & DRP1 & $\begin{array}{l}\text { OM assoziert/ } \\
\text { zytoplasmatisch }\end{array}$ & \begin{tabular}{|l} 
Fission der \\
Außenmembran
\end{tabular} \\
\hline & Fis 1 & FIS1 & OM integriert & $\begin{array}{l}\text { fördert die Fission/ } \\
\text { rekrutiert Dnm1/Drp1 }\end{array}$ \\
\hline & Mdv1 & & $\begin{array}{l}\text { OM assoziert/ } \\
\text { zytoplasmatisch }\end{array}$ & $\begin{array}{l}\text { bindet Dnm 1/ } \\
\text { Adapterprotein }\end{array}$ \\
\hline & Caf4 & & $\begin{array}{l}\text { OM assoziert/ } \\
\text { zytoplasmatisch }\end{array}$ & $\begin{array}{l}\text { bindet Dnm 1/ } \\
\text { Adapterprotein }\end{array}$ \\
\hline & & MFF & OM integriert & $\begin{array}{l}\text { fördert die Fission/ } \\
\text { rekrutiert Drp1 }\end{array}$ \\
\hline & & $\begin{array}{l}\text { MiD51 (MIEF1)/ } \\
\text { MiD49 }\end{array}$ & OM integriert & rekrutieren Drp1 \\
\hline \multirow{4}{*}{ Fusion } & Fzo 1 & MFN1/2 & OM integriert & $\begin{array}{l}\text { Fusion der } \\
\text { Außernmembran }\end{array}$ \\
\hline & Mgm 1 & OPA1 & IM integriert/IMS & $\begin{array}{l}\text { Fusion der } \\
\text { Innenmembran } \\
\end{array}$ \\
\hline & Ugo 1 & & OM integriert & $\begin{array}{l}\text { Interaktion von Fzo } 1 \\
\text { und Mgm } 1 \text { / verbindet } \\
\text { OM und IM Fusion }\end{array}$ \\
\hline & & MIEF1 & OM integriert & $\begin{array}{l}\text { fördert die Fusion der } \\
\text { Außenmembran (Mfn } \\
\text { unabhängig) }\end{array}$ \\
\hline
\end{tabular}


Außer dieser zentralen Komponenten der Fusions- und Teilungsmaschinerie gibt es eine Vielzahl weiterer Faktoren, die an diesem komplizierten Prozess beteiligt sind und inn regulieren (Okamoto \& Shaw, 2005; Westermann, 2010; Chan, 2012; Zhao et al., 2012; Escobar-Henriques \& Anton, 2013). Es wird auch vermutet, dass dem endoplasmatischen Retikulum (ER) eine wichtige Funktion bei der Fission zukommt, wie aus der Beobachtung, dass an Stellen der Fission das endoplasmatische Retikulum den mitochondrialen Tubulus umschließt, geschlossen wurde (Friedman et al., 2011). Dies scheint aber nur eine Funktion dieser durchaus stabilen Kontaktstellen zwischen Mitochondrium und endoplasmatischem Retikulum zu sein.

\subsubsection{Mitochondrien-ER Interaktionen}

Elektronenmikroskopische Aufnahmen zeigten, dass der Abstand zwischen den Membranen von Mitochondrien und ER an einigen Stellen nur ca. 10-30 nm beträgt (Csordas et al., 2006), was einen direkten Kontakt durch spezielle Membranproteine ermöglicht. Diese Kontaktstellen werden "Mitochondria-associated ER membrane“ (MAM) (Mitochondrienassoziierte ER Membran) genannt. Deren mögliche Funktionen liegen zum Beispiel in der Lipid-Biosynthese und der $\mathrm{Ca}^{2+}$-Homöostase.

Welche Proteinkomplexe verantwortlich für diese strukturell definierten Kontaktstellen sind, ist noch nicht gänzlich aufgeklärt und unterscheidet sich wahrscheinlich auch in den verschiedenen Organismen (Reviews s. (Elbaz \& Schuldiner, 2011; Rowland \& Voeltz, 2012)). In der Bäckerhefe wurde ein Proteinkomplex identifiziert, der „ER-mitochondria encouter structure" (ERMES) (ER-Mitochondrien-Begegnungs-Struktur) genannt wurde und dem bei der Vermittlung dieser Kontaktstellen eine wichtige Funktion zukommt (Abb.1.2). 


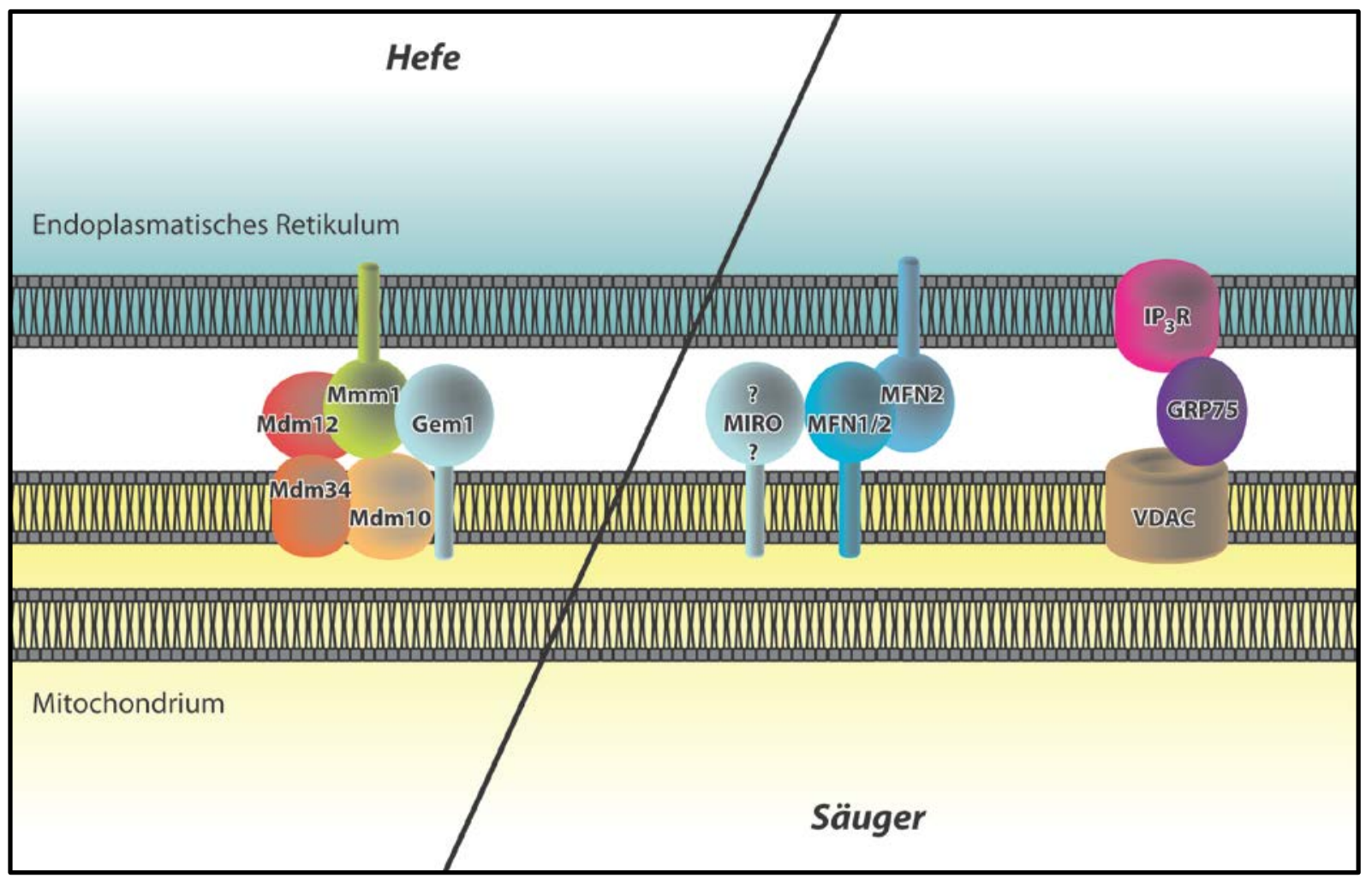

Abb. 1.2: Schematische Darstellung einiger Komponenten der ER-Mitochondrien-Interaktion.

Der ERMES-Komplex, dessen Proteine 2009 in einer Studie als entscheidende Komponenten für die mitochondriale Funktion der Mitochondrien-ER-Interaktion entdeckt wurden, wurde als aus vier Proteinen bestehend beschrieben (Kornmann et al., 2009). Diese Proteine sind die in der mitochondrialen Außenmembran lokalisierten Bestandteile Mdm10 und Mdm34, das periphere mitochondriale Außenmembranprotein Mdm12 und das ER-Membranprotein Mmm1. Eine weitere Komponente dieses Komplexes ist die GTPase Gem1 (Kornmann et al., 2011; Stroud et al., 2011). Gem1 ist ein integrales regulatorisches Protein und der einzige Bestandteil des Komplexes für den ein Ortholog in Säugerzellen bekannt ist. Dieses Ortholog ist die Miro-GTPase, die in zwei Isoformen - MIRO-1 (mitochondrial Rho 1) und MIRO-2 (mitochondrial Rho 2) - vorkommt. Und auch für MIRO-1 konnte eine Lokalisation nahe der ER-Mitochondrien-Kontaktstellen nachgewiesen werden (Kornmann et al., 2011).

In Säugerzellen ist jedoch kein einzelner Komplex bekannt, dem eine ähnlich prominente Bedeutung bei der Vermittlung der Mitochondrien-ER-Interaktion wie dem ERMES-Komplex in der Bäckerhefe zukommt. In Säugern gibt es eine Reihe an Proteinkomplexen, die an den 
MAMs eine Rolle spielen könnten. So wurde zum Beispiel gezeigt, dass der mitochochondriale "voltage dependent anion channel" (VDAC) über das zytosolische Chaperon GRP75 (glucose-regulated protein 75) an dem endoplasmatischen Calcium Kanal $I P_{3} R$ bindet (Abb.1.2), in Zellen ohne $I_{3} R$ die ER-Mitochondrien Kontaktstellen jedoch weiterhin bestehen bleiben (Csordas et al., 2006; Szabadkai et al., 2006). Weitere Vermittler der ER-Mitochondrien-Interaktion sind die Mitofusine (MFN) (Abb.1.2). Besonders MFN2, welches sowohl in Mitochondrien als auch im endoplasmatischen Retikulum zu finden ist, scheint dabei von besonderer Bedeutung zu sein, da MFN2 in MAMs angereichert ist und in MFN2-defizienten Zellen die Kontaktstellen zwischen beiden Organellen deutlich reduziert sind (de Brito \& Scorrano, 2008). Es gibt eine Vielzahl weiterer Proteine, die bei der Mitochondrien-ER-Interaktion eine Rolle spielen. Dazu gehören zum Beispiel PACS2 (phosphofurin acidic cluster sorting protein 2) (Simmen et al., 2005), FIS1 (mitochondrial fission protein 1) und BAP31 (B-cell receptor-associated protein 31) (Iwasawa et al., 2011), Trichoplein/Mitostatin (Cerqua et al., 2010), Presenelin 2 (Zampese et al., 2011) sowie der endoplasmatische Sigma-1 Rezeptor (Hayashi \& Su, 2007).

\subsubsection{Mitochondrien-Zytoskelett Interaktionen und Transport von Mitochondrien}

Der Transport und die Verteilung der Mitochondrien in der Zelle finden, ebenso wie die des endoplasmatischen Retikulums, entlang des Zytoskeletts statt (Abb.1.3). Hierbei zeigen sich wieder wesentliche Unterschiede zwischen Säuger- und Hefezellen. In Säugerzellen, in denen der Transport von Mitochondrien vor allem in Axonen von Nervenzellen untersucht wurde, scheint dieser im Wesentlichen entlang der Mikrotubuli stattzufinden (Boldogh \& Pon, 2007). Für den anterograden Transport sind hierbei zwei Motorprotein aus der Familie der Kinesine zuständig: Kinesin-1 (KIF5B) und Kinesin-3 (KIF1B). Diese binden über Adapterproteine an den Mitochondrien. Es sind einige solcher Adapterproteine bekannt. So hat zum Beispiel das Protein Syntabulin, welches ursprünglich als Mikrotubuli-assoziierter Interaktionspartner von Syntaxin beschrieben wurde (Su et al., 2004), eine Mitochondrien bindende Domäne, durch die sie dieses Organell mit Kinesin-1 verknüpfen könnte (Cai et al., 


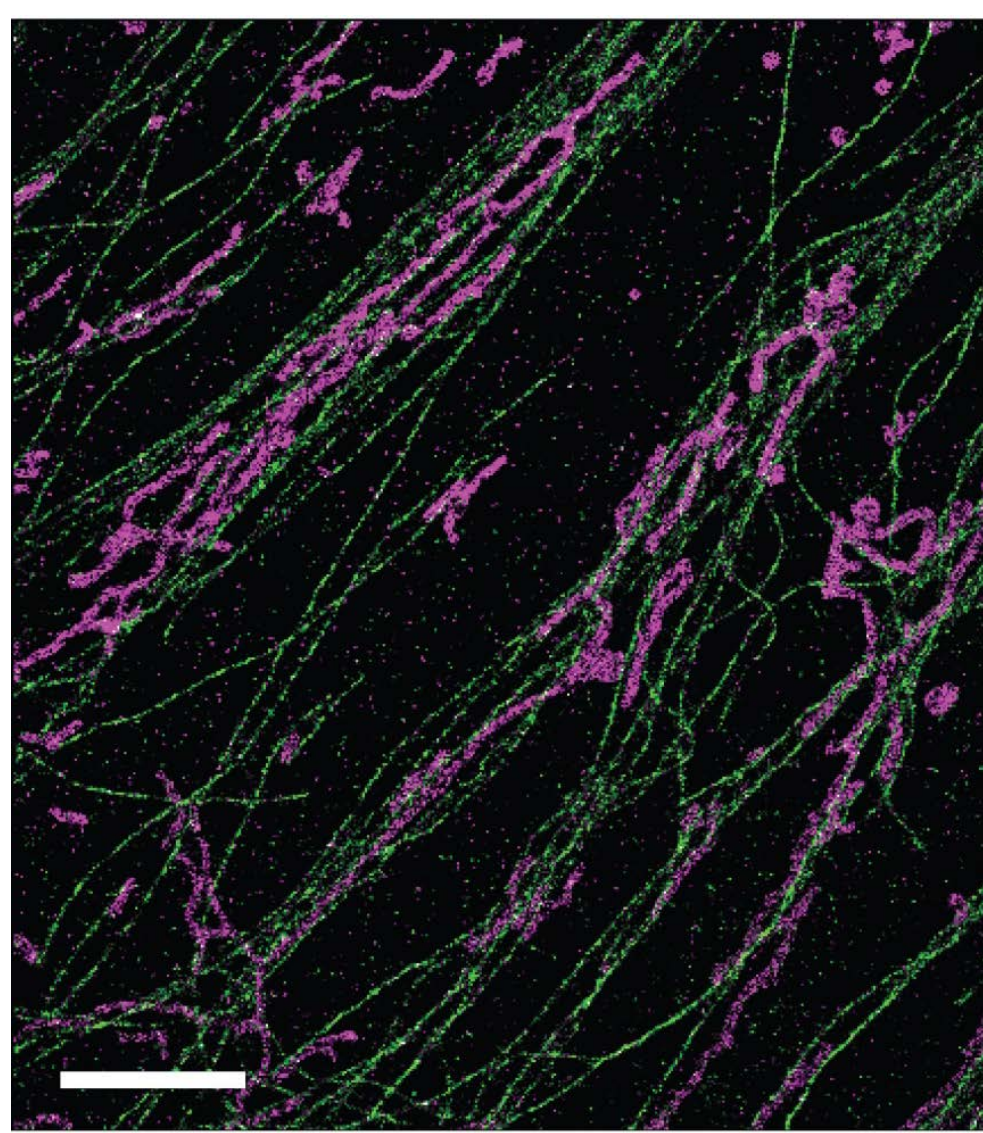

Abb. 1.3 Mitochondrien werden in Säuger-Zellen entlang des Mikrotubuli-Zytoskelettes transportiert.

$\mathrm{Zu}$ sehen ist ein Zweifarben-STORM-Bild einer Immunofluoreszenzfärbung der Mikrotubuli (grün) und der Mitochondrien (lila) in BSC-1 Zellen (Huang et al., 2008). (Größenbalken: 5 um)

2005). Ein weiterer Kandidat für einen solchen Adapter könnte eine Mitochondrien-spezifische Isoform von Kinectin sein (Santama et al., 2004). Die am besten, großenteils in Drosophila melanogaster untersuchten MitochondrienKinesin-Linker sind jedoch die Proteine Miro und Milton (Boldogh \& Pon, 2007). Miro ist ein mitochondriales integrales Außenmembranprotein, welches, wie schon in 1.2 .3 erwähnt, in Säugern in den zwei Isoformen MIRO-1 und MIRO-2 vorkommt. Milton wiederum hat in Säugern zwei Sequenzhomologe: TRAK1 (trafficking protein, kinesin binding 1) und TRAK2 (trafficking protein, kinesin binding 2). Miro und Milton bilden einen Komplex, der die Mitchondrien mit der schweren Kette von Kinesin verbindet (Brickley et al., 2005; Glater et al., 2006; Smith et al., 2006). Es gibt weitere Arbeiten, die physikalische und funktionale Interaktionen dieses Komplexes mit Pink1, einem Protein, das zusammen mit dem Protein Parkin eine wichtige Rolle bei der mitochondrialen Qualitätskontrolle durch Mitophagie spielt (Mutationen in den beiden Genen werden mit der autosomal rezessiven Form der Parkinsonerkrankung in Verbindung gebracht) und das mit dem Protein Mitofilin interagiert (Weihofen et al., 2009), sowie mit MFN2 (Misko et al., 2010) zeigen. Bei Versuchen in Säuger-Neuronen stellte sich jedoch heraus, dass die beiden Milton-Proteine 
TRAK1 und TRAK2 unterschiedliche Interaktionspartner haben und so jeweils beim Transport der Mitochondrien in verschiedene Richtungen eine Rolle spielen (van Spronsen et al., 2013). Das für den retrograden Transport von Mitochondrien entlang der Mikrotubuli verantwortliche Motorprotein ist das Dynein (Pilling et al., 2006). Es wurde gezeigt, dass eine leichte Kette von zytoplasmatischem Dynein - TCTEX1 (t-complex-associated-testisexpressed 1-like)/DYNLT1 (dynein light chain Tctex-type 1) - mit dem mitochondrialen Außenmembran-Kanal VDAC1 interagiert (Schwarzer et al., 2002). Aber auch die MiltonProteine binden, zumindest in Säuger-Neuronen, an Dynein/Dynactin (van Spronsen et al., 2013).

Intermediärfilamente scheinen ebenso einen Einfluss auf die Verteilung von Mitochondrien zu haben (Milner et al., 2000; Linden et al., 2001; Weisleder et al., 2004). Da jedoch keine Motorproteine oder direkten Interaktionen mit Mitochondrien bekannt sind und Intermediärfilamente keine Polarität aufweisen, sind diese Effekte wahrscheinlich eher einem Einfluss von Intermediärfilamenten auf die Mikrotubuli-Motoren zuzuschreiben (Boldogh \& Pon, 2007).

Das Actin-Zytoskelett spielt beim Transport von Mitochondrien in Säugerzellen vermutlich auch nur eine untergeordnete Rolle. Es wird spekuliert, ob der Transport durch die Myosine der Überbrückung von Stellen ohne Mikrotubuli und Stellen, an denen Mitochondrien den Kontakt zu Mikrotubuli verloren haben, oder der Immobilisierung von Mitochondrien dient (Saxton \& Hollenbeck, 2012). In der Bäckerhefe sowie in verschiedenen weiteren Organismen (z. B. Aspergillus und Pflanzenzellen) ist der Transport von Mitochondrien indes hauptsächlich Aktin-basiert (Boldogh \& Pon, 2006; Boldogh \& Pon, 2007). Es wurde in früheren Studien angenommen, dass hierbei Motorproteine keine wesentliche Rolle spielen und die Mitochondrien stattdessen durch Polymerisation der Actin-Fasern und die retrograde Bewegung der Filamente in beide Richtungen transportiert werden (Boldogh et al., 2001; Boldogh et al., 2005; Fehrenbacher et al., 2005; Boldogh \& Pon, 2006; Boldogh \& Pon, 2007). Als essentielle Elemente für diesen Transport wurden dabei drei Proteine, die zusammen Mitochore-Komplex genannt wurden, angegeben (Boldogh et al., 2003). Diese drei Proteine sind Mmm1 (maintenance of mitochondrial morpholgy 1), Mdm10 
(mitochondrial distribution and morphology 10) und Mdm12. Die Deletion eines dieser drei Proteine führt zu Defekten in der mitochondrialen Morphologie, einer Beeinträchtigung der Funktion des SAM- („sorting and assembly mashinery“) Komplexes, dem Verlust der mtDNA, sowie zu einem Verlust der Mobilität der Mitochondrien (Burgess et al., 1994; Berger et al., 1997; Hobbs et al., 2001; Hanekamp et al., 2002; Meisinger et al., 2004; Meisinger et al., 2007). Alle drei Proteine wurden in den früheren Studien als mitochondriale integrale Außenmembranproteine beschrieben, in neueren Studien werden diese Proteine dem ERMES-Komplex zugerechnet und Mmm1 wird als integrales Protein der ER-Membran beschrieben (s. 1.2.3). Es wurde vermutet, dass der Mitochore-Komplex die Mitochondrien mit dem Actin-Zytoskelett und über Jsn1 (Just Say No 1) und Puf3 (PUmilio-homology domain family 3) mit Arp2/3 verbindet (Fehrenbacher et al., 2005; Garcia-Rodriguez et al., 2007) und durch Actin-Polymerisation die Mitochondrien transportiert. Neuere Studien zeigen jedoch (im Widerspruch zu den oben angegebenen Studien von Boldogh und Pon), dass das Myosin Myo2 doch eine essentielle Rolle beim Transport von Mitochondrien in der Bäckerhefe spielt (Altmann et al., 2008; Fortsch et al., 2011). 


\subsection{Die Ultrastruktur von Mitochondrien}

Die Ultrastruktur der Mitochondrien, exemplarisch in Abb. 1.4 dargestellt, ist äußerst komplex und wird von einer Vielzahl von Faktoren beeinflusst. Der Durchmesser der in der Regel tubulären Mitochondrien variiert zwischen 150 und $500 \mathrm{~nm}$. Gemeinhin ist der mitochondriale Durchmesser innerhalb einer Zelle relativ gleichmäßig. Allerdings können viele Faktoren den Durchmesser und die Form der Mitochondrien beeinflussen, in humanen Neuronen sind veränderte mitochondriale Strukturen zum Beispiel ein charakteristisches Phänomen bei vielen neurodegenerativen Störungen (Perkins et al., 2009).

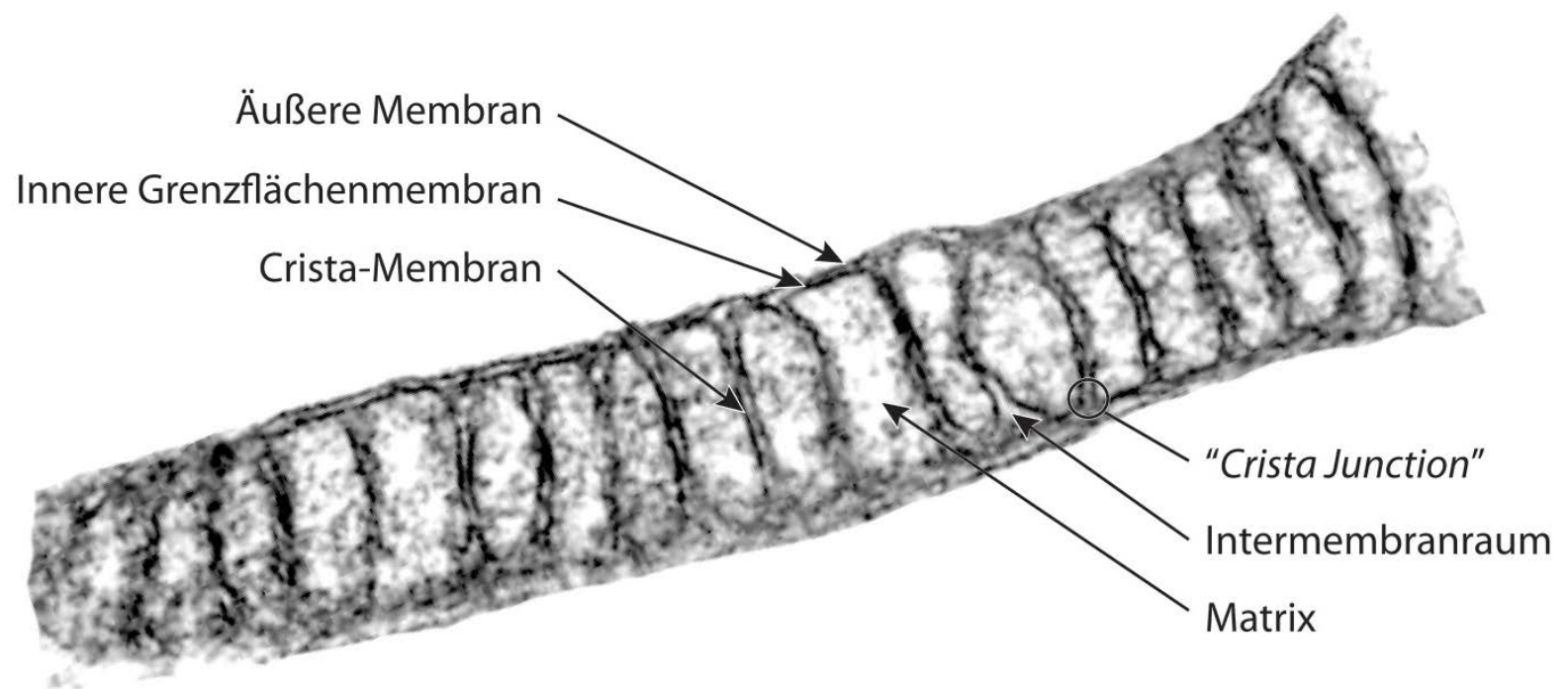

Abb. 1.4: Ultrastruktur und Subkompartimente eines Mitochondriums.

Dargestellt ist die transmissionselektronenmikroskopische Aufnahme eines Mitochondriums aus einer humanen Blastozystenzelle (innere Zellmasse) (bearbeitet aus (Sathananthan \& Trounson, 2000)).

Die äußere Membran umschließt die innere Membran, von der sie durch den Intermembranraum getrennt ist. Der Abstand der beiden Membranen (gemessen vom äußeren Rand der äußeren Membran zum inneren Rand der inneren Membran) beträgt 20-25 nm, wobei die beiden einzelnen Membranen jeweils eine Dicke von ca. $7 \mathrm{~nm}$ haben (Perkins et al., 1997). Elektronenmikroskopische Aufnahmen deuten jedoch auch auf direkte Kontaktstellen dieser beiden Membranen, die sogenannten "Contact sites", hin, an denen die äußere und die innere Membran direkt aneinander liegen und die daher nur eine Breite 
von zwei Membrandicken haben, also ca. 14 nm (Perkins et al., 1997). Der gesamte Teil der inneren Membran, der parallel zur äußeren Membran liegt, wird auch innere Grenzflächenmembran genannt. Von ihr lässt sich morphologisch ein weiteres Subkompartiment der inneren Membran unterscheiden: die Cristae-Membran. Cristae sind Invaginationen der inneren Membran, die in der Regel lamellare oder tubuläre Strukturen bilden, in verschiedenen Zelltypen und unter unterschiedlichen physiologischen Bedingungen aber diverse Morphologien aufweisen können (Abb. 1.5).
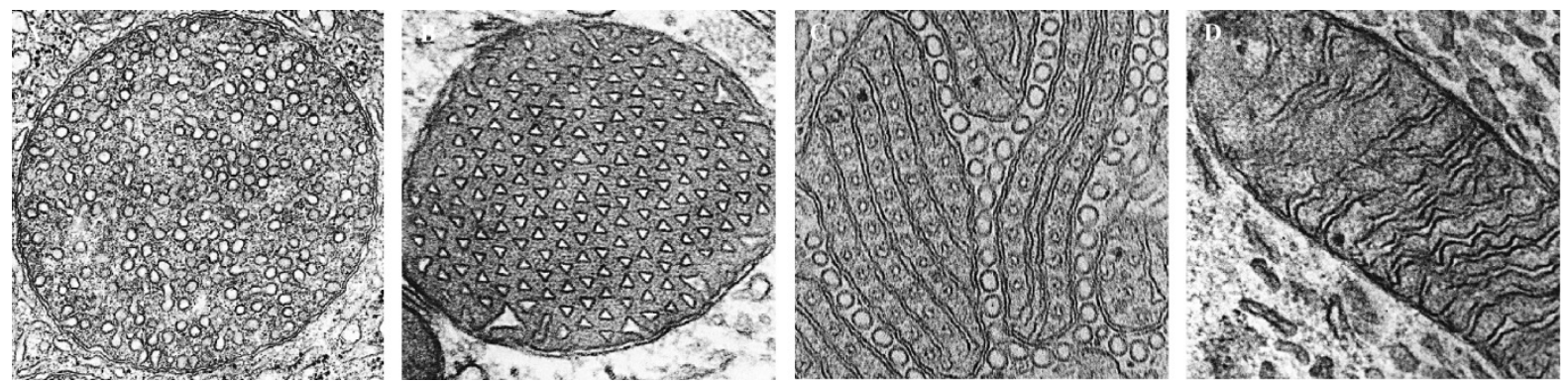

Abb. 1.5: Diversität der Cristaemorphologien in verschiedenen Zelltypen.

Dargestellt sind transmissionselektronenmikroskopische Aufnahmen von Mitochondrien aus Nebennierenrindenzellen (A), Astrozyten (B), Fisch Pseudobranch-Zellen (C) und ventrikularen Herzmuskelzellen (D) (Zick et al., 2009).

Die Außen- und die Innenmembran unterscheiden sich durch die Zusammensetzung ihrer Proteinbestandteile, aber auch durch die Komposition ihrer Lipide (s. Tab. 1.2). Selbst zwischen den Subkompartimenten der durchgängigen Innenmembran (Cristae- und innere Grenzflächenmembran) gibt es Unterschiede in ihrer Proteinzusammensetzung (Vogel et al., 2006; Wurm \& Jakobs, 2006).

Tab. 1.2: Lipidkomposition der mitochondrialen Membranen in Saccharomyces cerevisiae (Zinser et al., 1991).

\begin{tabular}{|l|c|c|c|c|c|c|}
\hline & $\begin{array}{c}\text { Phosphatidyl } \\
\text { cholin }\end{array}$ & $\begin{array}{c}\text { Phosphatidyl } \\
\text { ethanolamin }\end{array}$ & $\begin{array}{c}\text { Phosphatidyl } \\
\text { inositol }\end{array}$ & $\begin{array}{c}\text { Phosphatidyl } \\
\text { serin }\end{array}$ & $\begin{array}{c}\text { Phosphatid } \\
\text { säure }\end{array}$ & Cardiolipin \\
\hline $\begin{array}{l}\text { Innere } \\
\text { mitochondriale } \\
\text { Membran }\end{array}$ & $38,4 \%$ & $24,0 \%$ & $16,2 \%$ & $3,8 \%$ & $1,5 \%$ & $16,1 \%$ \\
\hline $\begin{array}{l}\text { Äußere } \\
\text { mitochondriale } \\
\text { Membran }\end{array}$ & $45,6 \%$ & $32,6 \%$ & $10,2 \%$ & $1,2 \%$ & $4,4 \%$ & $5,9 \%$ \\
\hline
\end{tabular}




\subsubsection{Cristae Junctions und Cristaemorphologie}

Die Ultrastruktur der Cristae, die als Invaginationen der inneren Mitochondrienmembran oft lamellare Strukturen - bevorzugt senkrecht zur Längsachse des Mitochondriums - bilden, wurde erstmals in den 50er Jahren in Arbeiten von Palade (Palade, 1953) und Sjöstrand (Sjostrand, 1953) beschrieben. Die Verbindungen dieser Cristae zur inneren Grenzflächenmembran durch runde Strukturen, die wir heute als "Cristae Junctions" kennen, wurden dann 1966 von Daems und Wisse untersucht, die sie pediculi cristae nannten (Daems \& Wisse, 1966). Mit Hilfe der Elektronen-Tomografie konnte in den 90er Jahren schließlich die dreidimensionale Struktur der mitochondrialen Innenmembran

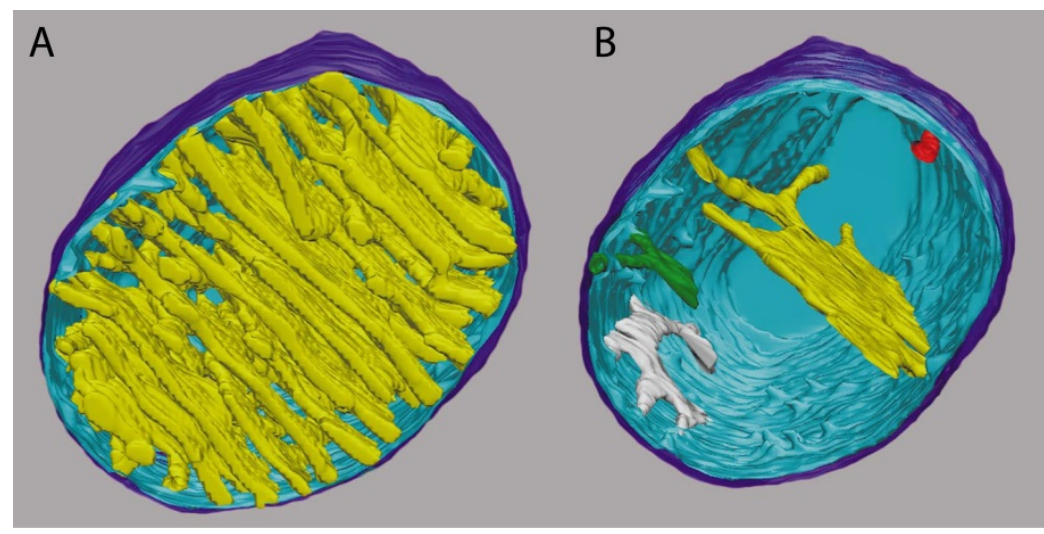

Abb. 1.6: Modell eines Hühner-Cerebellum-Mitochondriums erstellt aus einem segmentierten Tomogramm.

Die äußere Membran ist in dunkelblau und die innere Grenzflächenmembran in hellblau dargestellt. (A) zeigt das Gesamtmodell mit allen Cristae in gelb. In (B) sind nur einzelne Cristae aus dem Gesamttomogramm in verschiedenen Farben gezeigt (Frey \& Mannella, 2000) dargestellt werden (Mannella et al., 1994; Perkins et al., 1997; Perkins et al., 1998; Frey \& Mannella, 2000) (s. Abb.1.6).

Die Entstehung, das Aufrechterhalten und die Regulierung der Cristae sind äußerst komplexe Prozesse, deren Einzelaspekte in einer Vielzahl von Studien untersucht werden. Da diese Prozesse wahrscheinlich auch Auswirkungen auf eine Vielzahl mitochondrialer Funktionen haben, werden sie breit und kontrovers diskutiert (Mannella, 2006; Frey \& Sun, 2008; Mannella, 2008; Zick et al., 2009; Picard et al., 2013).

Die mitochondriale Innenmembran ist (wie unter 1.3 erwähnt) eine Lipidmembran mit definierter Lipidzusammensetzung, die sich von der anderer Membranen, wie z. B. der mitochondrialen Außenmembran unterscheidet (Tab. 1.2), sie ist aber auch besonders reich an Proteinen. In Massenanteilen ist die Menge der Proteine etwa dreimal so hoch wie die der Lipide (Ardail et al., 1990; Simbeni et al., 1991). 
Um die Mechanismen der Cristae-Gestaltung zu untersuchen, wurden in einer Vielzahl von Studien verschiedene Aspekte, die hierbei eine Rolle spielen, untersucht. In einigen Studien wurden zum Beispiel die Eigenschaften von Lipidmembranen und die daraus resultierenden Implikationen für die Cristae-Struktur untersucht. So wurden zum Beispiel Simulationen durchgeführt, die zeigten, dass die Vergrößerung der Oberfläche der inneren Membran bei konstanter, begrenzender Außenmembran spontan zu Cristae-artigen Invaginationen der Innenmembran führen kann (Renken et al., 2002). Weitere mathematische Modelle zeigten, dass Zugkräfte auf die innere Membran, die durch an den Cristae Junctions lokalisierte Proteine aufgebaut werden könnten, die lamellare Struktur der Cristae mit ihren runden Cristae Junctions, welche einen weitgehend homogenen Durchmesser von ca. 10-30 nm Durchmesser aufweisen (Perkins et al., 1997; Perkins et al., 1998; Renken et al., 2002; Perkins et al., 2003; Rabl et al., 2009; Ghochani et al., 2010), erklären können (Ghochani et al., 2010). Dass die Entstehung von Cristae-artigen Strukturen jedoch nicht rein mechanische Ursachen - wie die Vergrößerung der Innenmembranflächen gegen eine konstante Außenmembranfläche - haben muss, sondern auch durch lokale Variationen der Cardiolipin-haltigen Innenmembran auftreten können und dadurch Instabilitäten, die durch lokale pH-Veränderungen induzierbar sind, in diesen Membranen zu Cristae-artigen Strukturen führen können, zeigten Khalifat et. $a l$ in einer Studie an künstlich erzeugten Lipid-Membranen (Khalifat et al., 2011).

Da jedoch, wie oben angemerkt, die mitochondriale Innenmembran nicht nur als Lipidmembran zu sehen ist, sondern Proteine verschiedenster Funktionen den größeren Anteil dieser Membran ausmachen, haben diese Proteine einen entscheidenden Einfluss auf die Struktur der Cristae. Zum Beispiel ist das Protein Tafazzin, dessen Defekt die Ursache für das Barth-Syndrom ist (Bione et al., 1996), und das als Transacylase zwischen Phospholipiden - unter anderem auch Cardiolipin - Acylgruppen austauschen kann (Schlame, 2013), für eine normale Cristaemorphologie essentiell (Acehan et al., 2007; Acehan et al., 2009). Die Lipidzusammensetzung und die Lokalisation struktureller Innenmembranproteine bedingen und beeinflussen sich gegenseitig. So ist in Cardiolipinmutanten die Organisation der $\mathrm{F}_{1} \mathrm{~F}_{\mathrm{O}}$-ATP-Synthase Dimere beeinträchtigt (Acehan 
et al., 2011). Diese Dimere üben einen wichtigen Einfluss auf die Cristaemorphologie aus. Der knock-out einer der für die Dimerisierung zuständigen Komponenten der ATP-Synthase (Untereinheiten e und $\mathrm{g}$ ) führt $\mathrm{zu}$ einer zwiebelschalenartigen Anordnung der Cristaemembranen im Mitochondrium (Paumard et al., 2002; Arselin et al., 2004) (Abb. 1.7). Dies lässt zusammen mit der Beobachtung, dass die $F_{1} F_{0}$-ATP-Synthase Dimere vor allem in Cristaebereichen mit einer starken Krümmung in Reihen angeordnet zu finden sind (Abb. 1.7) vermuten, dass es sich bei diesem Komplex um eine entscheidende, gestaltgebende Komponente der Cristaemorphologie handelt, die die starke Krümmung an den CristaeRändern erst ermöglicht (Davies et al., 2011; Davies et al., 2012).
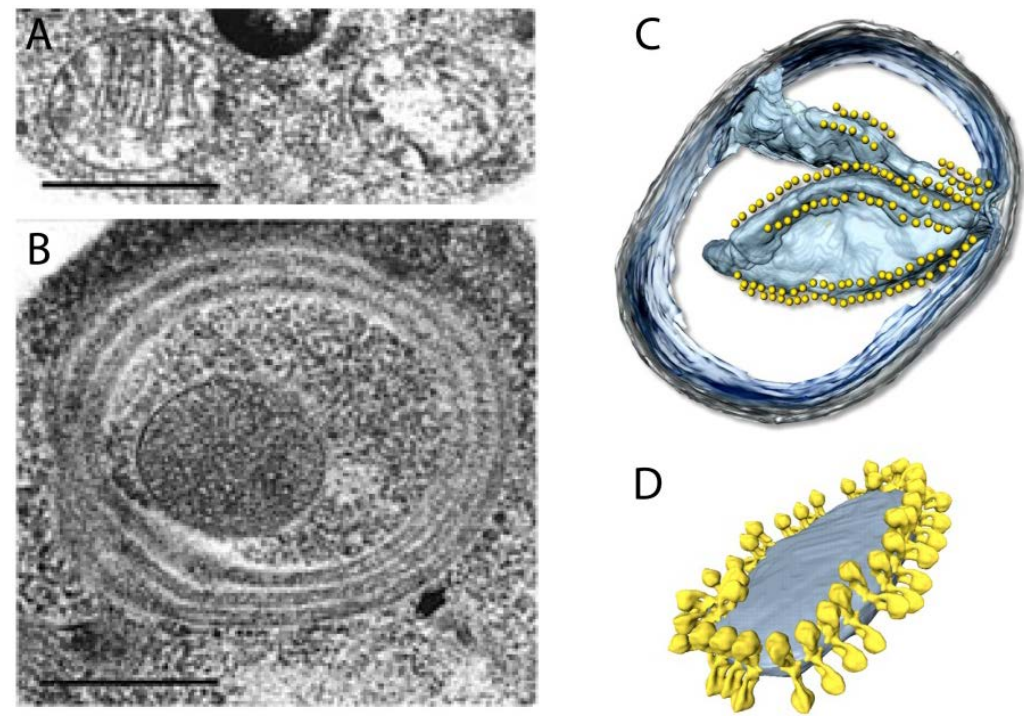

D

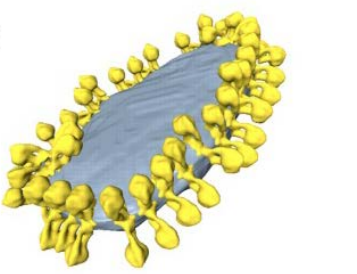

Abb. 1.7: ATP-Synthase-Dimere sind wichtige, strukturgebende Elemente der Cristaemorphologie.

Mitochondrien von $\triangle$ ATP20 Hefezellen zeigen eine zwiebelschalenartige Morphologie (B), die in den WTMitochondrien (A) nicht zu beobachten ist (Paumard et al., 2002). Die ATP-Synthase (gelb) ist in Reihen am Rand der Cristae-Lamellen lokalisiert (C; $\quad$ Segmentierte Oberflächenprojektion eines Tomogramms eines Mitochondriums aus Podospora anserina (Davies et al., 2011)), wo sie Dimere bildet ( $D$; Segmentierte Oberflächenprojektion eines Tomogramms einer isolierten mitochondrialen Membran aus Saccharomyces cerevisiae (Davies et al., 2012)). (Größenbalken: 0,5 $\mu \mathrm{m}$ )

Lokalisation entweder in der inneren Grenzflächenmembran oder in der Cristaemembran
Eine weitere wichtige Rolle für die Cristaemorphologie spielen die Cristae Junctions. Schon lange wurde vermutet, dass es sich bei diesen Strukturen auch um Diffusionsbarrieren zwischen der inneren Grenzflächenmembran und der Cristaemembran und zwischen dem Intercristaeraum und dem Intermembranraum handelt (Mannella et al., 1994). Dies wurde im Weiteren durch die Beobachtung gestützt, dass viele Membranproteine der durchgängigen Innenmembran eine bevorzugte 
aufweisen (Vogel et al., 2006; Wurm \& Jakobs, 2006). Untersuchungen scheinen auch darauf hinzudeuten, dass einige Cristaemembranproteine tatsächlich in ihrer Mobilität zum großen Teil auf ein Crista beschränkt sind und sich somit nicht leicht mit den Proteinen anderer Cristae mischen (Wilkens et al., 2013). Proteine die an diesen, für die CristaeStruktur entscheidenden, Strukturen (den Cristae Junctions) lokalisiert sind werden in 1.3.1.1 besprochen.

Es sind einige weitere Proteine bekannt, die einen Einfluss auf die Cristaemorphologie haben. Hierzu gehören zum Beispiel die Prohibitine PHB1 und PHB2 sowie das Protein OPA1 (optic atrophy 1). Sowohl die Prohibitine als auch OPA1 sind wichtig für eine normale Cristaemorphologie, wobei der Einfluss der Prohibitine wahrscheinlich in ihrer regulatorischen Funktion bei der OPA1-Prozessierung liegt (Griparic et al., 2004; Merkwirth et al., 2008). OPA1 kommt in einer kurzen und einer langen Form vor. Die kurze Form geht durch proteolytische Spaltung aus der langen Form hervor und das Verhältnis der beiden Varianten ist für ihre Funktion entscheidend (Duvezin-Caubet et al., 2006; Ishihara et al., 2006; Griparic et al., 2007). Wichtige Funktionen von OPA1 sind die Vermittlung der Fusion der inneren Mitochondrien-Membran (vgl. Tab. 1.1) sowie der Umstrukturierung der Cristae während der Apoptose, was zu einer Freisetzung von Cytochrom C aus den Cristae führt (Frezza et al., 2006). Mutationen des OPA1-Gens führen zur optischen Atrophie des Typs 1, eine dominant vererbte optische Neuropathie, die sich in einem progressiven Verlust der Sehschärfe äußert. Die Prohibitine bilden bemerkenswerterweise heterooligomere, ringförmige Komplexe, die einen Durchmesser von ca. 20-27 nm haben (Tatsuta et al., 2005). Es wird spekuliert, ob diese runden Elemente in der inneren Membran möglicherweise eine strukturierende Funktion einnehmen und so begrenzte Reaktionsräume schaffen (Osman et al., 2009). 


\section{Der MINOS/MitOS/MICOS-Komplex}

Ein weiteres für die Cristaemorphologie wichtiges Protein - Mitofilin (HMP; IMMT; MINOS2)

- wurde erstmals 1994 in einer Studie als besonders im Herzmuskel exprimiertes Protein beschrieben und daher zunächst HMP („heart muscle protein“"„Herz Muskel Protein“) genannt (Icho et al., 1994). In einer nächsten Studie wurde es dann als mitochondrial lokalisiertes Protein identifiziert (Odgren et al., 1996). Weiterhin konnte gezeigt werden, dass dieses mitochondriale Innenmembran-Protein einen bedeutenden Einfluss auf die Cristae-Morphologie hat: der knock-down von Mitofilin führt zu einem Verlust der Cristae Junctions und einem veränderten Verhältnis von Innenmembran- zu Außenmembranfläche (John et al., 2005).

Das Hefe-Homolog von Mitofilin Fcj1 („formation of cristae junction protein 1") (FMP13; Aim28), mit dem es vor allem die Domänenstruktur teilt, die aus einer Präsequenz, gefolgt von einer Transmembrandomäne und einem großen C-terminalen Teil, der in den Intermembranraum ragt und der eine coiled-coil Domäne, sowie eine hochkonservierte Mitofilin-Domäne enthält, besteht, wurde schließlich angereichert an Cristae Junctions gefunden, wobei auch der knock-out des Hefe-Proteins zu einem Verlust der Cristae Junctions führt (Rabl et al., 2009). 2011/2012 wurde schließlich in vier unabhängigen Studien ein großer Proteinkomplex beschrieben, der an den Cristae Junctions lokalisiert und der für die Cristae-Morphologie entscheidend ist, wobei Fcj1 eine der Kernkomponenten dieses Komplexes darstellt (Harner et al., 2011; Hoppins et al., 2011; von der Malsburg et al., 2011; Alkhaja et al., 2012). Gefunden wurde dieser Komplex durch sehr verschiedene Ansätze: durch einen genetischen Screen (Hoppins et al., 2011), durch die Analyse von Proteinen, die an Contact Sites angereichert sind (Harner et al., 2011) und die Suche nach Interaktionspartnern von Fcj1 (von der Malsburg et al., 2011) sowie nach kleinen unbekannten Innenmembranproteinen (Alkhaja et al., 2012). Es konnte gezeigt werden, dass dieser sehr große Proteinkomplex ( $>1 \mathrm{MDa}$ ) in der Hefe aus mindestens sechs verschiedenen Proteinen besteht und er wurde MINOS (,mitochondrial inner-membrane organizing system“), MitOS („,mitochondrial organizing structure“) oder MICOS (,mitochondrial contact site“) genannt (Tab. 1.3). 
Tab. 1.3 Untereinheiten des MINOS/MitOS/MICOS Komplexes.

In der Hefe wurden sechs Proteine identifiziert, von denen nur einzelne Homologe in den Metazoa haben. Die Molekülmassen und Längen von Mitofilin, MINOS1 und CHCHD3 beziehen sich auf die humanen Proteine, während es sich bei MOMA-1 um ein Protein aus C. elegans handelt, da es im Menschen nicht zu finden ist (APOOL ist ein entferntes humanes Homolog).

\begin{tabular}{|c|c|c|c|c|c|c|}
\hline \multicolumn{4}{|c|}{ Saccharomyces cerevisiae } & \multicolumn{3}{|c|}{ Metazoa } \\
\hline Name & Hefe ORF & $\begin{array}{l}\begin{array}{l}\text { Molekülmasse } \\
{[\mathrm{kDa}]}\end{array} \\
\end{array}$ & $\begin{array}{l}\text { Länge } \\
\text { [Aminosäuren] }\end{array}$ & Name & $\begin{array}{l}\text { Molekülmasse } \\
{[\mathrm{kDa}]}\end{array}$ & \begin{tabular}{|l|} 
Länge \\
[Aminosäuren]
\end{tabular} \\
\hline Fcj1/FMP13/Aim28 & YKR016W & 61.1 & 540 & Mitofilin/MINOS2/IMMT & 83.7 & 758 \\
\hline Mio10/Mcs10/Mos1 & YCL057C-A & 10.4 & 97 & MINOS1 & 8.8 & 78 \\
\hline Aim5/Mcs12 & YBR262C & 12.4 & 106 & & & \\
\hline Aim13/Mcs19 & YFR011C & 18.9 & 170 & $\begin{array}{l}\text { CHCHD3/MINOS3; } \\
\text { (CHCHD6/CHCM1) }\end{array}$ & 26.2 & 227 \\
\hline Aim37/Mcs27 & YNL100W & 27.0 & 234 & \multirow{2}{*}{ MOMA-1; (APOOL) } & \multirow{2}{*}{22.1} & \multirow{2}{*}{201} \\
\hline Mio27/Mcs29/Mos2 & YGR235C & 26.9 & 233 & & & \\
\hline
\end{tabular}

Alle Proteine des Hefe-MINOS-Komplexes - bis auf Aim13 - sind integrale Innenmembranproteine mit ein oder zwei Transmembrandomänen. Aim13 ist ein Innenmembran-assoziiertes Protein, das im Intermembranraum lokalisiert ist. Der knockout der einzelnen Komponenten dieses Komplexes führt zu einer abnormalen CristaeArchitektur, die durch einen Verlust der Cristae Junctions und übereinander geschichtete Cristae-Membranen gekennzeichnet ist. Dieser Phänotyp ist bei den verschiedenen knockouts unterschiedlich stark ausgeprägt. Das Fehlen von Fcj1 oder Mio10, der beiden KernKomponenten dieses Komplexes, führt zu einem vollständigen Verlust der Cristae Junctions, während Mio27 das andere Extrem darstellt und sein knock-out kaum einen (Harner et al., 2011) bis gar keinen (von der Malsburg et al., 2011) Effekt auf die Cristae-Morphologie hat. Die Proteine des Hefe-MINOS-Komplexes weisen eine Vielzahl von Interaktionen auf. Zu diesen zählen unter anderem Interaktionen mit Außenmembran-Komplexen, wie dem SAM/TOB (,sorting and assembly machinery"/"topogenesis of $\beta$-barrel proteins")-Komplex und dem TOM („translocase of the outer membrane“)-Komplex (Harner et al., 2011; Hoppins et al., 2011; von der Malsburg et al., 2011; Bohnert et al., 2012; Korner et al., 2012). Der TOM-Komplex scheint hierbei nur mit der MINOS-Kernkomponente Fcj1 zu 
interagieren und nicht mit den anderen MINOS-Komplex-Komponenten, deren knock-out auch keinen Einfluss auf die Fcj1-TOM-Komplex-Interaktion hat, während der SAM-Komplex hingegen über seine konservierte POTRA-Domäne wahrscheinlich mit dem gesamten MINOS-Komplex interagiert (Bohnert et al., 2012). Dies lässt vermuten, dass Fcj1 in mindestens zwei Subpopulationen auftritt, die jeweils unterschiedliche Interaktionspartner aufweisen. Außerdem deuten genetische Interaktionen auf eine Verbindung des MINOSKomplexes mit dem ERMES-Komplex (s. 1.2.3) hin (Hoppins et al., 2011) und das Protein Mdm10 ist sowohl eine Komponente des ERMES-, als auch des SAM-Komplexes. Dies führte zu der These, dass ein Netzwerk von Komplexen existiert, welches, drei Membranen überspannend, von den Cristae Junctions bis zum endoplasmatischen Retikulum reicht und daher ERMIONE (,ER-mitochondria organizing network") genannt wurde (van der Laan et al., 2012). Weiterhin konnten Interaktionen mit dem Außenmembran-Fusionsprotein Ugo1 (vgl. Tab. 1.1) und dem Außenmembran-Kanal Porin (VDAC) gezeigt werden (Harner et al., 2011; Hoppins et al., 2011). Zusätzlich wurde eine transiente Interaktion mit dem Intermembranraum-Protein Mia40, das für den Import und die Assemblierung von Intermembranraum-Proteinen zuständig ist, beobachtet (von der Malsburg et al., 2011).

Für einzelne Komponenten des MINOS-Komplexes sind Orthologe im Menschen bekannt. Neben der oben erwähnten Kernkomponente Mitofilin ist auch das zweite zentrale Protein des Komplexes Mio10 durch ein Homolog im Menschen vertreten. Dieses Protein wurde MINOS1 genannt und ist ebenso wie in der Hefe Teil eines großen Komplexes (Alkhaja et al., 2012). Eine weitere Komponente des Säuger-Komplexes ist das Protein CHCHD3 (MINOS3). Es ist ein Homolog des für die Cristae-Morphologie in C. elegans entscheidenden Proteins $\mathrm{CHCH}-3$ und weist Ähnlichkeiten mit der Hefe-MINOS-Komplex-Komponente Aim13 auf. CHCHD3 wurde in vielen Publikationen als für die Cristaemorphologie entscheidender Interaktionspartner von Mitofilin beschrieben (Xie et al., 2007; Darshi et al., 2011; An et al., 2012; Ott et al., 2012). Es gibt eine ganze Reihe weiterer Studien, die physikalische Interaktionen verschiedenster Proteine mit Mitofilin in Säugerzellen zeigen. So identifizierte eine Studie 2007 einen Komplex bestehend aus Mitofilin, den Außenmembranproteinen SAM50 und Metaxin 1 und 2, welche an der Assemblierung von $\beta$-barrel Proteinen der 
Außenmembran (SAM50) und dem Import von Proteinen (Metaxin 1 und 2) beteiligt sind, sowie den Proteinen CHCHD3, CHCHD6 und DnaJC11 (Xie et al., 2007). Bis auf CHCHD6 wurden alle diese Proteine in einer weiteren Veröffentlichung auch als Interaktionspartner von MINOS1 identifiziert (Alkhaja et al., 2012). CHCHD6 ist jedoch auch in einer weiteren Studie als Interaktionspartner von Mitofilin und als Regulator der Cristaemorphologie beschrieben worden (An et al., 2012). Eine Zusammenfassung der (physikalischen) Interaktionen von Mitofilin ist in Tab. 1.4 dargestellt.

Tab. 1.4 Interaktionspartner von Mitofilin (MINOS2; IMMT)

\begin{tabular}{|c|c|c|c|}
\hline Name & Lokalisation & Funktion & Referenz \\
\hline Metaxin 1 & $\begin{array}{l}\text { Mitochondriale } \\
\text { Außenmembran }\end{array}$ & Beteiligt am Protein-Import in Mitochondrien & (Xie et al., 2007) \\
\hline Metaxin 2 & $\begin{array}{l}\text { Mitochondriale } \\
\text { Außenmembran (peripher } \\
\text { assoziiert; zytosolseite) }\end{array}$ & Beteiligt am Protein-Import in Mitochondrien & (Xie et al., 2007) \\
\hline SAM50 & $\begin{array}{l}\text { Mitochondriale } \\
\text { Außenmembran }\end{array}$ & $\begin{array}{l}\text { Untereinheit des SAM-Komplexes; wichtig für die } \\
\text { Assemblierung von } \beta \text {-barrel-Außenmembranproteinen }\end{array}$ & $\begin{array}{l}\text { (Xie et al., 2007; Darshi } \\
\text { et al., 2011; Ott et al., } \\
\text { 2012) }\end{array}$ \\
\hline PINK1 & $\begin{array}{l}\text { Mitochondriale } \\
\text { Außenmembran }\end{array}$ & $\begin{array}{l}\text { Serin/Threonin-Kinase; schützt vor mitochondrialer } \\
\text { Dysfunktion; beteiligt an der Entsorgung beschädigter } \\
\text { Mitochondrien durch Mitophagie; Mutationen führen zu } \\
\text { einer Form der autosomal rezessiven Parkinsonerkrankung }\end{array}$ & (Weihofen et al., 2009) \\
\hline DISC1 & $\begin{array}{l}\text { Nucleus, Zytoplasma und } \\
\text { Mitochondrien }\end{array}$ & $\begin{array}{l}\text { Involviert in die Regulation der Neurogenese; Defekte } \\
\text { stehen im Zusammenhang mit der Entwicklung von } \\
\text { Schizophrenie und anderen psychischen Erkrankungen }\end{array}$ & $\begin{array}{l}\text { (Park et al., 2010; An } \\
\text { et al., 2012) }\end{array}$ \\
\hline OPA1 & $\begin{array}{l}\text { Mitochondriale } \\
\text { Innenmembran }\end{array}$ & $\begin{array}{l}\text { GTPase die die eine zentrale Rolle bei der Fusion der } \\
\text { mitochondrialen Innenmbran und der Regulation der } \\
\text { Apoptose spielt; Defekte führen zur optischen Atropie } \\
\text { Typ1 }\end{array}$ & (Darshi et al., 2011) \\
\hline DnaJC11 & Mitochondriales Protein & Unbekannte Funktion & (Xie et al., 2007) \\
\hline PARP1 & $\begin{array}{l}\text { Nucleus und Mitochondrien } \\
\text { (mitochondriale Lokalisation } \\
\text { direkt abhängig von Mitofilin) } \\
\end{array}$ & $\begin{array}{l}\text { Modifizierung nukleärer Proteine durch poly-ADP- } \\
\text { ribosylierung und involviert in die Basen-Excisions- } \\
\text { Reparatur der DNA }\end{array}$ & (Rossi et al., 2009) \\
\hline PNKP & Nucleus und Mitochondrien & DNA-Reparatur & (Tahbaz et al., 2012) \\
\hline CHCHD3 & $\begin{array}{l}\text { Mitochondriale } \\
\text { Innenmembran }\end{array}$ & $\begin{array}{l}\text { Essentielles Protein für die Cristae-Architektur und } \\
\text { mitochondriale Funktion }\end{array}$ & $\begin{array}{l}\text { (Xie et al., 2007; Darshi } \\
\text { et al., 2011; An et al., } \\
\text { 2012; Ott et al., 2012) }\end{array}$ \\
\hline CHCHD6 & $\begin{array}{l}\text { Mitochondriale } \\
\text { Innenmembran }\end{array}$ & $\begin{array}{l}\text { Essentielles Protein für die Cristae-Architektur und } \\
\text { mitochondriale Funktion }\end{array}$ & $\begin{array}{l}\text { (Xie et al., 2007; An et } \\
\text { al., 2012) }\end{array}$ \\
\hline MINOS1 & $\begin{array}{l}\text { Mitochondriale } \\
\text { Innenmembran }\end{array}$ & Essentielles Protein für die Cristae-Architektur & (Alkhaja et al., 2012) \\
\hline
\end{tabular}

Die Lokalisation der einzelnen Komponenten des MINOS-Komplexes wurde in der Hefe im Wesentlichen quantitativ durch Immungold-Lokalisationen in elektronenmikroskopischen Schnitten untersucht. Dabei wurde festgestellt, dass die bekannten Proteine des Komplexes an den Cristae Junctions angereichert sind (Harner et al., 2011). Die Lokalisation des Hefe- 
MINOS-Komplexes in Verbindung mit dem Phänotyp des knock-outs einzelner Komponenten des Komplexes (s. o.) führte zu der Vermutung, dass MINOS-Komplexe an den Cristae Junctions, in Kooperation mit den ATP-Synthase-Dimeren an den Rändern der Cristae (s. 1.3.1), die zentralen Regulatoren der Cristae-Morphologie darstellen (Hoppins et al., 2011). Eine lichtmikrokopische Studie deutete außerdem darauf hin, dass die Proteine des MINOS-Komplexes eine übergeordnete, miteinander verbundene, die Mitochondrien helixartig umschließende Struktur bilden (Hoppins et al., 2011). Dies wurde als Indiz für eine mögliche weitere Funktion des Komplexes als eine Art mitochondriales Skelett gewertet. Ein solches Skelett wäre für die gesamte strukturelle Integrität der Mitochondrien entscheidend und könnte möglicherweise als eine Art Plattform für die Organisation weiterer Proteine eine Rolle spielen (Hoppins et al., 2011). Über mögliche ähnliche Strukturen in Säugerzellen ist (obwohl Kenntnisse über dieselben, auch durch die vielen Interaktionspartner von MINOS-Komponenten, einen großen Einfluss auf das Verständnis pathologischer Prozesse, die mit mitochondrialen Veränderungen in Zusammenhang stehen, hätten (Zerbes et al., 2012)) bisher nichts bekannt und die Anordnung der bekannten Komponenten des SäugerMINOS-Komplexes ist ungeklärt.

Die strukturellen Annahmen über den Hefe-MINOS-Komplex beruhen jedoch auf einer fluoreszenzmikroskopischen Untersuchung, die mit konventionellen, beugungsbegrenzten Mikroskopen durchgeführt wurde. Diese unterliegen der Beschränkung, dass Strukturen, die in etwa halb so groß wie die Wellenlänge des verwendeten Lichtes sind, nicht mehr aufgelöst werden können (s. 1.4.1). Das kann dazu führen, dass kleinere, physikalisch tatsächlich getrennte Strukturen, als miteinander verbundene Strukturen erscheinen. Daher ist es unerlässlich, die für die jeweilige Fragestellung zu verwendende Methode den für eine Aussage notwendigen Anforderungen anzupassen. In diesem Falle muss eine mikroskopische Methode gewählt werden, die eine Auflösung bietet, die die Untersuchung kleiner Strukturen innerhalb von Mitochondrien ermöglicht. 


\subsection{Bildgebende Verfahren zur Untersuchung der mitochondrialen Ultrastruktur und Proteinlokalisationen}

Zur mikroskopischen Untersuchung sub-mitochondrialer Strukturen gibt es inzwischen eine Reihe an Methoden, die die hierzu notwendige Auflösung bieten.

\subsubsection{Hochauflösende Lichtmikroskopie (Nanoskopie)}

Die Fluoreszenzmikroskopie ermöglicht die Analyse von Proteinlokalisationen im Kontext intakter Zellen. Es stehen dabei eine Reihe verschiedener Methoden zu Verfügung um die zu untersuchenden Proteine spezifisch zu markieren. Durch die Fusion der Proteine mit Fluoreszenzproteinen oder spezifisch an Fluoreszenzfarbstoffen bindenden Markern (z. B. SNAP, CLIP oder HALO-Technologie), sowie durch die Markierung der endogenen Proteine mittels Farbstoff-gekoppelter Antikörper (oder anderer hochaffiner Binder wie z. B. Nanobodies, Affibodies, Aptamere oder DARPins) in fixierten Zellen, können diese Proteine mit hoher Sensitivität und Spezifität dargestellt werden. Lange Zeit stellte jedoch das Auflösungsvermögen, das mittels konventioneller Lichtmikroskopie erreicht werden kann, ein großes Hindernis bei der Erforschung sub-mitochondrialer Strukturen dar, da dieses Auflösungsvermögen in der gleichen Größenordnung wie der Durchmesser der Mitochondrien liegt (Abb. 1.8).

konfokale PSF Ausschnitt eines typischen Mitochondriums

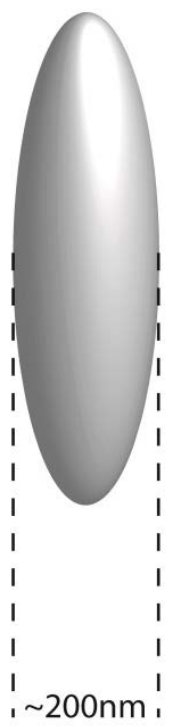

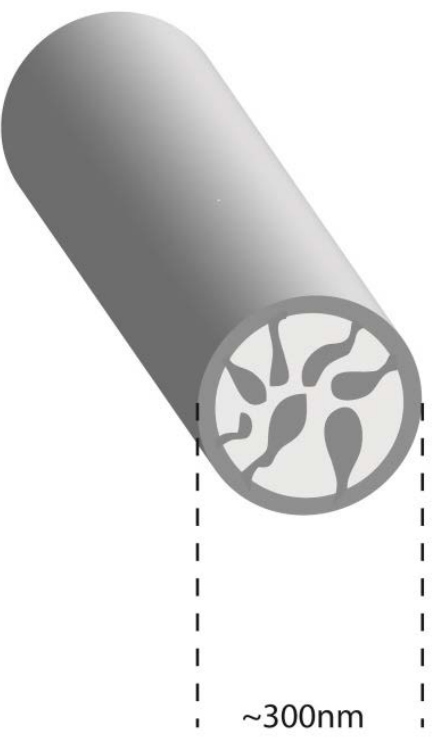

Abb. 1.8 Vergleich der Größe einer vereinfacht dargestellten konfokalen PSF („point spread function") mit der Größe eines typischen Mitochondriums. 
Dieses Problem wurde durch die Entwicklung der beugungsunbegrenzten NanoskopieTechniken behoben und heute stehen eine Vielzahl dieser Techniken zur Verfügung (Hell, 2007; Hell, 2009). Das grundsätzliche Prinzip all dieser Techniken beruht jedoch auf dem Schalten der Marker zwischen zwei unterscheidbaren (typischerweise Fluoreszenz-) Zuständen (Abb. 1.9). Dies wurde erstmals 1994 mit der Beschreibung des Prinzips der STED

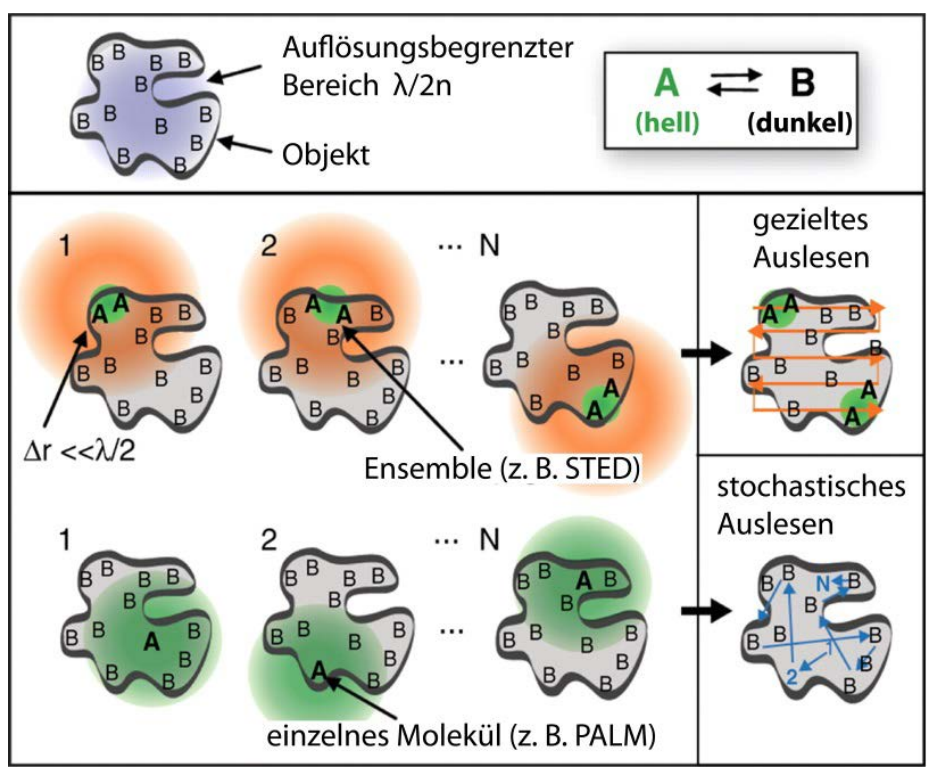

Abb. 1.9 Gezieltes Auslesen, verglichen mit stochastischem, zeit-sequenziellem Auslesen der Fluoreszenzmarker eines nanostrukturierten Objektes innerhalb eines beugungsbegrenzten Bereiches dessen Grenzen durch $\lambda / 2 n$ gegeben sind (bearbeitet aus (Hell, 2007)). Alle Techniken basieren auf dem Schalten zwischen zwei unterscheidbaren Zuständen (hier: A und B). Bei gerichtetem Schalten und Auslesen wird eine unbekannte Anzahl an Fluorophoren innerhalb des Zentrums eines beugungsunbegrenzten Bereiches in einen der beiden Zustände (hier: A) versetzt. Bei der stochastischen Methode wird sequenziell jeweils nur ein Fluorophor pro Zeitpunkt innerhalb des beugungsbegrenzten Bereiches in einen der beiden Zustände (hier: A) versetzt und durch die Bestimmung der Zentren der Einzelereignisse kann ein beugungsunbegrenztes Bild rekonstruiert werden. (,stimulated emmision depletion“)Mikroskopie vorgestellt (Hell \& Wichmann, 1994) und 2000 experimentell nachgewiesen (Klar et al., 2000).

Die einzelnen Techniken unterscheiden sich im Wesentlichen darin, welche unterscheidbaren Zustände verwendet werden und ob zwischen diesen gerichtet oder zufällig geschaltet (und damit auch ausgelesen) wird (Abb. 1.9). Diese Techniken sollen hier nicht alle im Detail vorgestellt werden, da dies den Rahmen sprengen würde und in der vorliegenden Arbeit nur die Methode der STED-Mikroskopie verwendet wurde.

In der STED-Mikroskopie wird, wie schon durch den Namen impliziert, zum Schalten zwischen den zwei Zuständen die stimulierte Emission genutzt. Dies bedeutet, dass Elektronen, die sich im angeregten Zustand befinden, aus dem sie normalerweise unter Aussendung eines Photons einer bestimmten Wellenlänge zurückfallen würden, durch Licht 
einer längeren Wellenlänge wieder in den Grundzustand gezwungen werden, wobei ein Photon derselben längeren (Stimulations-) Wellenlänge ausgesendet wird (Abb. 1.10). Dieser Effekt, der auch im Laser („light amplification by stimulated emission of radiation“) zur Amplifikation des Lichtes verwendet wird, wird im STED genutzt um die Fluoreszenz am Rand des beugungsbegrenzt angeregten Bereiches zu unterdrücken (Abb.1.10). Durch Verwenden dieses Prinzips kann die klassische Auflösungsgrenze nach Verdet, Abbé und Lord Rayleigh überwunden werden und die Auflösung ist nunmehr gegeben durch

$$
d \approx \frac{\lambda}{2 n \sin \alpha \sqrt{1+a I_{\max } / I_{\mathrm{s}}}}
$$

wobei $\lambda$ die Wellenlänge des Lichtes, $\mathrm{n}$ der Brechungsindex des Mediums, $\alpha$ der halbe Öffnungswinkel des Objektives, $a(>0)$ ein Faktor abhängig von der Form des „Nullpunktes“, $I_{\max }$ die maximale Intensität des zur stimulierten Emission genutzten Lichtes und $I_{\mathrm{s}}$ die „Sättigunsintensität“ des genutzten Farbstoffes ist (Hell, 2009). Die Auflösung ist daher theoretisch unbegrenzt, da für $I_{\max } / I_{\mathrm{s}} \rightarrow \infty$ die Auflösung gegen Unendlich geht. Für die klassische nicht-hochauflösende Lichtmikroskopie ist der Faktor $I_{\max }=0$.

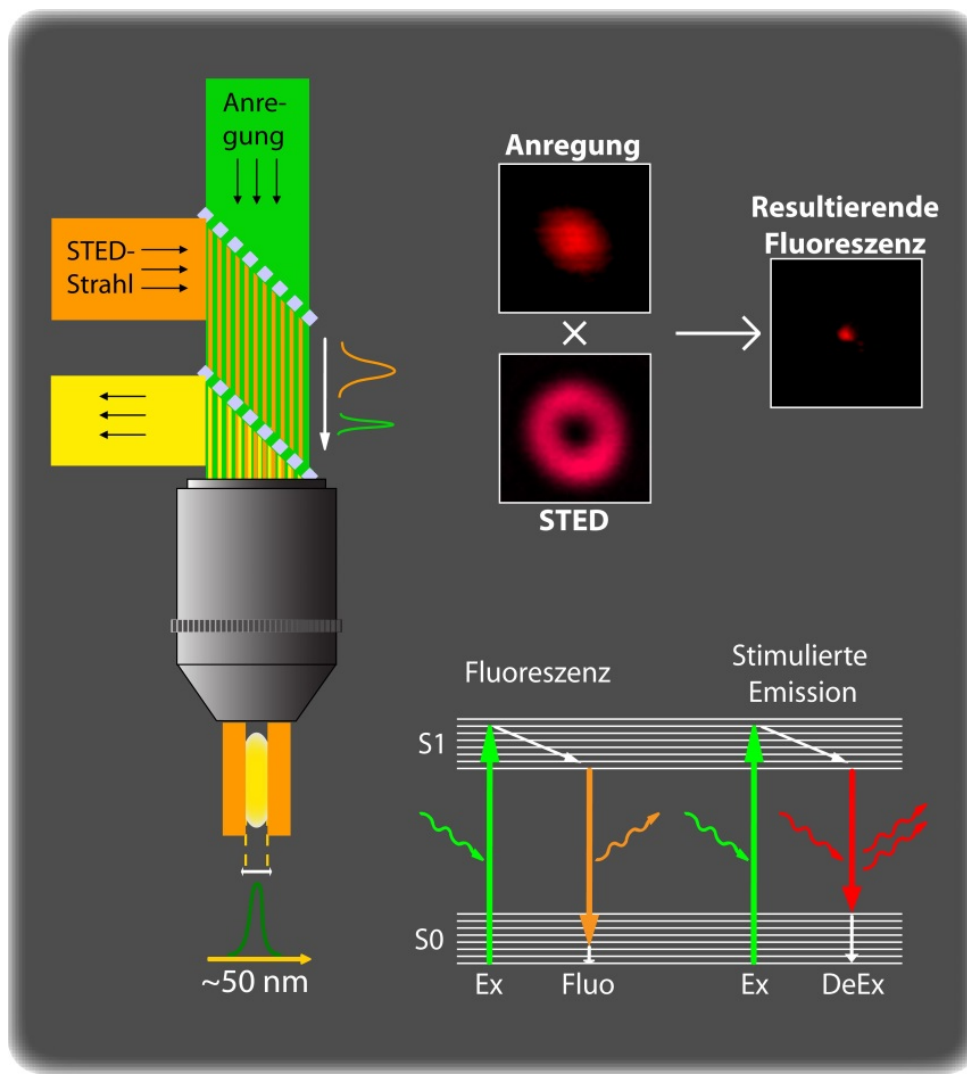

Abb. 1.10 Schematische Darstellung des Prinzips der STED-Mikroskopie.

Der STED-Strahl wird typischerweise als „Donut"-Form mit einem Nullpunkt im Zentrum erzeugt, so dass er die Fluoreszenz an den Rändern des beugungsbegrenzt angeregten Bereiches unterdrückt. Hierzu werden die Elektronen aus dem angeregten Zustand S1 wieder in den Grundzustand S0 gezwungen, wobei Photonen mit der gleichen Wellenlänge wie der STED-Strahl ausgesendet werden. 


\subsubsection{Elektronenmikroskopie}

Die Elektronenmikroskopie löst das Problem der begrenzten Auflösung durch die Verwendung eines Elektronenstrahls an Stelle des Lichtes. Da die Elektronen, abhängig von ihrer Beschleunigung, wesentlich kürzere Wellenlängen aufweisen, ist in der Elektronenmikroskopie die Auflösung nach Abbé per se wesentlich besser als bei der Verwendung von Licht. Sie ist theoretisch nur durch die Beschleunigung der Elektronen begrenzt, da die Wellenlänge $\lambda$ von Teilchen nach de Broglie durch folgende Gleichung gegeben ist

$$
\lambda=\frac{h}{p}=\frac{h}{m v} \sqrt{1-\frac{v^{2}}{c^{2}}}
$$

Hierbei ist $h$ das Plancksche-Wirkungsquantum, $p$ der Impuls des Teilchens, $m$ die Masse des Teilchens, $v$ die Geschwindigkeit des Teilchens und $c$ die Lichtgeschwindigkeit im Vakuum.

Durch Verwenden dieses Prinzips können in der Praxis Auflösungen von unter $1 \AA$

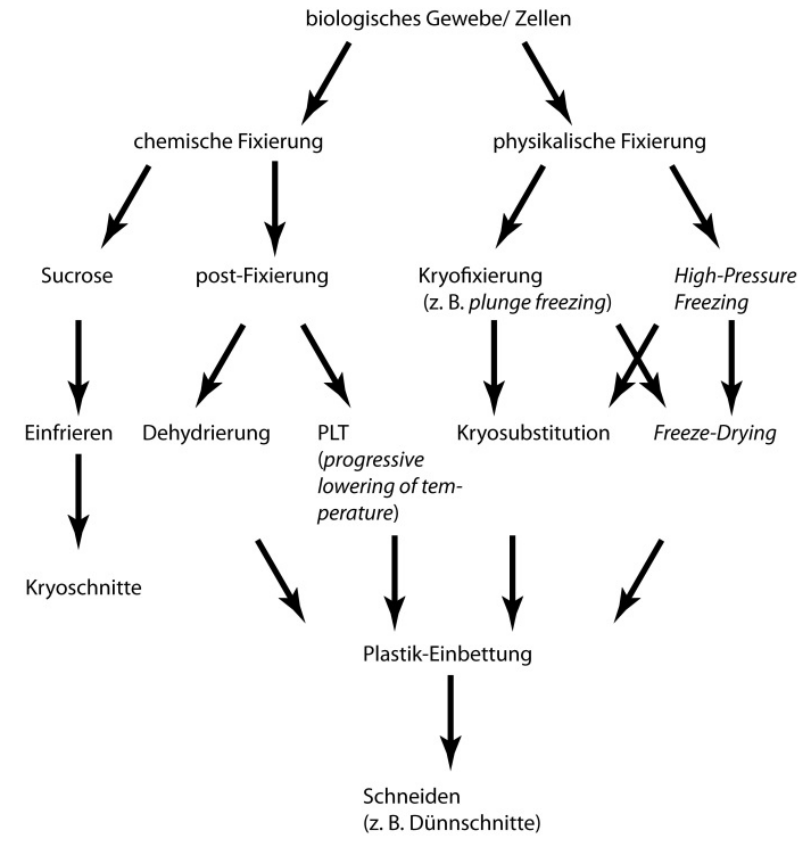

Abb. $\quad \mathbf{1 . 1 1}$ Schematische Darstellung verschiedener Möglichkeiten der Probenvorbereitung von biologischen Präparaten für die Transmissionselektronenmikroskopie.
(1 Ångström = 0,1 nm) erreicht werden. Der Kontrast in diesen Aufnahmen wird durch die Wechselwirkung der Elektronen mit den Elementen der Probe, in der hier verwendeten Transmissionselektronenmikroskopie durch die Streuung der Elektronen an der Probe, erzeugt. Ein Problem bei dieser Form der Mikroskopie stellt jedoch die Probenvorbereitung dar (Abb. 1.11). Damit die Probe im Elektronenstrahl platziert werden und der Strahl sie durchdringen kann, muss sie in ein Trägermedium eingebettet und in (Ultra-) Dünnschnitte zerteilt werden. 
Außerdem ist es für die meisten biologischen Anwendungen notwendig, die Probe zusätzlich zu kontrastieren, typischerweise mit schwermetallhaltigen Reagenzien. Dafür ist es bei entsprechender Aufarbeitung möglich in der Zelle beispielsweise alle Membranen darzustellen und so die Morphologie von Organellen im Kontext der Zelle zu erforschen. Es fehlen jedoch Möglichkeiten spezifische Proteine von Interesse in der gleichen Weise, wie in der Fluoreszenzmikroskopie nachzuweisen. Durch Photooxidation von Substanzen (in der Regel DAB (3,3'-Diaminobenzidin)) zu elektronendichten Präzipitaten können zwar die Bereiche der Lokalisationen der Proteine von Interesse dargestellt werden, es fehlt hierbei aber an der Spezifität des Signals. Eine weitere Möglichkeit stellt die quantitative ImmunoElektronenmikroskopie dar. Hierzu werden in der Regel Kryoschnitte verwendet, da die Erhaltung und die Zugänglichkeit der Epitope in diesen Proben am ehesten gegeben ist (Mayhew \& Lucocq, 2008). Durch Verwendung eines spezifischen Antikörpers und eines sekundären Gold-Konjugats können Proteinlokalisationen mit besserer Spezifität dargestellt werden. Bei dieser Methode fehlt es jedoch an Sensitivität, so dass eine statistische Auswertung der einzelnen Gold-Lokalisationen in einer Vielzahl von Bildern notwendig wird.

Es lässt sich festhalten, dass sowohl die Techniken der Fluoreszenzmikroskopie als auch der Elektronenmikroskopie jeweils ganz eigene, wesentliche Vorteile aufweisen und die Wahl der Methode daher genau auf die jeweilige Fragestellung abgestimmt werden muss. 


\subsection{Zielsetzung}

Der MINOS-Komplex ist ein für die Struktur der inneren Mitochondrienmembran entscheidender Komplex, der in Hefezellen an Cristae Junctions angereichert gezeigt wurde, wobei die sub-mitochondriale Verteilung der einzelnen Komponenten des Komplexes in Hefe-Mitochondrien aber großenteils und in Mitochondrien von Säugerzellen vollständig ungeklärt ist.

In der vorliegenden Arbeit sollte die Lokalisation der Kern-Komponenten des humanen MINOS-Komplexes (Mitofilin, MINOS1 und CHCHD3) mit beugungsunbegrenzten mikroskopischen Mitteln (STED-Mikroskopie) untersucht werden, um Erkenntnisse über die sub-mitochondriale Verteilung dieser Proteine zu gewinnen. Initial musste hierzu die Immunofluoreszenzfärbung der MINOS-Kernkomponenten für die hohen Anforderungen der hochauflösenden Lichtmikroskopie charakterisiert werden.

Es sollte überprüft werden, ob die MINOS-Kern-Komponenten erweiterte, zusammenhängende Strukturen bilden, die eine Funktion dieses Komplexes als eine Art mitochondriales Skelett ermöglichen würden. Weiterhin sollte die Verteilung der MINOSInteraktionspartner Sam50, Tom20 und DnaJC11 daraufhin untersucht werden, ob sich die Interaktion dieser Proteine mit dem MINOS-Komplex in einer vergleichbaren Lokalisation der Proteine äußert.

Insbesondere sollte die Lokalisation der MINOS-Kernkomponente Mitofilin durch quantitative Immuno-Elektronenmikroskopie in Bezug auf seine Position innerhalb der inneren Mitochondrienmembran analysiert und durch Elektronen-Tomographie die Architektur der inneren Mitochondrienmembran - vor allem die Anordnung der Cristae Junctions - in Hinblick auf eine mögliche Ordnung, die durch eine mögliche Ordnung der MINOS-Komponenten wiedergespiegelt wird, erforscht werden. 


\section{Material und Methoden}

\subsection{Material}

\subsubsection{Chemikalien}

Alle Chemikalien wurden, soweit nicht anders angegeben, im Reinheitsgrad „zur Analyse“ von den Firmen Sigma-Aldrich (München, Deutschland), Carl Roth (Karlsruhe, Deutschland), Merck (Darmstadt, Deutschland), Applichem (Darmstadt, Deutschland) und Serva (Heidelberg, Deutschland) bezogen.

Alle Lösungen und Puffer wurden mit Wasser aus der Reinstwasseraufbereitungsanlage ELGA (LabWater, Celle, Deutschland) angesetzt.

\subsubsection{Verwendete Antikörper}

\begin{tabular}{|l|l|l|l|}
\hline \multicolumn{1}{|c|}{ Antikörper gegen } & aus & Fluorophor & \multicolumn{1}{|c|}{ Hersteller } \\
\hline Mitofilin & Kaninchen & - & Abcam (ab48139) \\
\hline CHCHD3 & Kaninchen & - & $\begin{array}{l}\text { Atlas Antibodies } \\
\text { (HPA042935) }\end{array}$ \\
\hline MINOS1 (C1orf151) & Kaninchen & - & Abcam (ab84969) \\
\hline Tom20 & Kaninchen & - & $\begin{array}{l}\text { Santa Cruz } \\
\text { Biotechnology (sc- } \\
\text { 11415) }\end{array}$ \\
\hline DNAJC11 & Maus & - & $\begin{array}{l}\text { Abnova (H00055735- } \\
\text { B01P) }\end{array}$ \\
\hline Sam50 & Kaninchen & - & $\begin{array}{l}\text { Atlas Antibodies } \\
\text { (HPA034537) }\end{array}$ \\
\hline $\begin{array}{l}\text { ATP-Synthase, beta- } \\
\text { Untereinheit }\end{array}$ & Maus & - & Abcam (ab5432) \\
\hline$\alpha-T u b u l i n$ & Maus & - & Sigma Aldrich (T6074) \\
\hline DNA & Maus & - & Progen (61014) \\
\hline Kaninchen & Ziege & KK114 & selbst gekoppelt \\
\hline Maus & Schaf & KK114 & selbst gekoppelt \\
\hline Kaninchen & Ziege & Atto590 & selbst gekoppelt \\
\hline Maus & Schaf & Atto590 & selbst gekoppelt \\
\hline Kaninchen & Ziege & Cy3 & selbst gekoppelt \\
\hline Maus & Schaf & Selbst gekoppelt \\
\hline
\end{tabular}


Außerdem wurde ein Alexa Fluor 488 gekoppeltes Phaloidin-Konjugat (Life Technologies, Invitrogen (A12379)) zum Anfärben von Actin verwendet.

2.1.3 Eukaryotische Zellen

\section{Verwendete Zelllinien}

\begin{tabular}{|l|l|l|}
\hline Name & Organismus & Gewebe \\
\hline Hess & Mensch & Primäre, adulte Fibroblasten \\
\hline Neo & Mensch & Primäre, neonatale Fibroblasten \\
\hline Vero & Grüne Meerkatze (Chlorocebus sp.) & Nierenepithel \\
\hline HeLa & Mensch & Cervix-Krebs \\
\hline U2OS & Mensch & Osteosarkom \\
\hline
\end{tabular}

Alle Zellen wurden in DMEM-Medium kultiviert.

\section{Kultivierungsmedien}

\section{Reagenzien:}

\begin{tabular}{|l|l|l|}
\hline DMEM, high glucose, $1 \mathrm{x}$ & Gibco & $61965-059$ \\
\hline RPMI, $1 \mathrm{x}$ & Gibco & $61870-044$ \\
\hline FBS Gold & PAA & A15-151 \\
\hline Penicillin/ Streptomycin, $10.000 \mathrm{U} / \mathrm{ml} / 10.000 \mu \mathrm{g} / \mathrm{ml}$ & Biochrom & A2213 \\
\hline Natrium-Pyruvat, $100 \mathrm{mM}$ & Sigma-Aldrich & $\mathrm{S} 8636$ \\
\hline Trypsin/EDTA, 10x & Biochrom & L2153 \\
\hline
\end{tabular}


DMEM-Medium:

DMEM, high glucose

$10 \%$ FBS

1\% Na-Pyruvat

1\% Pen/Strep

Endkonzentration im Medium:

$\begin{array}{ll}\text { Na-Pyruvat } & 1 \mathrm{mM} \\ \text { Pen } & 100 \text { units } / \mathrm{ml} \\ \text { Strep } & 100 \mu \mathrm{g} / \mathrm{ml}\end{array}$

Einfriermedium:

70\% DMEM, high glucose

$20 \%$ FBS

10\% DMSO

\subsection{Methoden}

\subsubsection{Zellbiologische Methoden}

\section{Kultivierung von Hefezellen}

Flüssigkulturen von Hefezellen wurden für die Licht- und Elektronenmikroskopie bei $30^{\circ} \mathrm{C}$ und 150 rpm im Innova44 Schüttel-Inkubator (New Brunswick Scientific, Edison, NJ, USA) bis zu einer $\mathrm{OD}_{600}$ von 0,7 - 1,2 angezogen. Für die in dieser Arbeit gezeigten elektronenmikroskopischen Aufnahmen wurden die Hefen in YP Laktat-Medium (10 g/l Hefeextrakt, $20 \mathrm{~g} / \mathrm{l}$ Pepton aus Casein, $23 \mathrm{ml} / \mathrm{l}$ L(+)-Laktat (85\%), 0,02 g/l Uracil, 0,02 g/l Adeninsulfat). Für die Lichtmikroskopischen Aufnahmen wurden die Hefen in PM GalaktoseMedium (1,7 g/l Yeast Nitrogen Base, $5 \mathrm{~g} / \mathrm{l}\left(\mathrm{NH}_{4}\right)_{2} \mathrm{SO}_{4}, 5 \mathrm{~g} / \mathrm{l}$ Trypton, $20 \mathrm{~g} / \mathrm{l}$ Galaktose, 0,02 $\mathrm{g} / \mathrm{l}$ Adeninsulfat) angezogen und durch Uracil-Mangel auf das Plasmid das mitochondrial lokalisiertes GFP exprimierte selektiert. 


\section{Kultivierung von eukaryotischen Zellen}

Alle Zellinien wurden in Kultivierungsmedium (vgl. 2.1.4.2) in $75 \mathrm{~cm}^{2}$-Zellkulturflaschen (Greiner Bio-One, Frickenhausen, Deutschland) bei $37^{\circ} \mathrm{C}$ und $5 \% \mathrm{CO}_{2}$ in einem Hera Cell 240-Inkubator der Thermo Scientific kultiviert. Die Zellen wurden zwei bis drei Mal die Woche bei einer Konfluenz von $60-70 \%$ in einem Verhältnis von 1:40 in eine neue Flasche mit neuem Medium passagiert. Die adhärenten Zellen wurden durch Zugabe von jeweils $1 \mathrm{ml}$ Trypsin vom Flaschenboden gelöst.

Die Kontrolle der Zellen erfolgte mir einem Leica DMI3000B-Mikroskop, das mit einem Leica PL Fluotar (10x/0.30 PH1)-Objektiv ausgestattet war.

\section{Aussaat der Zellen für die mikroskopische Analyse}

Zur Aussaat der Zellen für die mikroskopische Analyse wurden die Zellen durch Zugabe von Trypsin vom Flaschenboden abgelöst und wieder in Kultivierungsmedium aufgenommen. Die gewünschte Zellzahl wurde auf sterilisierte (durch Isopropanol) Deckgläschen für die Mikroskopie $(8 \mathrm{~mm}, 10 \mathrm{~mm}$ oder $18 \mathrm{~mm}$ (Menzel GmbH \& Co KG, Braunschweig, Deutschland)) in Zellkulturschalen der jeweils gewünschten Größe (6-well, 12-well, 24-well Tissue Culture Testplates (alle: SPL Life Science) oder $100 \times 20$ mm Cell Culture Dish (Sarstedt)) gegeben und auf diesen Deckgläschen weitere 1 - 3 Tage kultiviert.

\section{Bestimmung der Zellzahl}

Die Bestimmung der Zellzahl erfolgte mit Hilfe einer Neubauer-Zählkammer (Brand, Wertheim, Deutschland). Die trypsinierten Zellen wurden zu diesem Zweck in Kultivierungsmedium (s. 2.1.4.2) aufgenommen und $10 \mu \mathrm{l}$ dieser Suspension zur Bestimmung der Zellzahl verwendet. Diese wurde durch Auszählung von vier Großquadraten nach folgender Formel bestimmt:

$$
\begin{aligned}
& \text { Zellzahl } / \mathrm{ml}=(\mathrm{n} / 4) \times 10^{4} / \mathrm{ml} \\
& \mathrm{n}=\text { Gesamtmenge ausgezählter Zellen }
\end{aligned}
$$




\subsubsection{Proteinbiochemische Methoden}

\section{Isolierung von Gesamtzellprotein}

Zur Isolierung von Gesamtzellprotein aus Säugerzellen wurden die Zellen nach dem Entfernen des Kulturmediums zweimal mit PBS gewaschen und durch Inkubation mit Trypsin/EDTA (5 min, bei $37^{\circ} \mathrm{C}$ ) vom Zellkulturgefäß gelöst. Die Zellen wurden durch Zentrifugation (2500 g, 4 min) pelletiert und zwei Mal in PBS gewaschen. Dann wurden die Zellen in SDS-Probenpuffer aufgenommen, dem ein Protease-Inhibitor-Gemisch (Complete Protease Inhibitor Cocktail; Roche, Mannheim, Deutschland) zugesetzt war.

\section{Proteinkonzentrationsbestimmung}

Die Konzentration der Proteine wurde durch Bradford-Assay bestimmt. Dazu wurde das „BioRad-Protein-Assay“ von BioRAD (Hercules, CA, USA) verwendet.

Zur Bestimmung der Konzentration wurden die Proben mit je $1 \mathrm{ml}$ einer 1:5 verdünnten Farbstofflösung gemischt. Nach einer Inkubationszeit von fünf Minuten bei Raumtemperatur wurde die Absorption der Probe bei $600 \mathrm{~nm}$ gemessen. Durch den Vergleich mit einer Eichkurve wurde anschließend die Proteinkonzentration in der Probe ermittelt.

\section{Western-Blot-Analyse}

Bei der Western-Blot-Analyse werden die einzelnen Proteine durch Gelelektrophorese aufgetrennt, auf eine Membran übertragen und dann durch Enzym-gekoppelte Antikörper nachgewiesen.

\section{Polyacrylamid-Gelelektrophorese}

Die Proteine wurden durch diskontinuierliche SDS Polyacrylamid- Gelelektrophorese (SDSPAGE) nach ihrer Größe aufgetrennt. Das Trenngel hatte eine Acrylamidkonzentration von $12,5 \%$ (w/v) $(6,3 \mathrm{ml} \mathrm{H} 2 \mathrm{O}, 5 \mathrm{ml}$ 1,5M Tris/HCl, 8,3 ml 30\% Acrylamid, $200 \mu \mathrm{l}$ 10\% SDS, $200 \mu \mathrm{l}$ 10\% APS, $20 \mu$ I TEMED). Das Sammelgel hatte eine Konzentration von 5\% (w/v) auf (5,6 ml 
$\mathrm{H}_{2} \mathrm{O}, 2,5 \mathrm{ml}$ 0,5 M Tris/HCl, 1,7 ml 30\% Acrylamid, $100 \mu \mathrm{l}$ 10\% SDS, $100 \mu \mathrm{l}$ 10\% APS, $10 \mu \mathrm{l}$ TEMED). Die Proteinextrakte wurden in Probenpuffer $(2 \%(w / v)$ SDS, 0,8 M ßMercaptoethanol, 10\% (v/v) Glyzerin, 0,2\% Bromphenolblau, 62,5 mM Tris/HCl) gelöst, für fünf Minuten auf $95^{\circ} \mathrm{C}$ erhitzt und anschließend auf das Polycrylamid-Gel aufgetragen. Die elektrophoretische Auftrennung der Proteine wurde bei 20 - $50 \mathrm{~mA} / \mathrm{Gel}$ durchgeführt. Als Elektrophorese-Puffer wurde Lämmli-Puffer (25 mM Tris/ HCl; 192 mM Glyzin; 0,1\% (w/v) SDS) verwendet. Zur Abschätzung der Größe der detektierten Proteine wurde als Größenreferenz ein Proteinmarker verwendet (PageRuler Prestained Protein Ladder, MBI Fermentas, Burlington, Canada).

\section{Coomassie-Färbung der Protein-Gele}

Die Proteine im SDS-Polyacrylamidgel wurden mit dem Farbstoffs Coomassie Brilliant Blau angefärbt. Die Gele wurden hierfür ca. 20 Minuten in die Färbelösung $(10 \%$ (v/v) Essigsäure, 25\% (v/v) Isopropanol, 0,1\% (w/v) Coomassie Blau R- 250) gelegt. Anschließend wurde die Gele in Entfärbelösung (10\% (v/v) Essigsäure) gewaschen.

\section{$\underline{\text { Transfer von Proteinen }}$}

Zur Detektion der Proteine wurden sie aus dem Protein-Gel durch Nass-Blot auf eine Nitrocellulose-Membran (Protran, Whatman GmbH, Dassel, Deutschland) übertragen. Dabei wurden die Membran und das Proteingel zwischen mehrere mit Transferpuffer $(20 \mathrm{mM}$ Tris/ $\mathrm{HCl}, 150 \mathrm{mM}$ Glycin, 20\% (v/v) Methanol) getränkte Filterpapiere und Schwämme gelegt. Die Proteine wurden elektrophoretisch für 16 Stunden bei $25 \mathrm{~V} / 100 \mathrm{~mA}$ bei $4^{\circ} \mathrm{C}$ in einem mit Transferpuffer gefüllten Tank auf die Membran übertragen.

\section{Ponceau-Färbung}

Zum Überprüfen der Effizienz des Proteintransfers auf die Membran wurden Färbungen mit Ponceau Rot durchgeführt. Die Membranen wurden dazu mit Wasser gewaschen und für zehn Minuten in Ponceau-Färbelösung $(0,3 \%(w / v)$ Ponceau S, 3\% (w/v) TCA in Wasser) inkubiert. Nach der Entfärbung in Wasser wurden die Proteinbanden dokumentiert. 
Anschließend wurde die Membran zur Entfernung des Farbstoffs mehrfach in PBS gewaschen.

Immunologischer Nachweis von Proteinen auf Membranen

Zur Detektion von Proteinen auf der Membran wurden spezifische Antikörper verwendet. Dazu wurde die Membran in Blockierungslösung (5\% (w/v) Magermilchpulver, 0,05\% (v/v) Tween20 in PBS) geblockt und anschließend zwei Stunden bei Raumtemperatur mit dem Erstantikörper inkubiert. Anschließend wurde die Membran mehrfach in Waschpuffer $(0,5 \%(\mathrm{w} / \mathrm{v})$ Magermilchpulver, 0,5\% Tween20 in PBS) gewaschen und mit dem Peroxidasegekoppelten Sekundärantikörper (in 5\% (w/v) Magermilchpulver; 0,05\% (v/v) Tween20 in PBS) für 1 Stunde bei Raumtemperatur inkubiert. Nach mehrmaligem Waschen in PBS wurde die an dem sekundären Antikörper gebundene Peroxidase (Horesradish Peroxidase, HRP) durch eine Detektionslösung (Western Lightning Plus ECL, Perkin Elmer LAS GmbH, Rodgau, Deutschland) nachgewiesen und die hierbei entstehende Chemilumineszenz mit einem Lumineszenz-Detektor (Lumi-Imager, Roche, Mannheim, Deutschland) detektiert. 


\subsubsection{Lichtmikroskopische Methoden}

\section{Kopplung von Sekundärantikörpern mit Fluoreszenzfarbstoffen}

- Säule (Sephadex G25 Säule (PD-10)) mit 30 ml PBS equilibrieren

- $\quad$ 2,0 mg Antikörper mit $100 \mu \mathrm{l} 1 \mathrm{M} \mathrm{NaHCO}_{3}$ versetzen

- Farbstoff in DMF (wasserfrei) lösen $(10 \mathrm{mg} / \mathrm{ml})$; zur Markierung werden $20 \mu \mathrm{l}$ (d.h. $0,2 \mathrm{mg}$ ) benötigt

- Proteine bei RT rühren, den gelösten Farbstoff zugeben und $1 \mathrm{~h}$ bei RT rühren

- Zugabe von $100 \mu \mathrm{ll}$ M Tris; 5 min rühren

- Aufreinigen über PD-10-Säule

- Proteinkonzentration bestimmen (Bradford Assay (Bio-Rad Protein Assay, Bio-Rad))

- $\quad$ Aliquotieren; einfrieren in flüssigem $\mathrm{N}_{2}$; Lagerung bei $-80^{\circ} \mathrm{C}$

\section{Immunofluoreszenzmarkierung}

- Fixieren: $5 \mathrm{~min}$ in $37^{\circ} \mathrm{C} \mathrm{4 \%} \mathrm{FA} \mathrm{(PFA} \mathrm{in} \mathrm{PBS)} \mathrm{(soweit} \mathrm{nicht} \mathrm{anders} \mathrm{angegeben)}$

- Permeabilisieren: 5 min 0,5\% Triton-X-100 in PBS (soweit nicht anders angegeben)

- Blocken: 5 min 5\% BSA/100 mM Glycin in PBS

- Primärantikörper: $1 \mathrm{~h}$ in 5\% BSA/100 mM Glycin in PBS

- 5 min 0,5\% Triton-X-100 in PBS (soweit nicht anders angegeben)

- 5 min 5\% BSA in PBS

- Sekundärantikörper: $1 \mathrm{~h}$ in 5\% BSA/100 mM Glycin in PBS

- 15 min in PBS waschen

- in Mowiol mit DABCO eindeckeln (soweit nicht anders angegeben)

\section{Immunofluoreszenzmarkierung mit zwei Primärantikörpern aus derselben} Spezies

- Fixieren: 5 min in $37^{\circ} \mathrm{C} 4 \%$ FA (PFA in PBS)

- Permeabilisieren: 5 min 0,5\% Triton-X-100 in PBS

- Blocken: 5 min 5\% BSA/100 mM Glycin in PBS 
- 1. Primärantikörper: $1 \mathrm{~h}$ in 5\% BSA/100 mM Glycin in PBS

- 5 min 0,5\% Triton-X-100 in PBS

- $\quad 5$ min 5\% BSA in PBS

- $\quad$ 1. Sekundärantikörper: $1 \mathrm{~h}$ in 5\% BSA/100 mM Glycin in PBS

- 15 min in PBS waschen

- Blocken der freien Bindestellen des 1. Sekundärantikörpers mit einem unspezifischen Antikörper aus der gleichen Spezies wie der 1. Primärantikörper: 40 min in 5\% BSA/100 mM Glycin in PBS

- Blocken der nicht markierten Stellen des 1. Primärantikörpers mit einem FabFragment gegen sie Spezies des 1. Primärantikörpers: 40 min in 5\% BSA/100 mM Glycin in PBS

- 10 min in PBS waschen

- Fixieren: 5 min in 4\% FA (PFA in PBS)

- 5 min in PBS waschen

- Permeabilisieren: 5 min 0,5\% Triton-X-100 in PBS

- Blocken: 5 min 5\% BSA/100 mM Glycin in PBS

- 2. Primärantikörper: 50 min in 5\% BSA/ 100mM Glycin in PBS

- 5 min 0,5\% Triton-X-100 in PBS

- $\quad 5$ min 5\% BSA in PBS

- 2. Sekundärantikörper: 40 min in 5\% BSA/100 mM Glycin in PBS

- 15 min in PBS waschen

- in Mowiol mit DABCO eindeckeln

\section{Epifluoreszenzmikroskopie:}

Für die Epifluoreszenzmikroskopie wurde das Leica Mikroskop DM6000B (Leica Microsystems, Wetzlar, Deutschland) verwendet. Das Mikroskop war ausgestattet mit einem 100x Ölimmersionsobjektiv (PL APO, 100x/ 1,40 - 0.70 Öl), einer CCD-Kamera (DFC350FX) und verschiedenen Filtern (A4 (Anregung: 360/40 nm; Emission: 470/40 nm), L5 (Anregung: 480/40 nm; Emission: 527/30 nm), GFP (Anregung: 470/40 nm; Emission: 
525/50 nm), N3 (Anregung: 546/12 nm; Emission: 600/40 nm), BGR (Anregung: 420/30 nm; 495/15 nm; 570/20 nm; Emission: 465/20 nm; 530/30 nm; 640/40 nm), SFRED (Anregung: 630/20 nm; Emission: 667/30 nm). Die Beleuchtung erfolgte durch eine Metallhalogenidlampe (EL6000, Leica Microsystems).

\section{Konfokalmikroskopie:}

Für die Konfokalmikroskopie wurde das Laser Raster Mikroskop TCS SP5 (Leica Microsystems) verwendet. Alle Aufnahmen wurden mit dem Öl-Immersionsobjektiv (HCX PL APO CS 63x/ 1,40 - 0.60 Öl) gemacht. Zur Anregung standen folgende Laser zur Verfügung: 405er Diode (405 nm), Argon-Laser (458 nm/ 476 nm/ 488 nm/ 496 nm/ 514 nm), DPSS 561 (561 nm) und HeNe-Laser (630 nm). Zur Detektion des Fluoreszenzsignals standen vier Photomultiplier (PMT) zur Verfügung, die im dynamischen Bereich betrieben wurden. Die Trennung von Anregung und Emission erfolgte durch einen AOBS (acusto optical beam splitter). In dieser Arbeit wurden alle Aufnahmen bei einer Scan-Geschwindigkeit von $400 \mathrm{~Hz}$ und einer Pinhole-Größe von einer Airy-Scheibe erstellt. Für Mehr-FarbenAufnahmen wurde das Mikroskop im sequenziellen Modus (between frames) benutzt und es wurden generell z-Stapel aufgenommen. Alle Voxel-Größen wurden gemäß des NyquistKriteriums gewählt. Jedes Bild wurde mindestens dreifach aufgenommen und gemittelt (line Average).

\section{STED-Mikroskopie}

\subsection{Ein-Farben-STED}

Für die STED-Aufnahmen in einem Kanal wurde ein nicht kommerzielles STED genutzt, dass eine Auflösung von 40 - 50 nm ermöglichte (Harke et al., 2008) (Abb. 2.1). Dieser Aufbau war mit einem 100x Ölimmersionsobjektiv (PL APO, NA 1,40) ausgestattet und zur Detektion wurde das Emissionslicht der Wellenlängen von 650 bis $690 \mathrm{~nm}$ auf vier APDs (avalanche photo diode) verteilt. Die Anregung erfolgte durch einen gepulsten Diodenlaser mit einer 
Wellenlänge von $635 \mathrm{~nm}$. Die Anregungspulse wurden (mit einem zeitlichen Versatz („delay“)) durch den STED-Laser getriggert. Bei dem STED-Laser handelt es sich um einen MIRA 900 der Firma Coherent (USA) der bei einer Wellenlänge von $760 \mathrm{~nm}$ betrieben wurde und der eine Repetitionsrate von $76 \mathrm{MHz}$ hat. Die Pulse dieses Femtosekunden-Lasers wurden durch eine 100 Meter single-mode-Faser auf eine Pulslänge von 300 ps gesteckt. Die „Donut“-Form des STED-Strahls wurde mit einer Vortex-Phasenplatte (RPC Photonics, Rochester, NY, USA), die zu einer helikalen Phasenverschiebung des STED-Strahls führt, erzeugt. Die Leistung dieses STED-Lasers betrug in der Rückapertur ca. 200 mW. Alle Proben die an diesem Aufbau gemessen wurden sind mit dem Infrarot-Fluoreszenzfarbstoff KK114 markiert worden.

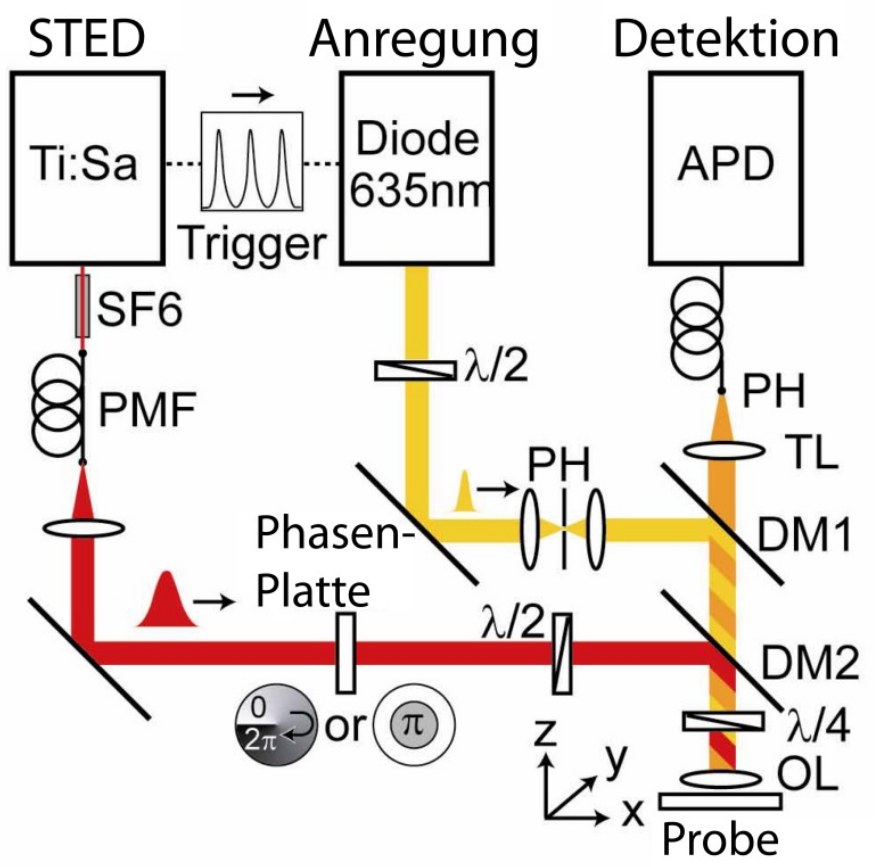

Abb. 2.1 Schematische Darstellung des Aufbaus, der für die ein-FarbenSTED-Mikroskopie verwendet wurde (bearbeitet aus (Harke et al., 2008)). (PMF: "polarisation maintaining fiber"=Polarisations-erhaltende Faser; APD: "avalanche photo diode $^{\prime \prime}=$ Avalanche Photo-Diode; $\mathrm{PH}$ : "pinhole"; TL: "tube lens"=Tubus-Linse; DM: "dichroic mirror"=dichroitischer Spiegel; OL: "objective lens"=ObjektivLinse; SF6: "glass rods"=Glas-Stäbe) 


\subsection{Zwei-Farben-STED}

Für die STED-Aufnahmen in zwei Kanälen wurde ein nicht kommerzielles STED genutzt, dass eine Auflösung von 40 - 50 nm in beiden Kanälen ermöglichte (Buckers et al., 2011) (Abb. 2.2). Dieser Aufbau war mit einem 100x Ölimmersionsobjektiv (PL APO, NA 1,40) ausgestattet und zur Detektion wurde das Emissionslicht der Wellenlängen 650 - 680 nm für den roten Kanal und 600 - 640 nm für den grünen Kanal durch jeweils eine APD (avalanche photo diode) detektiert. Die Anregungs- sowie die STED-Strahlen wurden durch einen einzelnen gepulsten Weißlichtlaser erzeugt (Supercontinuum SC450-PP-HE, Fianium, England), der eine Repetitionsrate von $1 \mathrm{MHz}$ hat. Die Anregungswellenlängen von $570 / 4 \mathrm{~nm}$ und 650/4 nm wurden durch einen AOTF (acousto-optical tunable filter) ausgewählt. Die STED-Wellenlängen von 720/20 nm und 755/30 nm wurden durch Prismen basierte Monochromatoren ausgewählt. Die „Donut“-Form der STED-Strahlen wurde mit Vortex-Phasenplatten (RPC Photonics, Rochester, NY, USA), die zu einer helikalen

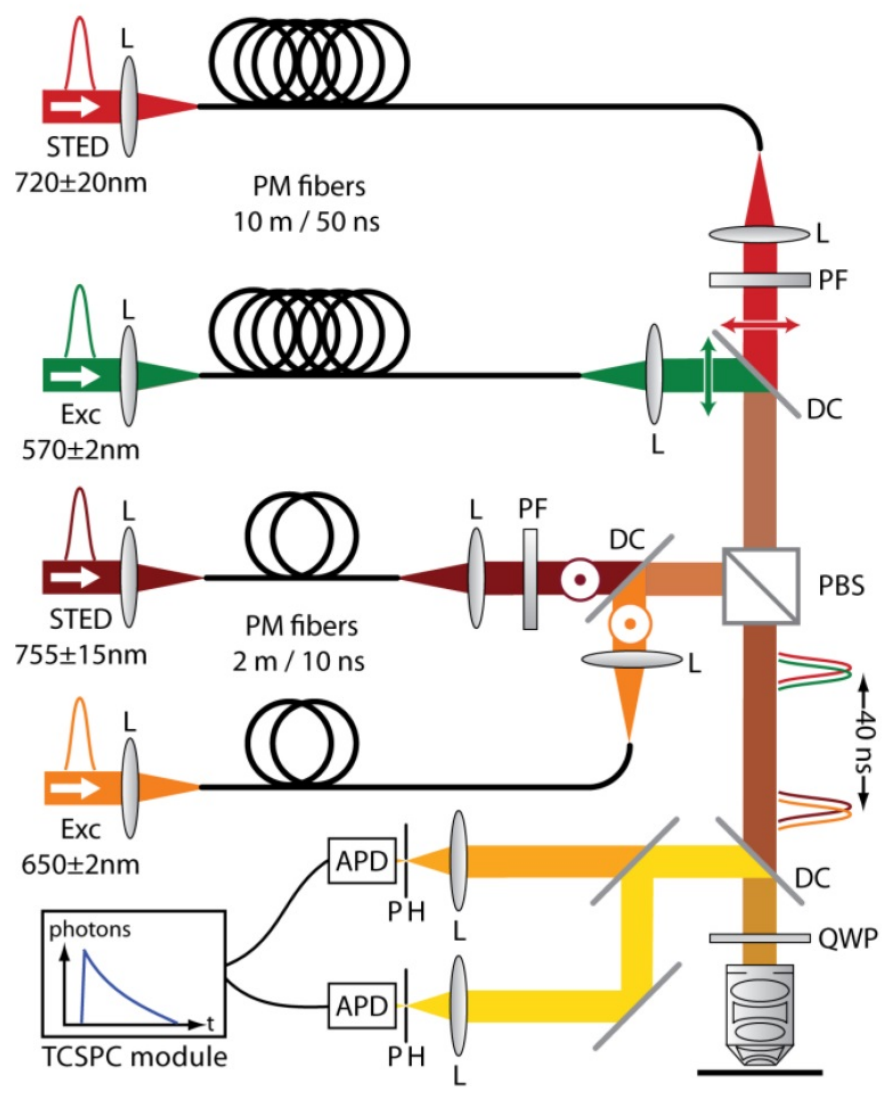

Abb. 2.2 Schematische Darstellung des Aufbaus, der für die zwei-FarbenSTED-Mikroskopie verwendet wurde (bearbeitet aus (Buckers et al., 2011)). (PM fiber: „polarisation maintaining fiber" $^{\prime \prime}$ Polarisations-erhaltende Faser; L: "lens"=Linse; PF: "phase filter"=Phasen-Filter; DC: "dichroic mirror"=dichroitischer Spiegel; PBS: „polarising beam splitter" $=$ polarisierender Strahlteiler; QWP: "quarter- wave plate"=Viertelwellenplatte; $\quad \mathrm{PH}$ : "pinhole"; APD: "avalanche photo diode"=Avalanche Photo-Diode; TCSPC: "time-correlated single-photon counting "=Zeit-korreliertes einzelPhotonen Zählen) 
Phasenverschiebung des STED-Strahls führen, erzeugt. Die Leistung des STED-Lasers betrug in der Rückapertur 1,5 mW. Alle Proben die an diesem Aufbau gemessen wurden sind mit dem Infrarot-Fluoreszenzfarbstoff KK114 und dem Fluoreszenzfarbstoff Atto590 markiert worden.

\subsection{Bildbearbeitung}

Die einzigen Nachbearbeitungen, die an den Bildern vorgenommen wurden, sind Kontrastanpassungen („,contrast stretching“), Glättung („smoothing“) oder Interpolation (Lagrange Interpolation, doppelte Pixelzahl). Die beiden letzten Nachbearbeitungen wurden mit der Software: Imspector_v0.10 (A. Schönle, Max-Planck-Institut für biophysikalische Chemie, Göttingen, Deutschland) durchgeführt. Die Kontrastanpassungen wurden entweder mit Imspector_v0.10 (A. Schönle, Max-Planck-Institut für biophysikalische Chemie, Göttingen, Deutschland) oder mit Adobe Photoshop CS3 (Version 10.0) durchgeführt.

\section{Simulation}

Für die Simulation wurde mit Imspector_v0.10 (A. Schönle, Max-Planck-Institut für biophysikalische Chemie, Göttingen, Deutschland) eine dreidimensionale Röhre simuliert. Auf dieser wurden zufällig Punkte verteilt und die Ergebnisse wurden mit einer typischen STED-PSF gefaltet. Für die einzelnen Operationen wurden folgende Formeln verwendet:

STED-PSF:

Röhre/Tubus:

zufällig verteilte Punkte:

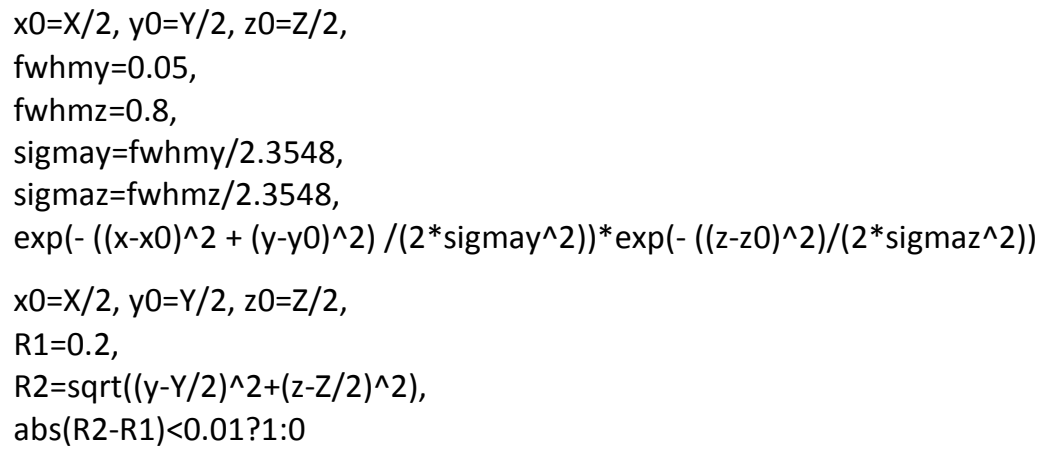




\subsubsection{Elektronenmikroskopische Methoden}

\section{Vorbereitung von Säugerzellen für die Elektronenmikroskopie und Elektronen-Tomographie}

- Zellen auf Aclar- Plättchen bis zu einer Konfluenz von ca. 90\% wachsen lassen

- adhärente Zellen für 15 min in 0,1\% GA + 4\% FA fixieren

- $15 \mathrm{~h}$ bei $4^{\circ} \mathrm{C}$ in $2,5 \% \mathrm{GA}$ in $0,1 \mathrm{M}$ Cacodylatpuffer

- $\quad 3 x$ in 0,1 M Cacodylatpuffer waschen

- $1 \%$ OsO4 in 0,1 M Cacodylatpuffer, $3 \mathrm{~h}$

- $\quad 1 x$ in $0,1 \mathrm{M}$ Cacodylatpuffer und $2 \mathrm{x}$ in $\mathrm{ddH}_{2} \mathrm{O}$ waschen

- ca. 30 min in $0,1 \%$ UAc (in $\mathrm{H}_{2} \mathrm{O}$ )

- Alkoholreihe: 30\%, 50\%, 70\%, 100\% Ethanol; je 5 min (bei 30\% 2-3x 5 min - zum Auswaschen des Uranylacetats)

- 5 min $100 \%$ Propylenoxid

- 1 h 50\%/50\% Propylenoxid/Epon

- $1 \mathrm{~h} \mathrm{100 \%} \mathrm{Epon}$

- $\quad 100 \%$ Epon über nacht

- Schneiden mit einem Ultramikrotom (Leica EM UC6, Leica Microsystems, Wetzlar, Deutschland) in $250 \mathrm{~nm}$ dicke Schnitte für die tomographischen Aufnahmen, ansonsten in $50 \mathrm{~nm}$ dicke Schnitte

- Übertragen der Schnitte auf Pioloform (0,7\%) beschichtete, Kohlenstoff-bedampfte 200 mesh-Grids

- Nachkontrastieren mit 1\% Uranylacetat und Bleicitrat

\section{Vorbereitung von Hefezellen für die Elektronenmikroskopie}

- Die Zellen wurden bei einer $\mathrm{OD}_{600}$ von 0,7 pelletiert und durch "high pressure freezing" (Leica EM HPM100, Leica Microsystems, Wetzlar, Deutschland) in $3 \mathrm{~mm}$ Trägerscheiben fixiert 
- Die Gefriersubstitution wurde in einem Leica EM AFS- Gefriersubstitutionsgerät (Leica Microsystems, Wetzlar, Deutschland) nach folgendem Programm durchgeführt:

\begin{tabular}{|c|l|l|}
\hline Dauer & \multicolumn{1}{|c|}{ Temperatur } & \multicolumn{1}{c|}{ Lösungen } \\
\hline $70 \mathrm{~h}$ & $-90^{\circ} \mathrm{C}$ & $1 \% \mathrm{H}_{2} \mathrm{O}+0,5 \% \mathrm{GA}$ in Aceton \\
\hline $7 \mathrm{~h}$ & $-90^{\circ} \mathrm{C}$ & $\begin{array}{l}0,1 \% \mathrm{UAC}+5 \% \mathrm{H}_{2} 0+0,5 \% \mathrm{GA} \\
\text { in Aceton }\end{array}$ \\
\hline $14 \mathrm{~h}$ & $-90^{\circ} \mathrm{C}->-20^{\circ} \mathrm{C}\left(+5^{\circ} \mathrm{C} / \mathrm{h}\right)$ & \\
\hline $18 \mathrm{~h}$ & $-20^{\circ} \mathrm{C}$ & \\
\hline $2,5 \mathrm{~h}$ & $-20^{\circ} \mathrm{C}->+5^{\circ} \mathrm{C}\left(+10^{\circ} \mathrm{C} / \mathrm{h}\right)$ & \\
\hline $2 \mathrm{~h}$ & $+5^{\circ} \mathrm{C}$ & $4 \times 30$ min mit Aceton waschen \\
\hline
\end{tabular}

- Anschließend Plättchen entfernt und Proben aus dem Gerät herausgenommen

- 5 min 100\% Propylenoxid

- 1 h 50\%/50\% Propylenoxid/Epon

- $1 \mathrm{~h} 100 \%$ Epon

- $\quad 100 \%$ Epon über Nacht

- Schneiden mit einem Ultramikrotom (Leica EM UC6, Leica Microsystems, Wetzlar, Deutschland) in $50 \mathrm{~nm}$ dicke Schnitte

- Übertragen der Schnitte auf Pioloform (0,7\%) beschichtete, Kohlenstoff-bedampfte 200 mesh-Grids

- Nachkontrastieren mit 1\% Uranylacetat und Bleicitrat

\section{Probenvorbereitung für die Immuno-Elektronenmikroskopie}

Die Proben für die Immuno-Elektronenmikroskopie wurden nach dem in der Literatur (Tokuyasu, 1973) angegebenen Protokoll angefertigt und in $80 \mathrm{~nm}$ Schnitte zerteilt. Die Schnitte wurden für 20 min mit polyklonalem Antiserum gegen Mitofilin und anschließend für 20 min mit $10 \mathrm{~nm}$ Protein-A-Gold inkubiert. Die Schnitte wurden anschließend mehrfach gewaschen und mit Uranylacetat/Methylzellulose für 10 min auf Eis kontrastiert. 


\section{Elektronenmikroskopische Aufnahmen}

Die Elektronenmikroskopischen Aufnahmen wurden mit einem Philips CM 120 Transmissions-Elektronen-Mikroskop, das mit einer TVIPS $2 \mathrm{k} \times 2 \mathrm{k}$ slow-scan CCD-Kamera ausgestattet war, durchgeführt. Die Tomographischen Aufnahmen wurden in $3^{\circ}$ Saxton Intervallen von $-64,5^{\circ}$ bis $64,5^{\circ}$ durchgeführt. Die Berechnung der Serien und die VolumenSegmentierung wurden semiautomatisiert mit der IMOD Software (Boulder Laboratory for 3-Dimensional Electron Microscopy of Cells, University of Colorado, USA) durchgeführt. 


\section{Ergebnisse}

\subsection{Analyse der sub-mitochondrialen Lokalisation des humanen MINOS-Komplexes}

Der MINOS („mitochondrial inner membrane organizing system“)-Komplex ist ein großer heterooligomerer Protein-Komplex, der in der inneren mitochondrialen Membran von Hefebis hin zu humanen Zellen zu finden ist. Er ist entscheidend an der Morphologie der Cristae beteiligt und das Fehlen einzelner seiner Komponenten, die in der Hefe an Cristae Junctions lokaliert gezeigt wurden, führt zu einem Verlust dieser Verbindungen zwischen den Cristae und der inneren Grenzflächenmembran (vgl. 1.3.1.1). Zusätzlich weist dieser Komplex sowohl in Säuger- als auch in Hefezellen - eine Vielzahl von Interaktionen auf, die diesen integralen Innenmembrankomplex mit Proteinen des Intermebranraumes, der äußeren Mitochondrienmembran und über letztere vielleicht sogar mit der Membran des endoplamatischen Retikulums in Verbindung bringt (vgl. 1.3.1.1).

2011 wurde in einer Arbeit versucht, die Struktur des MINOS-Komplexes lichtmikroskopisch zu beschreiben (Hoppins et al., 2011). Die Ergebnisse dieser Arbeit schienen auf eine übergeordnete Struktur schließen zu lassen, die durch die Komponenten des MINOSKomplexes erzeugt wird und möglicherweise zusätzlich eine Aufgabe als mitochondriales „Skelett" erfüllt.

Über den MINOS-Komplex in Säugerzellen ist bisher weit weniger bekannt als über sein Hefe-Gegenstück. Immerhin wurden auch hier zentrale Komponenten des Komplexes identifiziert (vgl. 1.3.1.1). Die Interaktionspartner dieser Komponenten stehen in Zusammenhang mit verschiedenen schwerwiegenden, großenteils neurologischen, Störungen und auch in Säugerzellen ist der Komplex von zentraler Bedeutung für die mitochondriale Morphologie, insbesondere der Cristae.

Wie zentrale Komponenten des humanen Komplexes angeordnet sind und ob diese in Säugern übergeordnete Strukturen bilden, blieb bisher ungeklärt und sollte in dieser Arbeit untersucht werden. 


\subsubsection{Nachweis von Mitofilin mit lichtmikroskopischen Mitteln}

Um die Lokalisation von Proteinen fluoreszenzmikroskopisch zu untersuchen, stehen generell verschiedene technische Möglichkeiten zur Verfügung. Prinzipiell kann man zwischen der direkten Markierung des Proteins durch Fusion mit einem Marker (z. B. einem Fluoreszenzprotein) und der Markierung von fixierten Zellen mit hochaffinen Bindern (wie z. B. Antikörpern) unterscheiden.

In humanen Zellen besteht jedoch das Problem, dass die gezielte genomische Markierung bisher nicht ohne Weiteres möglich ist. Es existieren zwischenzeitlich zwar Methoden mit denen sich dies bewerkstelligen lässt, zum Beispiel durch die Verwendung von synthetischen Nucleasen wie der Zink-Finger-Nucleasen, der TALENs („transcription acticator-like effector nuclease“) oder des CRISPR/Cas-Systems (CRISPR: „clustered regularly interspaced short palindromic repeats"), diese Systeme sind jedoch großenteils noch in der Entwicklungsphase und daher für einen breiten Einsatz noch nicht geeignet. Damit verbleibt zum direkten Markieren der Proteine - zum Beispiel mit Fluoreszenzproteinen - nur die Möglichkeit der transienten Expression dieser Fusionsproteine. Die transiente Expression führt jedoch zur Überexpression des Zielproteines, da das Fusionsprotein zusätzlich zum endogenen Protein exprimiert wird. Zwar besteht die Möglichkeit regulierbare oder endogene Promotoren zur Expression vom Plasmid zu nutzen, doch die grundsätzliche Problematik bleibt bestehen. Bei der Analyse der Lokalisationen des Proteins mit Hilfe der konventionellen, beugungsbegrenzten Lichtmikroskopie kann mit diesem Problem umgegangen werden, da hier nur darauf geachtet werden muss, dass es zu keinen groben Lokalisationsveränderungen durch die Überexpression und zu keinen die Morphologie verändernden Effekten (Überexpression von mitochondrialen Proteinen führt oft zur Fragmentierung der Mitochondrien) kommt. Bei der Untersuchung der Submitochondrialen Proteinlokalisation mittels der beugungsunbegrenzten Nanoskopie reicht dies jedoch nicht aus, da in diesem Maßstab die Proteinlokalisation auch bei moderater Überexpression verändert sein kann.

Aus diesem Grund wurde im Rahmen dieser Arbeit mit Immuno-Fluoreszenzfärbungen gearbeitet. Hierbei wurden kommerziell erhältliche Antikörper verwendet, die mit 
Fluoreszenzfarbstoff-gekoppelten Sekundärantikörpern nachgewiesen wurden. Dies führt zu einer Amplifikation des Signals, da mehrere Sekundärantikörper an einen Primärantikörper binden können und jeder Sekundärantikörper mit mehreren Fluorophoren gekoppelt sein kann.

Eine weitere wichtige Überlegung betrifft die Auswahl der zu verwendenden Zellen. Diese sollten ein paar wenige aber wichtige Kriterien erfüllen. Es sollten humane Zellen sein, die morphologisch für die mikroskopische Analyse geeignet sind. Das bedeutet, dass die Zellen nach Möglichkeit sehr flach sein und die Mitochondrien in diesen Zellen somit auch ausgebreitet in möglichst einer Ebene liegen sollten. Außerdem sollten Primärzellen verwendet werden, um einen möglichst natürlichen zellulären Kontext zu gewährleisten. Verschiedene unsterbliche Zelllinien sind zwar gut charakterisiert und in einer Vielzahl von Studien verwendet worden, es ist aber bekannt, dass diese Zellen eine Vielzahl genetischer und damit zellulärer Veränderungen aufweisen, die hier möglicherweise einen Einfluss auf die Ergebnisse haben könnten. Daher fiel die Wahl auf primäre, adulte Haut-Fibroblasten (Kukat et al., 2011), die alle oben geforderten Voraussetzungen erfüllen.

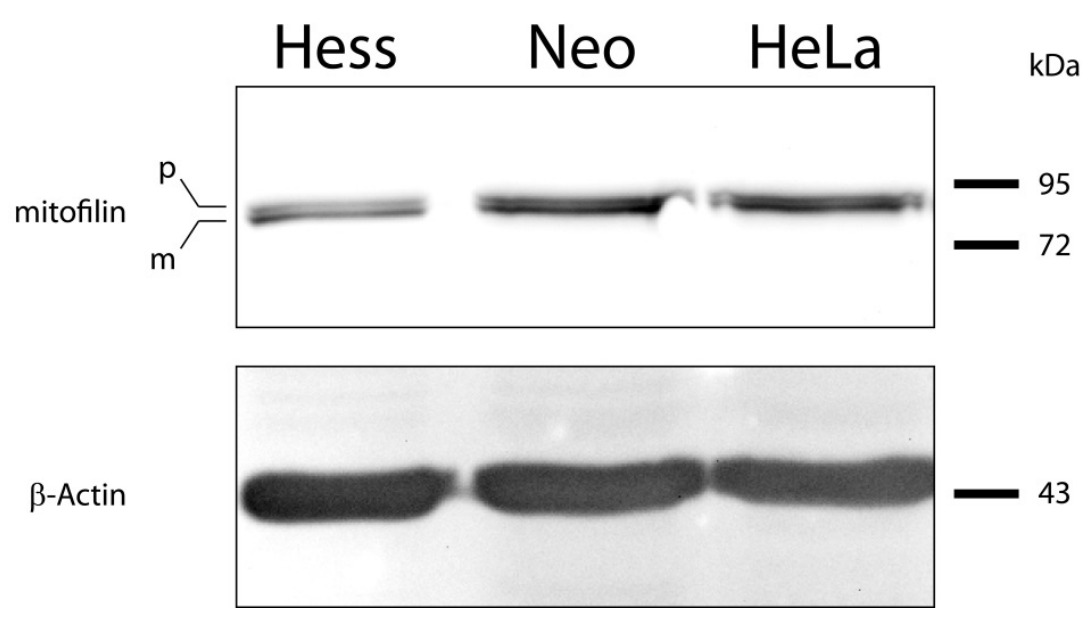

Abb. 3.1 Der Mitofilin-Antikörper erkennt spezifisch Mitofilin.

Western-Blot von Gesamtzelllysaten von primären, adulten, humanen Fibroblasten (Hess), primären, neonatalen, humanen Fibroblasten (Neo) und HeLa-Zellen. Die Membran wurde mit einem Antikörper gegen Mitofilin dekoriert. Es sind die Banden für die "precursor"-Form von Mitofilin $(p)$ und das reife Mitofilin $\left(m={ }_{\text {"mature }}\right)$ zu sehen. Als Ladekontrolle wurde $\beta$-Actin visualisiert.
Es stellte sich nun die Frage die Lokalisation welches Proteins in einem ersten Ansatz untersucht werden sollte. Da über die Zusammensetzung des MINOS-Komplexes in Säuger-Zellen wesentlich weniger gesicherte

Daten verfügbar sind als über die Zusammensetzung des Komplexes in Hefe- 
Zellen, fiel die Entscheidung auf eine der beiden Kernkomponenten des Komplexes (Mitofilin und MINOS1 in humanen Zellen - entsprechen Fcj1 und Mio10 in S. cerevisiae), da davon ausgegangen werden kann, dass diese beiden (Kern-)Komponenten bevorzugt im MINOS-Komplex lokalisiert sind, was sich nicht ohne Weiteres für verschiedene weitere mögliche Interaktionspartner voraussetzen lässt. Die bisher am besten charakterisierte Komponente ist Mitofilin. Daher wurde gegen dieses Protein ein geeigneter Antikörper gesucht, der dann sowohl im Western-Blot (Abb. 3.1), als auch in der Immunofluoreszenz (Abb. 3.2) getestet wurde.

Im Western-Blot zeigte sich, dass das verwendete polyklonale Antiserum gegen Mitofilin dieses Protein in verschiedenen Zelllinien spezifisch erkennt (Abb. 3.1). Da Gesamtzelllysate für den Versuch verwendet wurden, sind zwei distinkte, sehr dicht beieinander liegende Banden zu sehen, die den Mitofilin-Vorläufer („precursor“) mit der Präsequenz und das kürzere, reife Mitofilin („mature“) ohne Präsequenz repräsentieren (vgl. (John et al., 2005)). Da das Antiserum im Western-Blot gut funktionierte und Mitofilin damit spezifisch nachweisbar war, wurde es in einem nächsten Schritt in der Immunofluoreszenz getestet. Hierzu wurden primäre, adulte, humane Haut-Fibroblasten chemisch fixiert und mit dem Antiserum gegen Mitofilin dekoriert. Das Antiserum färbte das gesamte mitochondriale Netzwerk, das in diesen Fibroblasten weit ausgestreckte tubuläre Strukturen bildet, die über die ganze Zelle verteilt sind (Abb. 3.2). 


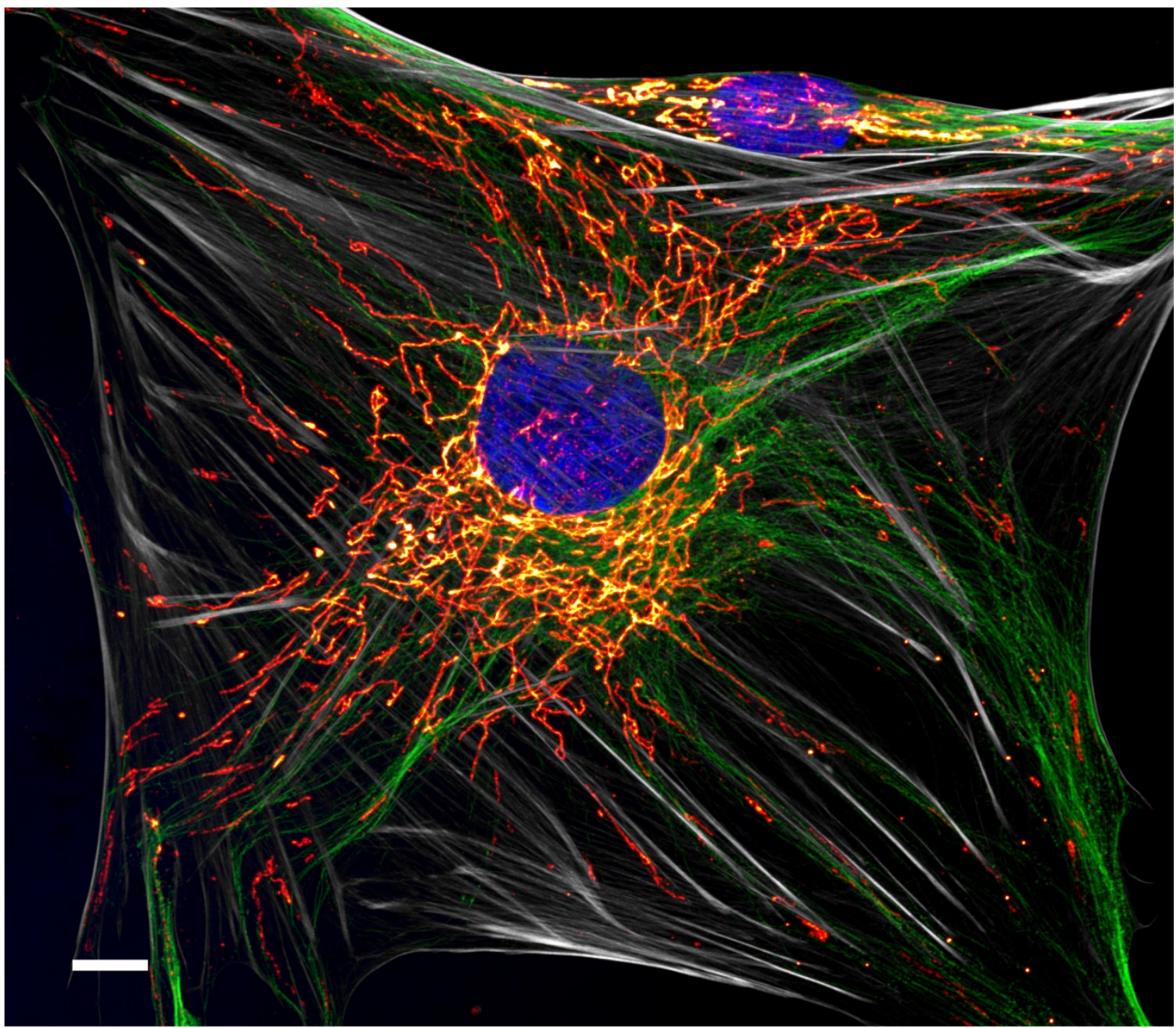

Abb. 3.2 Mitofilin ist ein mitochondriales Protein.

Humane adulte Fibroblasten wurden mit Antiserum gegen Mitofilin dekoriert (rot/gelb). Außerdem wurden zusätzlich die Mikrotubuli mit einem anti-Tubulin-Antikörper (grün), das AktinZytoskelett mit einem Phalloidin-Konjugat (grau) und die DNA mit DAPI (blau) angefärbt. (Größenbalken: $10 \mu \mathrm{m}$ )

Es konnte beobachtet werden, dass der verwendete (Mitofilin-) Antiköper kein nennenswertes Hintergrundsignal zeigte und somit eine hohe Spezifität aufweist. Außerdem konnte mit dem Antikörper ein starkes Signal erreicht werden. Beides sind sehr gute Voraussetzungen für die die Verwendung der Färbungen für eine STED-mikroskopische Analyse. Für diese Analyse wurden in einem nächsten Schritt mögliche Effekte zentraler Aspekte der Probenvorbereitung auf die Qualität der Bilder untersucht und für die STEDMikroskopie optimiert. 


\subsubsection{Optimierung und Kontrolle der Probenvorbereitung für die STED-Mikroskopie}

Die für die hochauflösende Lichtmikroskopie notwendige Probenvorbereitung ist zwar in allen Schritten beschrieben (Wurm et al., 2010), wie sie sich auf das Mitofilin-Signal und die Qualität dieser spezifischen Färbung auswirkte musste jedoch ermittelt werden.

Die Probenvorbereitung von Zellkulturzellen für die Fluoreszenzmikroskopie beinhaltet drei, für die Ultrastruktur und die Morphologie von Zellen und insbesondere von Mitochondrien in diesen Zellen kritische Schritte. Diese bestehen in der Fixierung, der Permeabilisierung und der Einbettung der Zellen.

Der erste dieser Schritte ist die Fixierung der Zellen. Für die Fluoreszenzmikroskopie werden
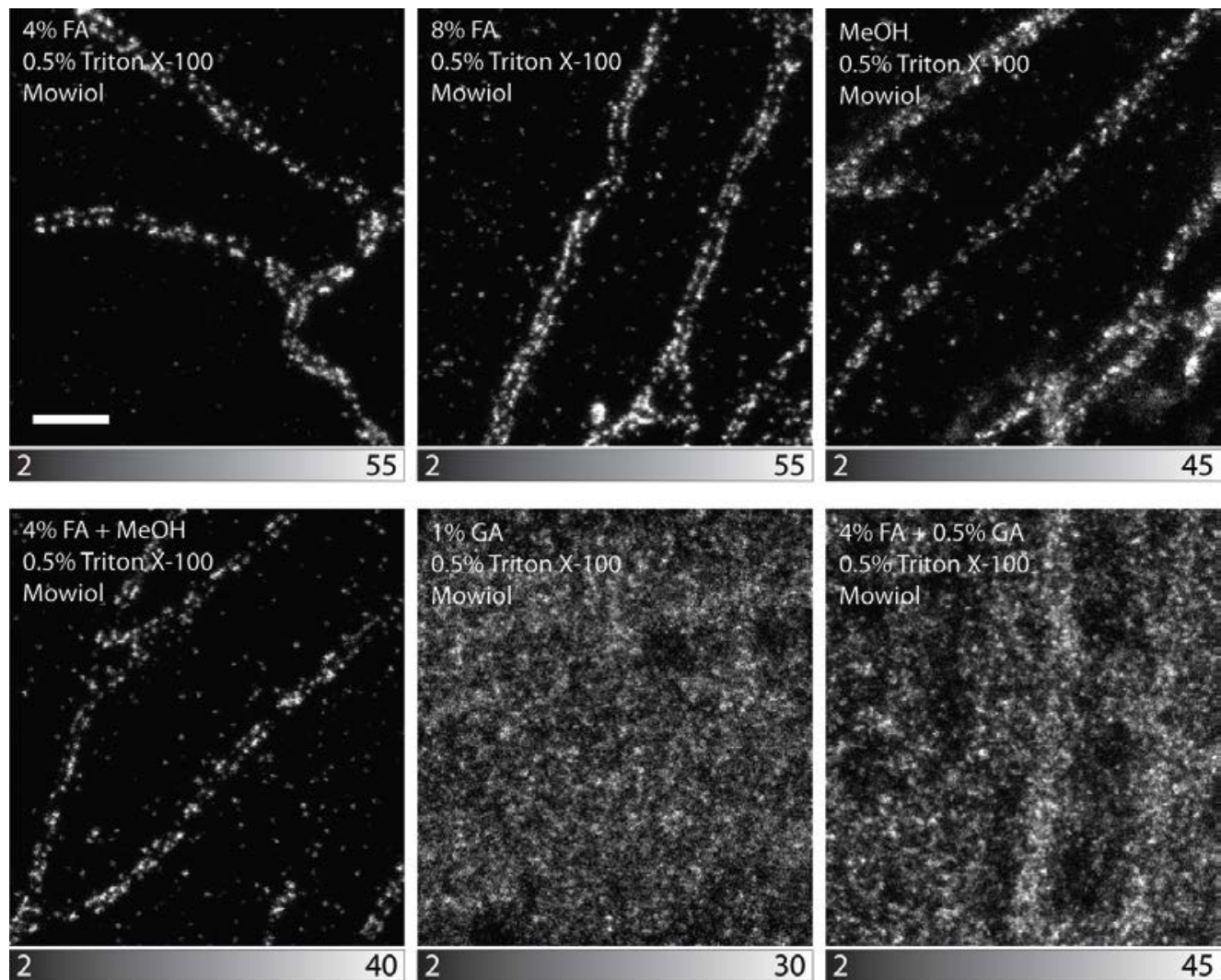

Abb. 3.3 Kontrolle des Mitofilin-STED-Signals in Mitochondrien primärer, humaner Fibroblasten bei Verwendung verschiedener Fixative.

Alle Bedingungen - außer dem verwendeten Fixativ - wurden in den verschiedenen Färbungen konstant gehalten. Es wurden die in den einzelnen Bildern angezeigten Fixative verwendet ( $F A=$ Formaldehyd; $\mathrm{MeOH}=$ Methanol; $\mathrm{GA}$ $=$ Glutaraldehyd). Zum Vergleich der Helligkeiten ist jeweils der Farbraum mit angegeben. (Größenbalken: $1 \mu \mathrm{m}$ ) 
Zellen typischerweise mit Aldehyden oder mit eiskalten Alkoholen (Methanol, Ethanol) bzw. Aceton fixiert. So wurden in einem ersten Schritt die gebräuchlichsten Fixative getestet und das Mitofilin-Signal auf seine Helligkeit und die Lokalisation der Cluster hin im STEDMikroskop untersucht (Abb. 3.3).

Die Lokalisation des Mitofilin-Signals war unter allen Fixativ-Bedingungen, unter denen Mitchondrien überhaupt aufgenommen werden konnten, unverändert (Abb. 3.3). D.h. die Lokalisation des Mitofilin-Signals ist nicht auf eine bestimmte Art der Fixierung zurückzuführen. Es sind jedoch klare Qualitätsunterschiede der resultierenden Bilder sowohl unspezifisches Hintergrundsignal als auch Helligkeit der Strukturen betreffend - zu erkennen. Die Verwendung von Glutaraldehyd resultierte gar in einem so starken Hintergrundsignal, dass keine spezifischen Strukturen mehr erkennbar waren. Die Autofluoreszenz von Aldehyden - insbesondere und vor allem von Glutaraldehyd - ist ein bekanntes Phänomen, kann aber z. B. durch Verwendung von Natrium-Borhydrid verbessert werden. Die Anwendung von Formaldehyd in einer Konzentration von 4\% in PBS führte jedoch zum besten Ergebnis und wurde daher im Folgenden weiter verwendet.

In einem zweiten Schritt wurden die zur Permeabilisierung der Zellen notwendigen Detergenzien getestet. Bei der Verwendung von organischen Lösungsmitteln zur Fixierung von Zellen werden diese auch gleichzeitig permeabilisiert, da hier jedoch Formaldehyd als bestes Fixativ zur Anwendung kam, bestand die Notwendigkeit eines extra Schrittes zur Permeabilisierung der Membranen. Hierzu steht eine große Vielfalt an Detergenzien zur Verfügung, von denen hier einige gängige getestet wurden. Triton-X-100 ist ein für die Fluoreszenzmikroskopie besonders geeignetes und breit eingesetztes nicht-ionischen Detergens (Wurm et al., 2010) und wurde daher in verschiedenen Konzentrationen verwendet. Außerdem wurden Tween 20, SDS („sodium dodecyl sulfate“) und zusätzlich Saponin als besonders mildes Detergens getestet (Abb. 3.4). 

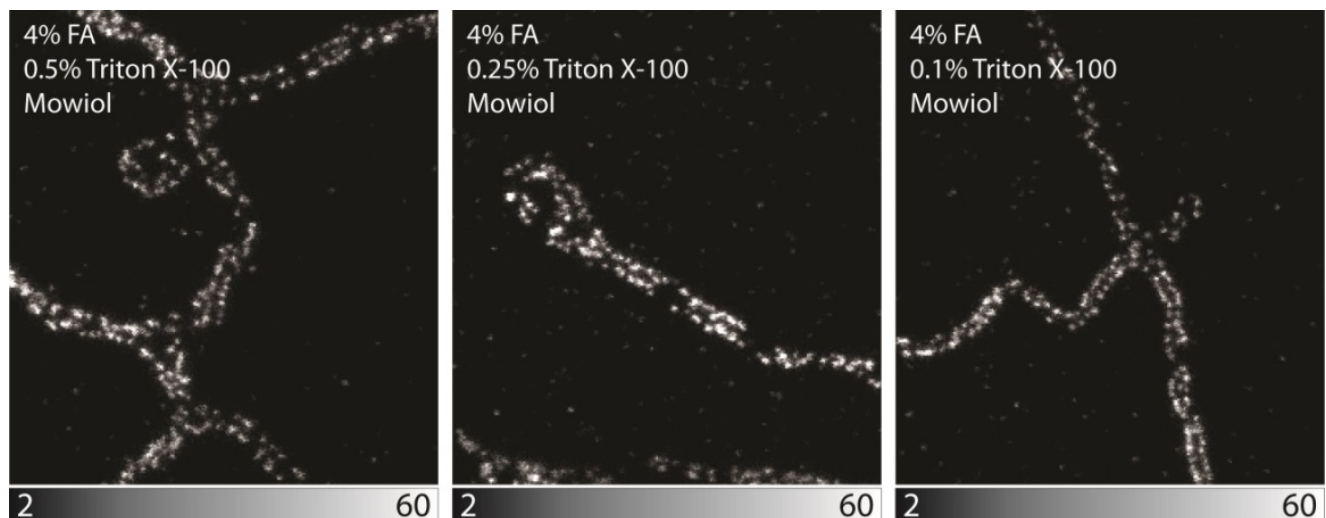

60

60
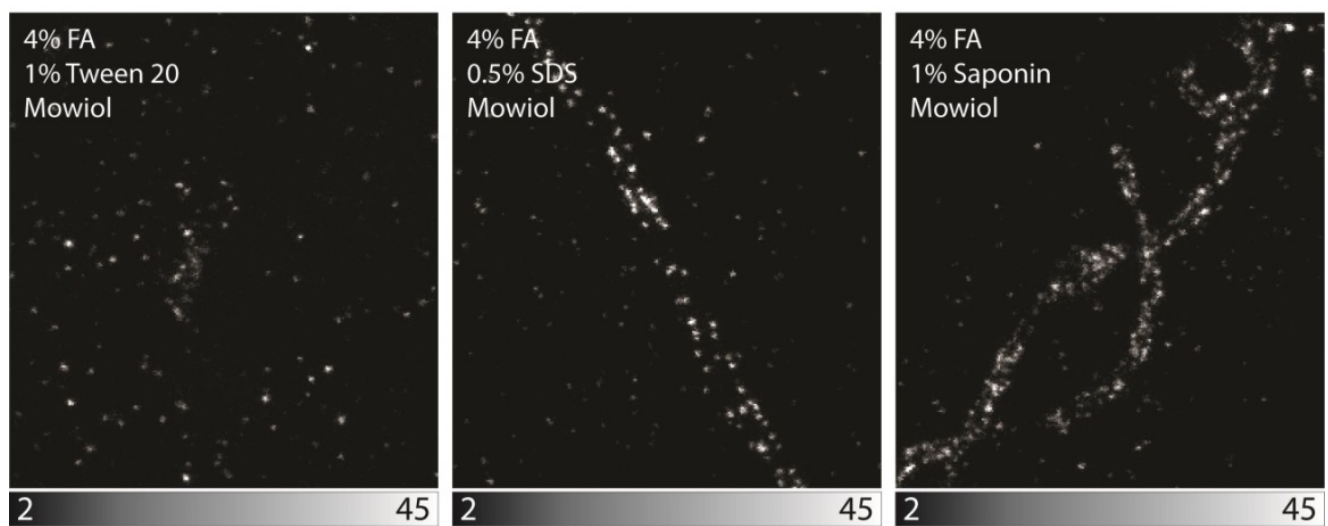

Abb. 3.4 Kontrolle des Mitofilin-STED-Signals in Mitochondrien primärer, humaner Fibroblasten bei Verwendung verschiedener Detergenzien.

Alle Bedingungen - außer dem verwendeten Detergens - wurden in den verschiedenen Färbungen konstant gehalten. Es wurden die in den einzelnen Bildern angezeigten Fixative verwendet. Zum Vergleich der Helligkeiten ist jeweils der Farbraum mit angegeben. (Größenbalken: $1 \mu \mathrm{m}$ )

Auch die Verwendung unterschiedlicher Detergenzien hatte keinen Einfluss auf die Lokalisation des Mitofilin-Signals (Abb. 3.4). Mit dem nicht-ionischen Detergens Tween 20 (=Polysorbat 20) konnte keine spezifische Mitofilin-Färbung durchgeführt werden, woraus sich schließen lässt, dass dieses Detergens in der verwendeten Konzentration die Zugänglichkeit von mitochondrialen Innermembranproteinen für Antikörper nicht gewährleisten konnte. Alle anderen verwendeten Detergenzien waren für die Immunofluoreszenz-Färbung von Mitofilin geeignet. Als bestes Detergens stellte sich TritonX-100 heraus, wobei kein entscheidender Unterschied zwischen verschiedenen Konzentrationen dieses Detergens beobachtet werden konnte. 

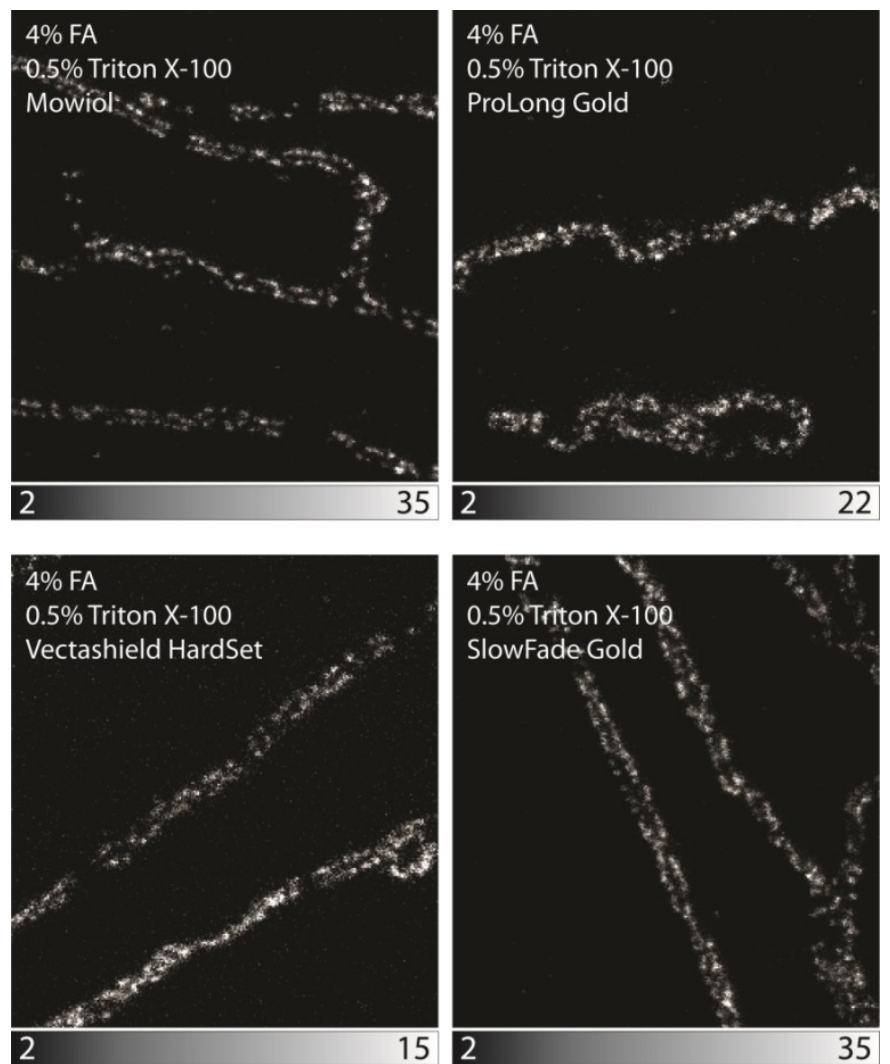

Abb. 3.5 Kontrolle des Mitofilin-STED-Signals in Mitochondrien primärer, humaner Fibroblasten bei Verwendung verschiedener Einbett-Medien.

Alle Bedingungen - außer dem verwendeten EinbettMedium - wurden in den verschiedenen Färbungen konstant gehalten. Es wurden die in den einzelnen Bildern angezeigten Medien verwendet. Zum Vergleich der Helligkeiten ist jeweils der Farbraum mit angegeben. (Größenbalken: $1 \mu \mathrm{m}$ )
Als letzter entscheidender Faktor wurde nun das Einbettmedium der Immunofluoreszenz-gefärbten Zellen getestet. Dem Einbettmedium kommt eine wichtige Rolle - vor allem bei der Verwendung hoch-numerischer Objektive - zu, da eine Diskrepanz zwischen dem refraktiven Index des Immersionsmediums (in diesem Fall Immersionsöl) und dem verwendeten Einbettmedium zu sphärischen Aberrationen führt. Ein weiteres mögliches Problem, das durch die Verwendung bestimmter Medien entstehen kann, ist die morphologische Veränderung von zellulären Strukturen, die durch Schrumpfungs-Effekte beim Aushärten einiger dieser Medien entstehen können. Daher sollte das Einbettmedium sorgfältig ausgewählt werden. Zusätzlich gewährleisten einige dieser Medien ein reduziertes Photobleichen der Fluorophore. Hier wurden vier verschiedene dieser Medien getestet, darunter Mowiol, dem DABCO (1,4-diazabicyclo[2.2.2]octan) als Antioxidans zur Reduzierung von Photobleichen zugesetzt wurde (Wurm et al., 2010), und drei verschiedene kommerzielle Einbettmedien (Abb. 3.5). Es ist zu erkennen, dass das Mitofilin-Signal in allen vier verwendeten Einbettmedien vergleichbar aussieht (Abb. 3.5). Die Qualität der Bilder, hier insbesondere der Helligkeit der Fluoreszenzsignale, unterschied sich jedoch signifikant und Mowiol (mit DABCO) erwies sich als beste Wahl für die vorliegenden Analysen. 
Zusammenfassend konnten die besten Bedingungen für die Probenvorbereitung für die STED-mikroskopische Analyse des Mitofilin-Signals gefunden werden. In einem nächsten Schritt sollte nun die Lokalisation von Mitofilin in den Mitochondrien der optimierten Proben untersucht werden.

\subsubsection{Das humane Mitofilin ist innerhalb der Mitochondrien in Clustern lokalisiert}

Primäre, humane Fibroblasten wurden gemäß dem optimierten Protokoll fixiert, permeabilisiert, mit dem Mitofilin-Antiserum markiert und eingebettet. Die
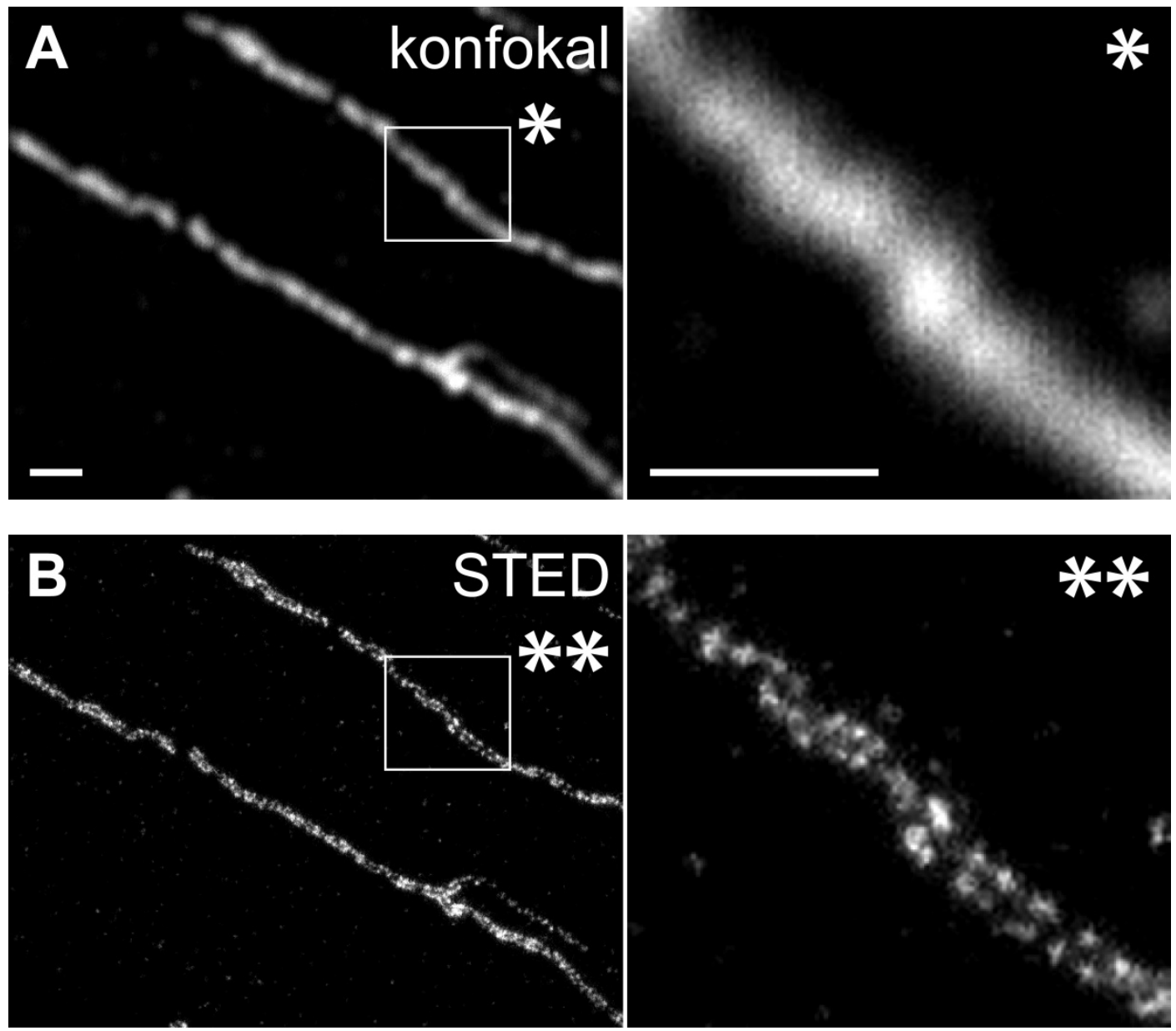

Abb. 3.6 Mitofilin ist in einzelnen Clustern in Mitochondrien primärer, adulter, humaner Fibroblasten lokalisiert (bearbeitet aus (Jans et al., 2013)).

Im STED-Bild (B) zeigt sich, dass Mitofilin in einzelnen, unterscheidbaren Clustern lokalisiert ist, während im konfokalen Bild (A) die Cluster nicht aufgelöst werden können, so dass sie als eine verwaschene, zusammenhängende Struktur erscheinen. (Größenbalken: $1 \mu \mathrm{m}$ ) 
Primärantikörper wurden dann mittels eines Sekundärantikörpers, der mit einem speziell für die STED-Mikroskopie besonders geeigneten Farbstoff gekoppelt war (KK114; compound 6 (Kolmakov et al., 2010)), nachgewiesen (Abb. 3.6). Für die Mikroskopie wurde ein InfrarotSTED-Aufbau genutzt, der die Aufnahme großer Bild-Bereiche (maximal $200 \times 200 \mu \mathrm{m}$ ) und eine Auflösung von circa 40-50 nm ermöglicht.

Mitofilin zeigt in STED-Bildern von lang ausgestreckten Mitochondrien (besonders in der Nähe der Zellperipherie) eine Lokalisation vorwiegend in einzelnen Clustern (Abb. 3.6 B), die mit einem konfokalen Mikroskop nicht auflösbar und daher nicht erkennbar sind (Abb. 3.6 A). Diese Cluster sind mit einem durchschnittlichen Durchmesser von ca. $85 \mathrm{~nm}$ größer als die Auflösung des verwendeten Mikroskops. Daraus lässt sich schließen, dass jeder der Cluster aus mehr als einem einzelnen Mitofilin-Protein besteht.

Mitofilin ist also ein Protein, das in den Mitochondrien in einzelnen Clustern, die mehr als ein einzelnes dieser Proteine enthalten, lokalisiert ist. Es stellte sich nun die Frage, wie diese Cluster innerhalb einer Zelle angeordnet sind und ob sich bei diesem für die Cristae-Struktur entscheidenden Protein vielleicht ein ähnlicher inner-zellulärer Gradient wie für Komponenten des TOM-Komplexes (Wurm et al., 2011) feststellen lässt.

\subsubsection{Die Mitofilin-Lokalisation weist einen intrazellulären Gradienten auf}

Zur Analyse der inner-zellulären Dichteverteilung der Mitofilin-Cluster wurden möglichst große Ausschnitte der verwendeten Fibroblasten aufgenommen. Es zeigte sich, dass die Dichte der Cluster in der Regel mit zunehmendem Abstand zur Mitte der Zelle (der Mitte des Zellkerns) abnimmt (Abb. 3.7). 

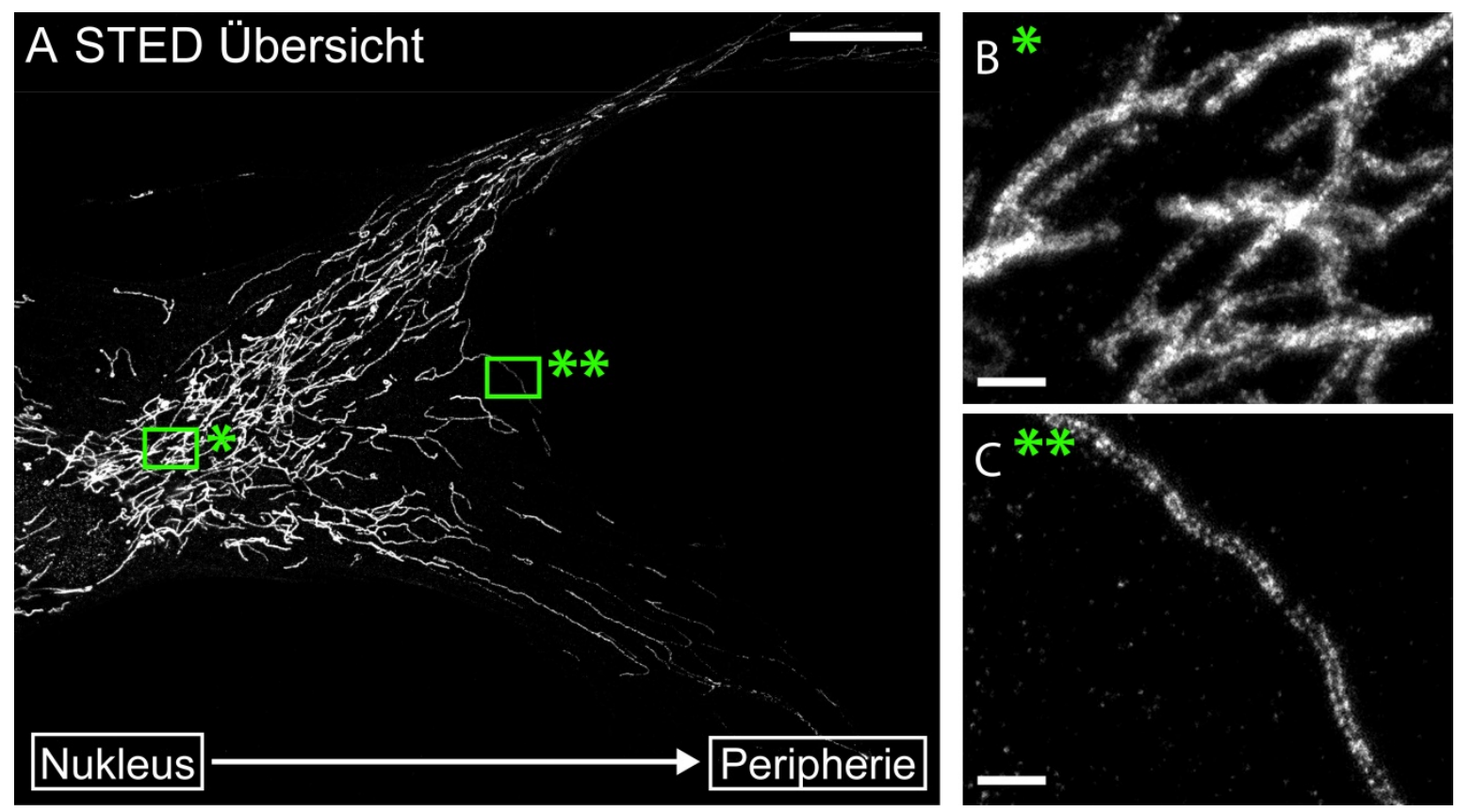

Abb. 3.7 Mitofilin-Cluster sind in der Nähe des Zellkerns dichter als am Rand der Zelle (bearbeitet aus (Jans et al., 2013)). (B und C) Vergrößerungen der umrandeten Bereiche in (A). (Größenbalken: $20 \mu \mathrm{m}$ in $A ; 1 \mu \mathrm{m}$ in $B$ und $C$ ).

Die Mitofilin-Cluster sind in Mitochondrien in der Nähe des Zellkernes deutlich dichter verteilt als in Mitochondrien am Rand der Zelle (Abb. 3.7). Rund um den Zellkern ist auch das mitochondriale Netzwerk weitaus dichter und stärker verzweigt als am Rand der Zelle und die Mitofilin Cluster in diesen perinukleären Mitochondrien sind oft so dicht, dass die Cluster nicht voneinander zu trennen sind (Abb. 3.7 B). In der Peripherie der Zelle sind die Mitofilin-Cluster hingegen deutlich weniger dicht verteilt (Abb. 3.7 C). Dies zeigte sich in einer Vielzahl von Zellen, um die Dichteverteilung der Mitofilin-Cluster jedoch objektiv beurteilen zu können, musste die Dichte automatisiert durch eine Varianzanalyse analysiert werden.

Die Varianzanalyse ist eine Möglichkeit, die Dichte von Clustern robust und relativ einfach unter einer Vielzahl von Bedingungen zu analysieren (Wurm et al., 2011). Bei der Varianzanalyse wurde die lokale Varianz in den Bildern innerhalb von ROIs (,region of interest") mit einem Durchmesser von sieben Pixeln ( 140 nm) bestimmt und das Ergebnis dem zentralen Pixel zugeordnet. Außerdem wurden die einzelnen Varianzen gegen die quadrierte durchschnittliche Intensität des entsprechenden ROIs normalisiert, um 

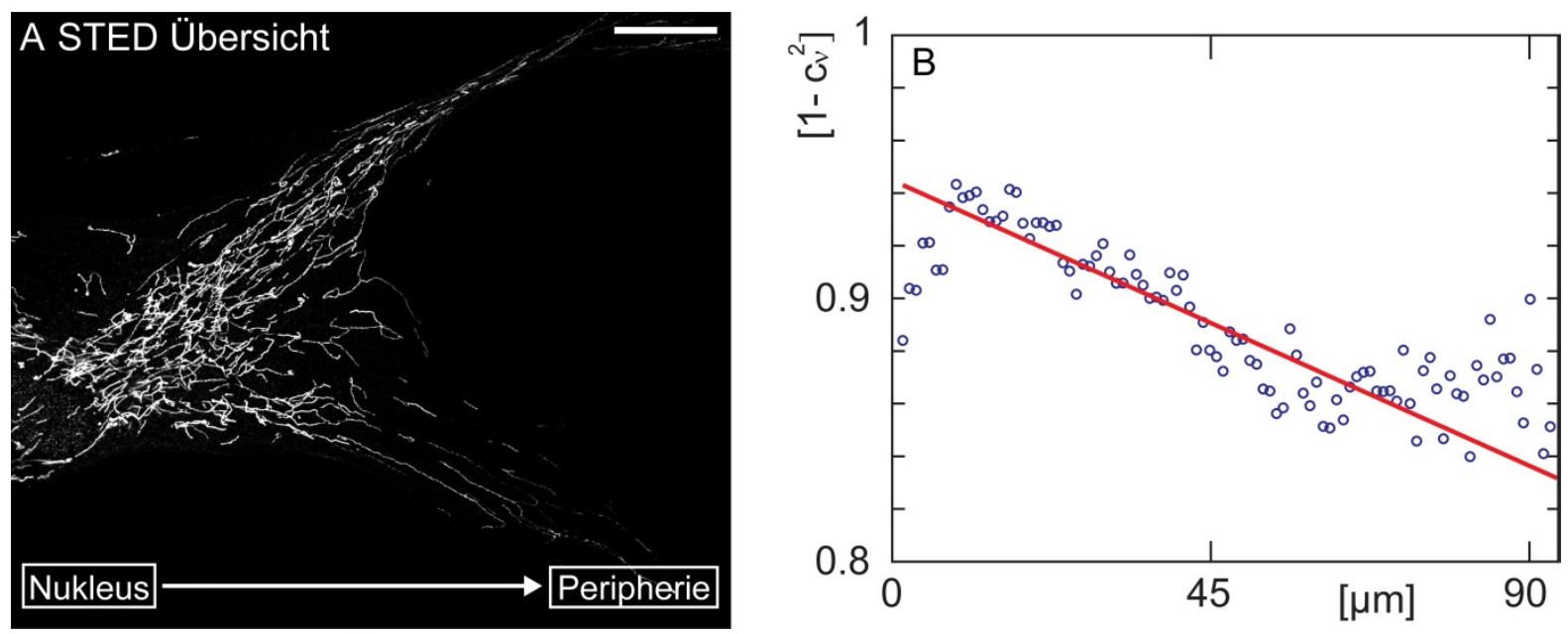

Abb. 3.8 Mitofilin-Cluster sind in der Nähe des Zellkerns dichter als am Rand der Zelle (bearbeitet aus (Jans et al., 2013)).

(A) Übersicht über dieselbe primäre, humane Fibroblastenzelle, die in Abb. 3.3 dargestellt ist. (B) Plot von $\left[1-c v^{2}\right]$ Werten, aufgetragen gegen den Abstand vom Zellkern. $c v^{2}$ ist dabei die normalisierte Varianz. Die blauen Kreise stehen für 100 bins, die ca. $9 \times 10^{5}$ individuelle [1-cv $\left.{ }^{2}\right]-$ Werte zusammenfassen. Die rote Linie repräsentiert eine lineare Regression der individuellen $\left[1-c v^{2}\right]$-Werte. Die negative Steigung zeigt an, dass die Cluster in der Nähe des Kerns dichter verteilt sind, als am Rand der Zelle. (Größenbalken: $20 \mu \mathrm{m}$ )

unabhängig von der absoluten Helligkeit der Strukturen zu sein. Dies wurde für jeden Pixel des Bildes wiederholt, so dass jeder Pixel am Ende die jeweilige normalisierte lokale Varianz

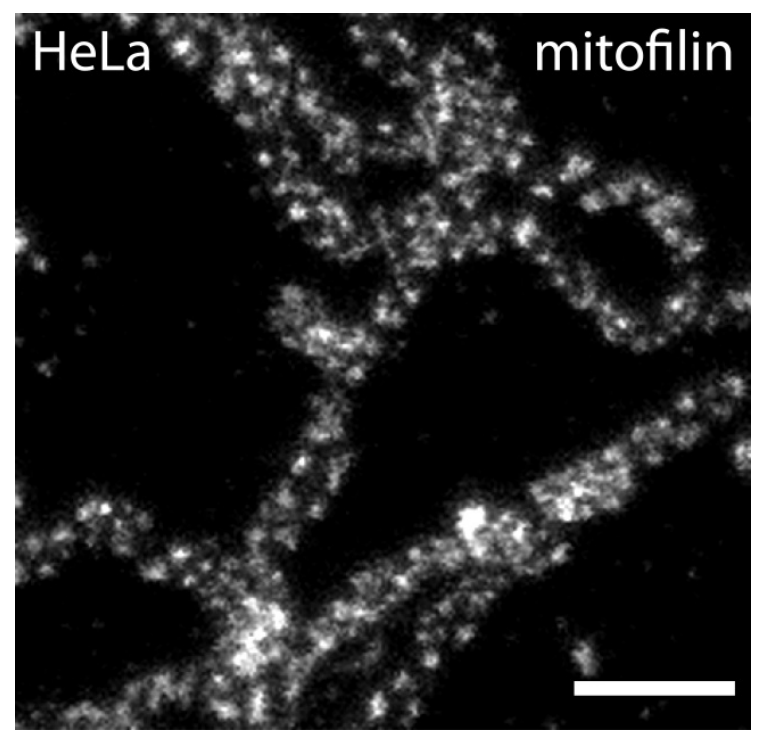

Abb. 3.9 Lokalisation von Mitofilin-Clustern in HeLa-Zell-Mitochondrien

Repräsentative STED-Aufnahme einer mit Mitofilin-Antikörper gefärbten HeLa-Zelle. (Größenbalken: $1 \mu \mathrm{m}$ ) $\left(c v^{2}\right)$ repräsentierte. Da ein niedriger normalisierter Varianzwert in diesem Ansatz eine dichte Clusterverteilung anzeigt (die normalisierte Varianz spiegelt jedoch eine Reihe von Faktoren wie zum Beispiel die Verteilung und die Größe der Cluster und das Verhältnis des Cluster-Signals zum mitochondrialen Hintergrundsignal wieder) und ein hoher normalisierter Varianzwert eine weniger dichte Clusterverteilung repräsentiert, wurde der [1- $\left.c v^{2}\right]$-Wert berechnet, so dass ein hoher Wert eine dichte Clusterverteilung und ein niedriger Wert eine 


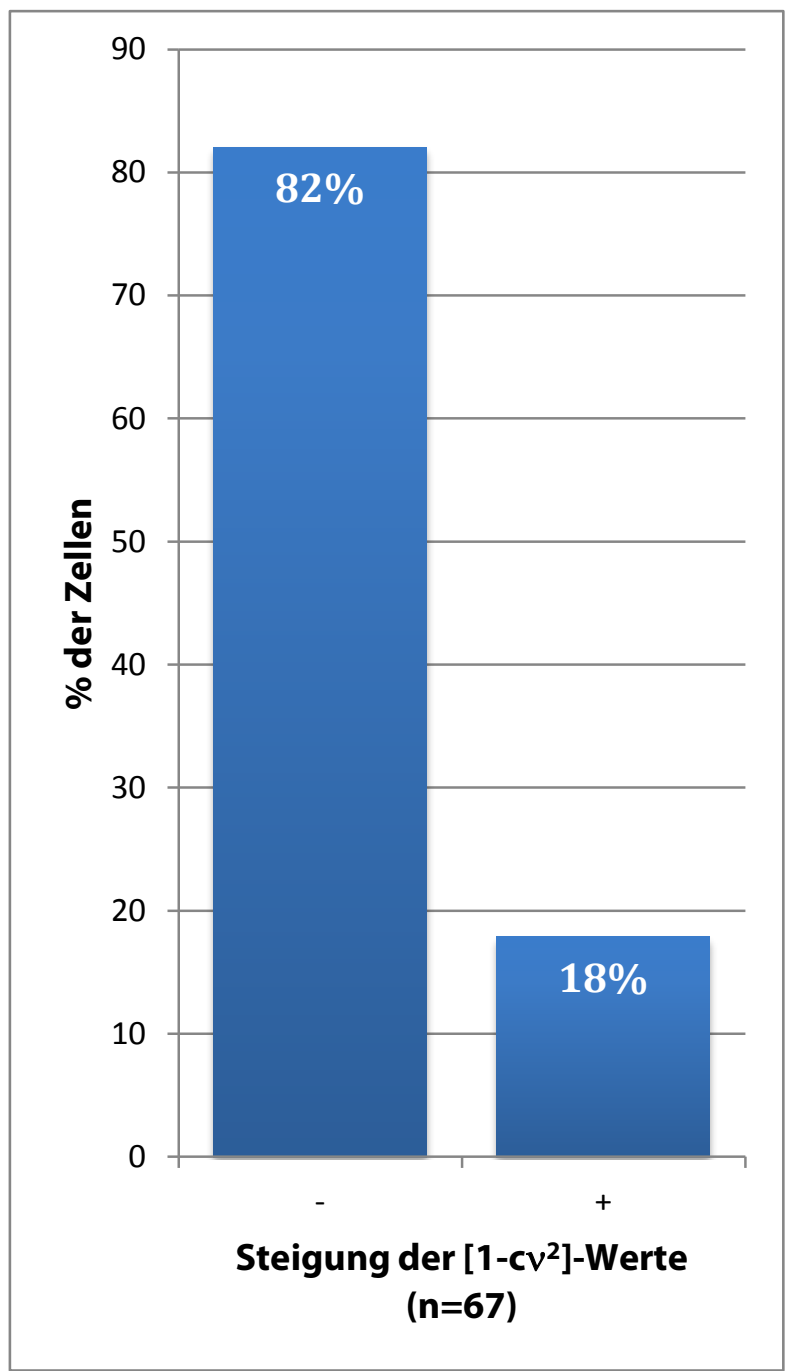

Abb. 3.10 Mitofilin-Cluster weisen in den meisten HeLa-Zellen einen Gradienten - von einer dichten Verteilung um den Zellkern zu einer weniger dichten Verteilung am Rand der Zelle - auf.

HeLa-Zellen wurden mit Mitofilin Antikörpern markiert und 67 Zellen mit einem STEDMikroskop aufgenommen. Die Bilder wurden einer Mitochondrien-Varianz-Analyse unterzogen und die Steigung der linearen Regression der Werte der Einzelzellen (vgl. Abb. 3.8) dargestellt (- : negative Steigung; + : positive Steigung). weniger dichte Clusterverteilung anzeigt.

Nun mussten nur durch einen Bild-

Segmentierungs-Algorithmus die

Mitochondrien identifiziert werden. Diese Maske wurde dann genutzt, um alle nichtmitochondrialen Varianzen auszuschließen. Die Ergebnisse dieser Analyse wurden anschließend gegen den Abstand der jeweiligen $\left[1-c v^{2}\right]$-Werte zur Mitte des Zellkerns geplottet und für die Werte eine Regressionsgerade bestimmt. Dies wurde für die in Abb. 3.7 dargestellte Zelle $\begin{array}{lll}\text { durchgeführt } \quad \text { (Abb. } & \text { 3.8). Die }\end{array}$ Regressionsgerade durch die $\left[1-c v^{2}\right]$-Werte der Mitochondrien dieser Zelle wies eine negative Steigung auf, was bestätigt, dass die Mitofilin-Cluster in dieser Zelle in Mitochondrien in der Nähe des Zellkernes dichter verteilt sind als in Mitochondrien an der Zellperipherie (Abb. 3.8. B).

Um die Dichte-Verteilung der MitofilinCluster an einer statistisch relevanten Menge von Zellen durchführen zu können, wurde dieses Prinzip der Varianzanalyse auch für die Verteilung von MitofilinClustern in HeLa-Zellen durchgeführt. Diese Zelllinie hat den Vorteil, dass die einzelnen Zellen wesentlich kleiner als die primären, adulten, humanen Fibroblasten sind und somit eine weit höhere Anzahl von Zellen in der gleichen Zeit aufgenommen werden kann. Da die 
Mitofilin-Cluster in diesen Zellen eine ähnliche Lokalisation wie in den Fibroblasten aufweisen (Abb. 3.9), wurden die HeLa-Zellen für diese Art der Analyse für geeignet befunden. Insgesamt wurden die STED-Daten der Mitofilin-Verteilung von 67 HeLa-Zellen ausgewertet. In den meisten dieser Zellen (82\%) konnte eine dichtere Mitofilin-ClusterVerteilung in Mitochondrien in der Nähe des Zellkernes als am Rand der Zelle beobachtet werden (Abb. 3.10).

Obwohl dieser Gradient in Übereinstimmung mit physiologischen intrazellulären Gradienten, wie z. B. dem Membranpotential und dem Gradienten für Komponenten der Translokase der äußeren Membran (TOM), zu sehen ist (Wurm et al., 2011), lässt sich nicht gänzlich ausschließen, dass ein solcher Dichte-Gradient mit einer intrazellulär ungleichmäßigen Färbeeffizienz zusammenhängt. Daher wurde dieses mögliche Problem untersucht.

\section{Der intrazelluläre Mitofilin-Gradient ist kein Färbeartefakt}

Um zu überprüfen, ob die in den beiden humanen Zelllinien beobachteten Mitofilin-ClusterDichte-Gradienten nicht darauf zurückzuführen sind, dass die Immunofluoreszenzfärbung rund um den Zellkern effektiver funktioniert als am Rand der Zelle, wurde die Intensität des Fluoreszenzsignals untersucht. Diese korreliert mit der Dichte der Cluster, was dazu führt, dass die Intensität des Mitofilin-Fluoreszenzsignals im Zentrum der Zelle höher ist als an der Peripherie (Abb. 3.11 A und B). Wäre der Gradient auf Unterschiede in der Färbeeffizienz zurückzuführen, müsste dieser bei allen Färbungen auftreten. Es zeigte sich jedoch, dass in Immunofluoreszenzbildern anderer Strukturen wie z. B. der Peroxisomen kein solcher Gradient bzw. in Teilen sogar ein umgekehrter Gradient zu beobachten ist (Abb. 3.11 C und D).

Eine weitere mögliche Fehlerquelle bei der Analyse von Clusterdichten innerhalb von Mitochondrien besteht darin, dass in Bereichen, in denen die mitochondrialen Tubuli sehr dicht verteilt sind (rund um den Zellkern), das Fluoreszenzsignal direkt übereinanderliegender Tubuli - aufgrund der konfokalen axialen Auflösung des 

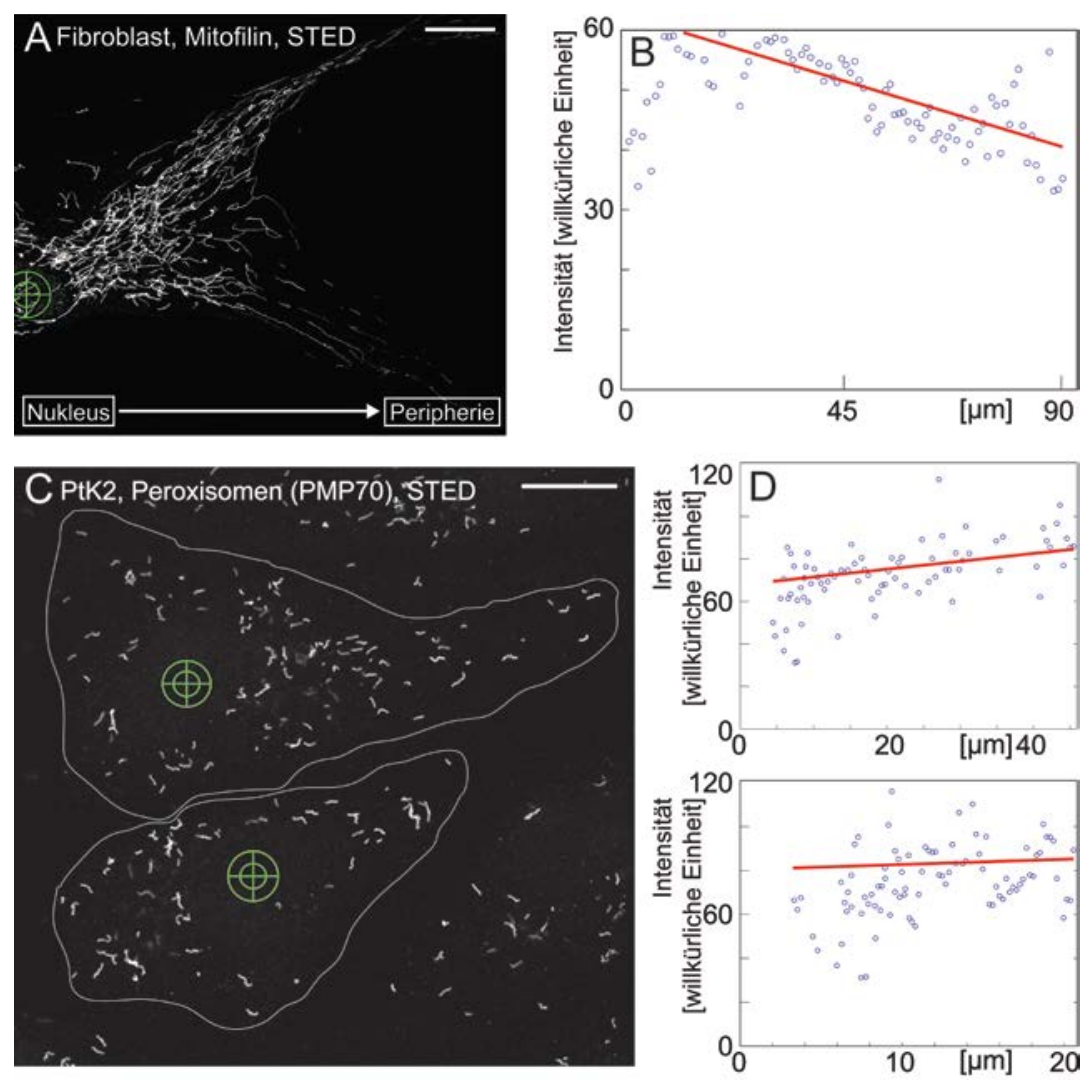

Abb. 3.11 Mitofilin weist einen Gradienten vom Zentrum zum Rand der Zelle hin auf, während das Peroxisomen-Protein PMP70 keinen bzw. einen umgekehrten Gradienten aufweist.

(A) Übersicht über dieselbe Zelle, die in Abb. 3.7 und 3.8 dargestellt ist. (B) In dieser Zelle weist das Mitofilin-Signal einen Intensitätsgradienten auf, der den Dichtegradienten (Abb. 3.7 und 3.8) wiederspiegelt. (C) Übersicht über das PMP70 (Peroxisomen)Signal in zwei PtK2-Zellen. (D) In diesen Zellen weist das PMP70Signal einen umgekehrten (oben) bzw. keinen (unten) Intensitätsgradienten auf. (Größenbalken: $20 \mu \mathrm{m}$ in (A); $10 \mu \mathrm{m}$ in (C))

aus den Auswertungen ausgeschlossen. Dies änderte jedoch nichts an dem Ergebnis, dass

Mitofilin in den untersuchten Zellen in Mitochondrien nahe des Zentrums der Zelle dichter verteilt ist als in Mitochondrien an der Zellperipherie.

Daraus lässt sich schließen, dass der in 3.1.4 beschriebene Gradient kein Artefakt ist,

sondern dass die Dichte der Mitofilin-Cluster tatsächlich vom Zentrum der Zelle zum Rand hin abnimmt. Nachdem die Dichteverteilung der Mitofilin-Cluster über das mitochondriale Netzwerk bestimmt worden war, wurde die sub-mitochondriale Verteilung von Mitofilin verwendeten STED-

Mikrokops - gleichzeitig

aufgenommen werden

und sich dadurch quasi

könnte in Bereichen mit

einem dichten

mitochondrialen Netzwerk

in der Auswertung zu

niedrigeren Varianz-

Werten (höheren [1- $\left.c v^{2}\right]-$

Werten) führen, die eine

dichtere Verteilung der

Cluster innerhalb dieser

Mitochondrien sug-

dieser möglichen

Fehlerquelle auszu-

schließen, wurden manuell

Bereiche, in denen

Mitochondrien möglicher-

weise übereinander liegen addieren kann. Dies

gerieren. Um den Einfluss Netzwerk bestimmt worden war, wurde die sub-mitochondriale Verteilung von Mitofilin 
untersucht. Da Hinweise auf zusammenhängende, übergeordnete Strukturen von MINOSKomplex-Komponenten in Hefe-Zellen (Hoppins et al., 2011) existieren, führte dies zu der Frage, ob es eine zusätzliche sub-mitochondriale Ordnung und Organisation der MitofilinCluster in den Mitochondrien von Säugerzellen gibt.

\subsubsection{Die sub-mitochondriale Mitofilin-Lokalisation ist hoch geordnet}

Die Untersuchung von Proteinlokalisationen innerhalb der Mitochondrien, die mit einem Durchmesser von 150-500 nm in der gleichen Größenordnung wie die Auflösung konventioneller Mikroskope sind (vgl. Abb. 1.8) erfordert eine mikroskopische Technik die eine Auflösung bietet, welche eine valide Analyse ermöglicht. Die in dieser Arbeit zur Analyse der MINOS-Komplex-Komponenten, hier von Mitofilin, verwendete Technik war die STED-Mikroskopie. Sie ermöglicht, wie in 1.4.1 ausgeführt, eine theoretisch unbegrenzte Auflösung - im Falle des hier verwendeten Mikroskops und des verwendeten Farbstoffes war die laterale Auflösung ca. 40-50 nm. Ein gewöhnliches STED-Mikroskop ermöglicht jedoch keine verbesserte axiale, sondern hat in dieser Richtung eine konfokale Auflösung. Dies führt dazu, dass bei Aufsicht auf ein Mitochondrium mit einem solchen Mikroskop (wie in einem konventionellen konfokalen Mikroskop) das resultierende Bild quasi eine Aufsummierung der Signale der ganzen Mitochondrienmembran entlang der z-Achse (axial) darstellt. Daraus ergibt sich die Frage, wie sich dieser Effekt auf die Bilder von Membranproteinen auswirkt und wie diese Bild-Daten folglich zu interpretieren sind. Aus diesem Grund wurden Simulationen durchgeführt, in denen angenommen wurde, dass das zu untersuchende Protein entweder in der äußeren Mitochondrienmembran oder in der inneren Grenzflächenmembran lokalisiert und über diese zufällig verteilt ist und die Daten mit einer dem verwendeten STED-Mikroskop vergleichbaren Auflösung detektiert werden (Abb. 3.12). 

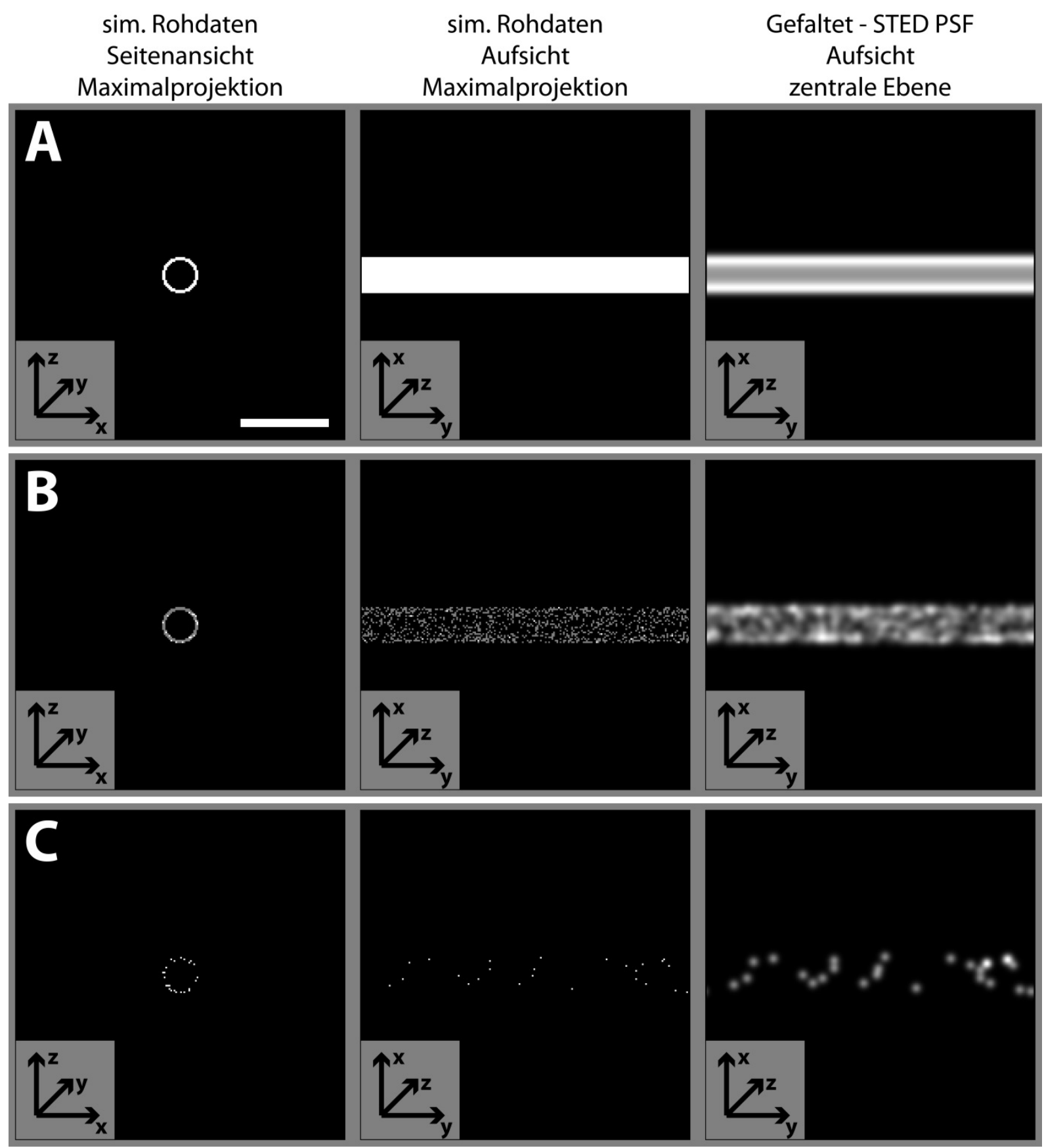

Abb. 3.12 Simulation verschiedener Dichten von zufällig verteilten Punkten auf einer dreidimensionalen Röhre mit einem Durchmesser von $200 \mathrm{~nm}$. Die einzelnen Punkte sind kleiner als die STED-PSF, für die hier eine Größe von $50 * 50 * 800 \mathrm{~nm}\left(x^{*} y * z\right)$ angenommen wurde. In (A) ist die Oberfläche der Röhre komplett gefüllt, während in (B) die einzelnen Punkte dicht und in (C) weniger dicht über die Oberfläche der Röhre verteilt sind. (Größenbalken: $500 \mathrm{~nm}$ )

Die Simulation zeigte, dass - wie oben besprochen - das Signal aller zufällig über die Oberfläche eines Tubulus (welcher einen - einem typischen Mitochondrium 
entsprechenden - Durchmesser von $200 \mathrm{~nm}$ hat) verteilter Punkte bei Fokussierung der zentralen Tubulus-Ebene und unter Annahme einer typischen STED-PSF im resultierenden Bild zu sehen ist (Abb. 3.12, A-C, rechte Spalte). Dies führt dazu, dass Punkte, die über die Oberfläche eines Tubulus verteilt sind (dies entspricht zum Beispiel einer Lokalisation in der äußeren Mitochondrienmembran oder in der inneren Grenzflächenmembran), im resultierenden Bild nicht außen an den Rändern des Tubulus zu sehen sind, sondern dass die Punkte über den gesamten Tubulus verteilt erscheinen (Abb. 3.12 B und C, rechte Spalte). In Abb. 3.12 C (rechte Spalte) lässt sich auch beobachten, dass solche zufällig verteilten Punkte im resultierenden Bild scheinbar Strukturen bilden können, da das Auge solche Punkte leicht verbindet und Strukturen in unstrukturierten Anordnungen sucht. Daher könnte man aus diesen Daten - besonders wenn die laterale Auflösung noch etwas schlechter wäre und die einzelnen Punkte daher noch etwas größer wären möglicherweise auch etwas wie eine Helix-Struktur herauslesen, ohne dass diese den Daten zugrunde läge.

Es konnte also gezeigt werden, dass das gesamte Signal von Strukuren, die über die Oberfläche eines mitochondrialen Tubulus verteilt sind, in den resultierenden STEDmikroskopischen Bildern praktisch aufsummiert erscheint und daher auch solche Signale (ebenso wie Signale, die im Inneren des Tubulus verteilt sind) innerhalb des Tubulus lokalisiert erscheinen. Außerdem wurde gezeigt, dass Lokalisationen von Signalen, die eine übergeordnete Struktur andeuten, mit besonderer Sorgfalt ausgewertet werden müssen, um Fehlinterpretationen zu vermeiden.

Um die sub-mitochondriale Lokalisation von Mitofilin zu untersuchen, wurden nun möglichst große Bereiche von primären, humanen Fibroblasten mit dem STED-Mikroskop aufgenommen und ausgewertet (Abb. 3.13). 

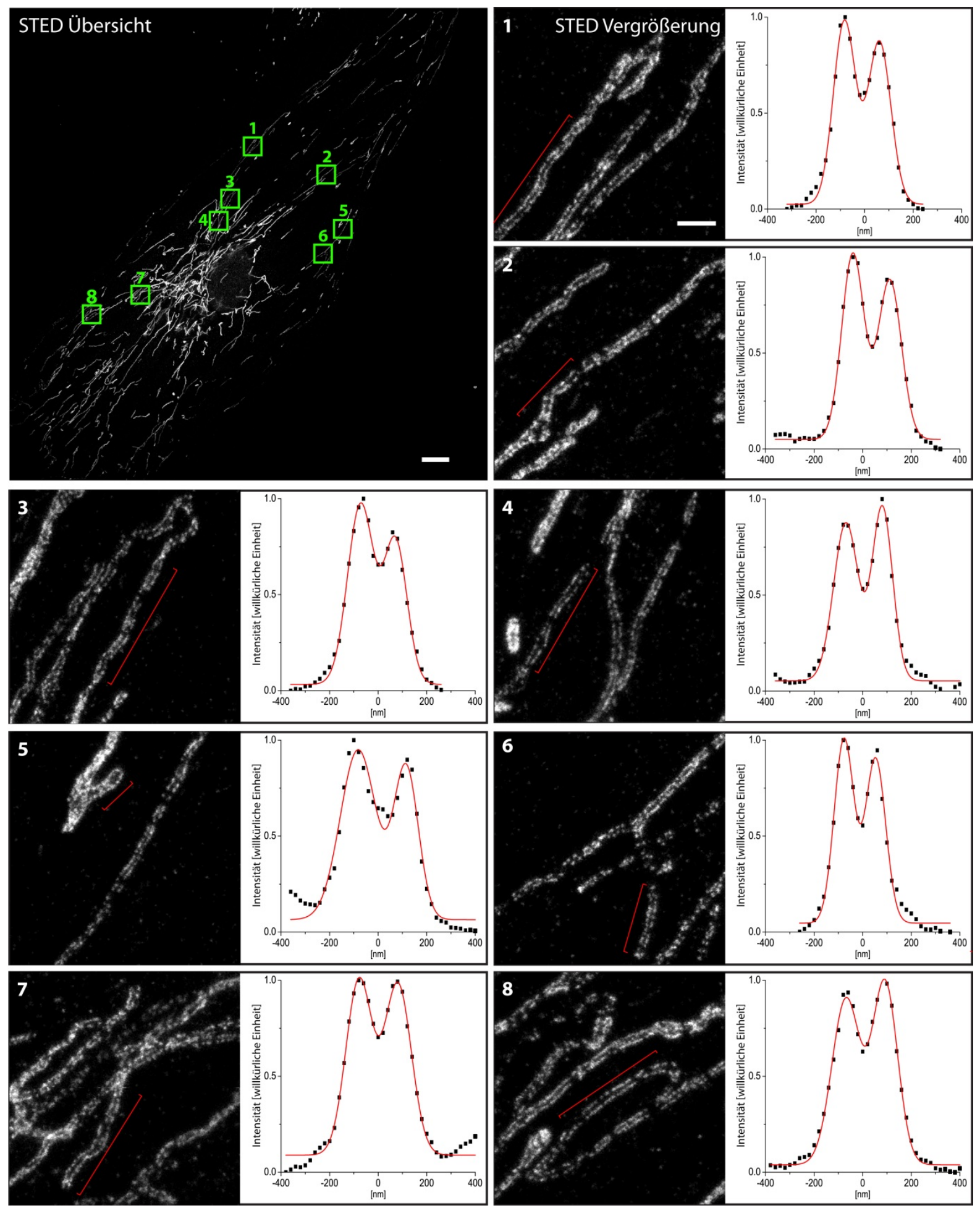

Abb. 3.13 Mitofilin ist am Rand der Mitochondrien lokalisiert (bearbeitet aus (Jans et al., 2013)).

Das große Bild zeigt die Übersicht über eine primäre, adulte, humane Fibroblastenzelle, die mit einem Antikörper gegen Mitofilin markiert und mit einem STED-Mikroskop aufgenommen wurde. Die nummerierten kleinen Bilder sind Vergrößerungen der jeweiligen umrandeten Bereiche. Die Graphen zeigen gemittelte Intensitätsprofile quer über die durch Klammern gekennzeichneten Bereiche der Mitochondrien. (Größenbalken: $10 \mu \mathrm{m}$ in dem großen Bild; $1 \mu \mathrm{m}$ in den Ausschnitten) 
Die Abbildung zeigt exemplarisch eine komplette mit Mitifilin-Antikörpern dekorierte hochaufgelöst aufgenommene primäre, humane Fibroblasten-Zelle (Abb. 3.13; STED Übersicht). Bei näherer Betrachtung verschiedener einzelner Bereiche der so gefärbten Mitochondrien zeigte sich, wie auch schon in anderen Abbildungen (Abb. 3.3, Abb. 3.4, Abb. 3.5, Abb. 3.6 B, Abb. 3.7 C und Abb. 3.9), dass in den allermeisten der horizontal zur Wachstumsebene ausgerichteten (und damit senkrecht zur Längsrichtung aufgenommenen) Mitochondrien eine hochgeordnete Lokalisation an den beiden Seiten des Mitochondriums zu sehen war. Es war zu sehen, dass in den primären, humanen Fibroblastenzellen diese Art der "strickleiterartigen“ oder "schienenartigen“ Anordnung der Mitofilin-Cluster ein allgemein zu beobachtendes Phänomen ist. Diese Entdeckung war aus zwei Gründen äußerst überraschend und unerwartet. Zum einen ist Mitofilin bekanntermaßen ein mitochondriales Innenmembranprotein (Gieffers et al., 1997) und würde als solches, wäre es gleichmäßig in der inneren Membran und somit auch in den Cristae lokalisiert, auch innerhalb des Mitochondriums ein Signal zeigen und nicht nur am Rand. Das spricht dafür, dass Mitofilin hauptsächlich in oder in der Nähe der inneren Grenzflächenmembran lokalisiert ist. Dies ist eine Voraussetzung für die beobachtete Lokalisation von Mitofilin, erklärt sie aber noch nicht hinreichend, da, wie oben ausgeführt und in der Simulation (Abb. 3.12 B und C, rechte Spalte) zu sehen, ein über die Oberfläche eines Tubulus verteiltes Protein trotzdem im resultierenden Bild Signale über das gesamte Mitochondrium zeigen würde. Das weist darauf hin, dass in diesen Zellen die Mitofilin-Cluster zum einen in oder in der Nähe der inneren Grenzflächenmembran lokalisiert sind aber zum anderen diese Cluster auch zusätzlich bevorzugt horizontal zur Wachstumsebene ausgerichtet sind. Das zeigt ein unerwartet hohes $\mathrm{Ma}$ an sub-mitochondrialer Organisation, die so für einzelne Proteine noch nicht gezeigt wurde.

Diese hochorganisierte Lokalisation von Mitofilin sollte - obwohl, wie oben ausgeführt und in der Simulation (Abb. 3.12) gezeigt, nur durch die horizontale Anordnung nahe der inneren Grenzflächenmembran zu erklären - in einem nächsten Schritt experimentell durch zwei-Farben-STED-Mikroskopie bestätigt werden. Hierzu wurden die Mitochondrien der Fibroblasten zusätzlich mit einem Antikörper gegen eine Untereinheit der ATP-Synthase (die 
beta-Untereinheit) angefärbt, von der bekannt ist, dass sie bevorzugt in den Cristae lokalisiert ist (Wurm \& Jakobs, 2006; Davies et al., 2011). Das ATP-Synthase-Signal markierte daher in den STED-Bildern das gesamte Innere der Mitochondrien, wodurch die Lokalisation des Mitofilin-Signals nun besser beurteilt werden konnte (Abb. 3.14 A). Zum Vergleich wurde zusätzlich die Lokalisation des Außenmembranproteins Tom20 im Verhältnis zur Lokalisation der beta-Untereinheit der ATP-Synthase untersucht (Abb. 3.14 B).
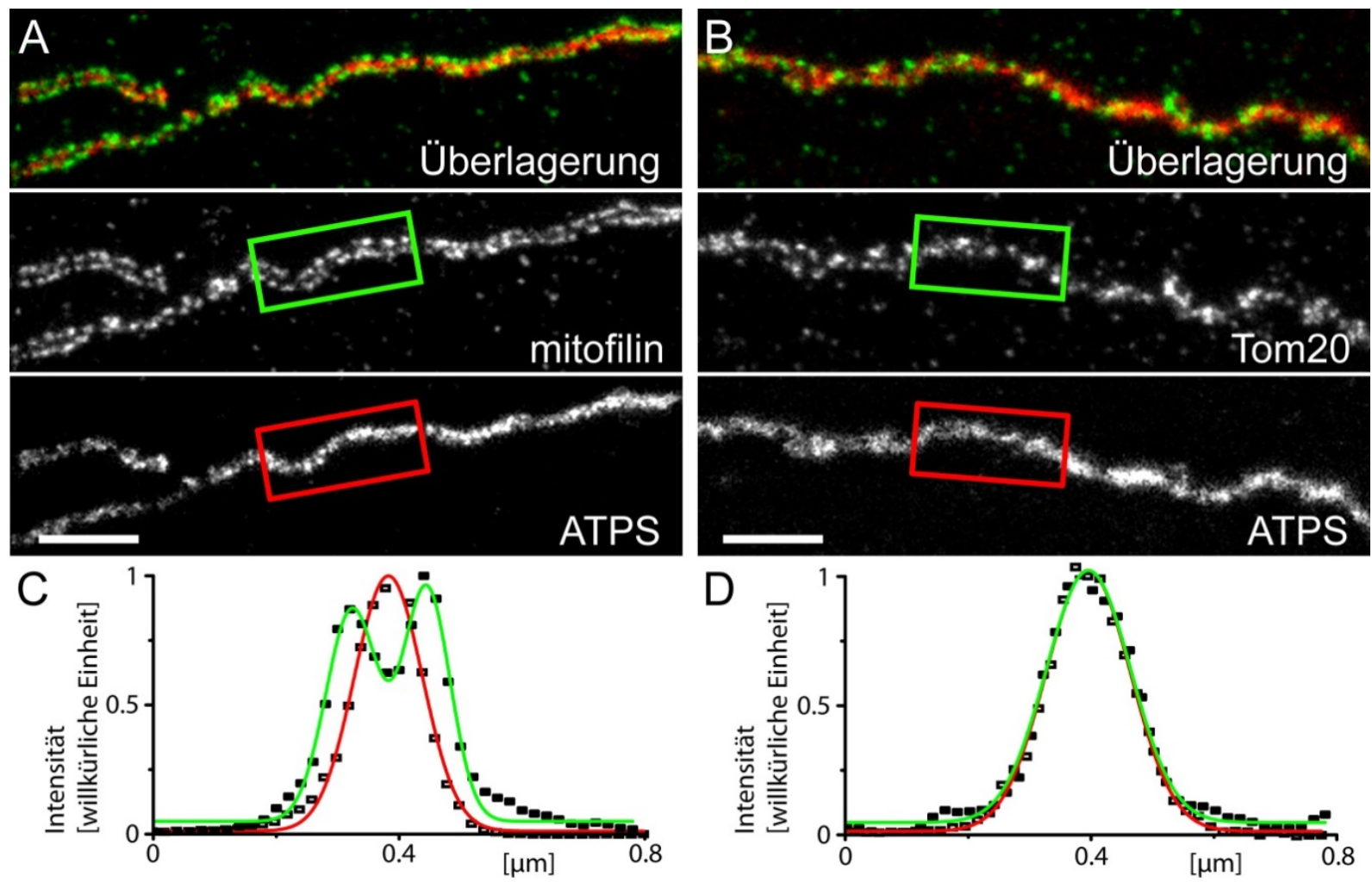

Abb. 3.14 Mitofilin-Cluster sind horizontal auf beiden Seiten der Mitochondrien lokalisiert (bearbeitet aus (Jans et al., 2013)).

(A und B) Zwei-Farben STED-Mikroskopie von mit Antikörpern gegen Mitofilin und die betaUntereinheit der ATP-Synthase (ATPS) (A) bzw. gegen das Außenmembranprotein Tom 20 und ATPS (B) markierten Fibroblasten-Mitochondrien. In den Überlagerungen ist ATPS in rot und Mitofilin bzw. Tom20 in grün dargestellt. ( $C$ und $D$ ) Gemittelte Intensitätsprofile quer über die Mitochondrien in den angezeigten Bereichen in (A) und (B). Das gemittelte Intensitätsprofil der ATPS ist in rot und das von Mitofilin bzw. von Tom20 in grün dargestellt. (Größenbalken: $1 \mu \mathrm{m}$ )

Die zwei-Farben-STED-mikroskopischen Bilder zeigen einen deutlichen Unterschied zwischen der Lokalisation des Innenmembranproteins Mitofilin (Abb. 3.14 A) und der des 
Außenmembranproteins Tom20 (Abb. 3.14 B). Mitofilin ist an den beiden Seiten des Mitochondriums lokalisiert, was durch den Vergleich mit dem ATP-Synthase-Signal deutlich (Abb. 3.14 A) und durch die gemittelten Intensitätsprofile der beiden Signale hervorgehoben wird (Abb. 3.14 C). Das gemittelte Intensitätsprofil von Mitofilin, das durch die Mittelung der - quer über das Mitochondrium gemessenen - Einzelintensitätsprofile in dem in Abb. 3.14 angezeigten Bereich erzeugt wurde, zeigt in der Mitte des Mitochondriums (entlang der mitochondrialen Längsachse) ein Minimum, während das gemittelte Intensitätsprofil des ATP-Synthase-Signals eine einfache gaußsche Verteilung und dadurch im gleichen Bereich ein Maximum aufweist. Das Signal des Außenmembranproteins Tom20 ist hingegen über das gesamte Mitochondrium verteilt (Abb. 3.14 B), was sich auch im gemittelten Intensitätsprofil über den angezeigten Bereich des Mitochondriums zeigte (Abb. 3.14 D). Das Intensitätsprofil von Tom20 wies - ebenso wie das Intensitätsprofil der ATP-Synthase in dem entsprechenden Bereich - kein Minimum in der Mitte des Mitchondriums (entlang der mitochondrialen Längsachse) auf, sondern entsprach einer einfachen Gauß-Verteilung.

Insgesamt belegt dies, dass die offensichtlich randständige Lokalisation von Mitofilin kein optischer Effekt ist, sondern dieses Protein tatsächlich physikalisch in einer horizontalen Ebene zu beiden Seiten des Mitochondriums angeordnet ist. In einem nächsten Schritt sollte nun geklärt werden, ob diese Lokalisation spezifisch für die verwendete primäre, humane Fibroblastenzelllinie ist oder ob sie ein generelles Phänomen in einer Vielzahl von Zellen darstellt.

\subsubsection{Mitofilin ist in einer Vielzahl von verschiedenen Zelllinien hoch geordnet}

Wie in Abschnitt 3.1.1 beschrieben, wurde zur Analyse der Mitofilin-Lokalisation im Wesentlichen mit primären, humanen, adulten Fibroblasten gearbeitet, da diese als Zellmodell mit natürlicher mitochondrialer Funktion und für die mikroskopische Analyse als besonders geeignet erachtet wurden. Die in 3.1.3 beschriebene hochgeordnete Lokalisation von Mitofilin führte jedoch zu der Frage, ob diese ein besonderes Merkmal der 
verwendeten Zellen ist oder ob sie auch in anderen Zellen auftritt und somit ein allgemeines Phänomen darstellt.

Zu diesem Zweck wurde die Mitofilin-Lokalisation in weiteren Zelllinien untersucht. Dazu gehörte die älteste und weithin genutzte unsterbliche HeLa-Zelllinie (humane CervixKrebszellen), weitere primäre, humane, aber neonatale Fibroblasten, die Vero-Zelllinie, die aus Nierenepithelzellen der afrikanischen grünen Meerkatze (Chlorocebus sp.) gewonnen wurde und die U2OS-Zelllinie, welche eine humane Osteosarcomazelllinie ist. Diese Zellen wurden mit dem Mitofilin-Antikörper markiert und im STED-Mikroskop aufgenommen (Abb. 3.15).
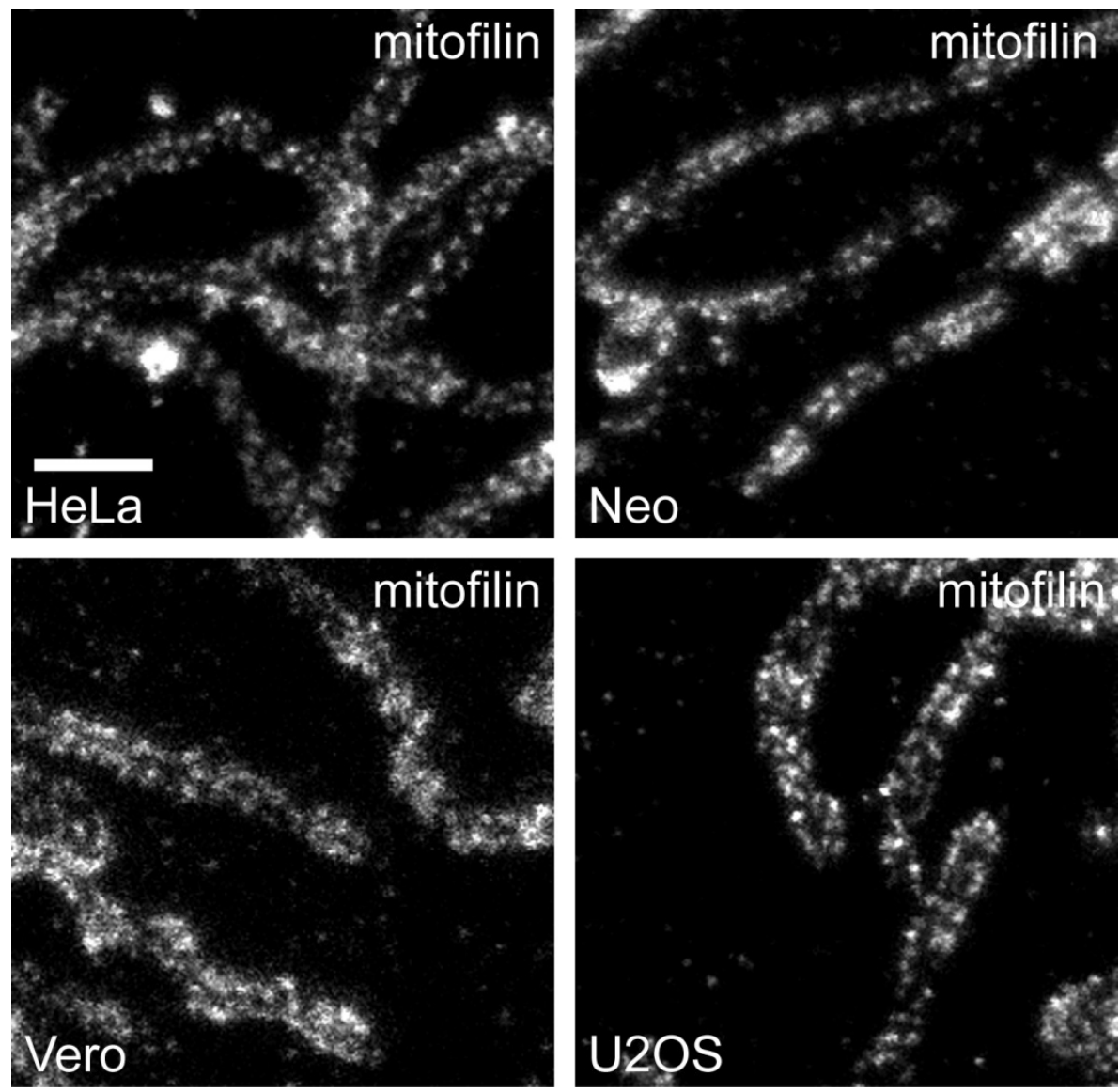

Abb. 3.15 Lokalisation von Mitofilin in verschiedenen Zelllinien (bearbeitet aus (Jans et al., 2013)).

Repräsentative STED-Aufnahmen von mit Mitofilin-Antikörpern gefärbten Zellen der angezeigten Zelllinien (HeLa-Zellen, neonatale humane Fibroblasten (Neo), Vero-Zellen und U2OS-Zellen). (Größenbalken: 1 m) 
In allen hier untersuchten Zelllinien war Mitofilin in einzelnen, distinkten Clustern lokalisiert (Abb. 3.15). Auch die charakteristische Mitofilin-Lokalisation an den beiden Seiten der Mitochondrien, horizontal zur Wachstumsoberfläche zeigte sich in den meisten der untersuchten Zelllinien deutlich. In den HeLa-Zellen, den neonatalen Fibroblasten und den Vero-Zellen war dies besonders gut zu sehen, während in den U2OS-Zellen diese Lokalisation nur in einzelnen kleinen Bereichen der Mitochondrien zu erkennen war (Abb. 3.15).

In allen untersuchten Zellen war eine Abhängigkeit der Sichtbarkeit dieser „Strickleiter“Anordnung der Mitofilin-Cluster von der Ausrichtung und Form der Mitochondrien erkennbar. So konnte beobachtet werden, dass lange, gerade Abschnitte der Mitochondrien, deren Längsrichtung möglichst senkrecht zur optischen Achse ausgerichtet war, am besten geeignet waren, um diese Lokalisation zu beobachten. In Mitochondrien, die viele Krümmungen und Abzweigungen aufwiesen oder oft unterbrochen waren und nur in kurzen Tubuli-Fragmenten vorlagen, war die Ordnung der Cluster häufiger unterbrochen und die horizontale Ausrichtung der Cluster in einer Art "Strickleiter"-Anordnung somit in diesen Mitochondrien oft nicht erkennbar.

Zusätzlich spielte bei der Sichtbarkeit der horizontalen „Stickleiter“-Anordnung von Mitofilin auch der Abstand der beobachteten Mitochondrien zum Zellkern eine Rolle, da zum einen die Cluster in der Nähe des Zellkernes - wie in 3.1.4 beschrieben - weitaus dichter angeordnet waren und somit eine Trennung der einzelnen Cluster schwieriger war und zum anderen die Mitochondrien rund um den Zellkern nicht so gleichmäßig wie am Rand der Zelle horizontal in einer Ebene mit der Wachstumsebene ausgerichtet sind.

Somit konnte gezeigt werden, dass die spezifische Lokalisation von Mitofilin ein allgemein in Mitochondrien von vielen adhärenten Zelllinien zu beobachtendes Phänomen ist, dessen Ausprägung jedoch - auch aufgrund der unterschiedlichen Ausrichtungen der Mitochondrien - variiert. Da Mitofilin eine Kernkomponente des MINOS-Komplexes ist, stellte sich jedoch die Frage, ob andere Komponenten des MINOS-Komplexes oder assoziierte Proteine auch eine ähnliche Lokalisation aufweisen. 


\subsubsection{Kernkomponenten des MINOS-Komplexes haben eine ähnliche Lokalisation wie} Mitofilin

Da die bisherigen Analysen mit der MINOS-Komplex-Kernkomponente Mitofilin durchgeführt wurden, sollten nun die Lokalisation anderer Komponenten des Komplexes oder assoziierter Proteine untersucht werden. Wie in 1.3.1.1 beschrieben, ist bisher wenig über die genaue Zusammensetzung des Komplexes in Säugern bekannt, es gibt jedoch eine Vielzahl möglicher Komponenten und Interaktionspartner. Die zweite Kernkomponente des Komplexes, die auch von Hefe- zu Säugerzellen konserviert ist, ist das Protein MINOS1 (Mio10 in der Hefe) (Alkhaja et al., 2012). Es bietet sich daher dafür an, zu untersuchen, ob die besondere Art der Lokalisation von Mitofilin nur auf dieses Protein zutrifft oder ob sie die Lokalisation des MINOS-Komplexes wiederspiegelt. Eine zusätzliche im Menschen konservierte Komponente des Komplexes ist $\mathrm{CHCHD3}$ (vgl. Tab. 1.3). Dieses Protein ist auch in einer Vielzahl von Veröffentlichungen als Interaktionspartner von Mitofilin bzw. von MINOS1 beschrieben worden (Xie et al., 2007; Darshi et al., 2011; Alkhaja et al., 2012; An et al., 2012; Ott et al., 2012). Es viele weiterer Proteine für die Interaktionen mit dem Komplex nachgewiesen wurden (s. Tab. 1.4 und (Alkhaja et al., 2012)), diese wurden jedoch alle durch biochemische Analysen gefunden. Daher sollte hier untersucht werden, ob sie auf Ebene einzelner Mitochondrien eine vergleichbare Lokalisation, wie der MINOS-KernKomplex aufweisen. Es zeigte sich, dass die Komponenten des MINOS-Komplexes Mitofilin, MINOS1 und CHCHD3 sehr ähnliche Lokalisationen zeigen (Abb. 3.16). Bei allen dreien dieser Proteine ist die „schienenartige“ Anordnung der Cluster zu beobachten. Um zu untersuchen, ob diese drei Proteine mit ähnlicher Lokalisation übergeordnete zusammenhängende Strukturen bilden wurden die Antikörper gegen diese drei Proteine zusammen auf die Fibroblastenzellen gegeben und es zeigte sich wieder eine „schienenartige“ Anordnung der Cluster, wobei die einzelnen Cluster eine der MitofilinCluster alleine vergleichbare Größe aufwiesen ( $85 \mathrm{~nm}$ ). Dieses Ergebnis spricht gegen eine größere Superstruktur, die von den Komponenten des MINOS-Komplexes gebildet wird (Hoppins et al., 2011), sondern für eine Organisation der Komponenten in diskreten Clustern. Es wurde im Rahmen dieser Arbeit auch versucht, die direkte Kolokalisation der 

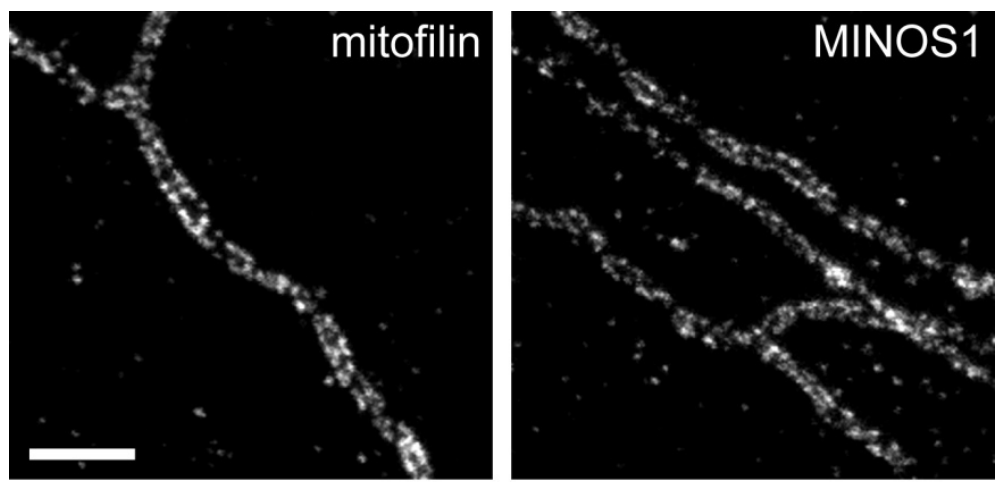

MINOS-Komplex-Komponenten

durch

zwei-Farben-STED-

Mikroskopie zu untersuchen. Da

alle für diese Untersuchung

verfügbaren Antiköper aus dem

gleichen

Organismus
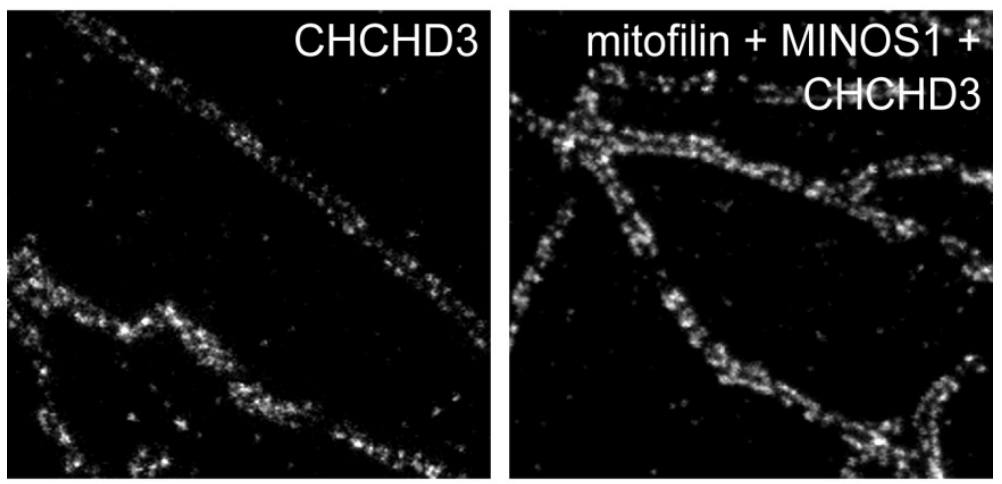

(Kaninchen) stammten, musste eine sequentielle Färbestrategie entwickelt werden, die eine Färbung jeweils zweier der Primärantikörper mit zwei verschiedenen Sekundärantikörpern ermöglichte. Durch
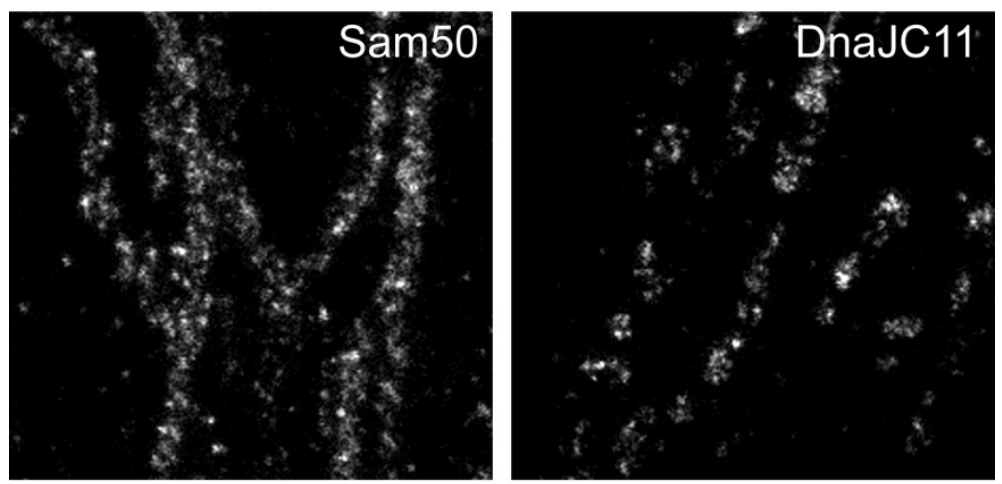

diese sequenzielle Immunofluoreszenzfärbung (vgl. 2.2.3.2) konnten die MINOSKernkomponenten in zwei Detektions-Kanälen hochaufgelöst aufgenommen
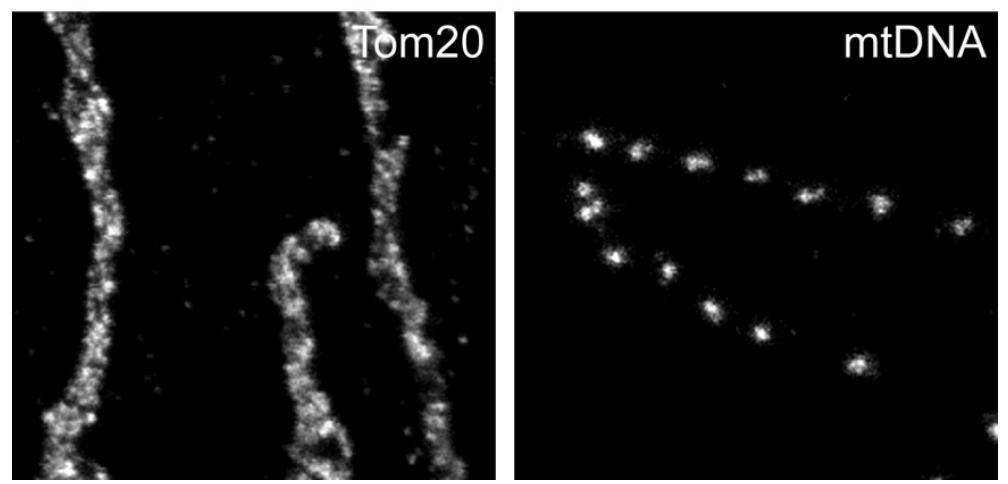

werden (Abb. 3.17). Damit konnte gezeigt werden, dass Mitofilin mit den MINOSKomplex-Komponenten CHCHD3 (Abb. 3.17 A) und MINOS1 (Abb. 3.17 B) zwar in

Abb. 3.16 STED-Mikroskopie von MINOS-KomplexKomponenten und möglichen Interaktionspartnern (bearbeitet aus (Jans et al., 2013)).

Primäre, humane Fibroblasten wurden mit Antikörpern gegen die angezeigten Proteine gefärbt und im STED-Mikroskop aufgenommen. (Größenbalken: $1 \mu \mathrm{m}$ )

großen Teilen kolokalisiert es

jedoch auch Cluster gibt, in

denen scheinbar nur eines der beiden angefärbten Proteine 

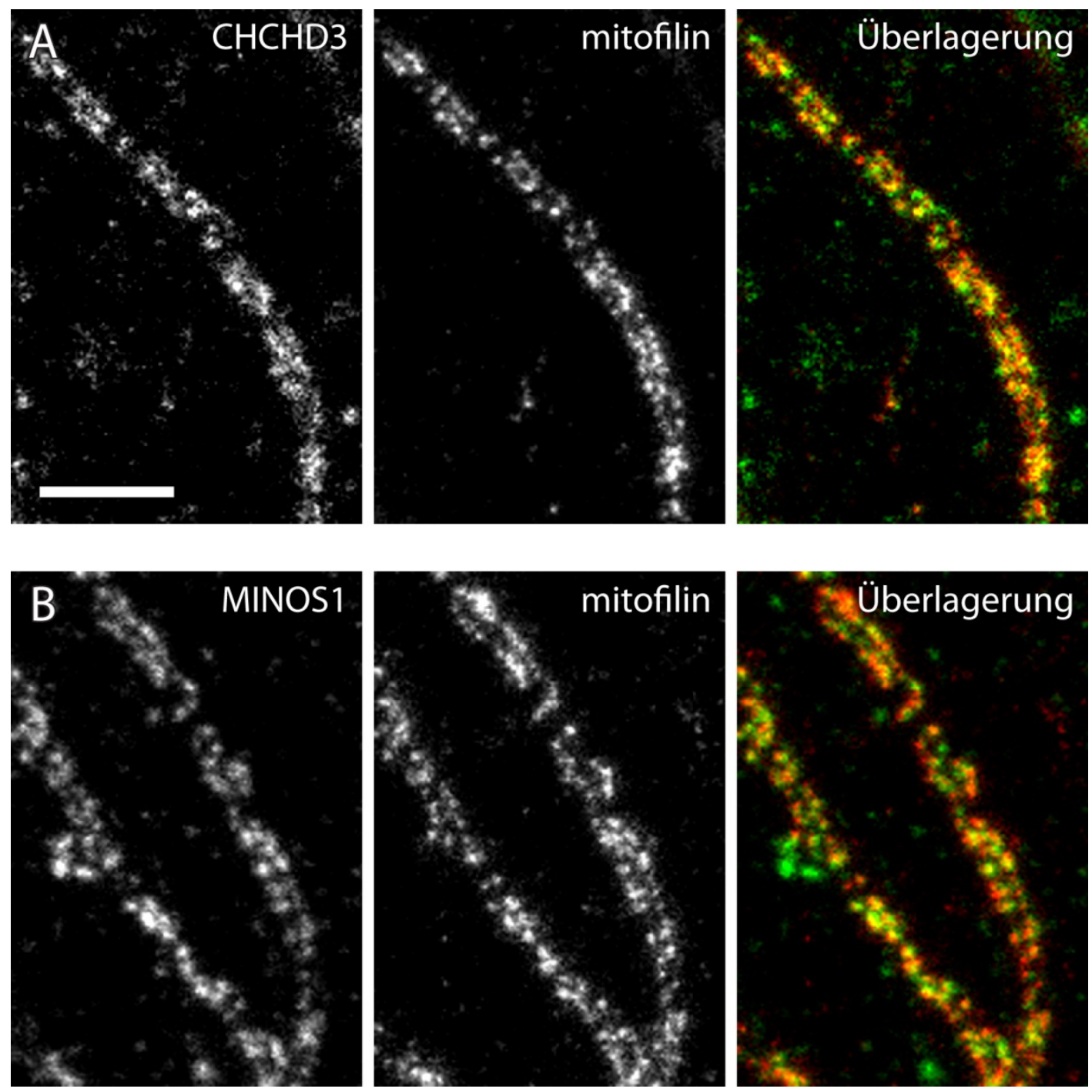

Abb. 3.17 Zwei-Farben STED-Mikroskopie von mit Antikörpern gegen $\mathrm{CHCHD3}$ und Mitofilin (A) sowie MINOS1 und Mitofilin (B) gefärbten primären, humanen Fibroblastenzellen (bearbeitet aus (Jans et al., 2013).

Die Mitochondrien der Fibroblastenzellen wurden durch einen sequenziellen Färbeansatz mit Antiköpern gegen die angezeigten Proteine markiert und im zweiFarben STED-Mikroskop aufgenommen. In den Überlagerungen ist Mitofilin in rot und CHCHD3 (A) bzw. MINOS1 (B) in grün dargestellt. (Gößenbalken: 1 $\mu \mathrm{m}$ )

vorkommt, was für verschiedene Subpopulationen dieses Komplexes spricht. Zur Analyse der Lokalisation der Interaktionspartner des MINOS-Komplexes wurden die drei Proteine SAM50, DnaJC11 und Tom20 herangezogen. Auch die Lokalisation weiterer möglicher Interaktionspartner des Komplexes wurde zu adressieren versucht, es konnten jedoch keine weiteren, für die hochauflösende Immunofluoreszenz-Mikroskopie verwendbaren Antikörper gefunden werden. SAM50 ist ein mitochondriales Außenmembranprotein, das 
als Untereinheit des SAM-Komplexes an der Assemblierung von $\beta$-barrelAußenmembranproteinen beteiligt ist. Es wurde in einer Vielzahl von Publikationen biochemisch gezeigt, dass dieses Protein mit MINOS-Komplex-Komponenten sowohl in Säuger- als auch in Hefezellen interagiert (Xie et al., 2007; Darshi et al., 2011; Alkhaja et al., 2012; Bohnert et al., 2012; Korner et al., 2012; Ott et al., 2012; Zerbes et al., 2012). In der vorliegenden Arbeit konnte gezeigt werden, dass die Lokalisation von SAM50 sich von der der drei MINOS-Komplex-Komponenten unterscheidet, da es gleichmäßig über die Membran der Mitochondrien verteilt ist (Abb. 3.16). Dies spricht gegen eine Interaktion der gesamten MINOS- und SAM-Komplex Populationen, sondern eher für eine teilweise Interaktion, möglicherweise von Subpopulationen dieser Komplexe. Ein ähnliches Resultat wurde für den peripheren Rezeptor der Translokase der äußeren Membran Tom20 erzielt. Auch für dieses Protein konnten in der Hefe biochemisch Interaktionen mit dem MINOSKomplex nachgewiesen werden (Bohnert et al., 2012; Zerbes et al., 2012), in den STEDBildern zeigte sich jedoch, dass Tom20 in Säugerzellen über die gesamte MitochondrienOberfläche verteilt ist und sich somit in der Lokalisation von den MINOS-Komponenten unterscheidet (Abb. 3.14 und 3.16). DnaJC11 als dritter untersuchter Interaktionspartner wies eine gänzlich andere sehr viel weniger dichte Lokalisation auf, so dass auch für dieses Protein mit weitgehend unbekannter Funktion (DnaJC11 ein Mitglied der 40 kDa Hitzeschockprotein-Subfamilie C) - obwohl es ebenso in verschiedenen Studien biochemisch als Interaktionspartner von MINOS-Komplex-Komponenten beschrieben wurde (Xie et al., 2007; Alkhaja et al., 2012) - eine komplette Kolokalisation und damit auch eine vollständige Interaktion mit allen MINOS-Komplexen ausgeschlossen werden konnte.

Es konnte also gezeigt werden, dass drei der Kernkomponenten des MINOS-Komplexes (Mitofilin, MINOS1 und CHCHD3) eine vergleichbare, hochgeordnete Lokalisation in Mitochondrien von adhärenten Säugerzellen aufweisen und großenteils kolokalisieren, wobei sie keine vergrößerten, zusammenhängenden Strukturen bilden, sondern in diskreten Clustern lokalisiert sind. Andere mit dem Komplex interagierende Proteine weisen eine gänzlich unterschiedliche Verteilung innerhalb der Mitochondrien auf. Das hohe Maß der Organisation der Lokalisation von MINOS-Kernkomponenten wirft die Frage auf, wo diese 
Komponenten ultrastrukturell innerhalb der inneren Mitochondrienmembran positioniert sind und ob die innere Mitochondrienstruktur diese Ordnung wiederspiegelt. 


\subsection{Analyse der Mitochondrien-Ultrastruktur und Position der Mitofilin-Cluster}

Die Struktur der Innenmembran von Mitochondrien ist in einer Vielzahl von Studien beschrieben worden (s. 1.3). In einer dieser Arbeiten wurde gezeigt, dass in bestimmten Synapsen (Calyx of Held) die Cristae bevorzugt so ausgerichtet sind, dass die meisten Cristae junctions in Richtung der präsynaptischen Membran ausgerichtet sind (Perkins et al., 2010). Ein hohes Maß an Organisation bei der Lokalisation der Cristae Junctions in Mitochondrien anderer Zellen und anderer Zellbereiche wurde jedoch nicht konstatiert. Da in 3.1 gezeigt wurde, dass der MINOS-Komplex in Mitochondrien ein hohes Maß an räumlicher Organisation aufweist, wirft dies die Frage auf, was das für die Ultrastruktur der inneren Mitochondrienmembran bedeutet. Wären die MINOS-Komplex-Cluster in Säugerzellen, wie elektronenmikroskopische Untersuchungen von Immunogold-Färbungen des Hefe-MINOSKomplexes nahelegen, auch im Wesentlichen an den Cristae Junctions lokalisiert, würde dies implizieren, dass die Cristae Junctions über die gesamte Zelle hoch organisiert und vorwiegend in einer Ebene angeordnet wären.

\subsubsection{Mitofilin ist an Cristae Junctions angereichert}

In einem ersten Schritt wurde daher die Lokalisation der MINOS-Kernkomponente Mitofilin im Mitochondrium analysiert.

Um die Ultrastruktur von Membranen im Detail untersuchen zu können, bietet sich, wie in 1.4.2 ausgeführt, die Elektronenmikroskopie an. Mit dieser Technik lassen sich die Membranen hochaufgelöst darstellen, es besteht jedoch das Problem, dass Lokalisationen von Proteinen nicht in der gleichen Weise darstellbar sind wie in der Fluoreszenzmikroskopie (vgl. 1.4). Eine Möglichkeit um Lokalisationen von Proteinen dennoch im Elektronenmikroskop untersuchen zu können, ist die Immunogold-Färbung. Hierzu werden Dünnschnitte der zu untersuchenden Zellen mit einem entsprechenden Primärantiköper und einem sekundären Gold-Konjugat dekoriert. Die Effizienz solcher Färbungen ist vor allem aufgrund der verhältnismäßig großen und schweren Goldpartikel 
sehr beschränkt und so müssen die Daten einer Vielzahl von Bildern quantitativ ausgewertet werden.

Im Rahmen dieser Arbeit wurden hierzu HeLa-Zellen vom Wachstumsuntergrund abgekratzt und pelletiert. Die Zellen wurden daraufhin in Zusammenarbeit mit Dirk Wenzel (Facility für Elektronenmikroskopie, Max-Planck-Institut für biophysikalische Chemie) nach der Tokuyasu-Methode behandelt (Tokuyasu, 1973) und ultradünne Kryoschnitte ( 80 nm) angefertigt, die dann mit einem primären Antikörper gegen Mitofilin und sekundärem 10 $\mathrm{nm}$ Protein A-Gold markiert und im Transmissionselektronenmikroskop aufgenommen wurden. Einige repräsentative Aufnahmen sind in Abb. 3.18 dargestellt.
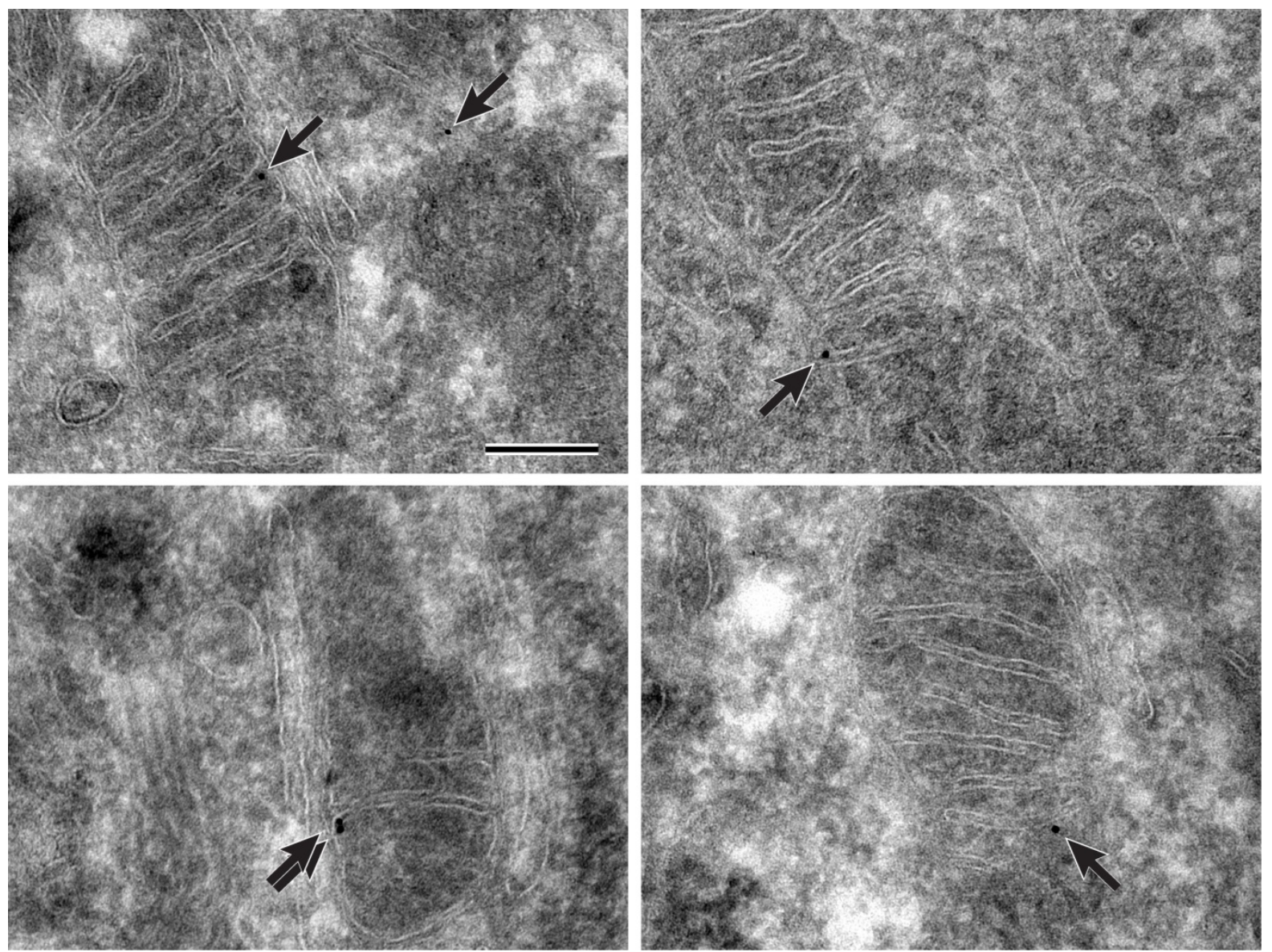

Abb. 3.18 Repräsentative transmissionselektronenmikroskopische Aufnahmen von HeLa-ZellMitochondrien, die mit einem primären Mitofilin-Antikörper und sekundärem Gold-Konjugat markiert wurden.

Die Membranen weisen durch die angewendete Methode (Tokuyasu, 1973) einen negativen Kontrast auf, während die Gold-Partikel aufgrund ihrer Elektronendichte als schwarze Kugeln zu sehen sind. Zur besseren Orientierung wurden die Gold-Partikel mit Pfeilen gekennzeichnet. (Größenbalken: $200 \mathrm{~nm}$ ) 
In den elektronenmikroskopischen Aufnahmen der mit Mitofilin-Antikörpern und einem sekundären Gold-Konjugat dekorierten HeLa-Zellen waren die Gold-Partikel in den meisten der Mitochondrien in der Nähe der Cristae Junctions lokalisiert (Abb. 3.18). Es ist in diesen Aufnahmen aber auch zu sehen, dass die Mitochondrien nur sehr vereinzelt Gold-Partikel aufwiesen. Das liegt zum einen an der oben angesprochenen generell schwachen

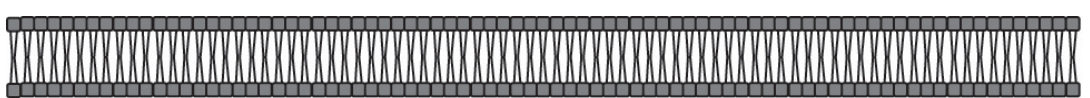

Färbeeffizienz dieser

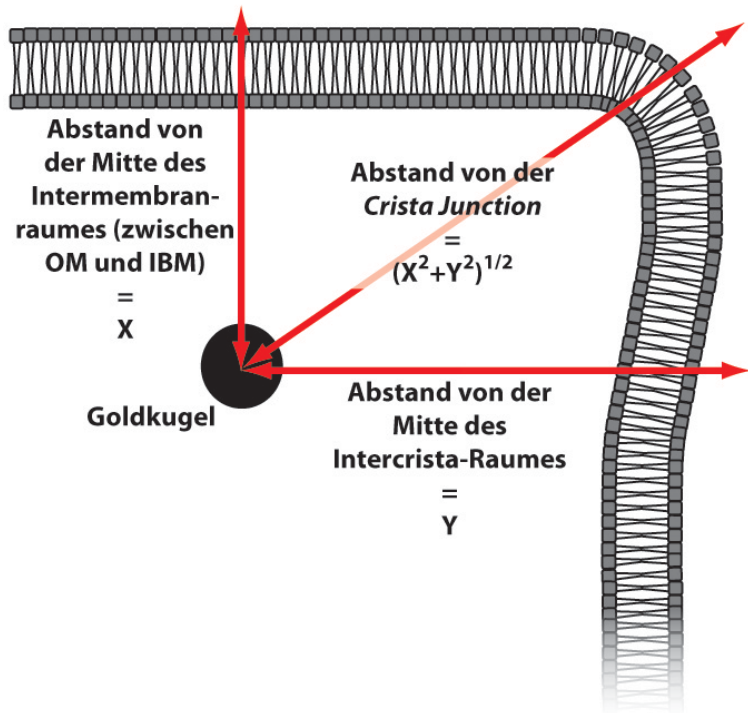

Abb. 3.19 Schematische Darstellung der Auswertung der einzelnen Gold-Lokalisationen in den transmissionselektronenmikroskopischen Aufnahmen von mit Mitofilin-Antikörpern markierten HeLa-Zell-Mitochondrien (exemplarisch in Abb. 3.18 gezeigt)

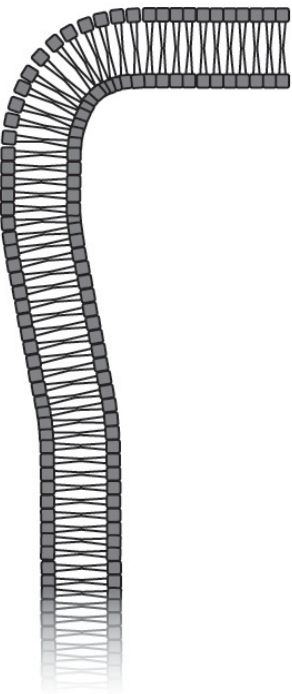

Partikel möglichst zu vermeiden. Daher musste eine Vielzahl dieser Bilder ausge-wertet werden. Dazu wurde, wie in Abb. 3.19 illustriert, der Abstand der einzelnen Gold-Partikel von der Mitte des Intermembranraumes (hier ist der Raum zwischen der äußeren Membran und der inneren Grenzflächenmembran gemeint) und von der Mitte des Intercrista-Raumes bestimmt. Aus diesen Daten konnte zum einen der Abstand zu einem gedachten Zentrum der Cristae Junctions ermittelt werden, zum anderen konnte ein Modell einer typischen Crista und der benachbarten Membranen erstellt und die aus den Bildern einzeln ermittelten Mitofilin-Gold-Lokalisationen auf dieses Modell übertragen werden. Das eröffnet die Möglichkeit, einen genauen Eindruck von der 
Mitofilin-Lokalisation in den HeLa-Zell-Mitochondrien zu bekommen. Das Resultat dieser Analyse ist in Abb. 3.20 dargestellt.

Mitofilin ist in den HeLa-Zell-Mitochondrien in der Nähe der Cristae Junctions angereichert

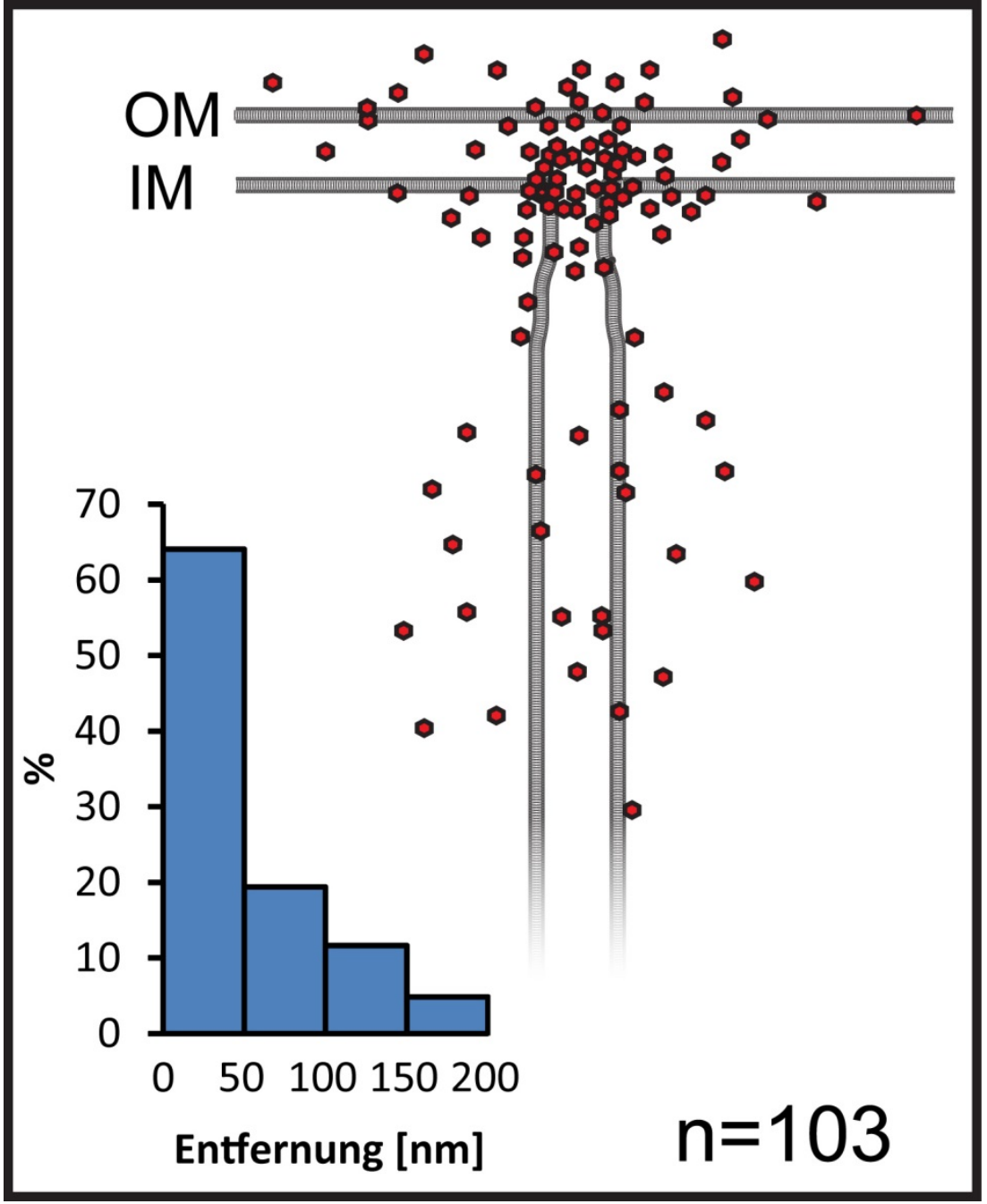

Abb. 3.20 Mitofilin ist in HeLa-Zell-Mitochondrien bevorzugt in der Nähe der Cristae Junctions lokalisiert (bearbeitet aus (Jans et al., 2013)).

Die einzelnen Lokalisationen der Gold-Partikel (rot) wurden aus den elektronenmikroskopischen Mitofilin-Immunogold-Aufnahmen von HeLa-Zell-Mitochondrien ermittelt (vgl. Abb. 3.18 und 3.19) und auf ein Modell einer Crista übertragen $(\mathrm{OM}=$ "outer membrane"=äußere Mitochondrienmembran; $\quad \mathrm{IM}=$ "inner membrane"=innere Mitochondrienmembran). Das Histogramm zeigt den Anteil der Gold-Lokalisationen in Abhängigkeit vom Abstand zur Crista Junction. Beide Darstellungen beruhen auf dem gleichen Datensatz.
(Abb. 3.20). Für die Analyse wurde die Lokalisation von 103 Gold-Partikeln untersucht und es zeigte sich, dass der Großteil der GoldPartikel und damit des Proteins Mitofilin rund um den Bereich der mitochondrialen Membran lagen, der gemeinhin als Crista Junction bezeichnet wird. Der Anteil der GoldPartikel in der Nähe der Cristae Junctions entsprach dabei in etwa den in der Literatur für das Hefe-Mitofilin-Homolog Fcj1 und andere Komponenten des MINOS-Komplexes angegebenen Werten (Rabl et al., 2009; Harner et al., 2011).

Mitofilin ist also 
tatsächlich vor allem an Cristae Junctions lokalisiert. Zusammen mit der Entdeckung, dass Mitofilin in einer mitochondrialen Ebene hochorganisiert vorliegt (3.1.3), führte dies zu der Annahme, dass die Cristae Junctions ihrerseits hochorganisiert in einer Ebene vorliegen und die Cristae entsprechend ausgerichtet sein müssten. Dies wurde in einem nächsten Ansatz überprüft.

\subsubsection{Cristae Junctions sind häufig parallel zur Wachstumsebene ausgerichtet}

Um eine solche vermutete, von der Ausrichtung zur Wachstumsebene abhängige Anordnung beobachten zu können, muss die Ausrichtung der Mitochondrien im Schnitt (der für die elektronenmikroskopische Aufnahme nötig ist) bekannt sein. Daher wurde die Ausrichtung der Cristae Junctions in Tomogrammen von Schnitten, die parallel zur Wachstumsebene angefertigt wurden, untersucht.

Zu diesem Zweck wurden primäre, humane Fibroblasten auf Aclar-Plättchen angezogen und bei einer Konfluenz von ca. 90\% schonend fixiert. Nach einer zusätzlichen Fixierung folgten die üblichen Kontrastierungs- und Dehydrierungs-Schritte (s. Material und Methoden) und die Zellen wurden in Epon (Agar 100) eingebettet. Die eingebetteten Zellen wurden nun streng parallel zur vorherigen Wachstumsebene in $250 \mathrm{~nm}$ dicke Schnitte zerteilt und nachkontrastiert. Die Dicke der Schnitte ermöglichte es somit, dass ein gesamter mitochondrialer Tubulus in das Volumen des Schnittes passte und war gleichzeitig dünn genug, um in dem verwendeten Transmissionselektronenmikroskop (Philips CM120) vom Elektronenstrahl durchdrungen werden zu können. Die Schnitte wurden in SaxtonIntervallen von $-64,5^{\circ}$ bis $+64,5^{\circ}$ im Mikroskop gedreht und aufgenommen. Um eine möglichst isotrope laterale Auflösung zu erreichen, wurden die Schnitte jeweils zweimal, um $90^{\circ}$ gedreht, aufgenommen. Ein Beispiel einer solchen tomographischen Aufnahme eines Mitochondriums, die in Zusammenarbeit mit Dietmar Riedel (Facility für Elektronenmikroskopie, Max-Planck-Institut für biophysikalische Chemie) erstellt wurde, ist in Abb. 3.21 gezeigt. 

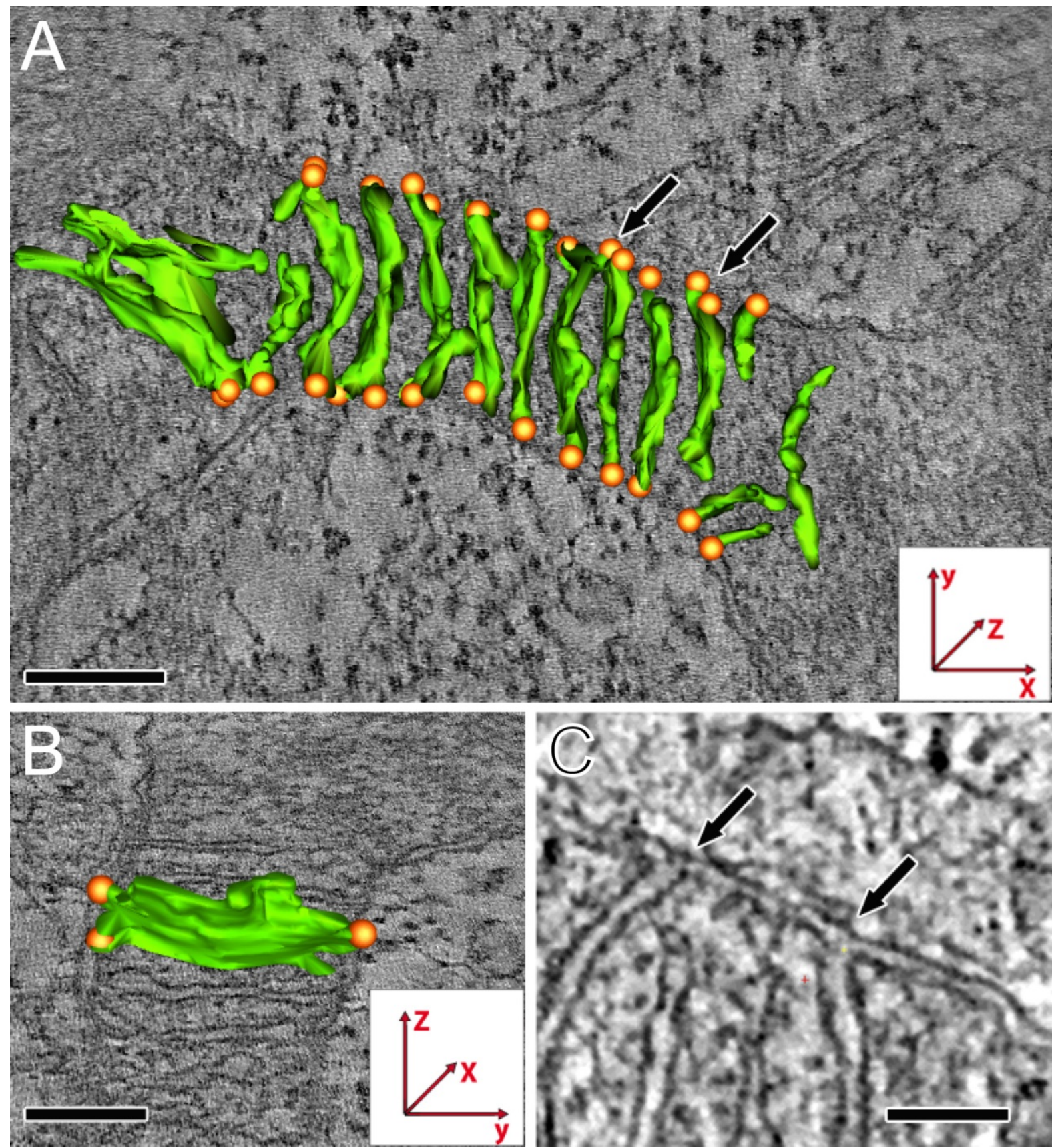

Abb. 3.21 Cristae Junction-Ausrichtung und Cristae-Morphologie in primären, humanen Fibroblastenmitochondrien, analysiert durch zwei-Achsen Elektronen-Tomographie (Jans et al., 2013).

(A und B) Eine einzelne Ebene des Tomogramms (grau) wurde überlagert mit einer Rekonstruktion der segmentierten Cristae Membranen (grün). Cristae Junctions sind durch orange Kugeln markiert. In (A) ist eine Aufsicht auf das Mitochondrium (das Tomogramm ist in einer Ebene mit der Wachstumsebene) und in (B) eine Seitenansicht desselben Mitochondriums zu sehen. Die lamellaren Cristae sind durch Cristae Junctions an den beiden Seiten des Organells (parallel zur Wachstumsoberfläche) mit der inneren Grenzflächenmembran verbunden. (C) Vergrößerung einer einzelnen Ebene des Tomogrammes (Aufsicht). Die Pfeile kennzeichnen dieselben Cristae Junctions die in (A) mit Pfeilen markiert sind. (Größenbalken: $100 \mathrm{~nm}$ in A und C; $50 \mathrm{~nm}$ in B) 
Die Cristae in den Mitochondrien der primären, humanen Fibroblasten weisen eine lamellare Struktur auf und sind großenteils senkrecht zur Längsrichtung des Mitochondriums ausgerichtet (Abb. 3.21). Vor allem zeigte sich aber, dass die Cristae Junctions in diesen Mitochondrien vorwiegend parallel zur Wachstumsebene angeordnet sind (Abb. 3.21). Auch in weiteren Aufnahmen wurden kaum Cristae Junctions gefunden, die nicht diese Ausrichtung aufwiesen. Dabei wurde darauf geachtet, dass in den analysierten Tomogrammen das gesamte Mitochondrium abgebildet war und nicht nur ein Ausschnitt. Dennoch musste eine mögliche Fehlerquelle dieser Analyse in Betracht gezogen werden: So haben die hier erstellten Tomogramme eine schlechtere axiale Auflösung, da für die Rekonstruktion der Tomogramme nur elektronenmikroskopische Aufnahmen der Schnitte in den Winkeln von $-64,5^{\circ}$ bis $+64,5^{\circ}$ gemacht werden konnten (bei einem steileren Winkel kann der Elektronenstrahl die Probe nicht mehr durchdringen). Daher fehlen die Aufnahmen in den Winkeln von $+/-64,5^{\circ}$ bis $+/-90^{\circ}$, die für eine optimale Rekonstruktion notwendig wären. Dies könnte die Identifizierung möglicher Cristae Junctions im oberen und unteren Teil des Tomogrammes möglicherweise verhindern. Daher wurden zusätzlich
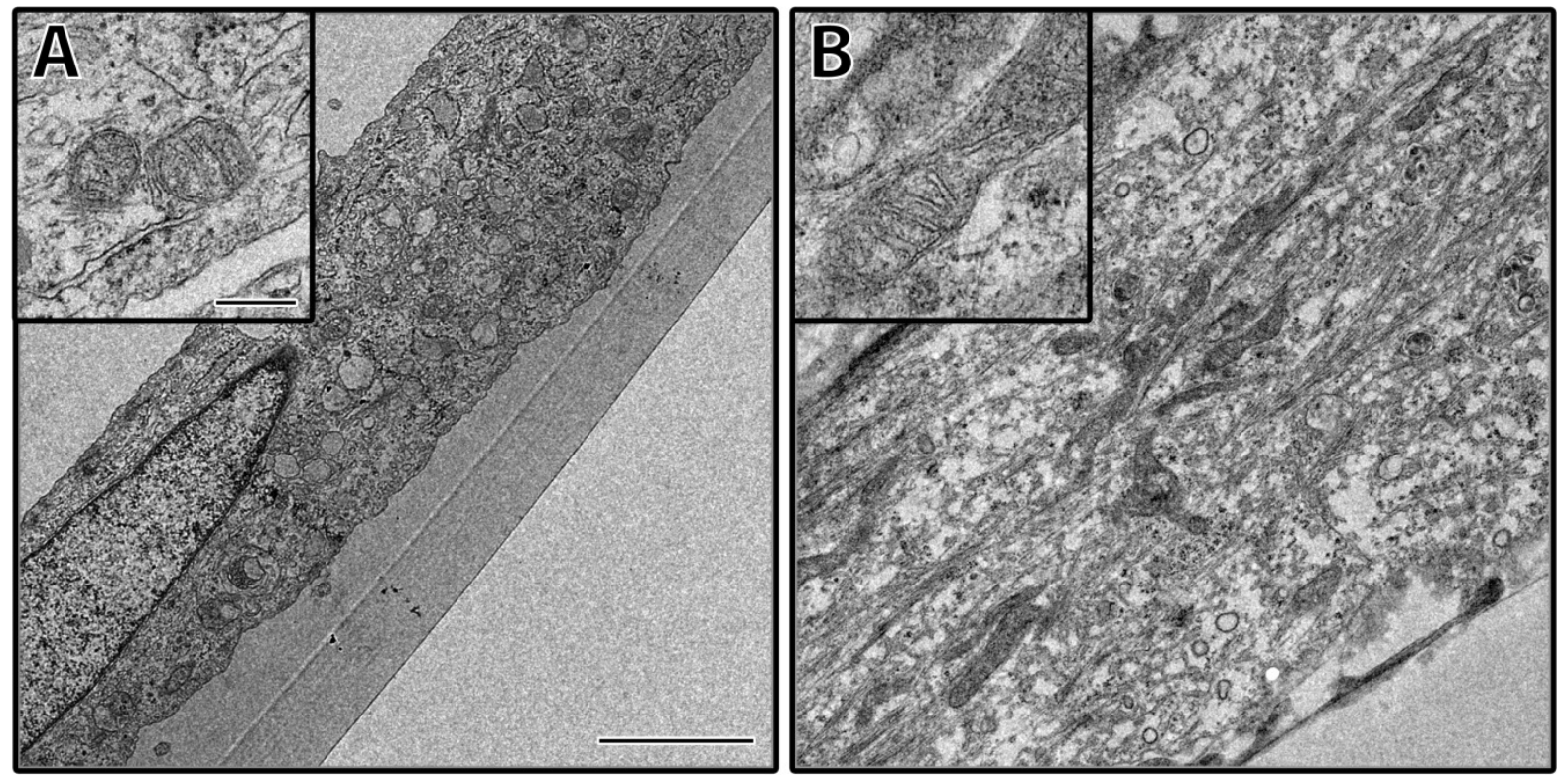

Abb. 3.22 Transmissionselektronenmikroskopische Aufnahmen von Dünnschnitten primärer, humaner Fibroblasten, die senkrecht (A) bzw. parallel (B) zur Wachstumsebene geschnitten und aufgenommen wurden. In den vergrößerten Ausschnitten sind jeweils Mitochondrien gezeigt, die in den senkrechten Schnitten bevorzugt rund $(A)$ und in parallelen Schnitten bevorzugt länglich (B) aussahen. (Größenbalken: $1 \mu \mathrm{m}$ in den großen Bildern; $200 \mathrm{~nm}$ in den vergrößerten Ausschnitten) 
zwei-dimensionale elektronenmikroskopische Aufnahmen von Dünnschnitten aus primären, humanen Fibroblasten parallel zur Wachstumsebene (wie im Tomogramm) und senkrecht zur Wachstumsebene erstellt (Abb. 3.22).

Das Erscheinungsbild der Mitochondrien hängt in der zwei-dimensionalen elektronenmikroskopischen Aufnahme stark von der Betrachtungsrichtung ab: Mitochondrien, die parallel zur Wachstumsebene und damit in der Längsebene angeschnitten wurden, sehen in der elektronenmikroskopischen Aufnahme bevorzugt länglich (tubulär) aus (Abb. 3.22 B), während senkrecht angeschnittene Mitochondrien rund aussehen (Abb. 3.22 A). Somit ist für eine elektronenmikroskopische, ultrastrukturelle Untersuchung der Mitochondrien im Kontext der Zelle, eine klar definierte Ausrichtung im Schnitt notwendig.

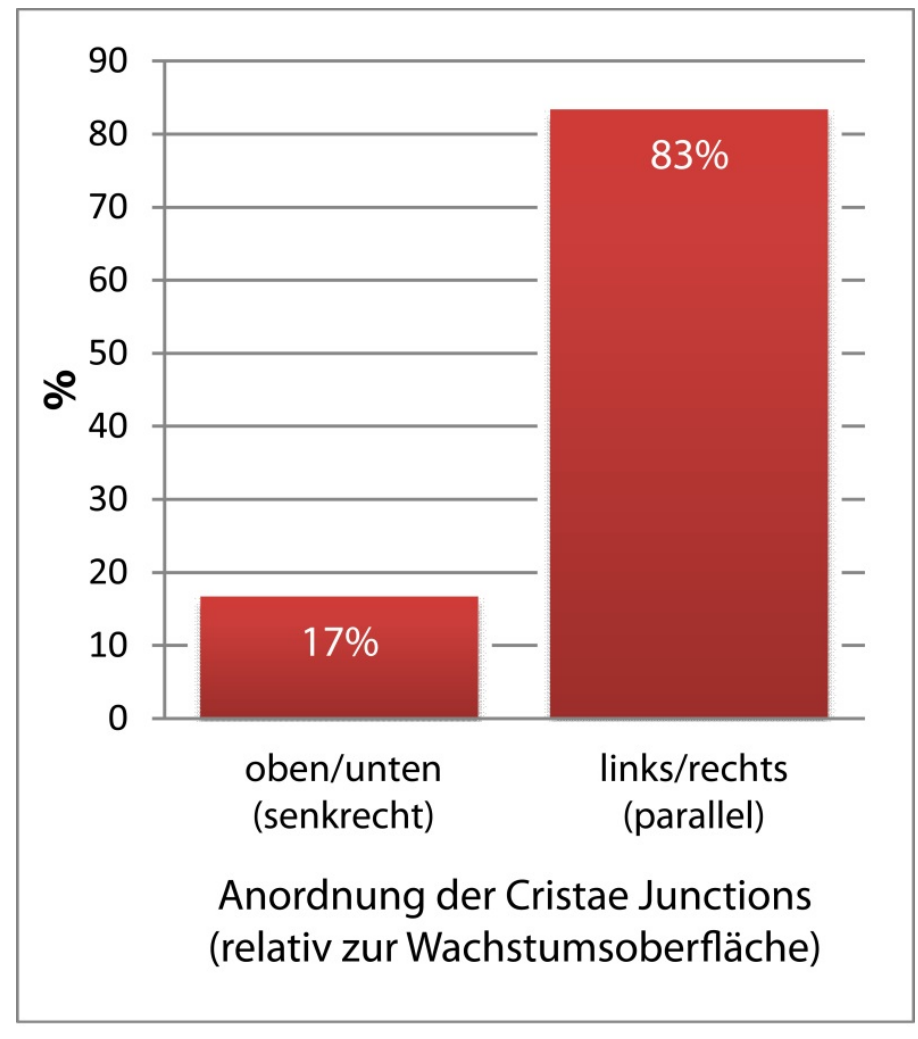

Abb. 3.23 Analyse der Ausrichtung von Cristae Junctions in senkrecht zur Wachstumsoberfläche angefertigten elektronenmikroskopischen Schnitten. Die meisten der Cristae Junctions sind in Übereinstimmung mit den Tomographie-Daten (Abb. 3.21) parallel zur Wachstumsebene ausgerichtet.
Um das oben angesprochene Problem der möglicherweise technisch bedingten Fehlinterpretation der tomographischen Daten zu adressieren, wurden eine Vielzahl der in Abb. 3.22 A gezeigten senkrecht angeschnittenen Mitochondrien, im Hinblick auf die Ausrichtung der Cristae Junctions, relativ zur Wachstumsoberfläche, untersucht. Dabei zeigte sich - in Übereinstimmung mit den Elektronen-Tomographie-Daten (vgl. Abb. 3.21) - eine bevorzugte Ausrichtung der Cristae Junctions an den beiden Seiten der Mitochondrien $183 \%$ der Cristae Junctions zeigten eine solche 
Ausrichtung), die parallel zur Wachstumsoberfläche liegen (Abb. 3.23).

Insgesamt konnte somit gezeigt werden, dass Mitofilin als Kern-Komponente des MINOSKomplexes in den Bereichen der Cristae Junctions angereichert ist. Die Kern-MINOSKomponenten bilden keine erweiterten, zusammenhängenden Strukturen, sondern sind alle - in unterschiedlicher Zusammensetzung - in denselben distinkten Clustern lokalisiert, welche einen Dichtegradienten vom Zentrum zum Rand der Zelle hin aufweisen. Andere Interaktionspartner des MINOS-Komplexes haben eine gänzlich unterschiedliche Lokalisation. Außerdem konnte gezeigt werden, dass die horizontale Ausrichtung der MINOS-Cluster in einer Art "Strickleiter"-Anordnung ein allgemein in den Mitochondrien von adhärenten Säugerzellen zu beobachtendes Phänomen ist, was eine generelle organisierte Ausrichtung der Cristae Junctions in all diesen Zellen impliziert.

Durch Elektronentomographie konnte gezeigt werden, dass die Cristae in den Mitochondrien humaner Fibroblasten meist eine lamellare Struktur haben, die über Cristae Junctions, die in der Regel parallel zur Wachstumsoberfläche angeordnet sind, mit der inneren Grenzflächenmembran verbunden sind. Daraus kann geschlossen werden, dass der Kern-MINOS-Komplex in Mitochondrien von kultivierten Säugerzellen in gleichmäßig angeordneten, diskreten Clustern an Cristae Junctions lokalisiert und parallel zur Wachstumsoberfläche angeordnet ist. 


\section{Diskussion und Ausblick}

\subsection{Der MINOS-Komplex als mögliches mitochondriales Skelett}

Dem Hefe-MINOS-Komplex, der in verschiedenen unabhängigen Publikationen als aus sechs Proteinen bestehend beschrieben wurde (Harner et al., 2011; Hoppins et al., 2011; von der Malsburg et al., 2011), werden eine Vielzahl struktureller Funktionen zugeschrieben. Hierzu gehört vor allem seine Funktion als Super-Komplex an den Cristae Junctions, für deren Aufrechterhaltung er essentiell ist. Der Verlust einer der Komponenten des Komplexes (bis auf Mio27) geht mit einer Reduzierung der Zahl der Cristae Junctions, bis hin zu einem nahezu vollständigen Verlust derselben, einher (Harner et al., 2011; von der Malsburg et al., 2011). Er wurde aber auch als wesentliches Element der Contact Sites beschrieben (Harner et al., 2011). Als solches vermittelt er direkte Kontakte der inneren mit der äußeren Mitochondrienmembran. In Übereinstimmung damit wurde nachgewiesen, dass der Komplex mit der Außenmembran- "sorting and assembly machinery" (SAM) interagiert (Harner et al., 2011; Bohnert et al., 2012; Korner et al., 2012; Zerbes et al., 2012). Zusätzlich wurden Interaktionen der MINOS-Kernkomponente Fcj1 mit dem TOM-Komplex gezeigt (von der Malsburg et al., 2011; Bohnert et al., 2012; Zerbes et al., 2012). Eine weitere mögliche Interaktion, die durch einen genetischen Screen identifiziert wurde, besteht mit dem ERMES-Komplex (Hoppins et al., 2011). Über diese wurde weiterhin spekuliert, dass der MINOS-Komplex damit Teil eines, die innere Mitochondrienmembran mit der äußeren Mitochondrienmembran und der Membran des endoplasmatischen Retikulums überspannenden Netzwerkes ist, das ERMIONE genannt wurde (van der Laan et al., 2012). Als zentrale Komponente einer solchen Vielzahl von Interaktionen liegt der Schluss nahe, dass der MINOS-Komplex eine Plattform und damit ein zentrales strukturgebendes Element der mitochondrialen Membran darstellt.

Es gibt eine Vielzahl an Proteinen, deren Fehlfunktion oder deren Fehlen, eine MorphologieVeränderung der normalerweise zumeist tubulären Mitochondrien bewirkt (Okamoto \& Shaw, 2005). So führen zum Beispiel Störungen in Prozessen, die an der Fusion und der Teilung von Mitochondrien beteiligt sind (vgl. 1.2.2), zur Fragmentierung oder Hyperfusion 
dieser Organellen. Auch das Fehlen von zentralen Proteinen weiterer Prozesse wie zum Beispiel der Ergosterol-Biosynthese, des Vesikel-Transports oder des mitochondrialen Protein-Imports kann zu einer veränderten mitochondrialen Morphologie in Hefen-Zellen führen (Altmann \& Westermann, 2005). Weitere, nur in der Hefe bekannte Proteine, wie z. B. Komponenten des ERMES-Komplexes (Mdm10, Mdm12, Mdm34, MMM1) und viele weitere Proteine - hierunter viele Mdm (,mitochondrial distribution and morphology“)Proteine - sind für die tubuläre Struktur von Mitochondrien essentiell (Dimmer et al., 2002; Wurm \& Jakobs, 2006). Ihr Fehlen führt oft zu vergrößerten kugelförmigen Mitochondrien. Damit wären diese Proteine interessante Kandidaten für die Suche nach einem möglichen mitochondrialen „Skelett“ oder „Rückgrat", das die Mitochondrien in ihrer tubulären Form hält. Für eine Vielzahl der Proteine, die in der Hefe für die tubuläre Struktur der Mitochondrien verantwortlich sind, kennt man jedoch keine Homologe in Säugerzellen.

Es stellt sich auch die Frage, ob es eine klar definierte Struktur, die eine solche Aufgabe als „Rückgrat“ der Mitochondrien erfüllt, überhaupt gibt oder geben muss. In einem anderen, mit den Mitochondrien eng verknüpften Organell, dem endoplasmatischen Retikulum (vgl. 1.2.3), sind solche strukturgebende Proteine bekannt. Hier bilden die sogenannten Reticulons und das Protein DP1/Yop1 oligomere Strukturen, die die Membrankrümmung

(A)

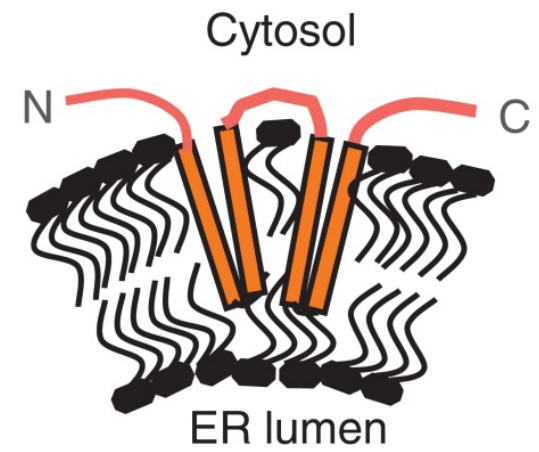

(B)

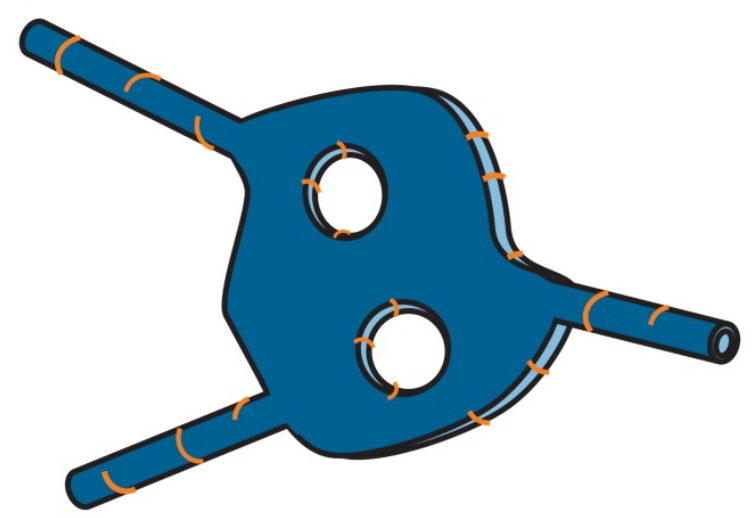

Abb. 4.1 Modell der Reticulons als formgebende Komponente der Membran des Endoplasmatischen Retikulums (ER) (Friedman \& Voeltz, 2011).

(A) Schematische Darstellung der Reticulon-Topologie in der Membran des ER. (B) Schematische Darstellung von ER-Cisternae und Tubuli (blau), in denen Reticulons (orange) in den Bereichen starker Membrankrümmung lokalisiert sind und diese regulieren. 
dieses Organells stabilisieren oder erzeugen (Voeltz et al., 2006; Hu et al., 2008; Shibata et al., 2008; Tolley et al., 2010; West et al., 2011; Zurek et al., 2011) (Abb. 4.1). Da auch Mitochondrien in der Regel - zumindest innerhalb einer einzelnen Zelle - einen relativ gleichmäßigen Durchmesser haben, scheint die Hypothese, dass auch dieses Organell eine Struktur hat, die als eine Art "Skelett" die Mitochondrien umschließt und so ihren Durchmesser definiert, plausibel.
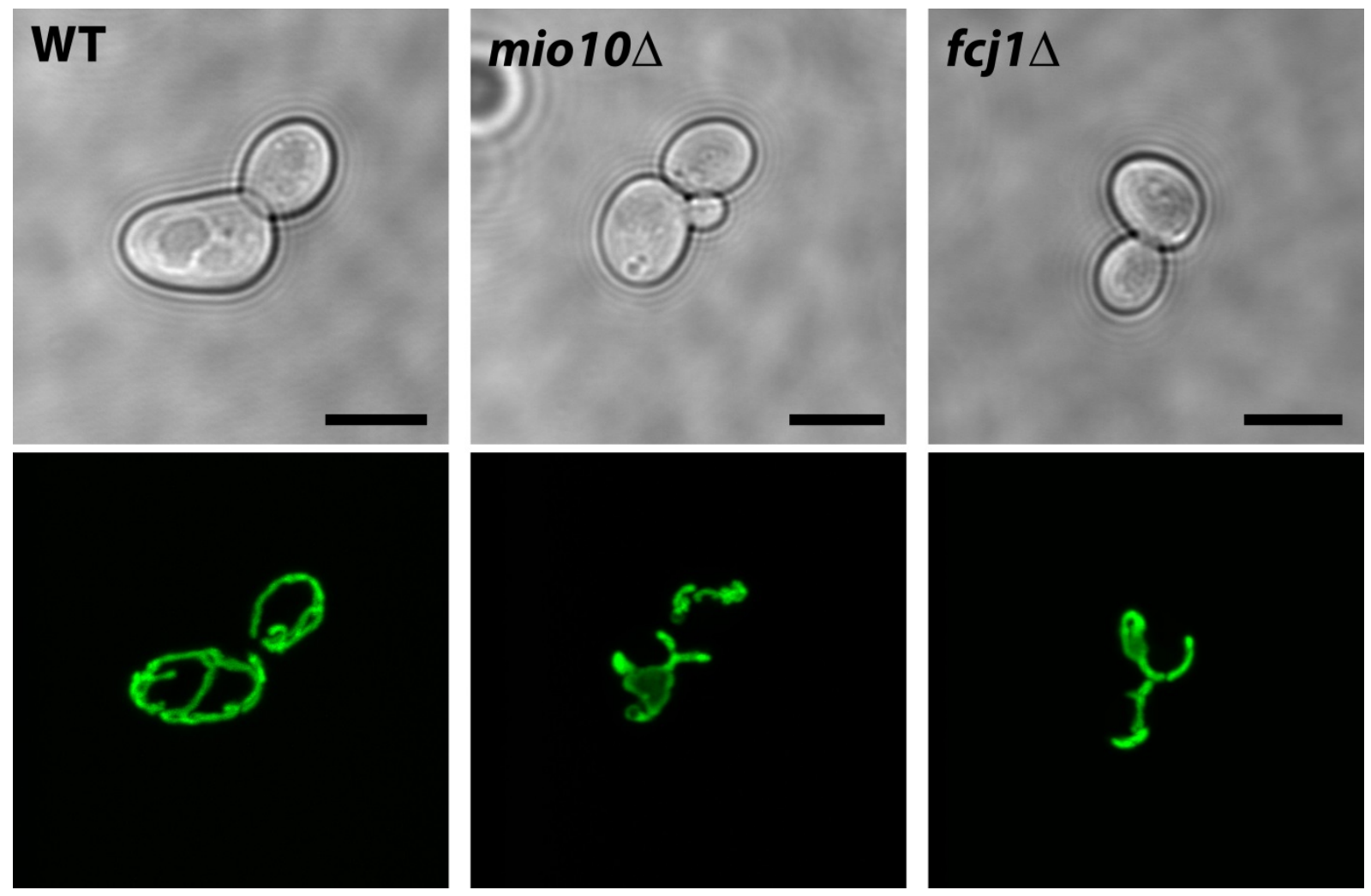

Abb. 4.2 Mitochondriale Morphologie von wildtypischen Hefezellen (WT) und von Hefezellen mit einem knock-out einer der Kernkomponenten des MINOS-Komplexes (Mio10 und Fcj1).

Die Übersicht über die Hefezellen wurde im Hellfeld aufgenommen (obere Zeile; grau) und die Mitochondrien wurden durch mitochondrial lokalisiertes GFP-Signal visualisiert (untere Zeile; grün) und es zeigt sich eine veränderte Morphologie des mitochondrialen Netzwerkes bei Fehlen einer der beiden Kern-Komponenten des MINOS-Komplexes. (Größenbalken: 5 um)

Das Fehlen von Kern-Komponenten des Hefe-MINOS-Komplexes führt zu morphologischen Veränderungen der Mitochondrien (Abb. 4.2). Diese sind jedoch weitaus schwächer ausgeprägt als Veränderungen, die durch das Fehlen anderer, die tubuläre Struktur der 
Mitochondrien beeinflussender Proteine hervorgerufen werden können (Okamoto \& Shaw, 2005). Dies widerspricht zunächst der These, dass der MINOS-Komplex eine zentrale Rolle für die tubuläre Struktur der Mitochondrien spielt. Entfaltete weitfeldmikroskopische Daten schienen jedoch darauf hinzuweisen, dass MINOS-Komponenten zusammenhängende Strukturen bilden, die die Mitochondrien umschließen und eine Art „Helix“-Struktur bilden (Hoppins et al., 2011). Diese Beobachtung wurde daher, auch durch die Vielzahl von Interaktionen des MINOS-Komplexes, als ein Hinweis auf ein mögliches mitochondriales "Skelett" und ein Indiz für eine zusätzliche Ebene der Organisation von Mitochondrien durch diesen vielseitigen Komplex gewertet (Hoppins et al., 2011) (Abb. 4.3).

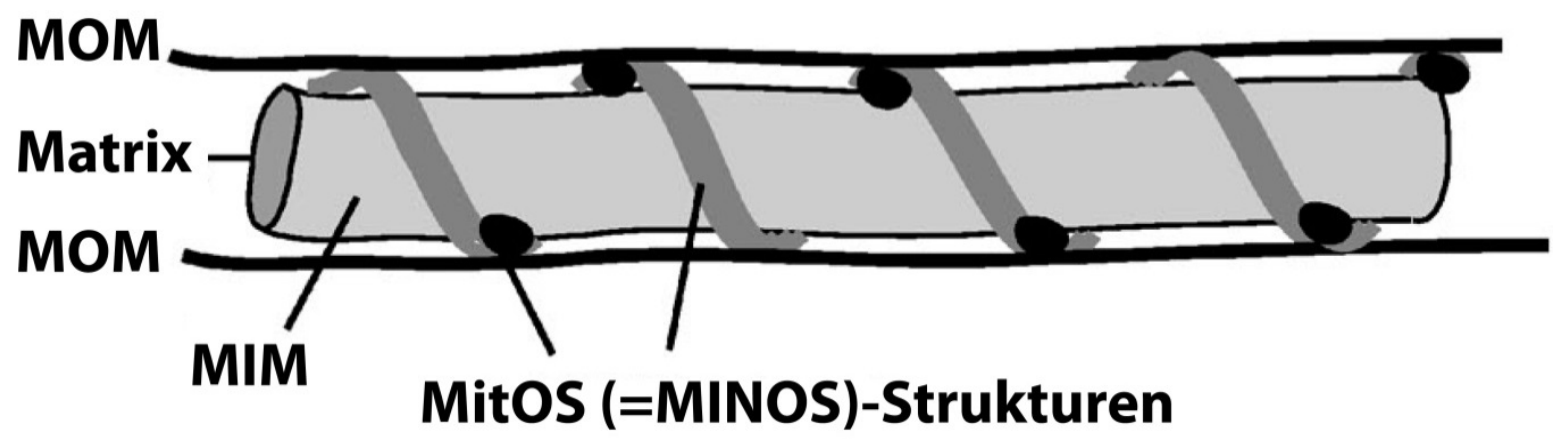

Abb. 4.3 Schematische Darstellung von MitOS (=MINOS) als komplexe, zusammenhängende Struktur, die die Mitochondrien umschließt und dadurch eine Art mitochondriales Skelett bildet (bearbeitet aus (Hoppins et al., 2011)).

Das Modell beruht auf weitfeldmikroskopischen Bildern von Hefe-MINOS (MitOS)-Komponenten. (MOM="mitochondrial outer membrane"=mitochondriale Außenmembran; MIM="mitochondrial inner membrane" =mitochondriale Innenmembran).

Der MINOS-Komplex ist in großen Teilen zwischen Hefe- und Säugerzellen konserviert (vgl. Tab. 1.3) und weist auch in Säugerzellen eine große Vielfalt an Interaktionen auf (vgl. Tab. 1.4). Daher wurden im Rahmen der vorliegenden Arbeit zusammenhängende, übergeordnete Strukturen in diesen Zellen (mit Mitteln, die eine solche Analyse valide ermöglichen) gesucht. Zu diesem Zweck wurde zunächst die Lokalisation der MINOSKernkomponente Mitofilin untersucht. Hierzu wurden Immunofluoreszenzfärbungen 
erstellt, mit dem STED-Mikroskop aufgenommen und analysiert. Es zeigte sich, dass Mitofilin in einzelnen, distinkten Clustern lokalisiert ist (Abb. 3.6). Dabei war auch klar zu sehen, dass für diese Analyse submitochondrialer Lokalisationen die hohe laterale Auflösung des STED-Mikroskops unerlässlich ist, da im STED-Bild einzeln erkennbare Cluster (Abb. 3.6 B) im konfokalen Bild (Abb. 3.6 A) nicht mehr auflösbar waren und daher scheinbar zusammenhängende Strukturen bildeten. Zusammen mit den Daten der Simulation zufällig über einen Tubulus verteilter Punkte (Abb. 3.12), die auch übergeordnete Strukturen suggerieren könnten (vgl. 3.1.5), führt dies zu der Frage, wie valide die Daten weitfeldmikroskopischer Untersuchungen in Hinblick auf Aussagen über sub-mitochondriale Organisationen von Proteinen überhaupt sein können. Durch Entfaltung der Bilder kann die Auflösung zwar verbessert werden (maximal verdoppelt (Willig et al., 2006)), für eine Aussagen zu übergeordneten Strukturen sollte die Auflösung jedoch höher sein als die Größe der untersuchten Strukturen. Dies ist im Fall des MINOS-Komplexes nur mit beugungsunbegrenzten mikroskopischen Methoden möglich, da die Kernkomponenten, wie in dieser Arbeit gezeigt, in Clustern mit einer Größe von ca. $85 \mathrm{~nm}$ lokalisert sind (vgl. 3.1.3 und 3.1.7).

Die Lokalisation des humanen Mitofilins in einzelnen Clustern kann jedoch noch nicht alleine als Entkräftung der These von zusammenhängenden, übergeordneten MINOSStrukturen gewertet werden, da andere Komponenten des Komplexes diese Cluster möglicherweise verbinden könnten. Daher wurde eine Kombination der (funktionierenden) Antiköper gegen die drei bekannten MINOS-Komponenten in Säugern (Mitofilin, MINOS1 und $\mathrm{CHCHD3)}$ verwendet und es zeigten sich erneut keine vergrößerten, zusammenhängenden Strukturen, sondern wieder Cluster, die einen der der Einzelfärbungen entsprechenden Durchmesser ( $\sim 55 \mathrm{~nm}$ ) aufwiesen (Abb. 3.16). Somit wurde geschlossen, dass die Kern-MINOS-Komponenten in Säugern, zumindest alleine, keine Art von mitochondrialem Skelett bilden können, welches als solches möglicherweise die tubuläre Struktur der Mitochondrien erzeugen würde, sondern dass sie in einzelnen Clustern lokalisiert sind (Abb. 4.4). 


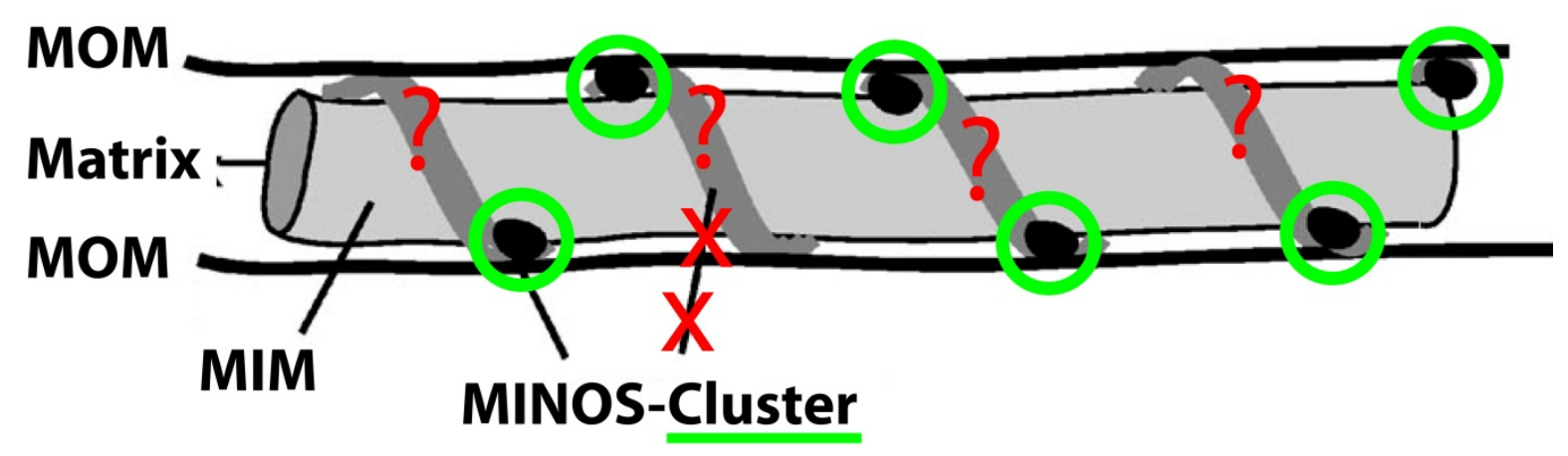

Abb. 4.4 Schematische Darstellung des veränderten Modells von (Hoppins et al., 2011) wie es sich durch STED-mikroskopische Analysen von MINOS-Kernkomponenten in Mitochondrien von adhärenten Säugerzellen darstellte. MINOS-Kernkomponenten sind in einzelnen Clustern organisiert (grüne Kreise), die alleine keine erweiterten, die Mitochondrien umschließende Strukturen bilden. $\mathrm{Ob}$ es die MINOS-Cluster verbindende Strukturen gibt, kann nicht ausgeschlossen werden (rote Fragezeichen), sie bestehen jedoch nicht aus den bekannten humanen MINOS-Kernkomponenten.

Das Ergebnis, dass MINOS-Kernkomponenten keine erweiterten Strukturen erzeugen, schließt jedoch nicht aus, dass weitere unbekannte Proteine die Cluster verbinden und somit möglicherweise doch eine Art mitochondriales Skelett bilden könnten. Aus diesem Grund ist es notwendig, weitere Komponenten des humanen Komplexes - sowie weitere, möglicherweise die Komplexe verbindende, Proteine - zu identifizieren und auf ihre Lokalisation in den Mitochondrien hin zu untersuchen. Außerdem müssten die hier für den Säuger-MINOS-Komplex durchgeführten Untersuchungen auf den Hefe-MINOS-Komplex übertragen und auch dieser mittels beugungsunbegrenzter Mikroskopie untersucht werden.

\subsection{Die Lokalisation des MINOS-Komplexes und seiner Interaktionspartner}

Der MINOS-Kernkomplex der Säugerzellen besteht, wie oben bereits beschrieben, aus den Komponenten Mitofilin, MINOS1 und CHCHD3. Mitofilin (MINOS2) ist das humane Ortholog des Hefe-MINOS-Proteins Fcj1 und führt bei Herunter-Regulation des Proteins zu einem dem knock-out von Fcj1 vergleichbaren Phänotyp, nämlich dem Verlust von Cristae Junctions (John et al., 2005). In der vorliegenden Arbeit wurde außerdem gezeigt, dass das humane Mitofilin wie sein Hefe-Ortholog an den Cristae Junctions lokalisiert ist (Abb. 3.20). MINOS1 ist das humane Ortholog von Mio10 in Hefen, das als zweite Kernkomponente des 
Komplexes für die Cristae-Morphologie ebenso entscheidend ist (Harner et al., 2011; von der Malsburg et al., 2011; Alkhaja et al., 2012). CHCHD3 (MINOS3) weist wiederum Ähnlichkeiten mit dem Hefe-MINOS-Protein Aim13 auf. Außerdem wurden in einer großen Vielfalt von Publikationen Interaktionen dieses Proteins mit Mitofilin oder MINOS1 und seine entscheidende Rolle für die Aufrechterhaltung der Cristae Junctions nachgewiesen (Xie et al., 2007; Darshi et al., 2011; Alkhaja et al., 2012; An et al., 2012; Ott et al., 2012). Ein weiteres "coiled-coil-helix-coiled-coil-helix domain containing"-Protein, das in diesem Komplex eine Rolle spielen könnte, ist CHCHD6. Es weist große Ähnlichkeit mit CHCHD3 auf, interagiert mit Mitofilin und ist auch für die Cristae-Morphologie wichtig (Xie et al., 2007; An et al., 2012). Leider konnten für dieses Protein keine für die hochauflösende Mikroskopie geeigneten Antikörper gefunden werden, so dass die Lokalisation dieses Proteins in der vorliegenden Arbeit nicht untersucht werden konnte. Zusätzlich zu diesen Proteinen wurde ganz aktuell ein weiteres Protein identifiziert, das in Säugerzellen mit den oben angesprochenen Komponenten des Komplexes interagiert, einen großen Einfluss auf die Cristae-Morphologie und zusätzlich zwei mögliche Homologe in der Hefe hat, die beide Komponenten des MINOS-Komplexes sind (Aim37 und Mio27): APOOL (apolipoprotein Olike protein) (Weber et al., 2013). Dieses Protein, das auch Cardiolipin bindet und damit eine Verbindung zwischen dem MINOS-Komplex und dem für die Architektur der inneren Mitochondrienmembran wichtigen Lipid (vgl. 1.3.1) darstellt, wird in Zukunft auf seine Lokalisation, in Beziehung zu den anderen Komponenten des MINOS-Komplexes, zu untersuchen sein.

Die drei hier untersuchten Kernkomponenten des MINOS-Komplexes (Mitofilin, MINOS1, $\mathrm{CHCHD3)}$ bilden, wie in 4.1 bereits beschrieben, zusammen keine erweiterten Strukturen und zeigten alle drei eine vergleichbare Lokalisation (Abb. 3.16). Dies führte zu der Frage, ob die MINOS-Komplexe klar definierte Strukturen sind, die immer in der gleichen Zusammensetzung der einzelnen Proteine existieren. Zu diesem Zweck wurden im Rahmen dieser Arbeit Kolokalisations-Studien einzelner dieser Proteine durchgeführt (vgl. 3.1.7; Abb. 3.17). Die Herausforderung bei dieser Art der Untersuchung bestand in der gleichzeitigen Immunoflureszenzfärbung jeweils zweier Proteine, da die verwendeten, für die 
Hochauflösung funktionierenden Antikörper alle aus dem gleichen Tier stammten (Kaninchen). Zu diesem Zweck wurde eine sequenzielle Färbestrategie entwickelt, die darin besteht, die Färbungen der beiden Proteine hintereinander, getrennt durch Absättigungsschritte, durchzuführen (s. 2.2.3.3). Diese Färbungen wurden dann im zweiFarben-STED-Mikroskop untersucht und es zeigte sich, dass viele der Cluster des einen Proteins mit Clustern des anderen Proteins (es wurden die Kolokalisationen von CHCHD3 mit Mitofilin und von MINOS1 mit Mitofilin untersucht) übereinstimmten (kolokalisierten) (Abb. 3.17). Es waren jedoch auch immer einzelne Cluster eines der beiden Proteine erkennbar, die sich nicht in Clustern des anderen Proteins an derselben Stelle wiederspiegelten. Zum einen zeigte dies, dass Kolokalisationen nicht durch Nebensignaleffekte (Crosstalk) hervorgerufen wurden, da sich dann die Signale des einen Kanals immer auch in den Signalen des anderen Kanals zeigen müssten, zum anderen aber auch, dass der MINOS-Komplex scheinbar in unterschiedlichen Kompositionen seiner Komponenten auftritt, dass es also verschiedene MINOS-Subkomplexe gibt. Dieses Ergebnis wird durch erste biochemische Hinweise, die auf Subkomplexe des Hefe-MINOS-Komplexes hindeuten, gestützt (Bohnert et al., 2012).

Die Fülle der Interaktionen des MINOS Komplexes, sowohl in der Hefe als auch in Säugern (vgl. 1.3.1.1), warfen weiterhin die Frage auf, ob sich die biochemisch gezeigten Interaktionen in einer vergleichbaren Lokalisation dieser Proteine wiederspiegeln. Ein sowohl in der Hefe als auch in Säugerzellen vielfältig beschriebener Interaktionspartner des MINOS-Komplexes ist Sam50 als Komponente des in der äußeren Mitochondrienmembran lokalisierten SAM-Komplexes (Xie et al., 2007; Darshi et al., 2011; Bohnert et al., 2012; Korner et al., 2012; Ott et al., 2012; Zerbes et al., 2012). Weiterhin wurde biochemisch in Säugerzellen gezeigt, dass SAM in einem großen Komplex zusammen mit Mitofilin und CHCHD3 existiert und es wurde daher ein "mitochondrial intermembrane space bridging" (MIB)-Komplex postuliert (Ott et al., 2012). Daher wurde die Lokalisation von Sam50 in Säugerzellen durch STED-Mikroskopie überprüft (Abb. 3.16). Es zeigte sich, dass Sam50 eine andere Lokalisation als die drei MINOS-Kernkomponenten aufweist. Auch Sam50 ist zwar in Clustern lokalisiert, diese sind jedoch über das ganze Mitochondrium verteilt und nicht hoch 
geordnet wie Mitofilin oder die anderen beiden Kern-Komponenten des Komplexes. Dies spricht gegen eine generelle stabile Interaktion aller SAM-Komplexe mit allen MINOSKomplexen, sondern eher dafür, dass nur ein Teil der SAM-Komplexe mit MINOSKomplexen interagiert. Ein ähnliches Ergebnis wurde bei der Untersuchung der Lokalisation der Untereinheit des TOM-Komplexes Tom20 erzielt. Auch für den TOM-Komplex wurden Interaktionen mit dem MINOS-Komplex, zumindest in Hefe-Zellen, gezeigt (von der Malsburg et al., 2011; Bohnert et al., 2012; Zerbes et al., 2012). Aber auch Tom20 ist in Clustern über das gesamte Mitochondrium verteilt, was eine Interaktion aller TOMKomplexe mit allen MINOS-Komplexen ebenso unmöglich macht (Abb. 3.16). DnaJC11, ein weiterer putativer Interaktionspartner des Säuger-MINOS-Komplexes (Xie et al., 2007; Alkhaja et al., 2012) zeigte in den STED-Bildern eine gänzlich andere Lokalisation und war ungleichmäßig und weiter verstreut als die anderen analysierten Proteine über die Mitochondrien verteilt (Abb. 3.16). Zusätzlich zu den oben erwähnten Proteinen wurde die Lokalisation der mitochondrialen DNA (mtDNA) visualisiert (Abb. 3.16). Sie zeigte die typische punktförmige Lokalisation in einzelnen Nucleoiden die in unregelmäßig weiten Abständen in der Matrix der Mitochondrien vorliegen (Kukat et al., 2011). Erstaunlicherweise sind in Säugerzellen jedoch auch zwei Interaktionspartner von Mitofilin identifiziert worden (PARP1 und PNKP), die in der DNA-Reparatur bzw. der Stabilität von DNA und der Regulation der Transkription eine wichtige Rolle spielen und sowohl im Zellkern als auch in den Mitochondrien lokalisiert sind (Rossi et al., 2009; Tahbaz et al., 2012). Diese Interaktionen deuten doch auf einen Zusammenhang zwischen der mitochondrialen DNA und dem MINOS-Komplex hin, der sich aber nicht in den Lokalisationen wiederspiegelt und daher wohl keine direkte, stabile Interaktion repräsentiert.

\subsubsection{Der MINOS-Komplex ist räumlich hoch organisiert}

Da in der vorliegenden Arbeit gezeigt wurde, dass der MINOS-Komplex in einzelnen Clustern lokalisiert ist, stellte sich die Frage, ob diese Cluster entlang der Mitochondrien gleichmäßig 
verteilt sind oder ob sie einen Gradienten aufweisen, wie er zum Beispiel in vorangegangenen Arbeiten für die Translokase der äußeren Membran gezeigt worden ist (Wurm et al., 2011). Zu diesem Zweck wurde die Verteilung der MINOS-Kernkomponente Mitofilin in einer Vielzahl von Zellen untersucht und es zeigte sich, dass die Mitofilin-Cluster in Mitochondrien nahe des Zellkernes in der Regel deutlich dichter waren als in Mitochondrien in der Peripherie der Zellen (Abb. 3.8 und Abb. 3.10). Diese Dichteverteilung der Mitofilin-Cluster deckte sich mit den Ergebnissen, die zur Dichteverteilung der Tom20Cluster vorliegen (Wurm et al., 2011). Auch Tom20-Cluster sind in der Nähe des Zellkernes dichter lokalisiert als in der Zellperipherie. Diese Gradienten spiegeln einen AktivitätsGradienten der Mitochondrien wieder (Wurm et al., 2011) und werfen die Frage auf, ob es sich hierbei um einen aktiv regulierten Gradienten handelt, der physiologisch funktionale Implikationen hat, oder um einen passiven Prozess, der durch zufällige Verteilungseffekte über die Fläche der Zellen zustande kommt. Da Mitofilin an den Cristae Junctions lokalisiert ist (Abb. 3.20), weist der hier gezeigte Mitofilin-Gradient auch auf einen Gradienten in der Dichte der Cristae in den Mitochondrien hin. Das erklärt auch den Gradienten des Membranpotentials (Wurm et al., 2011), da die Proteine der Atmungskette, die dieses Potential aufbauen, bevorzugt in den Cristae lokalisiert sind (Gilkerson et al., 2003; Vogel et al., 2006).

Zusätzlich zum beobachteten Gradienten der Kernkomponente des MINOS-Komplexes zeigte sich aber eine weitere Ebene submitochondrialer Organisation der Lokalisation dieses Komplexes. So ist in den Abbildungen 3.3, 3.4, 3.5, 3.6 B, 3.7 C, 3.9,3.13, 3.14 A, 3.15, 3.16 und $3.17 \mathrm{zu}$ sehen, dass Mitofilin - ebenso wie zwei weitere Kernkomponenten des Komplexes (Abb. 3.16 und 3.17) - hochgeordnet an den Seiten der Mitochondrien in einer Art „Schienen“- oder „Strickleiter“- Anordnung vorliegt. Wie in 3.1.5 ausgeführt erklärt sich diese Art der Anordnung in den STED-Bildern daraus, dass Mitofilin zum einen in oder in der Nähe der inneren Grenzflächenmembran und zum anderen horizontal zur Wachstumsebene ausgerichtet lokalisiert ist. Der Vergleich mit dem Außenmembranprotein Tom20 in zweifarben-STED-Aufnahmen, zusammen mit der beta-Untereinheit der ATP-Synthase, verdeutlichte diese spezielle Lokalisation und zeigte, dass über die ganze Membran verteilte 
Proteine keine solche Anordnung aufweisen können (Abb.3.14). Dies ist schematisch in Abbildung 4.5 dargestellt, wo die Aufsicht auf die Mitochondrien, wie sie in den STEDBildern (Abb. 3.14) zu sehen ist (Abb. 4.5, obere Zeile), in die dreidimensionale Anordnung der Cluster in Mitochondrien (Abb. 4.5, untere Zeile) übersetzt wurde.
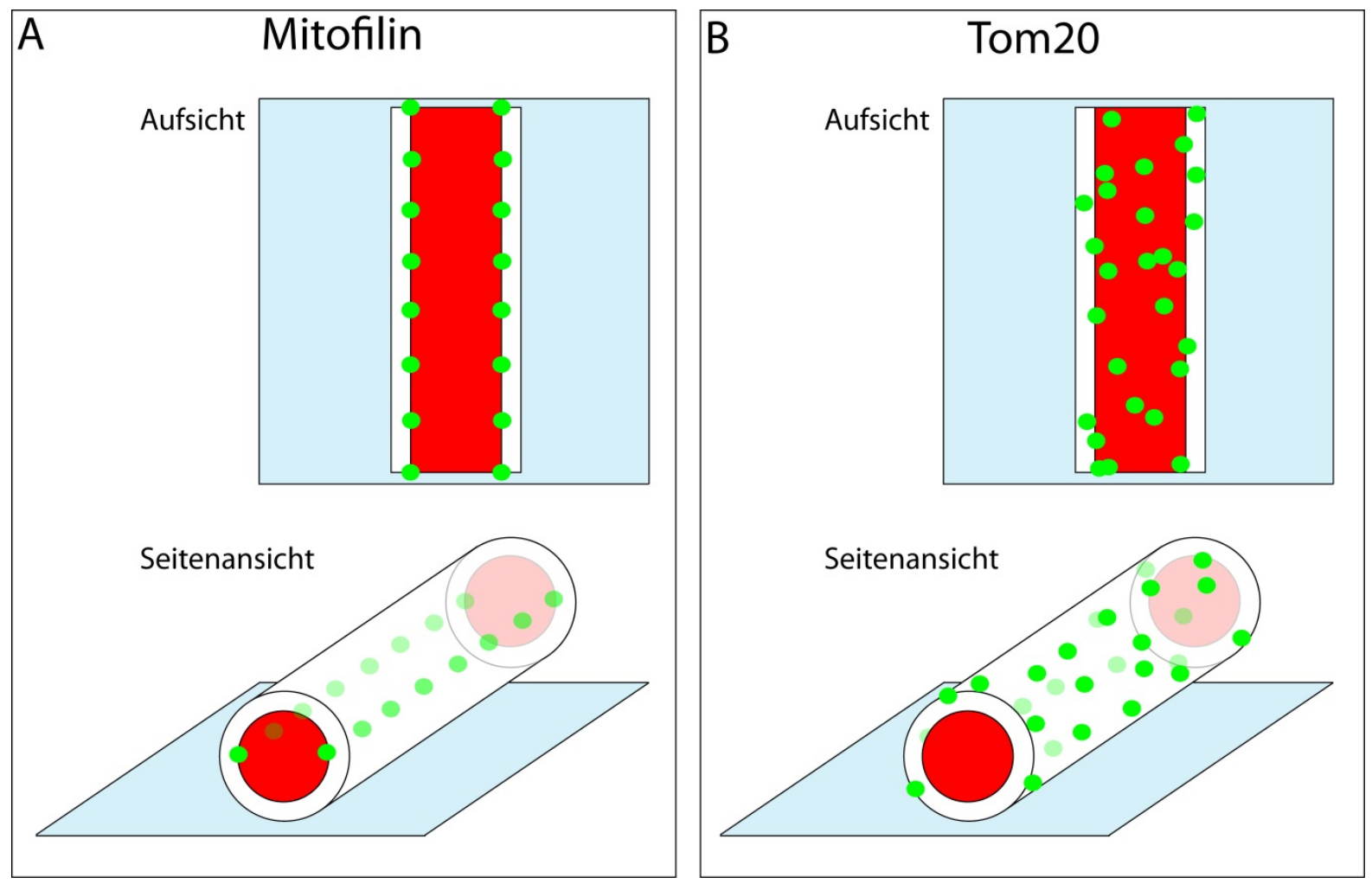

Abb. 4.5 Vereinfachte, schematische Darstellung der Clusterverteilung von Mitofilin (A) und von Tom20 (B) in Mitochondrien wie sie z. B. in Abb. 3.14 zu sehen ist.

Die in Abbildung 4.5 A schematisch dargestellte, hochgeordnete Organisation der MINOSKernkomponenten ist äußerst überraschend und wirft die Frage auf, woher die Mitochondrien die Positionsinformationen beziehen, so dass die Cluster auf eine solche Weise, relativ zur Wachstumsoberfläche, ausgerichtet werden können und wozu diese Ausrichtung notwendig ist. Wie in 1.2 beschrieben weisen Mitochondrien eine Vielzahl von Interaktionen mit anderen Zellkompartimenten, vor allem mit den Zytoskelett und dem 
endoplasmatischen Retikulum, auf. Daher wären diese Zellorganelle naheliegende Kandidaten für die Suche nach Vermittlern der Positionsinformation.

In humanen Zellen werden Mitochondrien im Wesentlichen entlang der Mikrotubuli transportiert (vgl. 1.2.4). Interessanterweise wurden bei der Suche nach Interaktionspartnern der MINOS-Kernkomponente MINOS1 in Säugerzellen in einem SILAC-

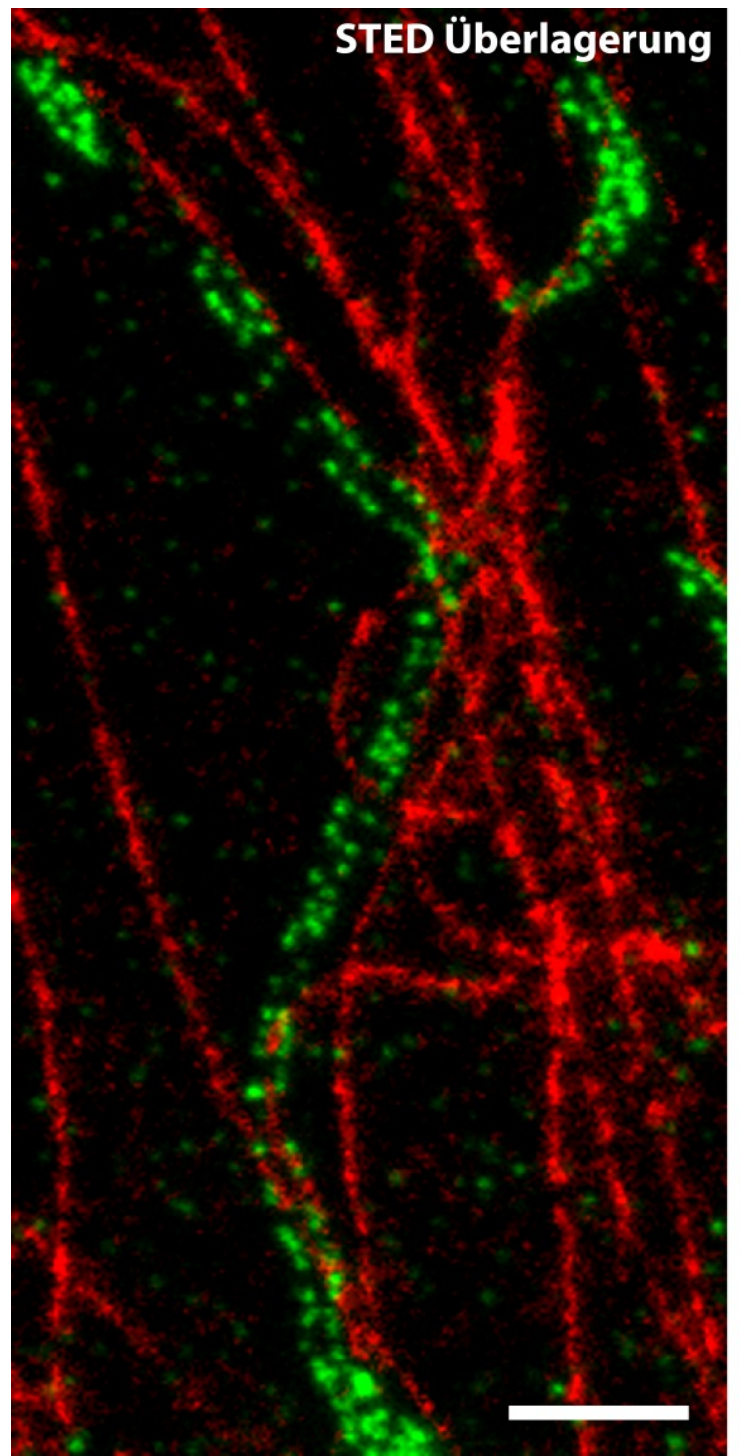

Abb. 4.6 Zwei-Farben STED-Mikroskopie von Mitofilin und $\alpha$ Tubulin.

In der Überlagerung (großes Bild) ist Mitofilin in grün und $\alpha$-Tubulin in rot dargestellt. (Größenbalken: $1 \mu \mathrm{m}$ )
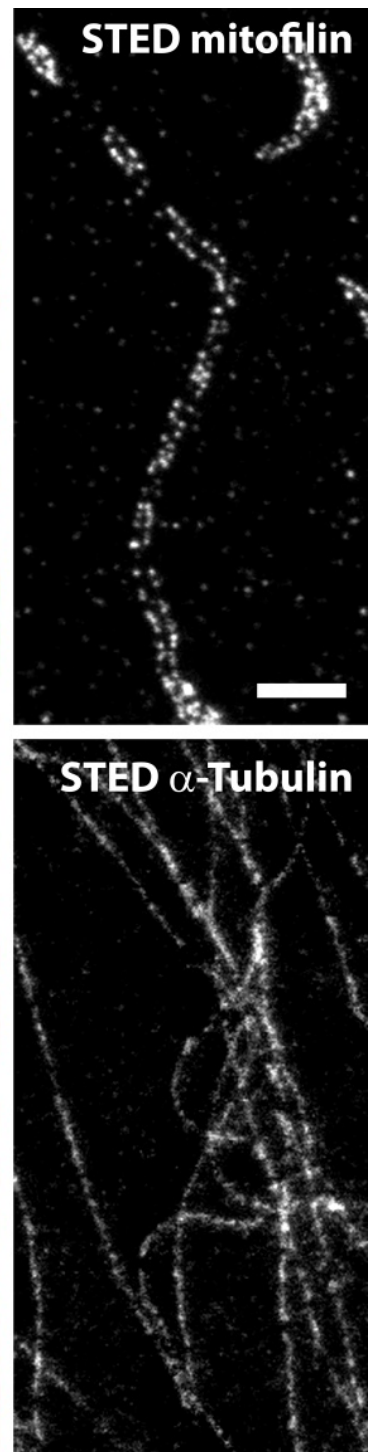

1.2.4) - vorkommt

(Weihofen et al., 2009).

Diese Hinweise lassen eine Verbindung zwischen dem MINOS-Komplex und dem Mikrotubuli-Zytoskelett vermuten und legen daher eine 
Rolle der Mikrotubuli bei der MINOS-Ausrichtung nahe. Zwei-Farben-STED-mikroskopische Aufnahmen dieser Strukturen zeigen zwar die bereits in verschiedenen Publikationen beschriebene, bevorzugte Ausrichtung der Mitochondrien entlang der Mikrotubuli (Heggeness et al., 1978; Boldogh \& Pon, 2007; Saxton \& Hollenbeck, 2012), klare Hinweise auf Interaktionen, lassen sich daraus aber nicht ableiten (Abb. 4.6). Die Interpretation dieser Daten wird auch erschwert, da das verwendete zwei-Farben-STED-Mikroskop keine erhöhte axiale Auflösung ermöglichte und daher eine genaue Aussage zur z-Position (axial; entlang der optischen Achse) der Signale im Verhältnis zueinander nicht möglich war. Zusätzlich wurde im Rahmen der vorliegenden Arbeit die Lokalisation von Mitofilin in Zellen, deren Mikrotubuli durch Taxol stabilisiert oder durch Nocodazol depolymerisiert worden waren, untersucht. Erste Ergebnisse ließen jedoch keine klaren Schlüsse zu, da die Lokalisation von Mitofilin in den so behandelten Zellen aufgrund der desorganisierten Mitochondrien nicht auswertbar ist. Somit lassen sich an diesem Punkt keine klaren Aussagen über einen möglichen Einfluss der Mikrotubuli auf die Verteilung der MINOS-Komplexe machen. Hierzu sind weitere Analysen nötig.

Weiterhin wird zur Erforschung der Positionierung der MINOS-Komplexe ein möglicher Zusammenhang mit dem ER zu untersuchen sein. Auf eine mögliche Verbindung deuten genetische Screens (Hoppins et al., 2011) und einzelne Proteine (Mdm10) hin, die sowohl im ERMES-Komplex als auch im SAM-Komplex vorkommen.

Es kann natürlich auch nicht ausgeschlossen werden, dass bisher unbekannte Komponenten und Mechanismen für die Positionsvermittlung an die MINOS-Komplexe in Mitochondrien verantwortlich sind oder dass die Lokalisation der MINOS-Komplexe in dieser Ausrichtung nur ein sekundärer Effekt ist, der durch die Lokalisation der MINOS-Komplexe an den Cristae Junctions, die wiederum durch andere Proteine in dieser Ausrichtung gehalten werden, zustande kommt.

Die funktionale Bedeutung dieser Ausrichtung und des hohen Grades der Organisation des MINOS-Komplexes liegt möglicherweise darin, auf diese Weise die mitochondrialen Funktionen auch lokal spezifisch auf die Erfordernisse der Zelle anpassen zu können. In einer weiteren Studie wurde die Ausrichtung der Cristae von Mitochondrien in der „Calyx of 
Held" untersucht und es wurde gezeigt, dass Cristae Junctions bevorzugt in Richtung der präsynaptischen Membran ausgerichtet sind (Perkins et al., 2010). Schon länger wurde außerdem vermutet, dass durch Cristae Junctions die Effizienz der ATP-Synthese reguliert werden kann (Mannella et al., 2001; Mannella, 2006). So erscheint die organisierte Ausrichtung der Cristae Junctions als eine Möglichkeit der Zelle, die Funktionen des Mitochodriums auf lokale Bedürfnisse fein abzustimmen.

\subsection{Der MINOS-Komplex und die Cristae (Junction)-Struktur}

Der MINOS-Komplex, dessen Kernkomponenten sowohl in der Hefe (Rabl et al., 2009; Harner et al., 2011) als auch in Säugern (Abb. 3.20) an den Cristae Junctions lokalisiert sind, ist für die Aufrechterhaltung derselben essentiell. Das Fehlen wesentlicher Komponenten des Hefe-Komplexes, deren Auswirkungen im Rahmen dieser Arbeit auch untersucht worden sind (Abb. 4.7), führt zu einem Verlust dieser Verbindungen zwischen den Cristae und der inneren Grenzflächenmembran, wodurch die Cristae isoliert in einer Art Zwiebelschalenanordnung gestapelt in den Mitochondrien vorliegen. Das entspricht den Beobachtungen, die in Säuger-Mitochondrien bei einem knock-down von Mitofilin gemacht wurden. Auch in Säugern führt dies zu einem Verlust der Cristae Junctions und einer Stapelung der Cristae-Membranen (John et al., 2005).

Da das Fehlen von Kernkomponenten des MINOS-Komplexes zu einem Verlust von Cristae Junctions führt, ergibt sich die Frage, welche genaue Funktion dem Komplex beim Aufrechterhalten derselben zukommt. In verschiedenen Publikationen wurde gezeigt, dass das Fehlen von Fcj1 und Mio10 zu einem vollständigen Verlust der Cristae Junctions führt (Rabl et al., 2009; Harner et al., 2011; von der Malsburg et al., 2011), in der vorliegenden Arbeit konnte in entsprechenden knock-out-Zellen jedoch "nur" eine starke Abnahme der Zahl an Mitochondrien mit einer normalen Cristae-Morphologie (mit Cristae Junctions) beobachtet werden (Abb. 4.7). Da einige wenige Mitochondrien der Zellen, in denen diese Kernkomponenten fehlten, immer noch Cristae Junctions aufwiesen, lässt sich vermuten, dass der MINOS-Komplex entweder für die Stabilisierung der Cristae Junctions, aber nicht 


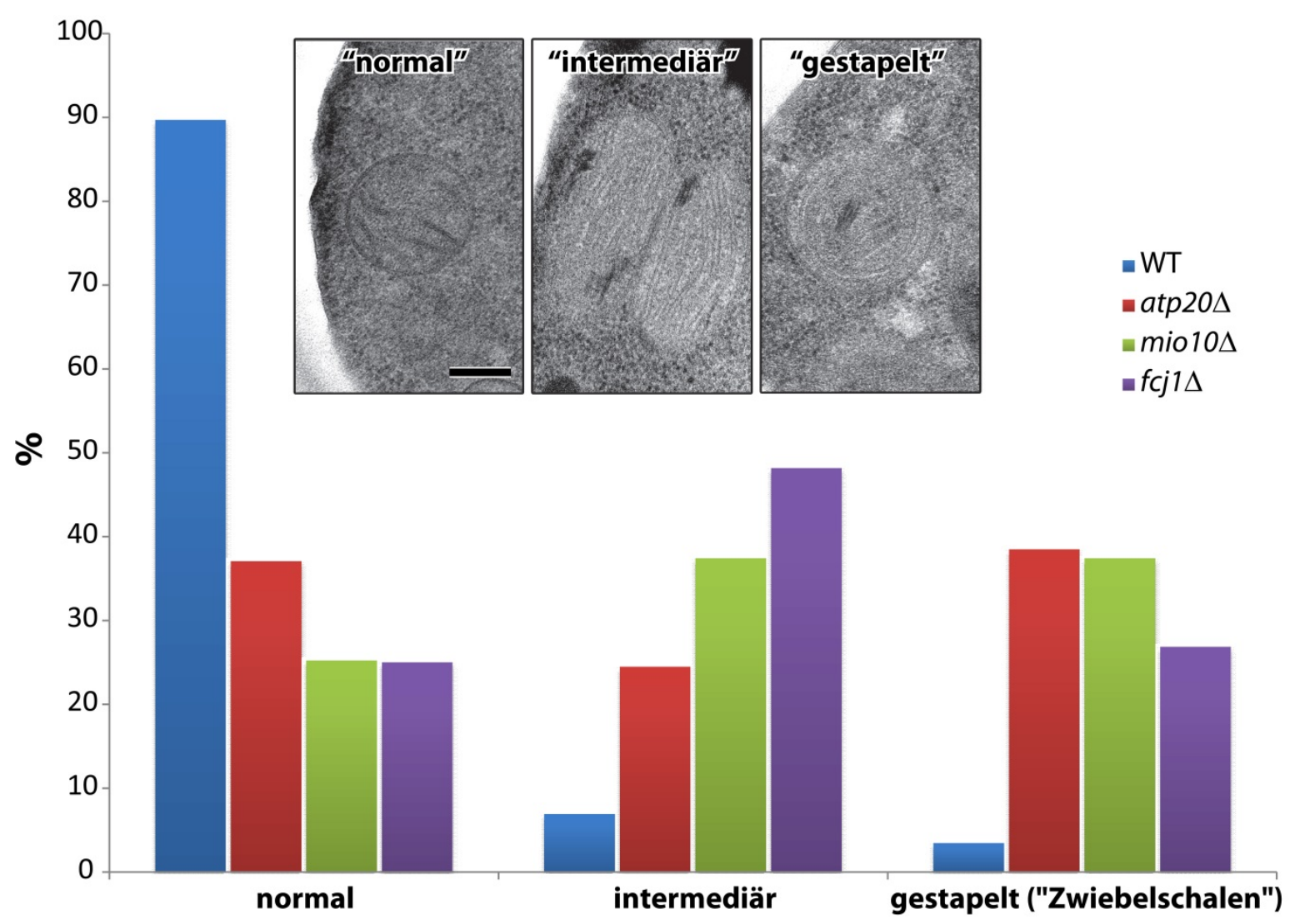

Abb. 4.7 Die Cristae-Morphologie von Hefezellen ist bei einem knock-out der MINOSKernkomponenten Mio10 und Fcj1 sowie bei einem knock-out der Untereinheit der ATP-Synthase Atp20 verändert (bearbeitet aus (Alkhaja et al., 2012)).

Dargestellt ist der Anteil der Mitochondrien, der in elektronenmikroskopischen Bildern von WT

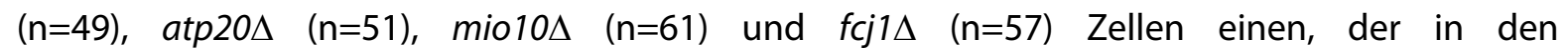
elektronenmikroskopischen Beispielbildern exemplarisch gezeigten Phänotypen aufwies. (Größenbalken: $200 \mathrm{~nm}$ )

für die Entstehung derselben, notwendig ist oder dass der Verlust dieser Komponenten zumindest teilweise durch andere Proteine kompensiert werden kann.

Wie in Abb. 4.7 auch zu sehen ist führt der Verlust von Atp20 (=Untereinheit $g$ der $F_{1} F_{O}$ ATPSynthase), einer für die Dimerisierung der ATP-Synthase wichtigen Untereinheit (vgl. 1.3.1), zu einem vergleichbaren Phänotyp der mitochondrialen Ultrastruktur. Es wurde jedoch gezeigt, dass die MINOS-Kernkomponente MINOS1 nicht stabil mit der $\mathrm{F}_{1} \mathrm{~F}_{\mathrm{O}}$ ATP-Synthase assoziiert ist (Alkhaja et al., 2012). Außerdem ist die ATP-Synthase, anders als der MINOSKomplex, vor allem an Bereichen mit starker Membrankrümmung an den Rändern der Cristae lokalisiert (Rabl et al., 2009; Davies et al., 2011; Davies et al., 2012). Der Verlust der 
Cristae Junctions beim Fehlen der für die Dimerisierung der ATP-Synthase wichtigen Untereinheiten ist also ein vom MINOS-Komplex unabhängiger Effekt und bewirkt wahrscheinlich primär eine Formveränderung der Cristae, die dadurch sekundär zu einem Verlust der Cristae Junctions führt.

Es stellt sich schließlich die Frage, ob der MINOS-Komplex „nur“ für die Aufrechterhaltung der Cristae Junctions wichtig ist oder ob der Komplex auch die Größe und Form dieser Strukturen reguliert und vielleicht doch eine den Reticulons im endoplasmatischen Retikulum ähnliche Funktion (Abb. 4.1), nicht für die Gesamtstruktur der Mitochondrien (vgl. 4.1), sondern für die Struktur der Cristae Junctions und der Cristae einnimmt (in diesem Falle würde der MINOS-Komplex den Reticulons in Abb. $4.1 \mathrm{~B}$ an den Tubuli und die ATPSynthase-Dimere den Reticulons in derselben Abbildung an den Rändern der Cisternae entsprechen).

\subsection{Die Ultrastruktur der inneren Membran}

Die innere Mitochondrienmembran ist komplex strukturiert und Gegenstand jahrzehntelanger Forschung (Palade, 1953; Sjostrand, 1953; Daems \& Wisse, 1966; Mannella et al., 1994; Frey \& Mannella, 2000; Rabl et al., 2009; Perkins \& Ellisman, 2011) (vgl. 1.3.1). Die Ultrastruktur wurde mit Hilfe elektronenmikroskopischer Methoden untersucht und die dreidimensionale Anordnung durch Elektronen-Tomographie aufgeklärt (vgl. Abb. 1.4, 1.5 und 1.6). Daher war die Entdeckung, dass die Cristae Junctions in Mitochondrien von adhärent gewachsenen Säugerzellen eine präferenzielle Ausrichtung aufweisen, unerwartet und wirft generelle Fragen über die Interpretation von elektronenmikroskopischen Daten in der Mitochondrienforschung auf. Die Bedeutung der Interpretation dieser Daten wird auch dadurch deutlich, dass Mitochondrien in Modellen sehr häufig als ovale oder „bohnenförmige" Strukturen mit tubulären Cristae, die durch einen Kontakt mit der inneren Grenzflächenmembran und eine einzelne Spitze („tip“) gekennzeichnet sind, dargestellt werden (Abb. 4.8, oben). 


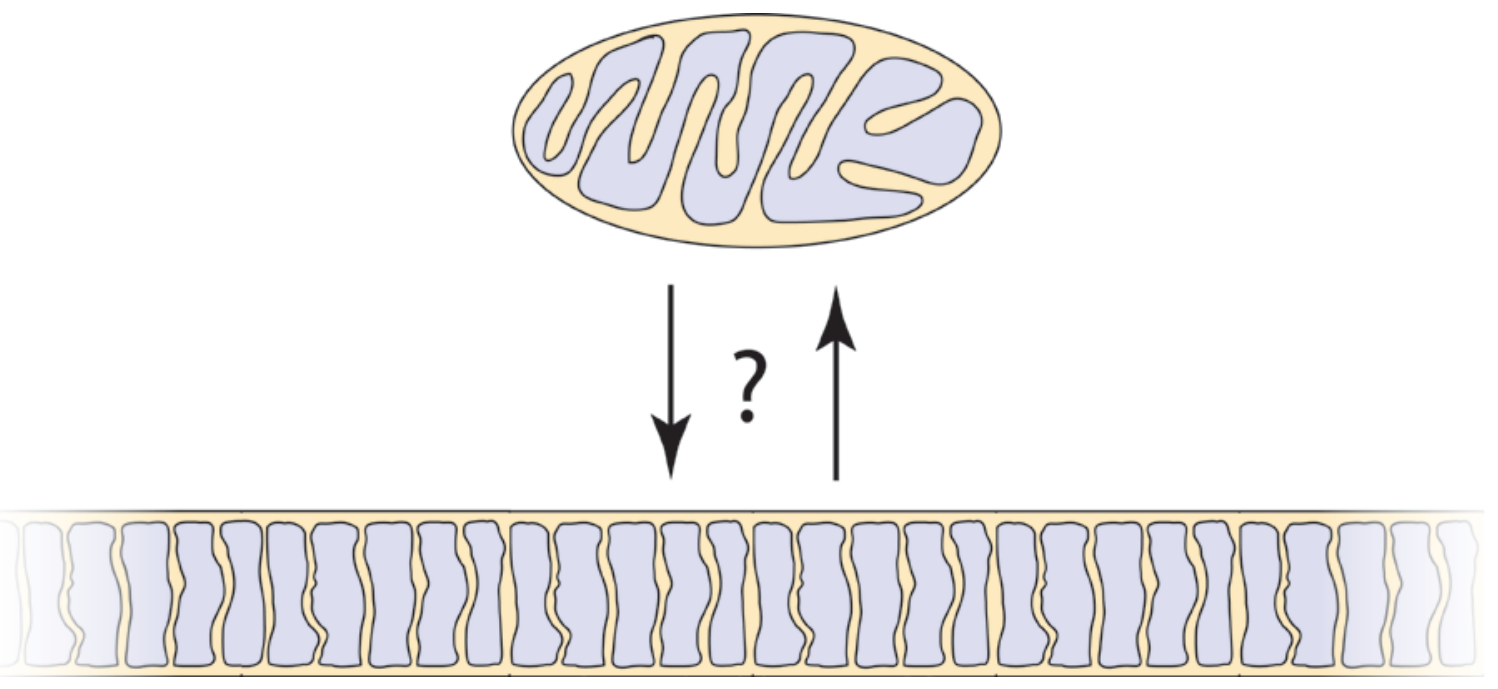

Abb. 4.8 Modell eines ovalen Mitochondriums mit tubulären Cristae und eines tubulären Mitochondriums mit lamellaren Cristae. Gibt es einen Widerspruch zwischen den Modellen?

Die oben angesprochenen ovalen Mitochondrien mit tubulären Cristae beruhen auf elektronenmikroskopischen Bildern von Mitochondrien. Wie in 1.4.2 ausgeführt ist es für diese Art der mikroskopischen Analyse jedoch unerlässlich, die Zellen und damit auch die Mitochondrien in (Ultra-) dünne Schnitte zu zerteilen. Daraus ergibt sich, dass solche Aufnahmen nur eine einzelne Ebene aus diesem Organell zeigen. Wie in Abb. 3.22 gezeigt, ist dabei die Ausrichtung der Mitochondrien durch den Anschnitt für das Erscheinungsbild maßgebend. Daher muss für den Vergleich von Morphologien der inneren mitochondrialen Membran die Ausrichtung der Mitochondrien in den Schnitten bekannt sein und berücksichtigt werden. Eine Fehlinterpretation, die bei der Analyse zwei-dimensionaler elektronenmikroskopischer Bilder entstehen könnte, ist, dass die in diesen Bildern tubulär aussehenden Cristae auch Tubuli sein müssen und dass die Enden der Cristae die Spitzen dieser Tubuli sein müssen. Zur richtigen Interpretation dieser Bilder muss jedoch berücksichtigt werden, dass Membranen in diesen Aufnahmen nur zu erkennen sind, wenn sie relativ senkrecht angeschnitten und damit auch aufgenommen werden. Zusammen mit der Einschränkung, dass in solchen Bildern nur eine Ebene abgebildet ist, hat dies zur Konsequenz, dass Tubuli in der dreidimensionalen Struktur tatsächlich auch Lamellen sein könnten, die senkrecht angeschnitten worden sind. In diesem Fall wären die so zu sehenden 

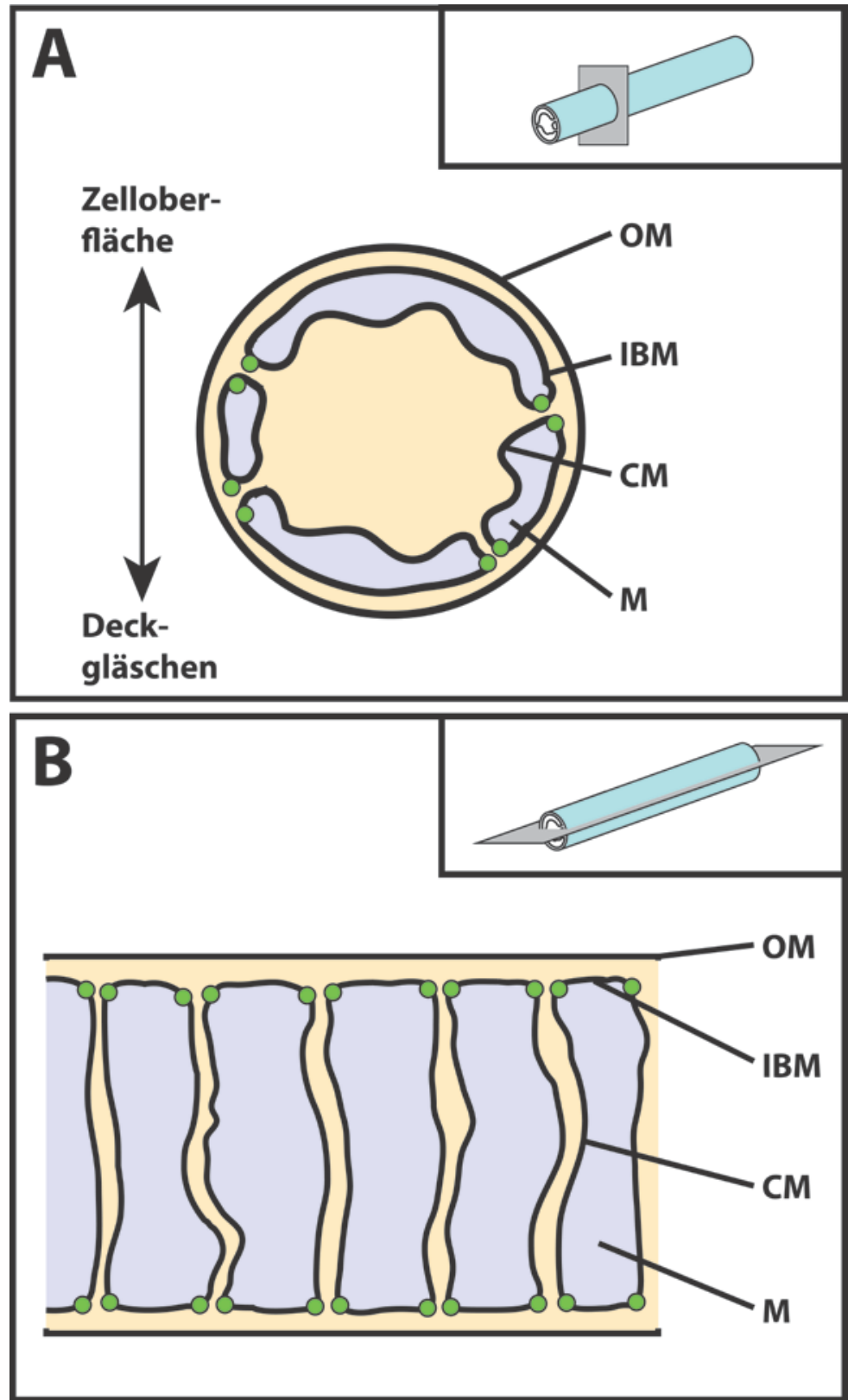

Abb. 4.9 Modell der Struktur der mitochondrialen Membranen, wie sie aus Elektronen-Tomographischen Daten adhärenter Säugerzellen (Abb. 3.21) hergeleitet werden kann.

(A) Querschnitt durch ein Mitochondrium. Die Cristae Junctions, an denen MINOS-Komplexe lokalisiert sind (grüne Keise), sind bevorzugt parallel zur Wachstumsoberfläche ausgerichtet. (B) Längsschnitt durch ein Mitochondrium. Die Cristae bilden lamellare Strukturen, die keine "Spitzen" ("tips"), sondern wie in (A) zu sehen, nur Ränder haben. $(\mathrm{OM}=$ "outer membrane"=äußere Mitochondrienmembran; $\mathrm{IBM}=$ "inner boundary membrane"=innere Grenzflächenmembran; $\quad \mathrm{CM}=$ "crista membrane"=Crista Membran; $\mathrm{M}=$ "matrix"=mitochondriale Matrix)
Spitzen der Tubuli tatsächlich nur die Ränder der Lamellen. Viele dieser Probleme können durch Einsatz der ElektronenTomographie umgangen werden und die innere Mitochondrienmembran kann mit dieser Methode dreidimensional dargestellt werden. Doch auch für die Elektronen-Tomographie müssen Schnitte angefertigt werden, so dass auch mit dieser Methode nur ein Ausschnitt aus einem Mitochondrium dargestellt werden kann, für den dann die Ausrichtung des Mitochondriums im Schnitt für Aussagen über relative Positionen von Strukturen bekannt sein muss.

Daher war für die Entdeckung der in der vorliegenden Arbeit gezeigten hochgeordneten Anordnung der MINOS-Cluster und damit auch der Cristae Junctions von entscheidender Bedeutung, dass die Verteilung der MINOS-Cluster mit Hilfe der STED-Mikroskopie im Kontext 
der gesamten intakten Zelle untersucht werden konnte. Somit konnte diese Regelmäßigkeit entdeckt werden, woraufhin die Mitochondrienmembranen in einer klar definierten Ausrichtung (relativ zur Wachstumsoberfläche) mit Hilfe der Elektronen-Tomographie untersucht wurden. Aus den Ergebnissen dieser Untersuchung (Abb. 3.21) lässt sich ein Modell der Struktur der inneren Mitochondrienmembran in adhärenten Säugerzellen ableiten (Abb. 4.9), wonach in diesen Zellen die Cristae lamellare Strukturen bilden, die durch Cristae Junctions bevorzugt an den Seiten des Mitochondriums, parallel zur Wachstumsebene, mit der inneren Grenzflächenmembran verbunden sind.

\subsection{Ausblick}

In der vorliegenden Arbeit wurde gezeigt, dass Kernkomponenten des MINOS-Komplexes eine hochorganisierte Lokalisation in einzelnen Clustern - die an den Seiten des Mitochondriums, parallel zur Wachstumsoberfläche, angeordnet sind und keine erweiterten Strukturen bilden - aufweisen. Die Anordnung dieser Cluster repräsentiert die Anordnung der Cristae Junctions, an denen der Kern-MINOS-Komplex lokalisiert ist. Andere biochemisch gezeigte Interaktionspartner des MINOS Komplexes wie der SAM-Komplex, der TOM-Komplex oder auch DnaJC11 weisen unterschiedliche Lokalisationen auf und sind deshalb in ihrer Gesamtheit keine stabilen Interaktionspartner des MINOS-Komplexes.

Daher ergibt sich die Frage, welche Anteile dieser Proteine und Komplexe mit den MINOSKomponenten interagieren. Wie in dieser Arbeit gezeigt wurde (und durch biochemische Daten auch gestützt wird (Bohnert et al., 2012)) liegen die MINOS-Komplexe nicht immer in derselben Zusammensetzung vor. Das spricht für Subkomplexe, die möglicherweise auch unterschiedliche Interaktionspartner und Funktionen haben. Dies wird in weiteren Studien genauer zu untersuchen sein. Hierzu wird es notwendig sein, durch zwei (oder mehr)Farben-Hochauflösung die verschiedenen Komponenten des Komplexes und die möglichen Interaktionspartner in verschiedenen Kombinationen aufzunehmen und quantitativ automatisiert (zum Beispiel durch Kreuzkorrelations-Analyse) auszuwerten. Zu diesem Zweck müssen für all diese Protein-Kombinationen geeignete Färbestrategien entwickelt 
werden, wobei - bei dieser Art von Analyse - auch die jeweilige Färbeffizienz der zu untersuchenden Proteine bedacht und in die Kalkulation mit einbezogen werden muss.

Weiterhin werden physiologische Einflüsse, wie die Überexpression oder Herunterregulierung einzelner Komponenten dieses Komplexes, sowie komplexere Einflüsse, wie zum Beispiel durch mitochondriale Krankheitsmodelle auf die Lokalisation der MINOS-(Sub?-) Komplexe und die Struktur der inneren Mitochondrienmembran, zu untersuchen sein.

Zu diesem Zweck werden auch korrelative Techniken, die die hochauflösende Methode der Elektronenmikroskopie, welche die detaillierte Darstellung der mitochondrialen Membranen ermöglicht, mit der hochauflösenden Fluoreszenzmikroskopie (Nanoskopie), die sensitiv und spezifisch Protein-Cluster darstellen kann, verbinden, einzusetzen und weiterzuentwickeln sein. Korrelative licht- und elektronenmikroskopische Techniken (CLEM: correlative light-electron microscopy) sind in einer Vielzahl von Publikationen dargestellt worden (Biel et al., 2003; van Rijnsoever et al., 2008; Nixon et al., 2009; Schieber et al., 2010; Kukulski et al., 2011; Kukulski et al., 2012; Lucas et al., 2012). Korrelative hochauflösende Lichmikroskopie (Nanoskopie) und Elektronenmikroskopie ist bisher jedoch nur in wenigen Veröffentlichungen beschrieben worden und zur Markierung der Proteine von Interesse für die hochauflösende Lichtmikroskopie wurden fluoreszierende Proteine verwendet (Watanabe et al., 2011; Watanabe \& Jorgensen, 2012; Watanabe et al., 2012). Aufgrund der in 3.1.1 ausgeführten Einschränkungen beim Einsatz fluoreszierender Proteine (in humanen Zellen lassen sich Proteine bisher nur durch transiente (Über-) Expression mit fluoreszierenden Proteinen markieren) muss diese Technik für die Verwendung von Immunofluoreszenzfärbungen angepasst werden. Das würde die Untersuchung der Komponenten des MINOS-Komplexes und möglicher Interaktionspartner im Kontext der mitochondrialen Membranen realisierbar machen. Hierdurch könnten auch weitere strukturelle Informationen, wie zum Beispiel über einen möglichen direkten Zusammenhang zwischen diesem Komplex und den Contact sites (s. 1.3), gewonnen werden (MINOSKomponenten wurden biochemisch an Contact sites angereichert gefunden, daher wurde dieser Komplex auch MICOS („mitochondrial contact site“) genannt (vgl. 1.3.1.1)). 
Weiterhin wird zu ermitteln sein, wie die Positionsinformation, welche die horizontale Ausrichtung der MINOS-Cluster und damit auch der Cristae Junctions ermöglicht, vermittelt wird. Zu diesem Zweck könnte die oben angesprochene korrelative Elektronenmikroskopie/Nanoskopie-Technik auch wichtige Informationen liefern, da hierdurch in den elektronenmikroskopischen Bildern sichtbare Membranen, wie zum Beispiel des ERs oder sichtbare Zytoskelettelemente, auf eine mögliche Interaktion mit MINOS-Komponenten untersucht werden könnten. Für diese Untersuchungen werden aber auch rein fluoreszenzmikroskopische (hochauflösende) Techniken zum Einsatz kommen können, um mögliche Verbindungen zwischen diesen Organellen und MINOS-Komponenten zu analysieren. Es werden weiterhin induzierte Veränderungen von möglichen MINOSInteraktionspartnern auf ihren Effekt auf die Zusammensetzung und Lokalisation der MINOS-Kernkomponenten zu erforschen sein, wodurch möglicherweise Rückschlüsse auf die Art der Vermittlung der Positionsinformation gezogen werden können.

Die Untersuchung des MINOS-Komplexes in Hefezellen mit Mitteln der hochauflösenden Lichtmikroskopie wird eine weitere Aufgabe sein. In der Hefe wurde mit Hilfe konventioneller Weitfeldmikroskopie zwar beschrieben, dass MINOS-Komponenten zusammenhängende Strukturen bilden (Hoppins et al., 2011), es wird aber zu untersuchen sein, ob sich diese übergeordneten Strukturen auch in beugungsunbegrenzten Bildern als solche darstellen. Dies wird auch dabei helfen, die mögliche Funktion des MINOSKomplexes als eine Art mitochondriales "Skelett“ in Hefe-Zellen zu untersuchen. Hierzu wird es nötig sein, auch in der Hefe die Lokalisation der verschiedenen Komponenten mit Hilfe von zwei (oder mehr)- Farben-Hochauflösung zu analysieren. Eine Rolle des Säuger-MINOSKomplexes, zumindest als ein Teil eines möglichen mitochondrialen Skelettes, wird durch die Identifikation und Lokalisationsanalyse weiterer Interaktionspartner des Komplexes zu untersuchen sein. 


\section{Literaturverzeichnis}

Acehan, D., Khuchua, Z., Houtkooper, R. H., Malhotra, A., Kaufman, J., Vaz, F. M., Ren, M., Rockman, H. A., Stokes, D. L. and Schlame, M. (2009). "Distinct effects of tafazzin deletion in differentiated and undifferentiated mitochondria." Mitochondrion 9(2): 86-95.

Acehan, D., Malhotra, A., Xu, Y., Ren, M., Stokes, D. L. and Schlame, M. (2011). "Cardiolipin affects the supramolecular organization of ATP synthase in mitochondria." Biophys J 100(9): 21842192.

Acehan, D., Xu, Y., Stokes, D. L. and Schlame, M. (2007). "Comparison of lymphoblast mitochondria from normal subjects and patients with Barth syndrome using electron microscopic tomography." Lab Invest 87(1): 40-48.

Alkhaja, A. K., Jans, D. C., Nikolov, M., Vukotic, M., Lytovchenko, O., Ludewig, F., Schliebs, W., Riedel, D., Urlaub, H., Jakobs, S. and Deckers, M. (2012). "MINOS1 is a conserved component of mitofilin complexes and required for mitochondrial function and cristae organization." Mol Biol Cell 23(2): 247-257.

Altmann, K., Frank, M., Neumann, D., Jakobs, S. and Westermann, B. (2008). "The class V myosin motor protein, Myo2, plays a major role in mitochondrial motility in Saccharomyces cerevisiae." J Cell Biol 181(1): 119-130.

Altmann, K. and Westermann, B. (2005). "Role of essential genes in mitochondrial morphogenesis in Saccharomyces cerevisiae." Mol Biol Cell 16(11): 5410-5417.

An, J., Shi, J., He, Q., Lui, K., Liu, Y., Huang, Y. and Sheikh, M. S. (2012). "CHCM1/CHCHD6, novel mitochondrial protein linked to regulation of mitofilin and mitochondrial cristae morphology." J Biol Chem 287(10): 7411-7426.

Ardail, D., Privat, J. P., Egret-Charlier, M., Levrat, C., Lerme, F. and Louisot, P. (1990). "Mitochondrial contact sites. Lipid composition and dynamics." J Biol Chem 265(31): 18797-18802.

Arselin, G., Vaillier, J., Salin, B., Schaeffer, J., Giraud, M. F., Dautant, A., Brethes, D. and Velours, J. (2004). "The modulation in subunits $e$ and $g$ amounts of yeast ATP synthase modifies mitochondrial cristae morphology." J Biol Chem 279(39): 40392-40399.

Berger, K. H., Sogo, L. F. and Yaffe, M. P. (1997). "Mdm12p, a component required for mitochondrial inheritance that is conserved between budding and fission yeast." J Cell Biol 136(3): 545553. 
Biel, S. S., Kawaschinski, K., Wittern, K. P., Hintze, U. and Wepf, R. (2003). "From tissue to cellular ultrastructure: closing the gap between micro- and nanostructural imaging." J Microsc 212(Pt 1): 91-99.

Bione, S., D'Adamo, P., Maestrini, E., Gedeon, A. K., Bolhuis, P. A. and Toniolo, D. (1996). "A novel Xlinked gene, G4.5. is responsible for Barth syndrome." Nat Genet 12(4): 385-389.

Bohnert, M., Wenz, L. S., Zerbes, R. M., Horvath, S. E., Stroud, D. A., von der Malsburg, K., Muller, J. M., Oeljeklaus, S., Perschil, I., Warscheid, B., Chacinska, A., Veenhuis, M., van der Klei, I. J., Daum, G., Wiedemann, N., Becker, T., Pfanner, N. and van der Laan, M. (2012). "Role of mitochondrial inner membrane organizing system in protein biogenesis of the mitochondrial outer membrane." Mol Biol Cell 23(20): 3948-3956.

Boldogh, I. R., Fehrenbacher, K. L., Yang, H. C. and Pon, L. A. (2005). "Mitochondrial movement and inheritance in budding yeast." Gene 354: 28-36.

Boldogh, I. R., Nowakowski, D. W., Yang, H. C., Chung, H., Karmon, S., Royes, P. and Pon, L. A. (2003). "A protein complex containing Mdm10p, Mdm12p, and Mmm1p links mitochondrial membranes and DNA to the cytoskeleton-based segregation machinery." Mol Biol Cell 14(11): 4618-4627.

Boldogh, I. R. and Pon, L. A. (2006). "Interactions of mitochondria with the actin cytoskeleton." Biochim Biophys Acta 1763(5-6): 450-462.

Boldogh, I. R. and Pon, L. A. (2007). "Mitochondria on the move." Trends Cell Biol 17(10): 502-510.

Boldogh, I. R., Yang, H. C., Nowakowski, W. D., Karmon, S. L., Hays, L. G., Yates, J. R., 3rd and Pon, L. A. (2001). "Arp2/3 complex and actin dynamics are required for actin-based mitochondrial motility in yeast." Proc Natl Acad Sci U S A 98(6): 3162-3167.

Brickley, K., Smith, M. J., Beck, M. and Stephenson, F. A. (2005). "GRIF-1 and OIP106, members of a novel gene family of coiled-coil domain proteins: association in vivo and in vitro with kinesin." J Biol Chem 280(15): 14723-14732.

Buckers, J., Wildanger, D., Vicidomini, G., Kastrup, L. and Hell, S. W. (2011). "Simultaneous multilifetime multi-color STED imaging for colocalization analyses." Opt Express 19(4): 3130-3143.

Burgess, S. M., Delannoy, M. and Jensen, R. E. (1994). "MMM1 encodes a mitochondrial outer membrane protein essential for establishing and maintaining the structure of yeast mitochondria." J Cell Biol 126(6): 1375-1391.

Cai, Q., Gerwin, C. and Sheng, Z. H. (2005). "Syntabulin-mediated anterograde transport of mitochondria along neuronal processes." J Cell Biol 170(6): 959-969. 
Cerqua, C., Anesti, V., Pyakurel, A., Liu, D., Naon, D., Wiche, G., Baffa, R., Dimmer, K. S. and Scorrano, L. (2010). "Trichoplein/mitostatin regulates endoplasmic reticulum-mitochondria juxtaposition." EMBO Rep 11(11): 854-860.

Chan, D. C. (2012). "Fusion and fission: interlinked processes critical for mitochondrial health." Annu Rev Genet 46: 265-287.

Csordas, G., Renken, C., Varnai, P., Walter, L., Weaver, D., Buttle, K. F., Balla, T., Mannella, C. A. and Hajnoczky, G. (2006). "Structural and functional features and significance of the physical linkage between ER and mitochondria." J Cell Biol 174(7): 915-921.

Daems, W. T. and Wisse, E. (1966). "Shape and attachment of the cristae mitochondriales in mouse hepatic cell mitochondria." J Ultrastruct Res 16(1): 123-140.

Darshi, M., Mendiola, V. L., Mackey, M. R., Murphy, A. N., Koller, A., Perkins, G. A., Ellisman, M. H. and Taylor, S. S. (2011). "ChChd3, an inner mitochondrial membrane protein, is essential for maintaining crista integrity and mitochondrial function." J Biol Chem 286(4): 2918-2932.

Davies, K. M., Anselmi, C., Wittig, I., Faraldo-Gomez, J. D. and Kuhlbrandt, W. (2012). "Structure of the yeast F1Fo-ATP synthase dimer and its role in shaping the mitochondrial cristae." Proc Natl Acad Sci U S A 109(34): 13602-13607.

Davies, K. M., Strauss, M., Daum, B., Kief, J. H., Osiewacz, H. D., Rycovska, A., Zickermann, V. and Kuhlbrandt, W. (2011). "Macromolecular organization of ATP synthase and complex I in whole mitochondria." Proc Natl Acad Sci U S A 108(34): 14121-14126.

de Brito, O. M. and Scorrano, L. (2008). "Mitofusin 2 tethers endoplasmic reticulum to mitochondria." Nature 456(7222): 605-610.

Dimmer, K. S., Fritz, S., Fuchs, F., Messerschmitt, M., Weinbach, N., Neupert, W. and Westermann, B. (2002). "Genetic basis of mitochondrial function and morphology in Saccharomyces cerevisiae." Mol Biol Cell 13(3): 847-853.

Duvezin-Caubet, S., Jagasia, R., Wagener, J., Hofmann, S., Trifunovic, A., Hansson, A., Chomyn, A., Bauer, M. F., Attardi, G., Larsson, N. G., Neupert, W. and Reichert, A. S. (2006). "Proteolytic processing of OPA1 links mitochondrial dysfunction to alterations in mitochondrial morphology." J Biol Chem 281(49): 37972-37979.

Elbaz, Y. and Schuldiner, M. (2011). "Staying in touch: the molecular era of organelle contact sites." Trends Biochem Sci 36(11): 616-623.

Escobar-Henriques, M. and Anton, F. (2013). "Mechanistic perspective of mitochondrial fusion: tubulation vs. fragmentation." Biochim Biophys Acta 1833(1): 162-175. 
Fehrenbacher, K. L., Boldogh, I. R. and Pon, L. A. (2005). "A role for Jsn1p in recruiting the Arp2/3 complex to mitochondria in budding yeast." Mol Biol Cell 16(11): 5094-5102.

Fortsch, J., Hummel, E., Krist, M. and Westermann, B. (2011). "The myosin-related motor protein Myo2 is an essential mediator of bud-directed mitochondrial movement in yeast." J Cell Biol 194(3): 473-488.

Frey, T. G. and Mannella, C. A. (2000). "The internal structure of mitochondria." Trends Biochem Sci 25(7): 319-324.

Frey, T. G. and Sun, M. G. (2008). "Correlated light and electron microscopy illuminates the role of mitochondrial inner membrane remodeling during apoptosis." Biochim Biophys Acta 1777(78): 847-852.

Frezza, C., Cipolat, S., Martins de Brito, O., Micaroni, M., Beznoussenko, G. V., Rudka, T., Bartoli, D., Polishuck, R. S., Danial, N. N., De Strooper, B. and Scorrano, L. (2006). "OPA1 controls apoptotic cristae remodeling independently from mitochondrial fusion." Cell 126(1): 177189.

Friedman, J. R., Lackner, L. L., West, M., DiBenedetto, J. R., Nunnari, J. and Voeltz, G. K. (2011). "ER tubules mark sites of mitochondrial division." Science 334(6054): 358-362.

Friedman, J. R. and Voeltz, G. K. (2011). "The ER in 3D: a multifunctional dynamic membrane network." Trends Cell Biol 21(12): 709-717.

Garcia-Rodriguez, L. J., Gay, A. C. and Pon, L. A. (2007). "Puf3p, a Pumilio family RNA binding protein, localizes to mitochondria and regulates mitochondrial biogenesis and motility in budding yeast." J Cell Biol 176(2): 197-207.

Ghochani, M., Nulton, J. D., Salamon, P., Frey, T. G., Rabinovitch, A. and Baljon, A. R. (2010). "Tensile forces and shape entropy explain observed crista structure in mitochondria." Biophys J 99(10): 3244-3254.

Gieffers, C., Korioth, F., Heimann, P., Ungermann, C. and Frey, J. (1997). "Mitofilin is a transmembrane protein of the inner mitochondrial membrane expressed as two isoforms." Exp Cell Res 232(2): 395-399.

Gilkerson, R. W., Selker, J. M. and Capaldi, R. A. (2003). "The cristal membrane of mitochondria is the principal site of oxidative phosphorylation." FEBS Lett 546(2-3): 355-358.

Glater, E. E., Megeath, L. J., Stowers, R. S. and Schwarz, T. L. (2006). "Axonal transport of mitochondria requires milton to recruit kinesin heavy chain and is light chain independent." J Cell Biol 173(4): 545-557. 
Gray, M. W., Burger, G. and Lang, B. F. (1999). "Mitochondrial evolution." Science 283(5407): 14761481.

Griparic, L., Kanazawa, T. and van der Bliek, A. M. (2007). "Regulation of the mitochondrial dynaminlike protein Opa1 by proteolytic cleavage." J Cell Biol 178(5): 757-764.

Griparic, L., van der Wel, N. N., Orozco, I. J., Peters, P. J. and van der Bliek, A. M. (2004). "Loss of the intermembrane space protein Mgm1/OPA1 induces swelling and localized constrictions along the lengths of mitochondria." J Biol Chem 279(18): 18792-18798.

Hanekamp, T., Thorsness, M. K., Rebbapragada, I., Fisher, E. M., Seebart, C., Darland, M. R., Coxbill, J. A., Updike, D. L. and Thorsness, P. E. (2002). "Maintenance of mitochondrial morphology is linked to maintenance of the mitochondrial genome in Saccharomyces cerevisiae." Genetics 162(3): 1147-1156.

Harke, B., Keller, J., Ullal, C. K., Westphal, V., Schonle, A. and Hell, S. W. (2008). "Resolution scaling in STED microscopy." Opt Express 16(6): 4154-4162.

Harner, M., Korner, C., Walther, D., Mokranjac, D., Kaesmacher, J., Welsch, U., Griffith, J., Mann, M., Reggiori, F. and Neupert, W. (2011). "The mitochondrial contact site complex, a determinant of mitochondrial architecture." EMBO J 30(21): 4356-4370.

Hayashi, T. and Su, T. P. (2007). "Sigma-1 receptor chaperones at the ER-mitochondrion interface regulate $\mathrm{Ca}(2+)$ signaling and cell survival." Cell 131(3): 596-610.

Heggeness, M. H., Simon, M. and Singer, S. J. (1978). "Association of mitochondria with microtubules in cultured cells." Proc Natl Acad Sci U S A 75(8): 3863-3866.

Hell, S. W. (2007). "Far-field optical nanoscopy." Science 316(5828): 1153-1158.

Hell, S. W. (2009). "Microscopy and its focal switch." Nat Methods 6(1): 24-32.

Hell, S. W. and Wichmann, J. (1994). "Breaking the diffraction resolution limit by stimulated emission: stimulated-emission-depletion fluorescence microscopy." Opt Lett 19(11): 780782.

Herzig, S. and Martinou, J. C. (2008). "Mitochondrial dynamics: to be in good shape to survive." Curr Mol Med 8(2): 131-137.

Hobbs, A. E., Srinivasan, M., McCaffery, J. M. and Jensen, R. E. (2001). "Mmm1p, a mitochondrial outer membrane protein, is connected to mitochondrial DNA (mtDNA) nucleoids and required for mtDNA stability." J Cell Biol 152(2): 401-410. 
Hoppins, S., Collins, S. R., Cassidy-Stone, A., Hummel, E., Devay, R. M., Lackner, L. L., Westermann, B., Schuldiner, M., Weissman, J. S. and Nunnari, J. (2011). "A mitochondrial-focused genetic interaction map reveals a scaffold-like complex required for inner membrane organization in mitochondria." J Cell Biol 195(2): 323-340.

Hu, J., Shibata, Y., Voss, C., Shemesh, T., Li, Z., Coughlin, M., Kozlov, M. M., Rapoport, T. A. and Prinz, W. A. (2008). "Membrane proteins of the endoplasmic reticulum induce high-curvature tubules." Science 319(5867): 1247-1250.

Huang, B., Jones, S. A., Brandenburg, B. and Zhuang, X. (2008). "Whole-cell 3D STORM reveals interactions between cellular structures with nanometer-scale resolution." Nat Methods 5(12): 1047-1052.

Icho, T., Ikeda, T., Matsumoto, Y., Hanaoka, F., Kaji, K. and Tsuchida, N. (1994). "A novel human gene that is preferentially transcribed in heart muscle." Gene 144(2): 301-306.

Ishihara, N., Fujita, Y., Oka, T. and Mihara, K. (2006). "Regulation of mitochondrial morphology through proteolytic cleavage of OPA1." EMBO J 25(13): 2966-2977.

Iwasawa, R., Mahul-Mellier, A. L., Datler, C., Pazarentzos, E. and Grimm, S. (2011). "Fis1 and Bap31 bridge the mitochondria-ER interface to establish a platform for apoptosis induction." Embo J 30(3): 556-568.

Jakobs, S., Stoldt, S. and Neumann, D. (2011). "Light microscopic analysis of mitochondrial heterogeneity in cell populations and within single cells." Adv Biochem Eng Biotechnol 124: 1-19.

Jans, D. C., Wurm, C. A., Riedel, D., Wenzel, D., Stagge, F., Deckers, M., Rehling, P. and Jakobs, S. (2013). "STED super-resolution microscopy reveals an array of MINOS clusters along human mitochondria." Proc Natl Acad Sci U S A 110(22): 8936-8941.

John, G. B., Shang, Y., Li, L., Renken, C., Mannella, C. A., Selker, J. M., Rangell, L., Bennett, M. J. and Zha, J. (2005). "The mitochondrial inner membrane protein mitofilin controls cristae morphology." Mol Biol Cell 16(3): 1543-1554.

Katz, L. A. (2012). "Origin and diversification of eukaryotes." Annu Rev Microbiol 66: 411-427.

Khalifat, N., Fournier, J. B., Angelova, M. I. and Puff, N. (2011). "Lipid packing variations induced by $\mathrm{pH}$ in cardiolipin-containing bilayers: the driving force for the cristae-like shape instability." Biochim Biophys Acta 1808(11): 2724-2733.

Klar, T. A., Jakobs, S., Dyba, M., Egner, A. and Hell, S. W. (2000). "Fluorescence microscopy with diffraction resolution barrier broken by stimulated emission." Proc Natl Acad Sci U S A 97(15): 8206-8210. 
Kolmakov, K., Belov, V. N., Bierwagen, J., Ringemann, C., Muller, V., Eggeling, C. and Hell, S. W. (2010). "Red-emitting rhodamine dyes for fluorescence microscopy and nanoscopy." Chemistry 16(1): 158-166.

Korner, C., Barrera, M., Dukanovic, J., Eydt, K., Harner, M., Rabl, R., Vogel, F., Rapaport, D., Neupert, W. and Reichert, A. S. (2012). "The C-terminal domain of Fcj1 is required for formation of crista junctions and interacts with the TOB/SAM complex in mitochondria." Mol Biol Cell 23(11): 2143-2155.

Kornmann, B., Currie, E., Collins, S. R., Schuldiner, M., Nunnari, J., Weissman, J. S. and Walter, P. (2009). "An ER-mitochondria tethering complex revealed by a synthetic biology screen." Science 325(5939): 477-481.

Kornmann, B., Osman, C. and Walter, P. (2011). "The conserved GTPase Gem1 regulates endoplasmic reticulum-mitochondria connections." Proc Natl Acad Sci U S A 108(34): 1415114156.

Kukat, C., Wurm, C. A., Spahr, H., Falkenberg, M., Larsson, N. G. and Jakobs, S. (2011). "Superresolution microscopy reveals that mammalian mitochondrial nucleoids have a uniform size and frequently contain a single copy of mtDNA." Proc Natl Acad Sci U S A 108(33): 1353413539.

Kukulski, W., Schorb, M., Welsch, S., Picco, A., Kaksonen, M. and Briggs, J. A. (2011). "Correlated fluorescence and 3D electron microscopy with high sensitivity and spatial precision." J Cell Biol 192(1): 111-119.

Kukulski, W., Schorb, M., Welsch, S., Picco, A., Kaksonen, M. and Briggs, J. A. (2012). "Precise, correlated fluorescence microscopy and electron tomography of lowicryl sections using fluorescent fiducial markers." Methods Cell Biol 111: 235-257.

Lill, R., Fekete, Z., Sipos, K. and Rotte, C. (2005). "Is there an answer? Why are mitochondria essential for life?" IUBMB Life 57(10): 701-703.

Linden, M., Li, Z., Paulin, D., Gotow, T. and Leterrier, J. F. (2001). "Effects of desmin gene knockout on mice heart mitochondria." J Bioenerg Biomembr 33(4): 333-341.

Lucas, M. S., Gunthert, M., Gasser, P., Lucas, F. and Wepf, R. (2012). "Bridging microscopes: 3D correlative light and scanning electron microscopy of complex biological structures." Methods Cell Biol 111: 325-356.

Mannella, C. A. (2006). "The relevance of mitochondrial membrane topology to mitochondrial function." Biochim Biophys Acta 1762(2): 140-147. 
Mannella, C. A. (2008). "Structural diversity of mitochondria: functional implications." Ann N Y Acad Sci 1147: 171-179.

Mannella, C. A., Marko, M., Penczek, P., Barnard, D. and Frank, J. (1994). "The internal compartmentation of rat-liver mitochondria: tomographic study using the high-voltage transmission electron microscope." Microsc Res Tech 27(4): 278-283.

Mannella, C. A., Pfeiffer, D. R., Bradshaw, P. C., Moraru, II, Slepchenko, B., Loew, L. M., Hsieh, C. E., Buttle, K. and Marko, M. (2001). "Topology of the mitochondrial inner membrane: dynamics and bioenergetic implications." IUBMB Life 52(3-5): 93-100.

Mayhew, T. M. and Lucocq, J. M. (2008). "Developments in cell biology for quantitative immunoelectron microscopy based on thin sections: a review." Histochem Cell Biol 130(2): 299-313.

Meisinger, C., Pfannschmidt, S., Rissler, M., Milenkovic, D., Becker, T., Stojanovski, D., Youngman, M. J., Jensen, R. E., Chacinska, A., Guiard, B., Pfanner, N. and Wiedemann, N. (2007). "The morphology proteins $\mathrm{Mdm} 12 / \mathrm{Mmm} 1$ function in the major beta-barrel assembly pathway of mitochondria." Embo J 26(9): 2229-2239.

Meisinger, C., Rissler, M., Chacinska, A., Szklarz, L. K., Milenkovic, D., Kozjak, V., Schonfisch, B., Lohaus, C., Meyer, H. E., Yaffe, M. P., Guiard, B., Wiedemann, N. and Pfanner, N. (2004). "The mitochondrial morphology protein Mdm10 functions in assembly of the preprotein translocase of the outer membrane." Dev Cell 7(1): 61-71.

Merkwirth, C., Dargazanli, S., Tatsuta, T., Geimer, S., Lower, B., Wunderlich, F. T., von Kleist-Retzow, J. C., Waisman, A., Westermann, B. and Langer, T. (2008). "Prohibitins control cell proliferation and apoptosis by regulating OPA1-dependent cristae morphogenesis in mitochondria." Genes Dev 22(4): 476-488.

Milner, D. J., Mavroidis, M., Weisleder, N. and Capetanaki, Y. (2000). "Desmin cytoskeleton linked to muscle mitochondrial distribution and respiratory function." J Cell Biol 150(6): 1283-1298.

Misko, A., Jiang, S., Wegorzewska, I., Milbrandt, J. and Baloh, R. H. (2010). "Mitofusin 2 is necessary for transport of axonal mitochondria and interacts with the Miro/Milton complex." J Neurosci 30(12): 4232-4240.

Mitra, K., Wunder, C., Roysam, B., Lin, G. and Lippincott-Schwartz, J. (2009). "A hyperfused mitochondrial state achieved at G1-S regulates cyclin E buildup and entry into $S$ phase." Proc Natl Acad Sci U S A 106(29): 11960-11965.

Mootha, V. K., Bunkenborg, J., Olsen, J. V., Hjerrild, M., Wisniewski, J. R., Stahl, E., Bolouri, M. S., Ray, H. N., Sihag, S., Kamal, M., Patterson, N., Lander, E. S. and Mann, M. (2003). "Integrated analysis of protein composition, tissue diversity, and gene regulation in mouse mitochondria." Cell 115(5): 629-640. 
Nixon, S. J., Webb, R. I., Floetenmeyer, M., Schieber, N., Lo, H. P. and Parton, R. G. (2009). "A single method for cryofixation and correlative light, electron microscopy and tomography of zebrafish embryos." Traffic 10(2): 131-136.

Odgren, P. R., Toukatly, G., Bangs, P. L., Gilmore, R. and Fey, E. G. (1996). "Molecular characterization of mitofilin (HMP), a mitochondria-associated protein with predicted coiled coil and intermembrane space targeting domains." J Cell Sci 109 ( Pt 9): 2253-2264.

Okamoto, K. and Shaw, J. M. (2005). "Mitochondrial morphology and dynamics in yeast and multicellular eukaryotes." Annu Rev Genet 39: 503-536.

Osman, C., Merkwirth, C. and Langer, T. (2009). "Prohibitins and the functional compartmentalization of mitochondrial membranes." J Cell Sci 122(Pt 21): 3823-3830.

Ott, C., Ross, K., Straub, S., Thiede, B., Gotz, M., Goosmann, C., Krischke, M., Mueller, M. J., Krohne, G., Rudel, T. and Kozjak-Pavlovic, V. (2012). "Sam50 functions in mitochondrial intermembrane space bridging and biogenesis of respiratory complexes." Mol Cell Biol 32(6): 1173-1188.

Palade, G. E. (1953). "An electron microscope study of the mitochondrial structure." J Histochem Cytochem 1(4): 188-211.

Park, Y. U., Jeong, J., Lee, H., Mun, J. Y., Kim, J. H., Lee, J. S., Nguyen, M. D., Han, S. S., Suh, P. G. and Park, S. K. (2010). "Disrupted-in-schizophrenia 1 (DISC1) plays essential roles in mitochondria in collaboration with Mitofilin." Proc Natl Acad Sci U S A 107(41): 1778517790.

Paumard, P., Vaillier, J., Coulary, B., Schaeffer, J., Soubannier, V., Mueller, D. M., Brethes, D., di Rago, J. P. and Velours, J. (2002). "The ATP synthase is involved in generating mitochondrial cristae morphology." EMBO J 21(3): 221-230.

Perkins, G., Bossy-Wetzel, E. and Ellisman, M. H. (2009). "New insights into mitochondrial structure during cell death." Exp Neurol 218(2): 183-192.

Perkins, G., Renken, C., Martone, M. E., Young, S. J., Ellisman, M. and Frey, T. (1997). "Electron tomography of neuronal mitochondria: three-dimensional structure and organization of cristae and membrane contacts." J Struct Biol 119(3): 260-272.

Perkins, G. A. and Ellisman, M. H. (2011). "Mitochondrial configurations in peripheral nerve suggest differential ATP production." J Struct Biol 173(1): 117-127. 
Perkins, G. A., Ellisman, M. H. and Fox, D. A. (2003). "Three-dimensional analysis of mouse rod and cone mitochondrial cristae architecture: bioenergetic and functional implications." Mol Vis 9: 60-73.

Perkins, G. A., Song, J. Y., Tarsa, L., Deerinck, T. J., Ellisman, M. H. and Frey, T. G. (1998). "Electron tomography of mitochondria from brown adipocytes reveals crista junctions." J Bioenerg Biomembr 30(5): 431-442.

Perkins, G. A., Tjong, J., Brown, J. M., Poquiz, P. H., Scott, R. T., Kolson, D. R., Ellisman, M. H. and Spirou, G. A. (2010). "The micro-architecture of mitochondria at active zones: electron tomography reveals novel anchoring scaffolds and cristae structured for high-rate metabolism." J Neurosci 30(3): 1015-1026.

Picard, M., Shirihai, O. S., Gentil, B. J. and Burelle, Y. (2013). "Mitochondrial morphology transitions and functions: implications for retrograde signaling?" Am J Physiol Regul Integr Comp Physiol 304(6): R393-406.

Pilling, A. D., Horiuchi, D., Lively, C. M. and Saxton, W. M. (2006). "Kinesin-1 and Dynein are the primary motors for fast transport of mitochondria in Drosophila motor axons." Mol Biol Cell 17(4): 2057-2068.

Rabl, R., Soubannier, V., Scholz, R., Vogel, F., Mendl, N., Vasiljev-Neumeyer, A., Korner, C., Jagasia, R., Keil, T., Baumeister, W., Cyrklaff, M., Neupert, W. and Reichert, A. S. (2009). "Formation of cristae and crista junctions in mitochondria depends on antagonism between Fcj1 and Su e/g." J Cell Biol 185(6): 1047-1063.

Renken, C., Siragusa, G., Perkins, G., Washington, L., Nulton, J., Salamon, P. and Frey, T. G. (2002). "A thermodynamic model describing the nature of the crista junction: a structural motif in the mitochondrion." J Struct Biol 138(1-2): 137-144.

Rossi, M. N., Carbone, M., Mostocotto, C., Mancone, C., Tripodi, M., Maione, R. and Amati, P. (2009). "Mitochondrial localization of PARP-1 requires interaction with mitofilin and is involved in the maintenance of mitochondrial DNA integrity." J Biol Chem 284(46): 3161631624.

Rowland, A. A. and Voeltz, G. K. (2012). "Endoplasmic reticulum-mitochondria contacts: function of the junction." Nat Rev Mol Cell Biol 13(10): 607-625.

Santama, N., Er, C. P., Ong, L. L. and Yu, H. (2004). "Distribution and functions of kinectin isoforms." J Cell Sci 117(Pt 19): 4537-4549.

Sathananthan, A. H. and Trounson, A. O. (2000). "Mitochondrial morphology during preimplantational human embryogenesis." Hum Reprod 15 Suppl 2: 148-159. 
Saxton, W. M. and Hollenbeck, P. J. (2012). "The axonal transport of mitochondria." J Cell Sci 125(Pt 9): 2095-2104.

Schieber, N. L., Nixon, S. J., Webb, R. I., Oorschot, V. M. and Parton, R. G. (2010). "Modern approaches for ultrastructural analysis of the zebrafish embryo." Methods Cell Biol 96: 425442.

Schlame, M. (2013). "Cardiolipin remodeling and the function of tafazzin." Biochim Biophys Acta 1831(3): 582-588.

Schwarzer, C., Barnikol-Watanabe, S., Thinnes, F. P. and Hilschmann, N. (2002). "Voltage-dependent anion-selective channel (VDAC) interacts with the dynein light chain Tctex1 and the heatshock protein PBP74." Int J Biochem Cell Biol 34(9): 1059-1070.

Scorrano, L. (2007). "Multiple functions of mitochondria-shaping proteins." Novartis Found Symp 287: 47-55; discussion 55-49.

Shibata, Y., Voss, C., Rist, J. M., Hu, J., Rapoport, T. A., Prinz, W. A. and Voeltz, G. K. (2008). "The reticulon and DP1/Yop1p proteins form immobile oligomers in the tubular endoplasmic reticulum." J Biol Chem 283(27): 18892-18904.

Sickmann, A., Reinders, J., Wagner, Y., Joppich, C., Zahedi, R., Meyer, H. E., Schonfisch, B., Perschil, I., Chacinska, A., Guiard, B., Rehling, P., Pfanner, N. and Meisinger, C. (2003). "The proteome of Saccharomyces cerevisiae mitochondria." Proc Natl Acad Sci U S A 100(23): 13207-13212.

Simbeni, R., Pon, L., Zinser, E., Paltauf, F. and Daum, G. (1991). "Mitochondrial membrane contact sites of yeast. Characterization of lipid components and possible involvement in intramitochondrial translocation of phospholipids." J Biol Chem 266(16): 10047-10049.

Simmen, T., Aslan, J. E., Blagoveshchenskaya, A. D., Thomas, L., Wan, L., Xiang, Y., Feliciangeli, S. F., Hung, C. H., Crump, C. M. and Thomas, G. (2005). "PACS-2 controls endoplasmic reticulummitochondria communication and Bid-mediated apoptosis." Embo J 24(4): 717-729.

Sjostrand, F. S. (1953). "Electron microscopy of mitochondria and cytoplasmic double membranes." Nature 171(4340): 30-32.

Smith, M. J., Pozo, K., Brickley, K. and Stephenson, F. A. (2006). "Mapping the GRIF-1 binding domain of the kinesin, KIF5C, substantiates a role for GRIF-1 as an adaptor protein in the anterograde trafficking of cargoes." J Biol Chem 281(37): 27216-27228.

Stroud, D. A., Oeljeklaus, S., Wiese, S., Bohnert, M., Lewandrowski, U., Sickmann, A., Guiard, B., van der Laan, M., Warscheid, B. and Wiedemann, N. (2011). "Composition and topology of the endoplasmic reticulum-mitochondria encounter structure." J Mol Biol 413(4): 743-750. 
Su, Q., Cai, Q., Gerwin, C., Smith, C. L. and Sheng, Z. H. (2004). "Syntabulin is a microtubuleassociated protein implicated in syntaxin transport in neurons." Nat Cell Biol 6(10): 941-953.

Szabadkai, G., Bianchi, K., Varnai, P., De Stefani, D., Wieckowski, M. R., Cavagna, D., Nagy, A. I., Balla, T. and Rizzuto, R. (2006). "Chaperone-mediated coupling of endoplasmic reticulum and mitochondrial Ca2+ channels." J Cell Biol 175(6): 901-911.

Tahbaz, N., Subedi, S. and Weinfeld, M. (2012). "Role of polynucleotide kinase/phosphatase in mitochondrial DNA repair." Nucleic Acids Res 40(8): 3484-3495.

Tatsuta, T., Model, K. and Langer, T. (2005). "Formation of membrane-bound ring complexes by prohibitins in mitochondria." Mol Biol Cell 16(1): 248-259.

Taylor, S. W., Fahy, E., Zhang, B., Glenn, G. M., Warnock, D. E., Wiley, S., Murphy, A. N., Gaucher, S. P., Capaldi, R. A., Gibson, B. W. and Ghosh, S. S. (2003). "Characterization of the human heart mitochondrial proteome." Nat Biotechnol 21(3): 281-286.

Tokuyasu, K. T. (1973). "A technique for ultracryotomy of cell suspensions and tissues." J Cell Biol 57(2): 551-565.

Tolley, N., Sparkes, I., Craddock, C. P., Eastmond, P. J., Runions, J., Hawes, C. and Frigerio, L. (2010). "Transmembrane domain length is responsible for the ability of a plant reticulon to shape endoplasmic reticulum tubules in vivo." Plant J 64(3): 411-418.

van der Laan, M., Bohnert, M., Wiedemann, N. and Pfanner, N. (2012). "Role of MINOS in mitochondrial membrane architecture and biogenesis." Trends Cell Biol 22(4): 185-192.

van Rijnsoever, C., Oorschot, V. and Klumperman, J. (2008). "Correlative light-electron microscopy (CLEM) combining live-cell imaging and immunolabeling of ultrathin cryosections." Nat Methods 5(11): 973-980.

van Spronsen, M., Mikhaylova, M., Lipka, J., Schlager, M. A., van den Heuvel, D. J., Kuijpers, M., Wulf, P. S., Keijzer, N., Demmers, J., Kapitein, L. C., Jaarsma, D., Gerritsen, H. C., Akhmanova, A. and Hoogenraad, C. C. (2013). "TRAK/Milton Motor-Adaptor Proteins Steer Mitochondrial Trafficking to Axons and Dendrites." Neuron 77(3): 485-502.

Voeltz, G. K., Prinz, W. A., Shibata, Y., Rist, J. M. and Rapoport, T. A. (2006). "A class of membrane proteins shaping the tubular endoplasmic reticulum." Cell 124(3): 573-586.

Vogel, F., Bornhovd, C., Neupert, W. and Reichert, A. S. (2006). "Dynamic subcompartmentalization of the mitochondrial inner membrane." J Cell Biol 175(2): 237-247.

von der Malsburg, K., Muller, J. M., Bohnert, M., Oeljeklaus, S., Kwiatkowska, P., Becker, T., Loniewska-Lwowska, A., Wiese, S., Rao, S., Milenkovic, D., Hutu, D. P., Zerbes, R. M., 
Schulze-Specking, A., Meyer, H. E., Martinou, J. C., Rospert, S., Rehling, P., Meisinger, C., Veenhuis, M., Warscheid, B., van der Klei, I. J., Pfanner, N., Chacinska, A. and van der Laan, M. (2011). "Dual role of mitofilin in mitochondrial membrane organization and protein biogenesis." Dev Cell 21(4): 694-707.

Watanabe, S. and Jorgensen, E. M. (2012). "Visualizing proteins in electron micrographs at nanometer resolution." Methods Cell Biol 111: 283-306.

Watanabe, S., Punge, A., Hollopeter, G., Willig, K. I., Hobson, R. J., Davis, M. W., Hell, S. W. and Jorgensen, E. M. (2011). "Protein localization in electron micrographs using fluorescence nanoscopy." Nat Methods 8(1): 80-84.

Watanabe, S., Richards, J., Hollopeter, G., Hobson, R. J., Davis, W. M. and Jorgensen, E. M. (2012). "Nano-fEM: protein localization using photo-activated localization microscopy and electron microscopy." J Vis Exp(70): e3995.

Weber, T. A., Koob, S., Heide, H., Wittig, I., Head, B., van der Bliek, A., Brandt, U., Mittelbronn, M. and Reichert, A. S. (2013). "APOOL Is a Cardiolipin-Binding Constituent of the Mitofilin/MINOS Protein Complex Determining Cristae Morphology in Mammalian Mitochondria." PLoS One 8(5): e63683.

Weihofen, A., Thomas, K. J., Ostaszewski, B. L., Cookson, M. R. and Selkoe, D. J. (2009). "Pink1 forms a multiprotein complex with Miro and Milton, linking Pink1 function to mitochondrial trafficking." Biochemistry 48(9): 2045-2052.

Weisleder, N., Taffet, G. E. and Capetanaki, Y. (2004). "Bcl-2 overexpression corrects mitochondrial defects and ameliorates inherited desmin null cardiomyopathy." Proc Natl Acad Sci U S A 101(3): 769-774.

West, M., Zurek, N., Hoenger, A. and Voeltz, G. K. (2011). "A 3D analysis of yeast ER structure reveals how ER domains are organized by membrane curvature." J Cell Biol 193(2): 333-346.

Westermann, B. (2010). "Mitochondrial dynamics in model organisms: what yeasts, worms and flies have taught us about fusion and fission of mitochondria." Semin Cell Dev Biol 21(6): 542549.

Wilkens, V., Kohl, W. and Busch, K. (2013). "Restricted diffusion of OXPHOS complexes in dynamic mitochondria delays their exchange between cristae and engenders a transitory mosaic distribution." J Cell Sci 126(Pt 1): 103-116.

Willig, K. I., Kellner, R. R., Medda, R., Hein, B., Jakobs, S. and Hell, S. W. (2006). "Nanoscale resolution in GFP-based microscopy." Nat Methods 3(9): 721-723. 
Wurm, C. A. and Jakobs, S. (2006). "Differential protein distributions define two sub-compartments of the mitochondrial inner membrane in yeast." FEBS Lett 580(24): 5628-5634.

Wurm, C. A., Neumann, D., Lauterbach, M. A., Harke, B., Egner, A., Hell, S. W. and Jakobs, S. (2011). "Nanoscale distribution of mitochondrial import receptor Tom20 is adjusted to cellular conditions and exhibits an inner-cellular gradient." Proc Natl Acad Sci U S A 108(33): 1354613551.

Wurm, C. A., Neumann, D., Schmidt, R., Egner, A. and Jakobs, S. (2010). "Sample preparation for STED microscopy." Methods Mol Biol 591: 185-199.

Xie, J., Marusich, M. F., Souda, P., Whitelegge, J. and Capaldi, R. A. (2007). "The mitochondrial inner membrane protein mitofilin exists as a complex with SAM50, metaxins 1 and 2, coiled-coilhelix coiled-coil-helix domain-containing protein 3 and 6 and DnaJC11." FEBS Lett 581(18): 3545-3549.

Zampese, E., Fasolato, C., Kipanyula, M. J., Bortolozzi, M., Pozzan, T. and Pizzo, P. (2011). "Presenilin 2 modulates endoplasmic reticulum (ER)-mitochondria interactions and Ca2+ cross-talk." Proc Natl Acad Sci U S A 108(7): 2777-2782.

Zerbes, R. M., Bohnert, M., Stroud, D. A., von der Malsburg, K., Kram, A., Oeljeklaus, S., Warscheid, B., Becker, T., Wiedemann, N., Veenhuis, M., van der Klei, I. J., Pfanner, N. and van der Laan, M. (2012). "Role of MINOS in mitochondrial membrane architecture: cristae morphology and outer membrane interactions differentially depend on mitofilin domains." J Mol Biol 422(2): 183-191.

Zerbes, R. M., van der Klei, I. J., Veenhuis, M., Pfanner, N., van der Laan, M. and Bohnert, M. (2012). "Mitofilin complexes: conserved organizers of mitochondrial membrane architecture." Biol Chem 393(11): 1247-1261.

Zhao, J., Lendahl, U. and Nister, M. (2012). "Regulation of mitochondrial dynamics: convergences and divergences between yeast and vertebrates." Cell Mol Life Sci.

Zick, M., Rabl, R. and Reichert, A. S. (2009). "Cristae formation-linking ultrastructure and function of mitochondria." Biochim Biophys Acta 1793(1): 5-19.

Zinser, E., Sperka-Gottlieb, C. D., Fasch, E. V., Kohlwein, S. D., Paltauf, F. and Daum, G. (1991). "Phospholipid synthesis and lipid composition of subcellular membranes in the unicellular eukaryote Saccharomyces cerevisiae." J Bacteriol 173(6): 2026-2034.

Zurek, N., Sparks, L. and Voeltz, G. (2011). "Reticulon short hairpin transmembrane domains are used to shape ER tubules." Traffic 12(1): 28-41. 


\section{Veröffentlichungen und Konferenzbeiträge}

\section{Veröffentlichungen}

Alkhaja, A. K., Jans, D. C., Nikolov, M., Vukotic, M., Lytovchenko, O., Ludewig, F., Schliebs, W., Riedel, D., Urlaub, H., Jakobs, S. and Deckers, M. (2012). "MINOS1 is a conserved component of mitofilin complexes and required for mitochondrial function and cristae organization." Mol Biol Cell 23(2): 247-257.

Jans, D. C., Wurm, C. A., Riedel, D., Wenzel, D., Stagge, F., Deckers, M., Rehling, P. and Jakobs, S. (2013). "STED super-resolution microscopy reveals an array of MINOS clusters along human mitochondria." Proc Natl Acad Sci U S A 110(22): 8936-8941.

Vukotic, M., Oeljeklaus, S., Wiese, S., Vögtle, F. N., Meisinger, C., Meyer, H. E., Zieseniss, A., Katschinski, D. M., Jans, D. C., Jakobs, S., Warscheid, B., Rehling, P. and Deckers, M. (2012) "Rcf1 mediates cytochrome oxidase assembly and respirasome formation, revealing heterogeneity of the enzyme complex." Cell Metab 15(3): 336-47.

\section{Konferenzbeiträge}

Jans, D. C., Wurm, C. A. and Jakobs, S. (2013) "Mitochondrial protein distributions analyzed by STED microscopy." Focus On Microscopy 2013, 24.03.2013-27.03.2013, Maastricht, Niederlande.

Wurm, C. A., Neumann, D. Jans. D. C., Stoldt, S., Stagge, F., Hell, S. W. and Jakobs, S. (2011) "Protein Distributions within Mitochondria - STED microscopy as a tool in mitochondrial research." 34. Jahrestagung der Deutschen Gesellschaft für Zellbiologie, 30.03.2011-02.04.2011, Bonn, Deutschland. 


\section{Danksagung}

Ich danke Herrn Prof. Dr. Stefan Jakobs für die freundliche Aufnahme in seiner Arbeitsgruppe, die Betreuung meiner Arbeit und die Übernahme des Korreferats. Seine Ratschläge und viele hilfreiche Diskussionen haben entscheidend zum Gelingen dieser Arbeit beigetragen.

Ich danke Herrn PD Dr. Thomas Teichmann für die Übernahme des Referats und die konstruktive Begleitung dieser Arbeit. Viele hilfreiche Diskussionen haben zum Gelingen dieser Arbeit beigetragen.

Ich danke Herrn Prof. Dr. Dr. Stefan W. Hell für die freundliche Aufnahme in der Abteilung NanoBiophotonik und für seine Bereitschaft in der Prüfungskommission diese Arbeit zu begutachten.

Ich danke Herrn Prof. Dr. Peter Rehling für die tolle Zusammenarbeit, die äußerst interessanten Diskussionen und für seine Bereitschaft in der Prüfungskommission diese Arbeit zu begutachten.

Ich danke Herrn Prof. Dr. Michael Meinecke und Herrn Prof. Dr. Gerhard Braus für ihre Bereitschaft in der Prüfungskommission diese Arbeit zu begutachten.

Ich danke meinem Kollegen Dr. Christian A. Wurm für die großartige Zusammenarbeit, für unzählige interessante Diskussionen und wertvolle Ratschläge, die sehr zum Gelingen dieser Arbeit beigetragen haben.

Ich danke Herrn Dr. Markus Deckers für die tolle Zusammenarbeit, seine Hilfsbereitschaft und die vielen interessanten Diskussionen.

Ich danke Herrn Dr. Dietmar Riedel und Herrn Dr. Dirk Wenzel für die tolle Zusammenarbeit, ihre Hilfsbereitschaft und viele interessante Diskussionen.

Ich danke allen weiteren Autoren der Veröffentlichungen Alkhaja et al. 2012, Jans et al. 2013 und Vukotic et al. 2012 für die fruchtbare Zusammenarbeit.

Ich danke Rita Schmitz-Salue, Sylvia Löbermann, Tanja Gilat und Ellen Rothermel für großartige technische Hilfe und Unterstützung.

Ich danke meinen lieben "Mit-Biologen" aus der Gruppe „Mitochondrial Structure and Dynamics" für eine tolle Zeit inner- und außerhalb des Labors und viele hilfreiche Diskussionen. Besonders möchte ich meinem Kollegen und „Büro“-Nachbarn („Bay-boys!“) Dr. Stefan Stoldt für seine Ratschläge und tolle Gespräche danken und meiner Kollegin Fransiska Stagge für die fruchtbare Zusammenarbeit.

Ich danke meinen Kollegen aus der Abteilung NanoBiophotonik für ihre Hilfsbereitschaft.

Abschließend möchte ich mich ganz besonders bei meiner Familie für die fortwährende Unterstützung in allen Bereichen danken. 


\section{Lebenslauf}

\section{Persönliche Daten}

Name:

Christian Daniel Jans

Anschrift:

Stauffenbergring 1

37075 Göttingen

Geburtsdatum/-ort:

10.09.1982 in Neuwied

Familienstand:

Staatsangehörigkeit:

ledig

deutsch

\section{Schulischer Bildungsweg}

1988

$1989-1992$

$1992-1994$

$1994-2001$

\section{Grundwehrdienst}

01.07.2001-30.06.2002

\section{Studium}

01.10 .2002

April 2008

November 2007 - Januar 2008
Grundschule in Konz

Grundschule in Wilhelmshaven

Orientierungsstufe Nogatstraße, Wilhelmshaven Gymnasium am Mühlenweg, Wilhelmshaven Abschluss: Abitur (Note 2,3)

\section{Luftwaffen Sanitätsstaffel, JaboG 36, Friesland}

Studienbeginn an der Universität des Saarlandes

Studiengang Biologie (Diplom)

Vordiplom

Diplomprüfungen

Hauptfach:

Genetik

1,7

Nebenfächer:

Virologie

3,7

Biophysik

1,3

Zusatzprüfung:

Bioinformatik 
$03 / 2008-12 / 2008$

13.02.2009

$10 / 2009-09.08 .2013$

09.08 .2013
Diplomarbeit in der Genetik/Epigenetik,

AG Prof. Walter (Universität des Saarlandes)

Verleihung des akademischen Grades:

Diplom - Biologe (Gesamtnote: GUT)

Doktorarbeit im Grundprogramm Biologie der Georg-August University School of Science (GAUSS) angefertigt am MaxPlanck-Institut für biophysikalische Chemie, Abteilung Nanobiophotonik, AG Mitochondrial Structure and Dynamics

Promotionsprüfung

Gesamtprädikat: „magna cum laude“

Bewertung der Dissertation mit dem Titel „Untersuchung der sub-mitochondrialen Lokalisation des MINOSKomplexes in humanen Zellen": magna cum laude

Bewertung Disputation: magna cum laude 